\title{
SUBMARINE SLOPE FAILURES IN GASSY SOILS
}

by

\author{
(C) Shantanu Kar \\ A thesis submitted to the \\ School of Graduate Studies \\ in partial fulfillment of the requirements for the degree of
}

\section{Masters of Engineering}

Faculty of Engineering and Applied Science

Memorial University of Newfoundland

\section{May 2016}

St. John's

Canada 


\begin{abstract}
Submarine slope stability has become an important concern and a subject of research with increasing demand for offshore developments and technological advancement for harsh and challenging environments. The consequences of submarine slope failure adjacent to oil and gas facilities would have a large financial, safety and regulatory impact. This current research work investigates potential failure of submarine gassy slopes triggered by tidal variations. Due to tidal variations, failure of an unsaturated slope may occur under specific combinations of increasing degree of saturation and soil permeability, and decreasing tidal period. Novel physical model tests in a geotechnical centrifuge were undertaken to examine submarine slope failure mechanisms containing gassy sediments. The model preparation techniques, measurement systems and results are presented. The response observed in the model test is discussed and further developments proposed. The buried PPT's response of the submarine slope are comparable in terms of attenuation and phase lag with Nagaswaran (1983) and with field measurements of Atigh and Byrne (2004) in terms of phase lag.
\end{abstract}




\section{ACKNOWLEDGEMENTS}

First, I would like to express my sincerest thanks to my supervisor, Dr. Ryan Phillips, for his continuous support, patience, guidance, and above all, encouragement over the last two years to accomplish the research. His effective and sincere guidance helped me to overcome numerous difficulties in my experimental setup. I also would like to thank my co-supervisor, Dr. Bipul Hawlader, for his motivational and inspirational advice throughout the program.

Without great help from Gerry Piercey, Karl Kuehnemund, Derry Nicholl and Karl Tuff from C-CORE, development of my centrifuge experimental setup was impossible and I am very grateful to them. Specifically, the long hours worked helped a lot to finish all the jobs on time. Their dedicational support, advice and overall guidance impressed me and made the experimental model development successful. I learned a lot while working with them. I am also grateful to Shawn Organ from MUN's soil lab for his help in my research.

I would like to acknowledge Dr. Peter Byrne of University of British Columbia and Dr. Jocelyn Grozic of University of Calgary for their suggestions in the physical model design and preparation techniques. The financial support of Chevron Canada Limited for the research, Hibernia Management \& Development Corporation for C-CORE centrifuge access for graduate students, and the School of graduate studies of Memorial University is gratefully acknowledged. 
Finally, I would like to thank my parents, wife, brother and my friends at MUN for their continuous love, support and encouragement throughout the program. 


\section{Table of Contents}

ABSTRACT .................................................................. ii

ACKNOWLEDGEMENTS .................................................. iii

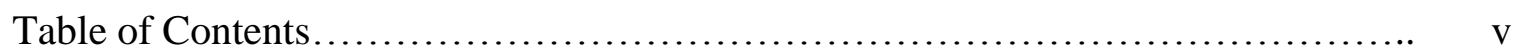

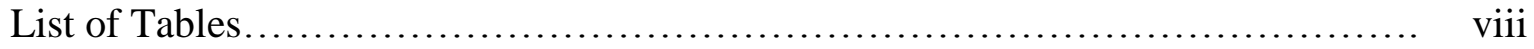

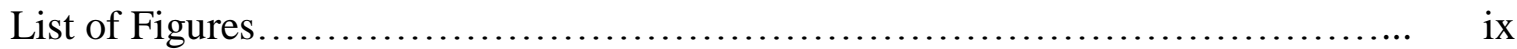

List of Symbols and Abbreviations.......................................... xiii

Chapter 1 Introduction................................................... 1

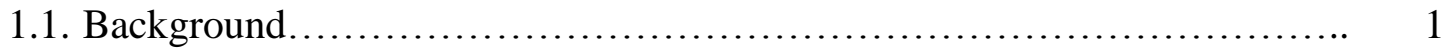

1.2. Objectives.................................................... 2

1.3. Thesis Outline ...................................................... 3

Chapter 2 Literature Review................................................... 5

2.1. Introduction........................................................... 5

2.2. Submarine slope failures........................................ 6

2.3. Triggering factors................................................... 7

2.3.1 Earthquakes............................................ 8

2.3.2 Wave loading......................................... 10

2.3.3 Gas hydrate.............................................. 10

2.3.4 Sedimentation............................................. 11

2.3.5 Oversteepening ........................................ 12

2.3.6 Tidal variation.............................................. 12

2.4. Gassy sediments............................................. 13

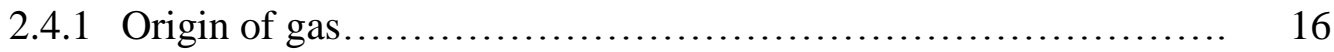

2.4.1.1 Organic origins................................ 17

2.4.1.2. Inorganic origins............................. 18

2.5. Liquefaction flow slides in submarine slopes......................... 18

2.6. Case studies related to gassy soils.................................. 19

2.6.1. Fraser river delta......................................... 19

2.6.2. Eastern Gulf of Cadiz...................................... 22 
2.6.3. Mississippi River delta, California, United States .................. 24

2.6.4. Var Delta front landslide, SE France ............................. 25

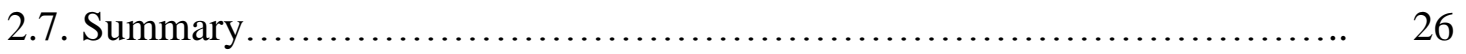

Chapter 3 Centrifuge Model Design.......................................... 27

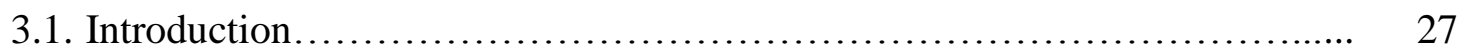

3.2. Proposed centrifuge design........................................... 28

3.3. Centrifuge slope geometry.......................................... 30

3.4. Model material and relative density .................................... 31

3.5. Gas selection and initial pressure ...................................... 32

3.6. Measurement of degree of saturation................................... 36

3.6.1. Water Scout SM 100 soil moisture sensor...................... 36

3.6.2. Time Domain Reflectometry (TDR) ......................... 38

3.6.3. VH400 soil moisture sensor .............................. 40

3.6.3.1. Simple calibration.................................... 40

3.6.3.2. Column calibration.............................................. 41

3.7. Measuring of global degree of saturation................................ 46

Chapter 4 Centrifuge and Experimental Procedure.................................. 49

4.1. Centrifuge modeling ................................................. 49

4.1.1 Principle of centrifuge modeling ............................... 49

4.1.1.1. Scaling laws........................................... 50

4.1.1.2. Scaling errors.................................... 52

4.1.1.3. Scaling factors...................................... 54

4.1.1.4. Application of centrifuge modeling..................... 56

4.2. Experimental setup ................................................. 57

4.2.1. C-CORE Geotechnical centrifuge............................ 57

4.2.2. Supporting equipment..................................... 59

4.2.2.1. High pressure box..................................... 59

4.2.2.2. Sand raining equipment............................ 60

4.2.2.3. Ethylene mixing container............................. 61 
4.2.2.4. Peristaltic pump.................................. 62

4.2.2.5. Tidal actuator...................................... 63

4.2.2.6. Hydraulic cylinder.................................. 67

4.2.2.7. Lights and camera................................... 68

4.3. Centrifuge model preparation......................................... $\quad 70$

4.3.1. Instrumentation............................................. 70

4.3.2. Model saturation by vacuum................................ 73

4.3.3. Model saturation by ethylene mixed water....................... $\quad 76$

4.3.3.1. Preparation of ethylene mixed water................... 76

4.3.3.2. Flushing of ethylene mixed water...................... 79

4.3.4. Data acquisition system.............................................. $\quad 80$

4.3.5. Model placement in centrifuge arm.............................. 81

4.4. Centrifuge test procedures........................................... 84

4.5. Time required for making centrifuge model.............................. $\quad 85$

Chapter 5 Experimental Testing Results....................................... 87

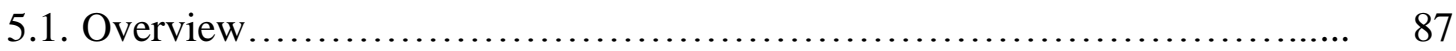

5.2. First centrifuge proof test.......................................... 87

5.2.1. PIV Analysis during tidal cycles.............................. 90

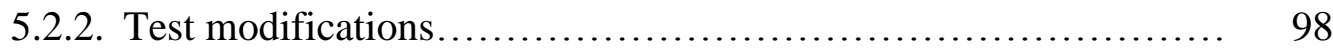

5.3. Second centrifuge test.............................................. 100

5.3.1. PIV Analysis during tidal Cycles............................... 107

5.4. Discussions.......................................................... 117

Chapter 6 Conclusions and Recommendations................................. 118

6.1. Conclusions ......................................................... 118

6.2. Recommendations................................................ 119

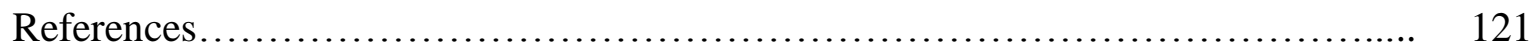

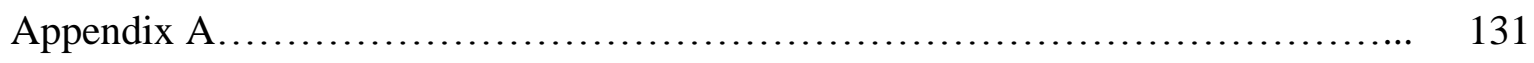

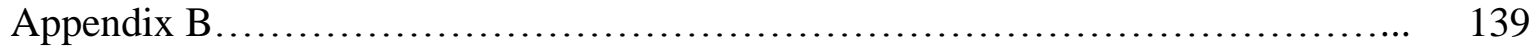




\section{List of Tables}

Table 2.1: Causes of submarine landslide, Hampton et al. (1996) 8

Table 2.2: Earthquake induced flow slides in submarine deposit, Chillarige et al 9 (1997 a)

Table 2.3: Statically induced liquefaction case studies, Haththotuwa and Grozic (2011)

Table 2.4: Source of Natural Gases. Grozic (1999)

Table 3.1: Strongbox pressure variation during the test with ethylene as a pore fluid gas [All pressures are absolute]

Table 3.2: Strongbox pressure variation during the test with argon as a pore fluid gas [All pressures are absolute]

Table 4.1: Scaling factors in centrifuge tests (Coulter, 2008) 54

Table 4.2: Time elapsed for making slope model for centrifuge test 86

Table 5.1: Pore pressure variation with box pressure change 106 


\section{List of Figures}

Figure 2.1: Schematic diagram showing main offshore geohazards, Chiocci and 5 Cattaneo (2011).

Figure 2.2: Classification of submarine mass movements proposed by the 7 ISSMGE Technical Committee on Landslides (TC-11) (Locat and Lee, 2000)

Figure 2.3: Three structure of unsaturated or partially saturated soil, a. Low degree of saturation level, b. Intermediate degree of saturation level, c. High degree of saturation level. (Wroth and Houlsby, 1985)

Figure 2.4: Microstructure of gassy soil. (a) When bubble size smaller than pore 15 space, (b) When bubble size larger than particle size, (Wheeler 1988).

Figure 2.5: Fraser River Delta front, Mckenna et. al. (1992)

Figure2.6: Map showing the gulf of Cadiz and surrounding area.(https://en. 23 wikipedia.org/wiki/Gulf_of_C\%C3\%A1diz\#/media/File:AlboranSea _map .png)

Figure 2.7: Location of the Var Delta (Anthony and Julian, 1997) 25

Figure 3.1: Horizontal movements caused by $2.5 \mathrm{~m}$ tide 28

Figure 3.2: Geometry of the slope proposed by Byrne (2003) 28

Figure 3.3: Predicted stability zones 29

Figure 3.4: Tidal variations recommendations, Byrne (2003) 30

Figure 3.5: Model geometry 31

Figure 3.6: Alwhite \#00 silica sand grain size distribution 32

Figure 3.7: Slope geometry with pressure variation 35

Figure 3.8: Water Scout SM 100 Soil Moisture Sensor. (http://www.specmeters 37

.com/ weather-monitoring/sensors-and-accessories/sensors/soil-moist ure-sensors/sm 100

Figure 3.9: Calibration of SM 100 Soil Moisture sensor in Alwhite \#00 fine silica sand 
Figure 3.10: Tektronix 1502 B metallic TDR unit. (http://www.testequipmentd epot.com/usedequipment/Tektronix/tdrs/1502b1503b.htm?gclid=CN _b4cCZ98gCFc8YhwmCUBMw)

Figure 3.11: Calibration of TDR unit in Alwhite \#00 fine silica sand 39

Figure 3.12: VH400 soil moisture sensor $\quad 40$

Figure 3.13: Calibration of VH400 sensor in Alwhite \#00 fine silica sand 41

Figure 3.14: Sand column geometry.

Figure 3.15: Lab setup of sand column test 42

Figure 3.16 (a) Sensor in vertical direction. (b) Sensor in horizontal direction. 43

Figure 3.17: Soil moisture reading for both sensor orientations. 44

Figure 3.18: Sensor response to decreasing pressure 45

Figure 3.19: Lab setup for measuring global degree of saturation. 46

Figure 3.20: Released gas measurements $\quad 47$

Figure 4.1: Schematic of beam centrifuge (Muff, J.D. 1996) 50

Figure 4.2: Vertical stress representation in model and prototype. 51

Figure 4.3: Comparison of stress vary with depth in a centrifuge model and its 52 corresponding prototype (Taylor, 1995)

Figure 4.4: C-CORE Acutronic 680-2 Geotechnical Centrifuge (Phillips et al. 58 1994)

Figure 4.5: C-CORE Centrifuge specification. $\quad 58$

Figure 4.6: High pressure box $\quad 60$

$\begin{array}{ll}\text { Figure 4.7: Sand raining equipment } & 61\end{array}$

Figure 4.8: water ethylene saturation container $\quad 62$

$\begin{array}{ll}\text { Figure 4.9: Peristaltic pump } & 63\end{array}$

$\begin{array}{ll}\text { Figure 4.10: Tidal actuator } & 64\end{array}$

Figure 4.11: Displacement block $\quad 65$

Figure 4.12a: Water pressure vs. piston movement (Centrifuge test 1) 65

Figure 4.12 b: Water pressure vs. piston movement (Centrifuge test 2) 66

Figure 4.13 a: Dimensions of pneumatic cylinder 66 
Figure 4.13 b: Pneumatic cylinder $\quad 67$

Figure 4.14: Hydraulic cylinder and servo controlled valve $\quad 68$

Figure 4.15: Mounted lights and Cannon G7 camera 69

Figure 4.16: Video camera (GoPro and webcam) $\quad 70$

Figure 4.17: Centrifuge test instrumentation $\quad 71$

Figure 4.18: Placement of the pore pressure transducer (PPT) in the sand model 72

$\begin{array}{ll}\text { Figure 4.19: Carbon dioxide flushing } & 74\end{array}$

Figure 4.20: Flushing of distilled deaired water into high pressure box $\quad 75$

Figure 4.21: Lab setup for ethylene mixed water 76

Figure4.22: Relationship with temperature and solubility of ethylene 77 (http://www.engineeringtoolbox.com/gases-solubility-waterd_1148.html)

Figure 4.23: Container pressure and tub temperature while ethylene mixed with 78 water

$\begin{array}{ll}\text { Figure 4.24: Lab setup for ethylene flushing } & 79\end{array}$

Figure 4.25: Centrifuge platform layout with whole package $\quad 81$

Figure 4.26 (a): After placement of all centrifuge model package in first test 82

Figure 4.26 (b): After placement of all centrifuge model package in second test 83

Figure 4.27: Estimated gas solution times, Holocher (2003) 85

Figure 5.1: Pneumatic cylinder pressure vs. voltage $\quad 88$

Figure 5.2: Pressure transducer response during the test 89

Figure 5.3: PIV analysis during tidal action at 100\% target degree of saturation $\quad 91$

Figure 5.4: PIV analysis during tidal action at 95\% target degree of saturation 91

Figure 5.5: PIV analysis during tidal action at 90\% target degree of saturation 92

Figure 5.6: PIV analysis during tidal action at $80 \%$ target degree of saturation 92

Figure 5.7: PIV analysis during tidal action at 70\% target degree of saturation 93

Figure 5.8: PIV analysis during swing down 94

Figure 5.9: PIV analysis during target Sr, (100-95)\%, 95

Figure 5.10: PIV analysis during target Sr, (95-90)\% 95 
Figure 5.11: PIV analysis during target Sr, (90-80)\% 96

Figure 5.12: PIV analysis during target $\mathrm{Sr},(80-70) \% \quad 96$

Figure 5.13: Slope immediately after swing down 97

Figure 5.14: Slope after 45 minutes of swing down 97

Figure 5.15: Modified strongbox for second test 99

Figure 5.16: Pressure transducer response during the test 100

Figure 5.17: PPT and strongbox transducer response during the test 101

Figure 5.18: Pressure transducers response with (a) $15 \mathrm{~s}$ and (b) $2.5 \mathrm{~s}$ cycling at 103 $90 \%$ target $\mathrm{Sr}$

Figure 5.19: Pressure transducers response with (a) $15 \mathrm{~s}$ and (b) $2.5 \mathrm{~s}$ cycling at 104 $80 \%$ target $\mathrm{Sr}$

Figure 5.20: Pressure transducers response with (a) $15 \mathrm{~s}$ and (b) $2.5 \mathrm{~s}$ cycling at 105 $70 \%$ target $\mathrm{Sr}$

Figure 5.21: PPT A attenuation with tidal period at different target $\mathrm{Sr} \quad 107$

Figure 5.22: PIV analysis during target Sr, (90-80)\% 108

Figure 5.23: PIV analysis during target $\mathrm{Sr},(80-70) \%$

Figure 5.24: PIV analysis during target Sr, 70\% to atmospheric 109

Figure 5.25: PIV analysis during tidal action at 90\% target degree of saturation $\quad 110$

Figure 5.26: PIV analysis during tidal action at 80\% target degree of saturation $\quad 111$

Figure 5.27: PIV analysis during tidal action at 70\% target degree of saturation 111

Figure 5.28: PIV analysis during tidal action at atmospheric condition 112

Figure 5.29: Slope immediately after swing down in second test 112

Figure 5.30: Slope after 45 minutes of swing down in second test 113

Figure 5.31: Presence of gas bubbles at 95\% target $\mathrm{Sr} \quad 114$

Figure 5.32: Presence of gas bubbles at 90\% target $\mathrm{Sr} \quad 115$

Figure 5.33: Presence of gas bubbles at $80 \%$ target $\mathrm{Sr} \quad 115$

Figure 5.34: Presence of gas bubbles at 70\% target $\mathrm{Sr} \quad 116$

Figure 5.35: Presence of gas bubbles at atmospheric 116 


\section{List of Symbols and Abbreviations}

\begin{tabular}{|c|c|}
\hline$\sigma_{\mathrm{v}}$ & Total vertical stress \\
\hline CANLEX & Canadian Liquefaction Experiment \\
\hline $\mathrm{CH}_{4}$ & Methane \\
\hline $\mathrm{C}_{2} \mathrm{H}_{6}$ & Ethylene \\
\hline $\mathrm{CO}_{2}$ & Carbon dioxide \\
\hline DAQ & Data Acquisition \\
\hline $\mathrm{D}_{\mathrm{p}}$ & Prototype depth \\
\hline $\mathrm{D}_{\mathrm{m}}$ & Model depth \\
\hline $\mathrm{D}_{\mathrm{r}}$ & Relative density \\
\hline $\mathrm{g}$ & Earth's gravity \\
\hline $\mathrm{H}$ & Henry's constant \\
\hline $\mathrm{k}$ & Permeability \\
\hline $\mathrm{m}$ & Metres \\
\hline $\mathrm{mm}$ & Millimetres \\
\hline $\mathrm{S}_{\mathrm{r}}$ & Degree of saturation \\
\hline$\rho$ & Density \\
\hline $\mathrm{P}$ & Pressure \\
\hline PIV & Particle image velocimetry \\
\hline PPT & Pore pressure transducer \\
\hline TDR & Time domain reflectometry \\
\hline $\mathrm{r}$ & Radius \\
\hline $\mathrm{r}_{\mathrm{e}}$ & Effective radius \\
\hline $\mathrm{v}$ & Voltage \\
\hline $\mathrm{V}$ & Volume \\
\hline VWC & Volumetric water content \\
\hline$\omega$ & Angular rotational speed \\
\hline
\end{tabular}




\section{Chapter 1: Introduction}

\subsection{Background}

Over the last few decades, the exploration of oil and gas in deep water sites has increased tremendously because of high demand for energy. Geohazards and associated ground movements in offshore environment are a great threat to these offshore industries. Therefore, the stability of a submarine slope is an important issue that must be taken into consideration during the exploration and design of offshore facilities. The consequences of slope failure on adjacent oil and gas facilities would have a large financial, safety and regulatory impact. Moreover, submarine slope failures and tsunami generated due to associated landslides may cause considerable loss of life in near shore areas.

There are several possible potential triggering mechanisms for submarine slope failure, such as: wave action, gas hydrate dissociation, tidal variation, earthquake, glaciations and volcanic activities. Many liquefaction flow slide events have occurred in and near the Fraser River Delta. McKenna et al., (1992) identified the main reasons behind the flow liquefaction in Fraser River Delta as rapid sedimentation, presence of gas, tidal variation and seismic activities. Atigh and Byrne, (2004) developed and calibrated a numerical model of such slope failures caused by tidal variations on gassy sediments based on the

observation of Chillarige et al., (1997 a). In this study, centrifuge tests are conducted to confirm this numerical analysis. 
Physical modelling has proved invaluable in understanding offshore geotechnical issues, but has yet to be applied for slope stability in sediments containing gas. This research designed and developed the necessary experimental techniques and equipment to undertake such novel model tests. Centrifuge tests were then conducted at C-CORE to experimentally investigate the stability of the submarine gassy slopes under tidal variation.

\subsection{Thesis objectives}

The main objective of this research program is to identify a flow failure condition of a submarine gassy slope during tidal cycles.

The following approaches are used to fulfill these objectives:

$>$ Development of experimental technique to manufacture, control and measurement of degree of saturation (percentage of gas) in soft soil sediments

$>$ Development of an actuator system to cause tidal variations and pressure change on the slope

$>$ Prepare models of submarine slope for physical modelling Investigate the condition of submarine slopes during tidal variations Analysis of flow failure conditions 


\subsection{Organization of Thesis}

This thesis is organized into six chapters and two appendices which follow the sequences of the work performed to investigate the stability of submarine slope failure.

Chapter 1 is an introduction that describes the reason behind the study. The objectives for this experimental program and the contributions of this work are also described in this chapter.

Chapter 2 reviews the available literature on various aspects of submarine slope stability, including: geohazards, submarine slope failures, triggering mechanism, gassy sediments and case studies from previous slope failures.

Chapter 3 of this thesis discusses the centrifuge model design. Proposed centrifuge model design by Byrne (2003), centrifuge slope geometry, model material and relative density of the centrifuge model are discussed in this chapter. Gas selection and different measurement procedures of degree of saturation are also explained in this chapter.

Chapter 4 discusses the centrifuge and experimental procedures. A brief overview of the principle in centrifuge modeling and scaling laws are discussed. Experimental setup and instrumentations, centrifuge model preparation and test procedures are explained in this chapter.

Chapter 5 presents and discusses the testing results that were obtained from two centrifuge model tests.

Chapter 6 presents the conclusions and some recommendations for further development. 
The appendices at the end present the technical contribution of this thesis. Two conference papers have been published from this thesis. 


\section{Chapter 2: Literature Review}

\subsection{Introduction}

A geohazard is defined as "A geological state, which represents or has the potential to develop further into a situation leading to damage or uncontrolled risk" by Vanneste (2010). Geohazards are found in all parts of the earth and are always related to geological conditions and processes. Important offshore geohazards include instability of slope and wasting processes of slope mass (including debris flows, gravity flows), pore pressure phenomena, shallow gas accumulations, shallow water flows, mud diapirism and mud volcanism, fluid vents, pockmarks and seismicity. Figure 2.1 shows a schematic diagram which contains typical offshore geohazard after Chiocci and Cattaneo (2011).

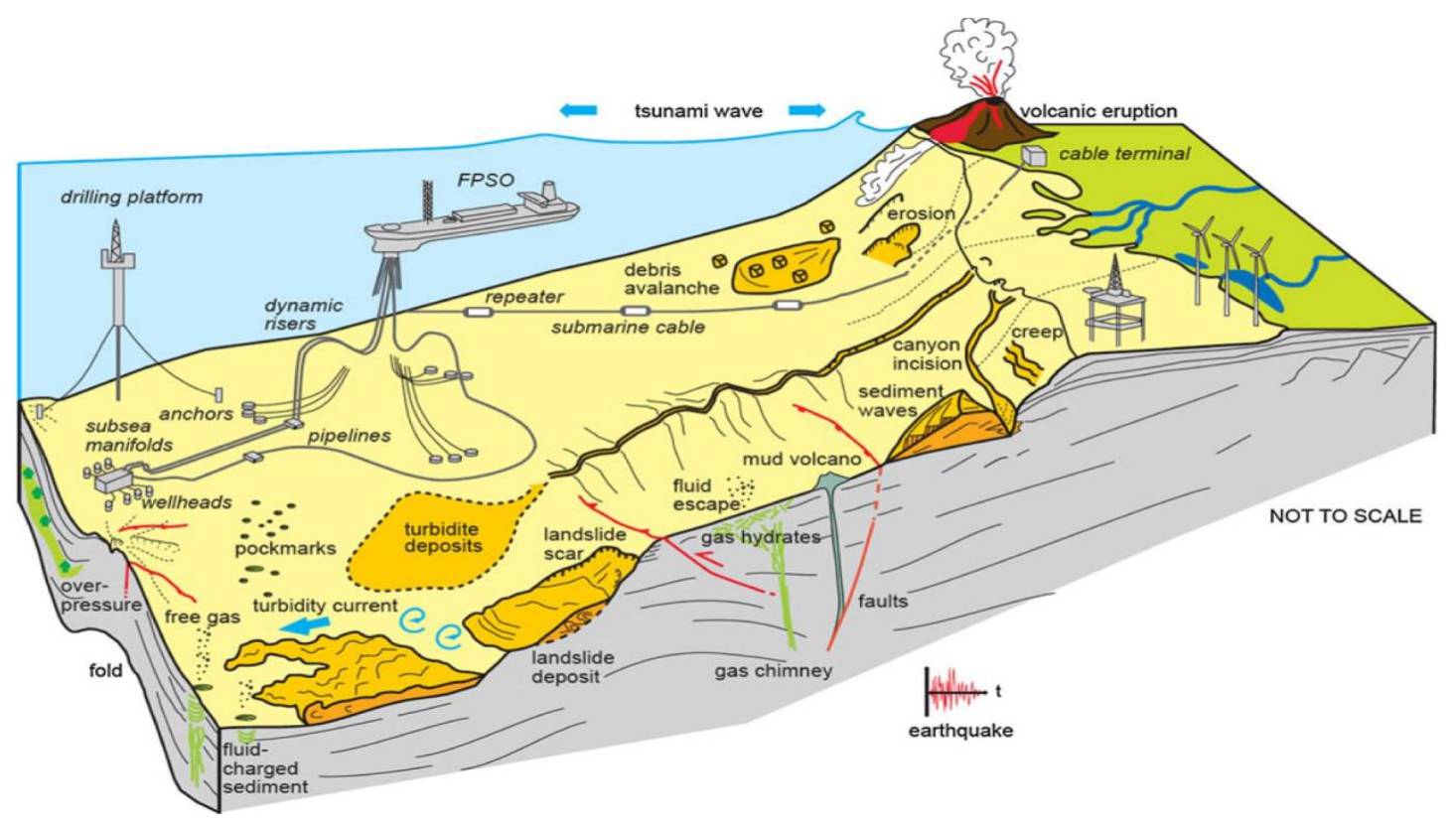

Figure 2.1: Schematic diagram showing main offshore geohazards (after Chiocci and Cattaneo, 2011). 
Geohazards and associated ground movements in an offshore environment are a great threat at both local and regional scales. Submarine slope failure is one of the most common geohazards, which takes place in different parts of the world. Submarine slope instability has gained wide attention because of the catastrophic impact to the safety of people and coastal structures such as jetties, breakwaters, lighthouses, pipelines, and offshore platforms. The consequences of slope failure near oil and gas facilities would have a large financial, safety and regulatory impact. Moreover, submarine slope failures and tsunami generated due to associated landslides in shore areas may cause considerable loss of life.

\subsection{Submarine slope failures}

Understanding the phenomena of submarine slope failures and their inherent consequences is mostly needed due to the development of natural resources either near the shore or in deeper water, coastal development and the protection of the marine environment and the impact of global climate changes. Stability of submarine slopes is an important concern and a matter for research as offshore and near shore exploration and developments become more prominent and technologically advanced. In the past, various classification systems of submarine mass movements have been proposed. Classification of submarine mass movements proposed by the technical committee on landslides (TC11) of the International Society for Soil Mechanics and Geotechnical Engineering (ISSMGE) is shown in Figure 2.2. 


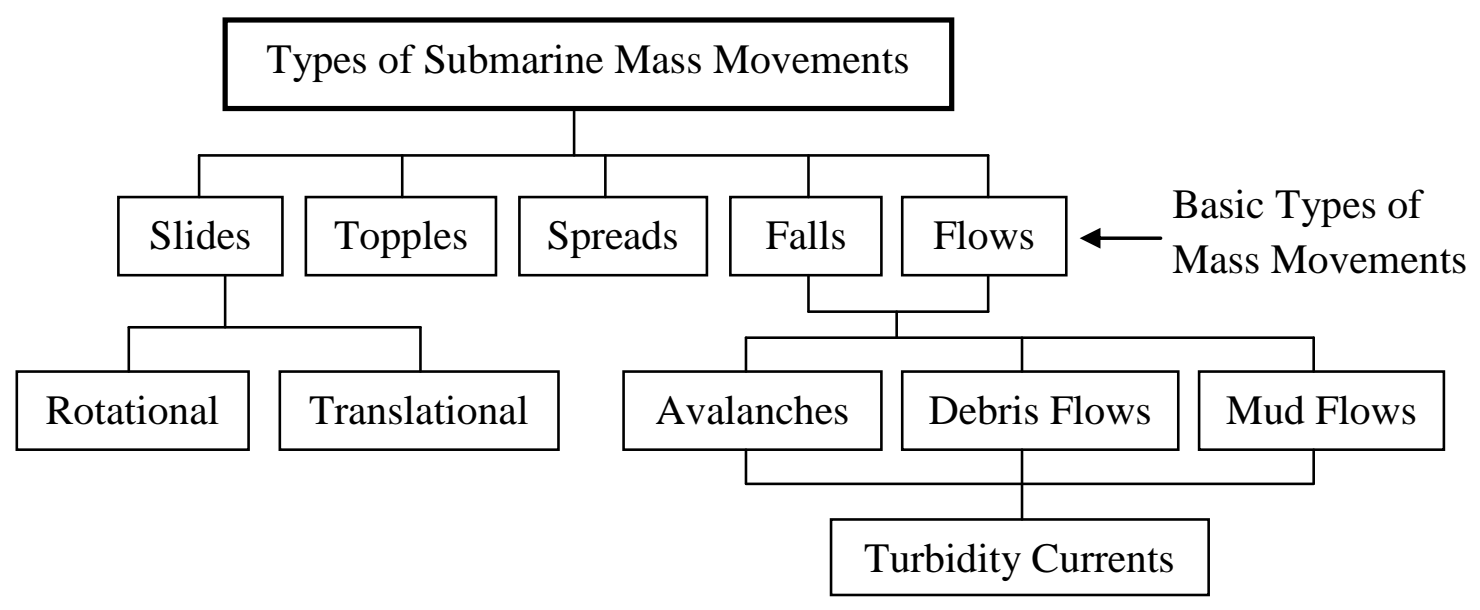

Figure 2.2: Classification of submarine mass movements proposed by the ISSMGE Technical Committee on Landslides (TC-11) (Locat and Lee, 2000)

A wide variety of soils can be found in the seabed. Submarine slope failures have been observed over a wide range of slope angles from less than half a degree up to about $30^{\circ}$ (Mitchell et al., 1972). The failure pattern focus in this study is a liquefaction flow slide. Silvis and Groot (1995) discussed how flow liquefaction occurs in the submarine slope if the slope angle is steeper than $18.4^{\circ}$. Just for the offshore hydrocarbon industry, the cost of damage to pipelines caused by submarine slope failures is $\sim \$ 400$ million each year (Mosher et al., 2010). Some slides can travel hundreds of kilometers without noticeable transformation into turbidity currents and others transforms entirely into turbidity currents after starting from their source (Masson et al., 2006).

\subsection{Triggering factors}

Submarine slopes are susceptible to a wide variety of forces that may contribute to their instability and subsequent failure. Submarine slides may be initiated by different potential 
triggering factors such as earthquakes, rapid sedimentation, wave action, gas hydrate dissociation, artesian water pressure, over steeping by erosion and minor slides, human activities, volcanic activities, tide, sea level change, and glaciations (Locat and Lee, 2000; Masson et al., 2006). Hampton et al. (1996) presented that landslides are initiated in the slope when the shear stress oriented down slope (driving shear stress) exceeds the shear strength or resisting stress of the material forming the slope. Table 2.1 shows some causes of submarine landslide by reducing the strength or increasing the stress during submarine slope failure (Hampton et al., 1996).

Table 2.1: Causes of submarine landslide, (Hampton et al., 1996)

\begin{tabular}{|c|c|}
\hline \multicolumn{2}{|c|}{ Factor of safety $=\frac{\text { Resisting forces }}{\text { Gravitational forces }}$} \\
\hline Reducing the strength: & Increasing the stress: \\
\hline Earthquakes & Earthquakes \\
Wave loading & Wave loading \\
Weathering & Diapirism \\
Sedimentation & Sedimentation \\
Gas & Erosion \\
Tidal changes & Tidal changes \\
\hline
\end{tabular}

\subsubsection{Earthquakes}

Earthquake created ground motions are caused by the movement of a tectonic plate. Over a long period of time, energy is built up slowly at the tectonic faults and when the energy 
is released large earth motions are experienced over a large area. The main effect of earthquakes is the creation of horizontal shear waves. In case of submarine slopes, these waves will cause significant shear stress and may also reduce soil resistance. Table 2.2 shows a list of earthquake induced submarine landslides.

Table 2.2: Earthquake induced flow slides in submarine deposit, (Chillarige et al.,1997 b)

\begin{tabular}{|c|c|c|c|c|c|}
\hline Slide & Magnitude & Deposit & Nature of soil & Slope angle $\left({ }^{\circ}\right)$ & References \\
\hline \multicolumn{6}{|l|}{ New Madrid earthquake, } \\
\hline Mississippi River banks, 1811 & - & River bank & Sands & - & Seed 1968 \\
\hline Yakutat, Alaska, 1899 & - & Submarine deposit & $\begin{array}{c}\text { Deltaic marine sediments } \\
\text { (silty sand and gravel) }\end{array}$ & - & Seed 1968 \\
\hline Valdez, Alaska, 1908 & - & Submarine deposit & $\begin{array}{c}\text { Deltaic marine sediments } \\
\text { (silty sand and gravel) }\end{array}$ & - & Seed 1968 \\
\hline Messina cone, 1908 & 7.5 & Submarine deposit & Sand-silt & 4 & Schwarz 1982 \\
\hline Valdez, Alaska, 1911 & 6.9 & Submarine deposit & $\begin{array}{l}\text { Deltaic marine sediments } \\
\text { (silty sand and gravel) }\end{array}$ & - & Seed 1968 \\
\hline Valdez, Alaska, 1912 & 7.25 & Submarine deposit & $\begin{array}{c}\text { Deltaic marine sediments } \\
\text { (silty sand and gravel) }\end{array}$ & - & Seed 1968 \\
\hline Chile, 1922 & 8.3 & Submarine deposit & Sand with salt & 6 & Morgenstern 1967 \\
\hline Sagami Wan, 1923 & - & Submarine deposit & Sand & - & $\begin{array}{l}\text { Menard 1964; } \\
\quad \text { Morgenstern } 1967\end{array}$ \\
\hline Kwanto, Tokyo, 1923 & 8.2 & Coastal hillsides & - & - & Seed 1968 \\
\hline Grand Banks, 1929 & 7.2 & Submarine deposit & Fine sand and silt & 3.5 & Heezen and Ewing 1952 \\
\hline Suva, Fizi, 1953 & 6.75 & Submarine deposit & Sand & 3 & Houtz and Wellman 1962 \\
\hline Orleansville, 1954 & 6.7 & Submarine deposit & Sand & $4-20$ & Heezen and Ewing 1965 \\
\hline San Fransico, 1957 & 5.3 & Lake banks & Aeolin beach sands & - & Seed 1968 \\
\hline Puerito Montt, Chile, 1960 & 8.4 & Coastal deposits & Loose sands and silts & - & Seed 1968 \\
\hline Valdez, Alaska, 1964 & 8 & Submarine deposit & Silty sand and gravel & $15-20$ & Holish and Hendron 1975 \\
\hline Seward, Alaska, 1964 & 8.3 & Submarine deposit & $\begin{array}{l}\text { Loose to medium sand, } \\
\text { gravel }\end{array}$ & $15-20$ & $\begin{array}{c}\text { Holish and Hendron } \\
\text { 1975; Seed } 1968\end{array}$ \\
\hline Valdez, Alaska, 1964 & 8.3 & Submarine deposit & Silty sands and gravel & $4-10$ & $\begin{array}{l}\text { Morgenstern 1967; } \\
\quad \text { Seed } 1968\end{array}$ \\
\hline Seattle, 1965 & 6.7 & Coastal bluff & - & - & Seed 1968 \\
\hline $\begin{array}{l}\text { Klamath River delta, } \\
\text { California, } 1980\end{array}$ & 6.5 & Submarine deposit & Fine sand & 0.25 & Field et al. 1982 \\
\hline
\end{tabular}

Due to the cyclic loading effect of earthquakes soil liquefaction can also happen. One of the most famous examples is the 1929 Grand Banks event on the continental slope south of the island of St Pierre. A magnitude 7.2 earthquake located $250 \mathrm{~km}$ south of Newfoundland led to a series of small regressive slumps with resultant turbidity currents have broken twelve submarine transatlantic cables (Piper et al., 1999). The landslide occurred over a period of 12 hours and moved at a speed of approximately $15 \mathrm{~m} / \mathrm{s}$. This 
landslide created a tsunami which killed 27 people and caused millions of dollars of damage (Batterson et al., 1999).

\subsubsection{Wave loading}

Instability may occur in the seabed due to wave loading. Wave induced shear and wave induced liquefaction are the main failure pattern as discussed by Poulos (1988). Wave action produces large amount of stress and this stress generates excess pore water pressure on sea floor. These stresses act as a driving force and effect on the stability of the sea bed. Wave action also increases excess pore water pressure which is a function of wave period, wave length, wave height and depth of water (Wiegel, 1964). Wave loading may produce transient and residual pore pressure in the sea floor (Poulos, 1988). Transient pore pressures are produced from the coupled response of the soil skeleton and the pore water to wave loads and the residual pressure by the cyclic shear stresses generated by the dynamic wave pressures. In sandy or silty soil, wave induced liquefaction may occur. Cyclic shear stress occurs in the sea floor due to the differential wave loading which causes the increment in pore water pressure and reduction in strength. Significant deformation or liquefaction in the sea bed occurs when the induced shear stress exceeds the shear strength over a sufficient zone. In 1969, sea floor instability occurred in the Gulf of Mexico due to wave loading produced by Hurricane 'Camille.'

\subsubsection{Gas hydrate}

"Gas hydrates are ice like compounds composed of water and methane gas in a very compact form" as defined by Nixon and Grozic (2006). A large amount of gas and water 
is released into the soil sediment when the gas hydrates dissociate. Gas hydrate will cause an increase in fluid pressure and a decrease in effective stress and thus result in loss of the shear strength upon dissociation. The potential mechanism by which gas hydrate decomposition contributes to submarine slope failure is explained by Nixon and Grozic (2006). Three criteria must be met for slope failure from gas hydrates decomposition as explained by Dillon and Max (2000): (1) Gas hydrate must be widespread; (2) Submarine slope failure must originate within the gas hydrate boundaries; (3) Under the hydrate zone sediments of low permeability must be present to permit the build up of excess pore water pressure which can destabilize slopes during sea level reductions. Changes in pressure and/or temperature can cause the hydrates to dissociate, resulting in the release

of gases. Several case studies such as Storegga slide, Cape Fear Slide. Beaufort Sea, Gulf of Mexico and Blake Ridge Collapse have suggested that there is a link between submarine slope failure and gas hydrates dissociation. Mienert et al., (2005), Jung and Vogt (2004) and Sultan et al., (2004) noted in the Norwegian continental margin that large submarine slides occurred due to gas hydrates dissociation.

\subsubsection{Sedimentation}

Sedimentation rates and types can affect the shear strength of the submarine soils. When sediment is deposited rapidly there is a rapid increase and delayed dissipation of pore pressure which reduces the strength of the soil. Kostaschuk and McCann (1989) showed how rapid sedimentation has caused slope failure in the Bella Coola Fjord in British Columbia. 


\subsubsection{Oversteepening}

Oversteepening is a gravity driven process which can make submarine slopes unstable. Schwab et al., (1991) explained that, when the seafloor becomes too steep due to tectonic movement, there is an increase of the shear stress experienced by the various soil layers. When slopes become steep enough, other triggering mechanism can easily initiate the failure of the slope. The same type of failure occurs in the northern slope of Puerto Rico as discussed by Schwab et al., (1991).

\subsubsection{Tidal variation}

Tidal drawdown in gassy seabed areas needs to be considered as a mechanism of instability. Tidal variations can cause unequal pore-pressure generation with depth and time due to the compressibility of the pore fluid. The effective stresses will be reduced during low tides and may initiate liquefaction flow of slopes due to partial drainage conditions (Atigh and Byrne, 2004). Under tidal variations on an unsaturated slope, failure is expected to occur for specific combinations of degree of saturation, soil permeability and tide period. For a specified degree of saturation and soil permeability, the possibility of failure increases as the tide period decreases. Tidal drawdown in the presence of gassy sediments was the triggering factor for the 1985 slope failure in the Fraser River Delta, (Chillarige et al., 1997 a). Robertson and Fear (1995) discussed about static and cyclic liquefaction of sands due to monotonic and earthquake loading. Table 2.3 shows statically induced liquefaction triggered by low tides. Haththotuwa and Grozic (2011) presented several case studies of submarine slope failures. 
Table 2.3: Statically induced liquefaction case studies, (Haththotuwa and Grozic, 2011)

\begin{tabular}{|c|c|c|c|}
\hline Site & Type of failure & Predominant soil type & Reference \\
\hline Howe Sound, 1955 & Low tides & Fine sand and gravel & Terzaghi 1956 \\
\hline Kitimat Fjord, 1975 & Low tides of $6 \mathrm{~m}$ & Loose silty sand & Morrison 1984 \\
\hline Nerlerk sand berms, 1983 & Fill placement & Loose sand & Sladen et al. 1985 \\
\hline Fraser River delta, 1985, & Low tides of $5 \mathrm{~m}$ & Loose fine sand silt & $\begin{array}{l}\text { McKenna and Luternauer, } \\
1987\end{array}$ \\
\hline The Netherlands & Low tides & Loose fine sand & Koppejan et al. 1948 \\
\hline Magdalena River delta, 1935 & Rapid sedimentation & Sand and silt & $\begin{array}{l}\text { Menard 1964; Morgenstern } \\
1967\end{array}$ \\
\hline Helsinki Harbour, 1935 & Rapid filling & Sand and silt & Andresen and Bjerrum 1967 \\
\hline Follafjord slides, 1952 & Dumping of dredged soils & Loose fine sand, silt & Terzaghi 1956; Bjerrum 1971 \\
\hline Orkdalsfjord, 1930 & Low tides & Loose fine sand, silt & $\begin{array}{l}\text { Terzaghi 1956; Andresen and } \\
\text { Bjerrum } 1967\end{array}$ \\
\hline Finnivaka slide, 1940 & Low tides & Loose fine sand, silt & Bjerrum 1971 \\
\hline Hommelvika, 1942 & Low tides & Loose fine sand & Bjerrum 1971 \\
\hline Trondheim, 1888 & Low tides & Loose fine sand, silt & Terzaghi 1956; Bjerrum 1971 \\
\hline Scripps Canyon, 1959, 1960 & Free gas and storm waves & Sand & Dill 1964; Morgenstern 1967 \\
\hline Puget Sound. 1985 & Low tides & Loose sand & Kraft et al. 1992 \\
\hline Skagway, Alaska, 1994 & Low tides of $4 \mathrm{~m}$ & Loose silty sand, silt & $\begin{array}{l}\text { N.R. Morgenstern, } \\
\text { unpublished } \\
\text { data, } 1995\end{array}$ \\
\hline
\end{tabular}

\subsection{Gassy sediments}

Gassy soils are commonly found in the seabed in the form of gas-charged sediments and are known to be widely distributed throughout the world. Sobkowicz and Morgenstern (1984) defined gassy soils as those which contain a large amount of dissolved gas in the pore fluid. Gas can exist in the seabed in three forms: in solution in the pore water, undissolved in the form of gas-filled voids, or as clathrates (gas hydrates). In the first case, the gas will have little effect on the physical properties of the seabed unless the ambient pressures are reduced. In the second case, the gas will affect the engineering properties of the seabed due to the high compressibility of the gas. In the third case, the gas only becomes hazardous if the clathrate melts (Sills and Wheeler, 1992). When the soil pore is filled with gas, it will behave like unsaturated or partially saturated soil unless

(a) the gas is very soluble as the case for methane in oil or $\mathrm{CO}_{2}$ in water or oil, or (b) very 
high in situ initial fluid pressure mentioned by Sobkowicz (1982). In the case of unsaturated or partially saturated soil, the voids of soil matrix being partially filled with water at pressure $u_{\mathrm{w}}$ and partly at a different pressure $u_{\mathrm{g}}$ with gas. Wroth and Houlsby (1985) defined three different types of unsaturated soil as shown in Figure 2.3.

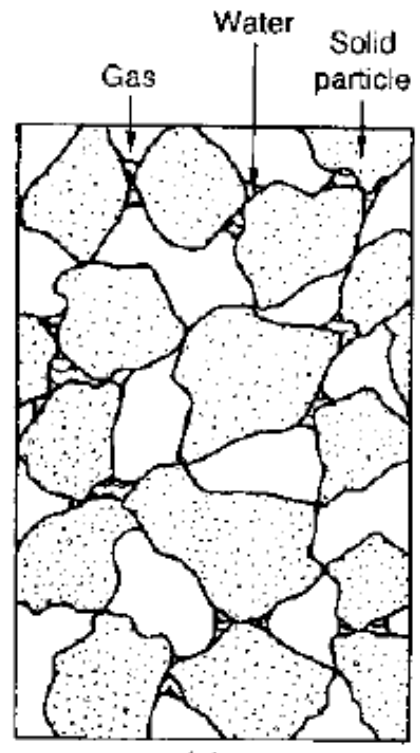

(a)

Continuousgas

Discontinuous water

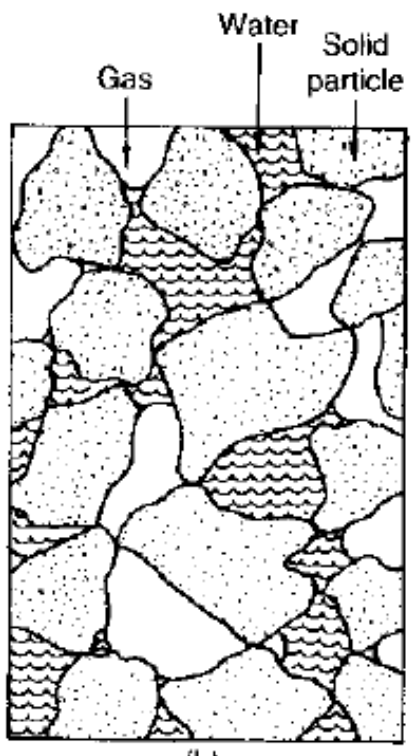

(b)

Continuous gas Continuous water

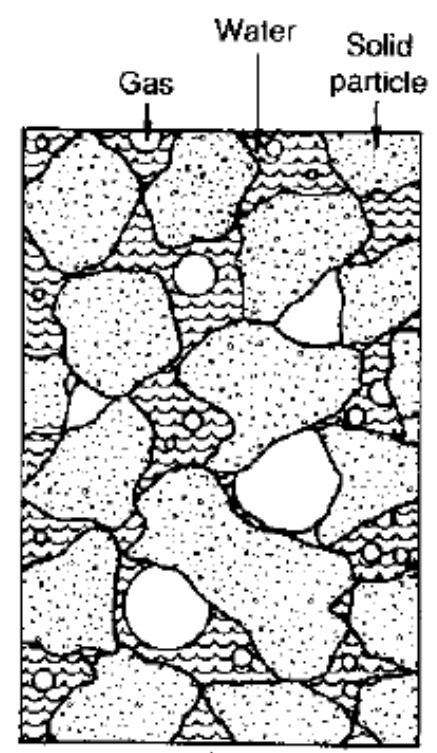

(c)

Discontinuous gas Continuous waler

Figure 2.3: Three structures of unsaturated or partially saturated soil, a. Low degree of saturation level, b. Intermediate degree of saturation level, c. High degree of saturation level. (Wroth and Houlsby, 1985)

In the case of low degree of saturation the gas phase is continuous and water phase is discontinuous, as shown in Figure 2.3(a). At an intermediate degree of saturation level both gas and water are continuous like Figure 2.3(b), while at high degree of saturation level the water is continuous but the gas in the form of bubbles is discontinuous as Figure 2.3(c). Wheeler (1988) noted that, the matrix of soils containing discrete bubbles can 
considerably vary, depending on the relative sizes of the soil particles and gas bubbles. If the gas bubbles are small compared to the particle size as shown in Figure 2.4 (a), then bubbles will fit within the void space without distortion of the soil structure (mainly coarse grained soil). Soil with small gas bubbles follows the same effective stress law as saturated soil, and the effect of the gas bubbles is to change the compressibility of the pore fluid. Figure 2.4(b) illustrates the opposite condition where the bubble sizes are much larger than the normal particle size (mainly fine grained soil). Gas pushes back the soil skeleton in the region of each bubble leaving a large gas filled void. Gas-water interfaces are formed by large number of small menisci which bridge the gap between the particles.

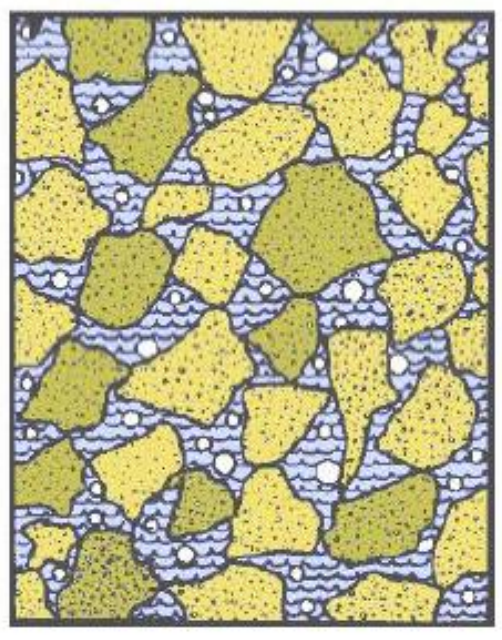

(a)

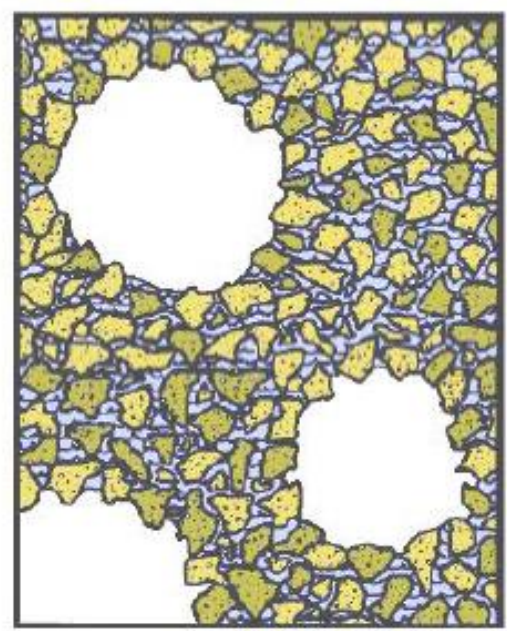

(b)

Figure 2.4: Microstructure of gassy soil. (a) When bubble size smaller than pore space,

(b) When bubble size larger than particle size (Wheeler, 1988). 
Offshore investigations in different locations sometimes indicated the presence of gas bubbles in the seabed. The occurrence of gassy sediments has been reported in all of the world's oceans at any depth by many researchers: North Sea (Hovland, 1993), Baltic Sea (Soderberg and Floden, 1992), Irish Sea (Taylor, 1992), Gulf of Mexico, Alaska (Esring and Kirby, 1977; Bryant and Roemer, 1983; MacDonald et al., 1990), Mississippi River Delta front (Whelan et al., 1978) and the marine sediments off Hong Kong (Premchitt et al., 1992). High concentrations of gas have been observed in the pore fluid of the Fraser River Delta sediments in British Columbia, (Christian et al., 1997 a). Soils found in marine environments are affected by the presence of free gas, with significant geotechnical implications with only a small amount of free gas. The presence of gas may alter the shear strength and settlement characteristics. Gas filled sediment could result in instability of the gassy soil matrix and contribute to flow liquefaction.

\subsubsection{Origin of gas}

The main gases found in seabed soils are carbon dioxide, hydrogen sulphide, ethane and methane. However, methane is the most common gas. Gas that occurs within the topmost $1000 \mathrm{~m}$ of seabed sediment is called shallow gas. All gases have either organic or inorganic origins. Grozic (1999) mentioned natural sources of gas, which are summarized in Table 2.4. 
Table 2.4: Source of Natural Gases (Grozic, 1999)

\begin{tabular}{lll}
\hline \multicolumn{2}{c}{ Sources of natural gas } \\
\hline Organic origins & Microbial degradation of organic matter in sediments & Biogenic \\
& Thermal degradation of organic matter in sediments & Thermogenic \\
& Destabilizating gas hydrates & \\
Inorganic origins & Volcanic and hydrothermal & Abiogenic \\
& "Deep-earth"/primordial gas
\end{tabular}

\subsubsection{Organic origins}

Gases produced from organic origins can be classified as either biogenic or petrogenic (thermogenic). In the top few meters of seabed sediments biogenic gas is generated mainly from bacterial activity. Off the coast of Peru bacterial activity was found hundreds of meters down (Parkes et al., 1990). Much of the gas produced by biogenic process escape to the surface and is lost to the atmosphere because the growth and metabolism of bacteria is very slow; the effects could be significant over a long period of time. In areas where rapid sedimentation occurs, shallow biogenic gas accumulations can be buried to depths well below those at which they were generated. Thermogenic gas is produced at high temperature and pressure from organic precursors and consequently normally at depths greater than $1000 \mathrm{~m}$. This gas is derived from organic material by thermal alteration and is hence sometimes referred to as thermogenic gas, (Floodgate and Judd, 1992). This gas migrates towards the surface and may be trapped as shallow gas 
accumulations. Most of the thermogenic hydrocarbons are formed in fine grained sedimentary rock.

\subsubsection{Inorganic origins}

Gases produced from inorganic origins are referred to as abiogenic. These gasses usually come from volcanic or hydrothermal sources or may be deep-earth gas. In certain conditions abiogenic carbon dioxide gas accumulations could be found in areas of limestone rock affected by geothermal heating. One such accumulation was found during excavations for the ENEL VI \& VI11 Nuclear Power Plants in Alto Lazio, Italy, (Grozic, 1999).

Gas hydrates represents another potential source of shallow gas. Gas hydrates are crystalline, ice-like compounds of water and natural gas. These gas hydrates occur in high pressure, low temperature regions. Gas from destabilized gas hydrates can migrate towards the seabed and be trapped as shallow gas.

\subsection{Liquefaction flow slides in submarine slopes}

Instability in cohesionless submarine slopes may occur due to liquefaction flow slides. Liquefaction can be a main reason for submarine slope failure and it has become a major concern due to its frequent occurrence. For a triggering flow slide in under water slope three conditions must be met, (Kramer, 1988): (1) soil must be susceptible to liquefaction; (2) slope must be relatively steep and high; and (3) an initiation mechanism must be present. A sudden local change in water pressure due to waves, increase of 
ground water outflowing during an extreme low tide, quick change in soil pressure due to dredging activities or pile driving could be an initiation mechanism (Silvis and Groot, 1995). Reduction of shearing resistance causes an increment of large strain during soil liquefaction. Liquefaction flow slides can be initiated by dynamic and static effects. Dynamic effects are earthquakes, surface waves and vibrations and static effects are tidal changes and sedimentation. Chillarige et al., (1997 a) discussed that, off the west coast of Canada, submarine liquefaction flow slides occurred in deltaic sand and silts which contain gas and were mainly triggered by tidal drawdown. In a gassy seabed soil, because of the compressibility of gas, pore pressure may increase during tidal variation. Change in pore pressure during low tide does not follow the total seabed pressure changes. These may reduce the effective stress and may lead to flow liquefaction failure of submarine slopes.

\subsection{Case studies related to submarine flow slides in gassy soils}

In order to explain the significance of submarine flow slides some detailed case histories are presented in this section.

\subsubsection{Fraser River Delta}

Fraser River Delta is the largest river in terms of both water and sediment discharge on the west coast of Canada. It is more than $1200 \mathrm{~km}$ long and drains an area in southern British Columbia in excess of $230,000 \mathrm{~km}^{2}$. It comprises a dyked floodplain, encompassing $1,000 \mathrm{~km}^{2}$, extending $23 \mathrm{~km}$ westward into the Strait of Georgia and south into Boundary Bay from a narrow gap in the Pleistocene uplands at New Westminster 
(Christian et al., 1997 a). McKenna et al., (1992) discussed the area around the Strait of Georgia as shown in Figure 2.5. The end of the submarine channel in Fraser River mouth is called the Sand Heads Sea valley and recognized as an area of seabed instability, (Kenyon and Turcotte, 1985). The mean annual discharge of the Fraser River is 3,400 $\mathrm{m}^{3} / \mathrm{s}$. Approximately $88 \%$ of the sediment-laden water is discharged by the main channel of Fraser River into the Strait of Georgia, (McKenna et al., 1992). Over 50\% of this sediment load is sand, (Milliman, 1980). Near the Sand Heads sediments are mostly medium to fine sand on the seafloor to fine silty sand to the seaward, (Kostaschuk et al., 1992). The mean and extreme tidal range at Sand Heads is $2.6 \mathrm{~m}$ and $5.4 \mathrm{~m}$ respectively, (McKenna et al., 1992). The Fraser River Delta is in a seismically active region and the largest zone of the delta soil is susceptible to seismic liquefaction, (Watts et al., 1992). Numerous site investigations on Fraser River Delta, British Columbia were investigated by Christian et al., (1997 a) who identified loose sand sediments mixed with gas at the mouth of the Fraser River main channel. In addition, the site investigations identified the existence of free gas comprising of methane up to $30 \mathrm{~m}$ below the seabed. The degree of saturation of the seabed is between 0.85 and 1.00. Tidal drawdown in the presence of gassy sediments was the main triggering factor for the 1985 slope failure in the Fraser River Delta, (Chillarige et al., 1997 a). Five known liquefaction flow slides were investigated by McKenna et al., (1992) near Sand Heads in the Fraser River Delta between 1970 and 1985. 


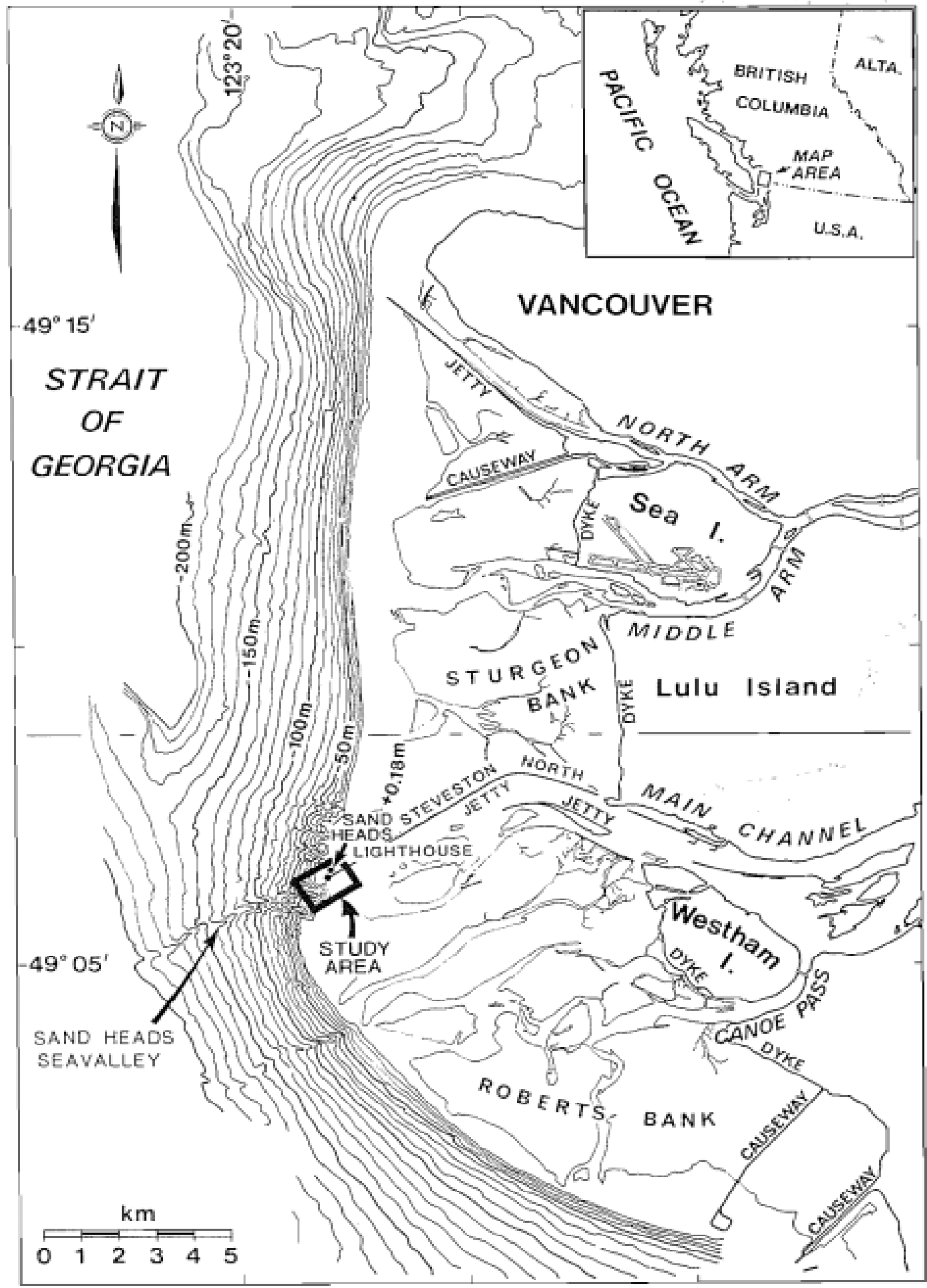

Figure 2.5: Fraser River Delta front, (Mckenna et al., 1992) 
These events were related to rapid sedimentation, tidal current waves, seismic activities and the presence of gas. At that time near Sand Heads a liquefaction flow event occurred with a loss of at least one million cubic meters of sediments and the failure pattern was retrogressive (Christian et al., 1997 a). Chillarige et al. (1995 a) examined the effect of tidal drawdown on gassy sediments. It was observed that the residual pore pressures in the sediments during low tide conditions could lead to triggering of flow liquefaction failures. Christian et al. (1997 b) concluded that the falling tide caused a reduction in effective stress leading to flow liquefaction in Fraser River Delta, is largely caused by the presence of small amount of gas. Extreme low tide condition triggers flow liquefaction failures. The initial flow slide removes support for the remaining gaseous sediments. These sediments will also be experiencing partially drained residual pore pressures during low tides. An undrained stress redistribution, as presented by Gu et al. (1993), can cause strain softening of the remaining unsupported sediments, which results in another flow slide. Progressive failure of the deposits, thus, continues generating a retrogressive flow slide.

\subsubsection{Eastern Gulf of Cadiz}

The Gulf of Cadiz is situated in the east-central Atlantic, west of the Strait of Gibraltar and southwestern Iberian Peninsula, Figure 2.6. The geological history of the Gulf of Cadiz is intimately related to plate tectonics and it is the interaction between Southern Eurasia and North Africa and is driven by two major mechanisms. More than one third offshore hazards resulted from sedimentary, oceanographic and tectonic process in Gulf 
of Cadiz (Baraza et al., 1999). In their work they also discussed that the main geologic hazards in Gulf of Cadiz are (a) failure of submarine slope; (b) erosion and sediment removal due to bottom currents; and (c) presence of sediments with biogenic gas.

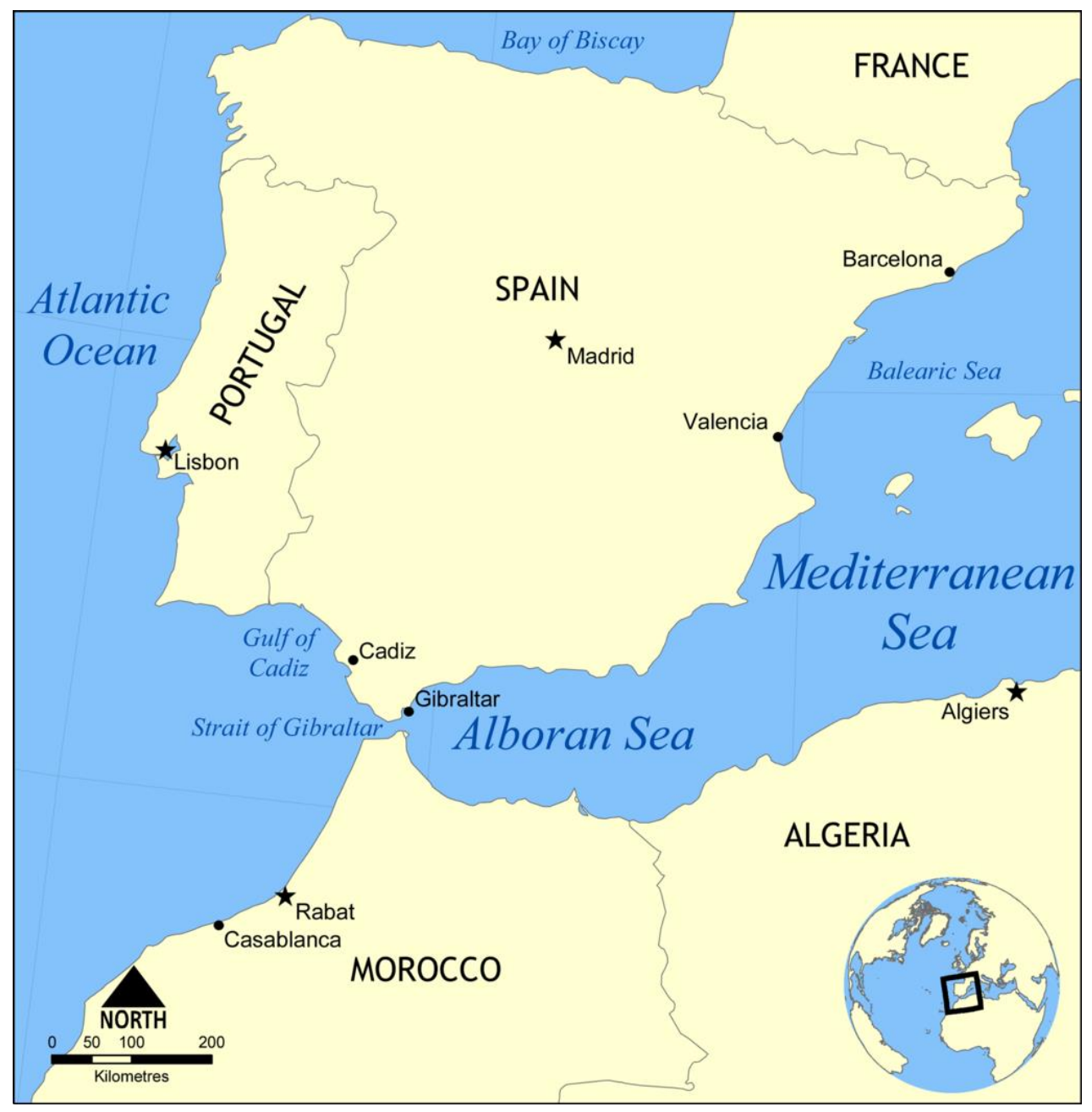

Figure 2.6: Map showing the gulf of Cadiz and surrounding area.(https://en.wikipedia.org / wiki/Gulf_of_C\%C3\%A1diz\#/media/File:Alboran_Sea_map.png)

In the Gulf of Cadiz gassy sediments cover more than $240 \mathrm{~km}^{2}$ in the upper slope and the gases are mainly biogenic gas. In the seabed the gas occurs at a near constant depth of 20 
$\mathrm{m}$ in areas covered by muddy sediment slope, (Baraza and Ercilla, 1996). Bouma et al., (1981) noted two main reasons for potential hazards due to presence of free gas: (a) may cause reduction of the sediment strength and favors the occurrence of instability; (b) sudden blowout of large volume of gas through the sediment may reduce the buoyancy of artificial structures or produce large seafloor collapse. Baraza and Ercilla, (1996) presented that the sediments downslope of the gassy area show evidence of being affected by the gravitational process.

\subsubsection{Mississippi River Delta, United States.}

The Mississippi is the largest river system in North America, which drains an area of $3,344,560 \mathrm{~km}^{2}$ with an average discharge approximately 15,360 cubic meters per second at the delta (Coleman et al., 1974). They also mentioned the approximate amount of sediment discharge is approximately $6.21 \times 10^{11} \mathrm{~kg}$ per year and the bed load was $90 \%$ fine sand. The suspended load is characterized by $65 \%$ of clay and $35 \%$ of silt and very fine sand. The delta lies on the coast of Louisiana, Gulf of Mexico, and is highly susceptible to submarine slope failures during extreme surface waves due to presence of large amount gas (Whelan et. al., 1975). They observed high concentrations of methane gas by investigating four core samples of Mississippi River Delta which correspond to lower shear strength zone. A submarine slope failure was reported in the vicinity of South pass block of Mississippi River delta, Gulf of Mexico in 1969 (Bea et al., 1983). Coleman et al. (1991) noted the main reason for slope failure around this area was large concentrations of methane gas triggered by the wave action. 


\subsubsection{Var Delta front landslide, SE France}

The location of the Var sedimentary system is in the Ligurian Sea (Northwest Mediterranean) and extends from the Nice coastline (Southeast France) shown in Figure 2.7 (Anthony and Julian, 1997).

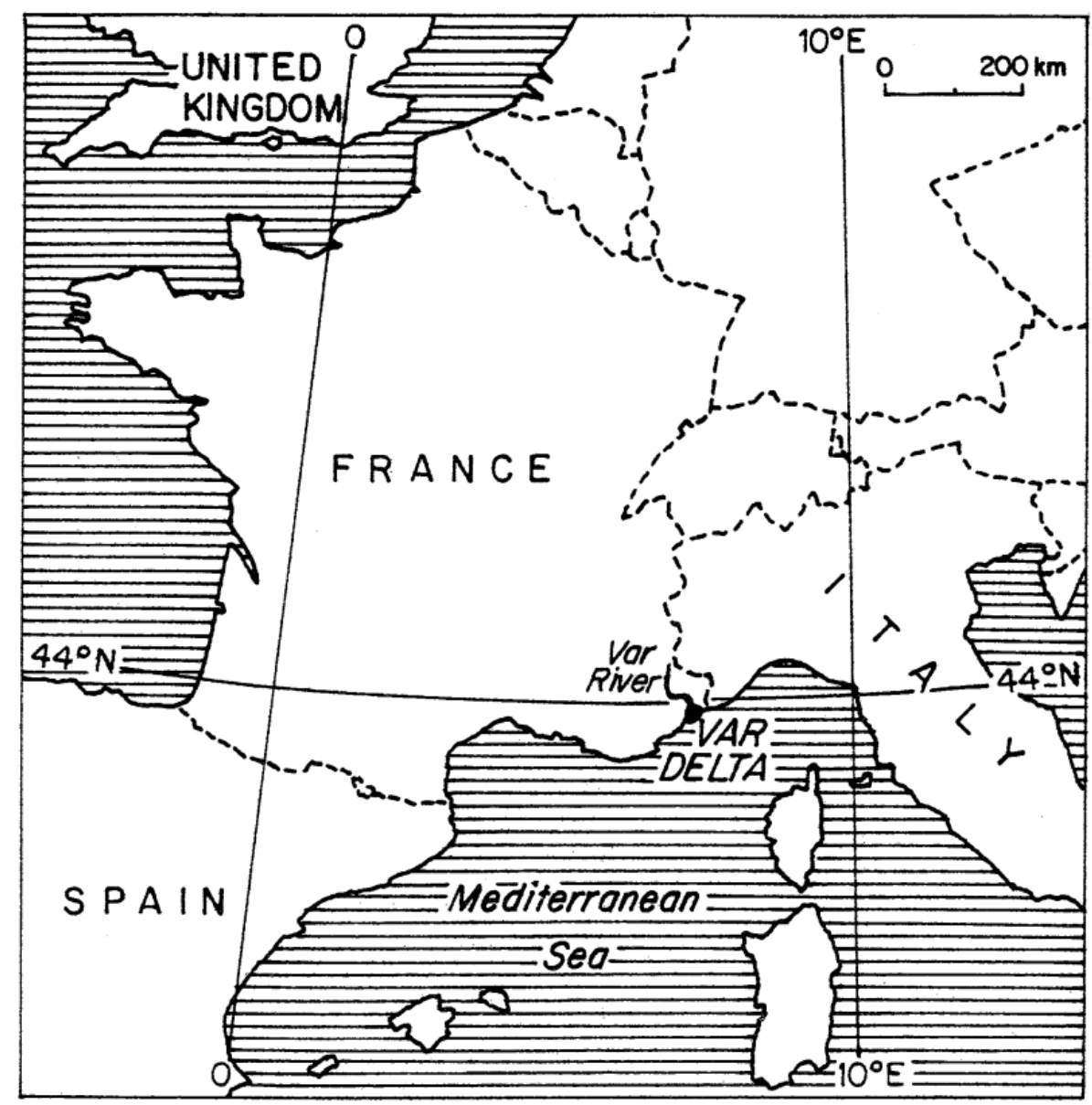

Figure 2.7: Location of the Var Delta (Anthony and Julian, 1997)

Anthony and Julian, (1997) also noted the slope of Var Delta front are cut by major canyons with numerous smaller steep-sided valleys and gullies. Several landslides occur at different places along the delta front. In 1979, there was a catastrophic submarine 
landslide in Var Delta which resulted in several casualties and damage to infrastructure (Anthony and Julian, 1997; Sultan et. al., 2010). According to Seed et al. (1988), tidal drawdown resulting from the deep offshore submarine slide initiated static liquefaction of loose sand of the Var Delta in 1979. Sultan et al. (2010) discussed some investigations carried out in 2007 near the slide zone of Var Delta and they found the presence of shallow gas in the sediment.

\subsection{Summary}

Understanding the stability of submarine slopes is very important to protect the offshore structure from the devastating impact of slope failures. As discussed earlier, slope failure can occur due to some potential triggering factors. Chillarige et al. (1997 a) and Haththotuwa and Grozic (2011) discussed flow liquefaction of submarine gassy slopes triggered by tidal variation especially at low tides. Partially saturated seabed of newly deposited Fraser River sands contain methane gas and possess susceptibility to flow liquefaction due to a time lag between tidal drawdown and pore pressure response as noted by Christian et al. (1997 b). Atigh and Byrne (2004) numerically modeled the liquefaction flow of loose Fraser River sand. In this current study, a novel physical model test was designed to investigate the stability of submarine gassy slopes triggered by tidal variations in a geotechnical centrifuge. The centrifuge model design, appropriate model preparation techniques and control and measurement systems were successfully developed and are discussed in the next chapters. 


\section{Chapter 3: Centrifuge Model Design}

\subsection{Introduction}

Submarine slope failure due to flow liquefaction is a major concern because of its effect on coastal and seabed infrastructure. Flow liquefaction may occur due to reduction in effective stress, when pore water pressure in soil elements rises under constant shear stress (Atigh and Byrne, 2004). In submarine gassy slopes, tidal variations as a triggering factor can cause unequal pore pressure generation with depth and time (Atigh and Byrne, 2004). The reduction of effective stress will occur during low tides and may induce flow liquefaction of slopes due to partial drainage conditions.

An effective stress approach based on an elastic-plastic stress-strain relationship was developed at the University of British Columbia (UBC) to model flow liquefaction of sand (Atigh and Byrne, 2003). Their fully coupled FLAC finite-difference analysis evaluated the behavior of both saturated and gassy deposits of loose Fraser River sand and Ottawa sand. Triggering of liquefaction resulting in retrogressive flow slides was predicted for a gassy underwater $3 \mathrm{H}$ : 1V slope similar to those observed near Sand Heads at the front of the Fraser River Delta (Figure 3.1). The main focus of this study is to observe the submarine slope failure of medium dense gassy sand triggered by tidal variation. Two centrifuge tests were conducted at C-CORE to experimentally investigate the stability of the submarine gassy slopes under tidal variation. 


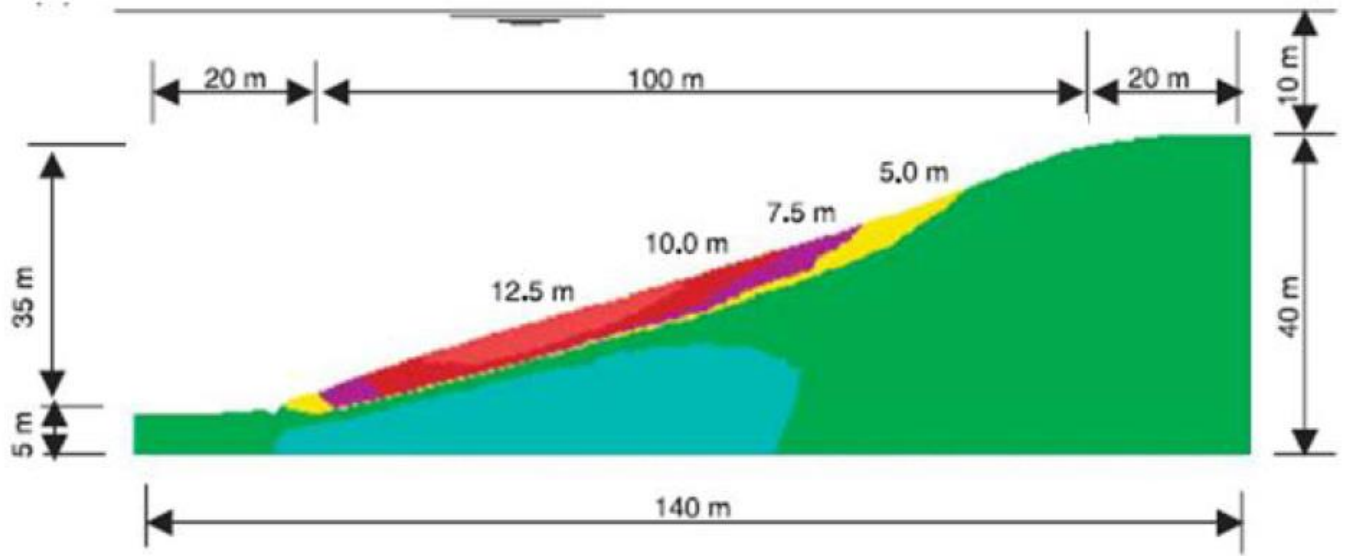

Figure 3.1: Horizontal movements caused by 2.5m tide, (Atigh and Byrne, 2003)

\subsection{Proposed centrifuge design:}

Following the success of CANLEX Modeling, Byrne (2003) designed a $1 / 50^{\text {th }}$ scale physical model test for 50g based on Atigh and Byrne (2004) analyses. A $2.5 \mathrm{~m}$ tidal range should induce failure of a gassy loose sand $2 \mathrm{H}$ : $1 \mathrm{~V}$ slope, within some constraints of the C-CORE centrifuge. Figure 3.2 shows the proposed geometry for the centrifuge model test.

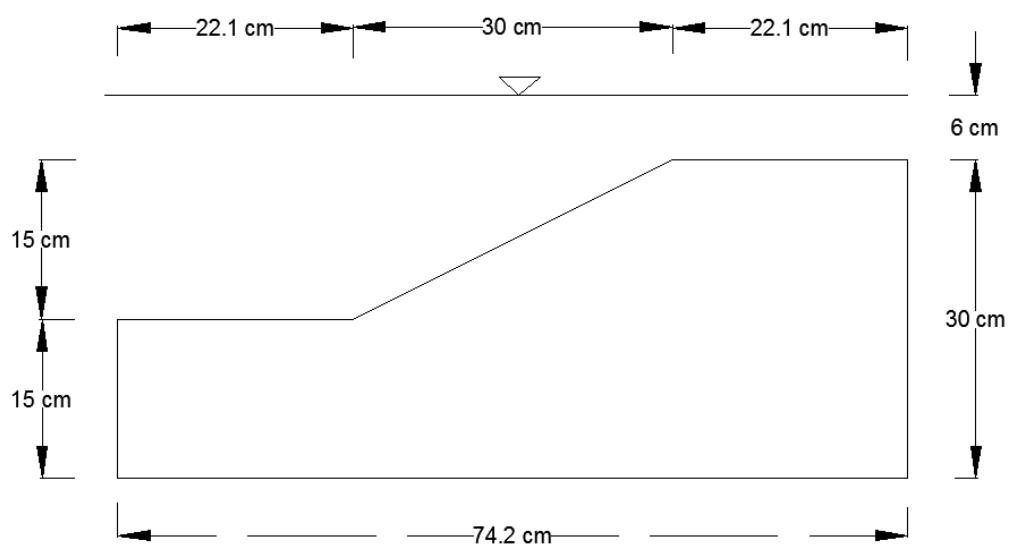

Figure 3.2: Geometry of the slope proposed by Byrne (2003) 
Tidal periods expected to cause model slope instability under $50 \mathrm{~g}$ were assessed using their FLAC analysis for loose gassy sand of varying degrees of saturation, $S_{\mathrm{r}}$ and saturated sand permeability. The expected delineations between a stable slope and a flow slide are shown in Figure 3.3.

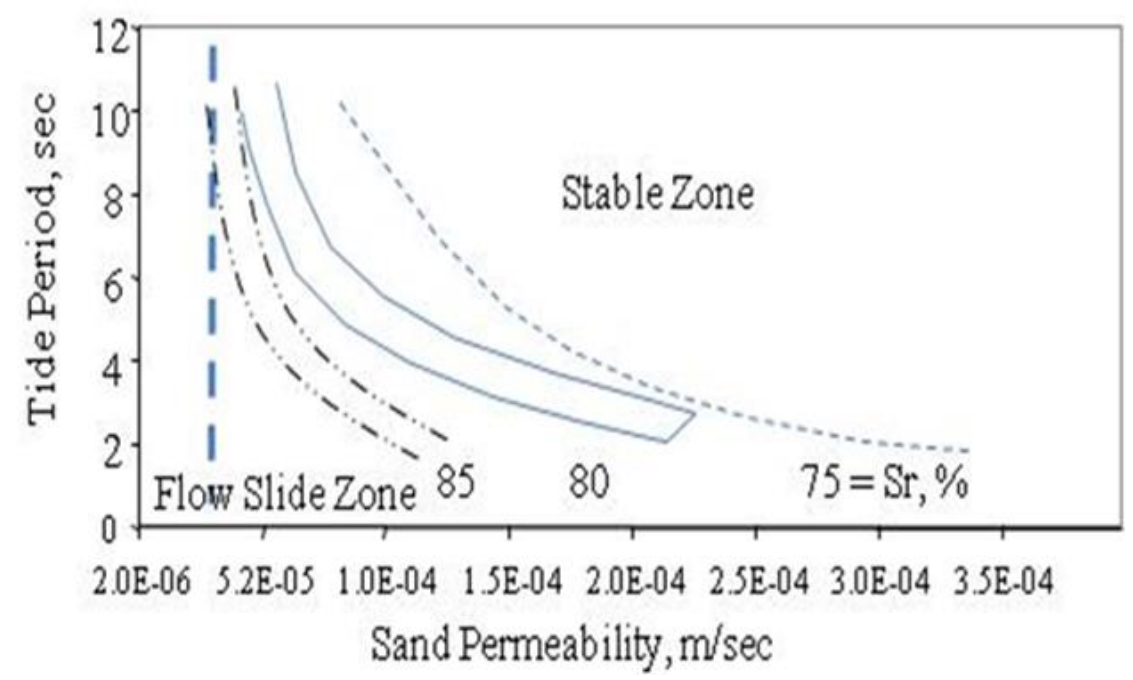

Figure 3.3: Predicted stability zones, Byrne (2003)

The model design of Byrne (2003), proposed successively decreasing the tidal period from say 20 to $2.5 \mathrm{sec}$ with a fixed tidal range of $25 \mathrm{kPa}$, on a slope model with a uniform degree of saturation, $S_{\mathrm{r}}$. The boundary for minimum tide period is defined by the minimum tidal period that will not result in dynamic wave effects. Two high or two low tides occur each day after 12 hours, which is equivalent to 17.3 seconds at $50 \mathrm{~g}$. Tidal period of 20 seconds at $50 \mathrm{~g}$ represents the actual tidal scenario of a day. Figure 3.4 shows the tidal variations in terms of change in water level for tide periods of 20, 10, 5 and 2.5 seconds. The slope model $S_{\mathrm{r}}$ could be decreased between tidal motion packets, releasing 
gas from the sand slope and the overlying free fluid. Up to 32 and 7 liters of gas and water were expected to be released from decreasing the $655 \mathrm{kPa}$ air pressure to atmospheric.

Centrifuge Test

Water level variation for tide of $+/-2.5 \mathrm{~m}=5 \mathrm{~m}$ and $\mathrm{T}=20,10,5$ and 2.5

sec

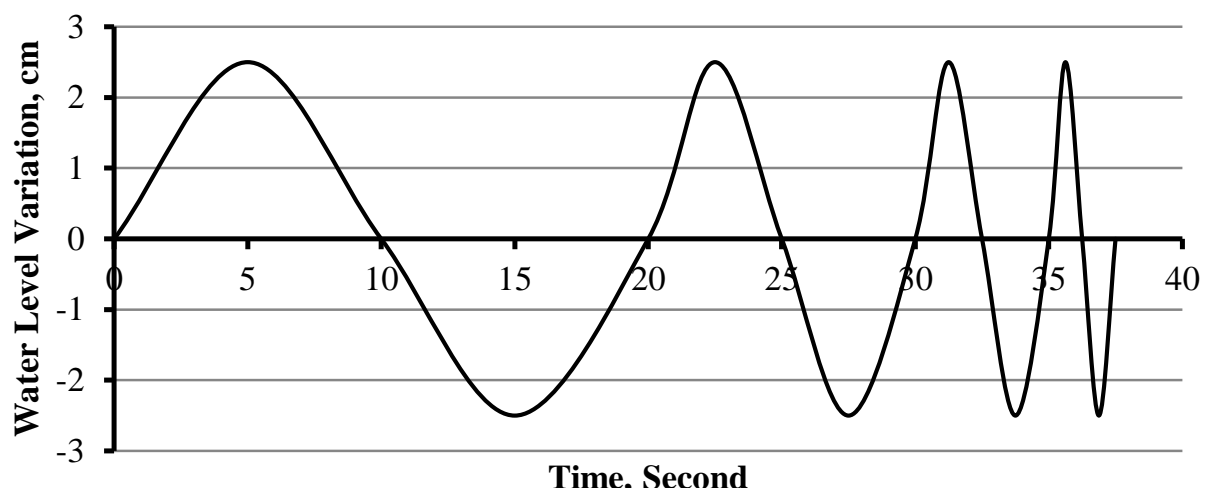

Time, Second

Figure 3.4: Tidal variations recommendations, Byrne (2003)

\subsection{Centrifuge slope geometry}

The internal dimensions of the high pressure box used in the centrifuge model preparation are $500 \mathrm{~mm}$ wide, $500 \mathrm{~mm}$ length and $500 \mathrm{~mm}$ height. The design slope geometry provided by Byrne (2003) was shortened in the toe and crest to $100 \mathrm{~mm}$ to fit the high pressure box (Figure 3.5). The model height was increased to $450 \mathrm{~mm}$ to minimize the pore fluid volume within the high pressure box. The slope angle of $26.5^{\circ}$ $(2 \mathrm{H}: 1 \mathrm{~V})$ used in this study is steeper than the $18.4^{\circ}$ submarine slopes identified to be susceptible to flow liquefaction by Silvis and Groot (1995). Sand was pluviated into the model container and vacuumed to achieve the slope profile shown in Figure 3.5. 


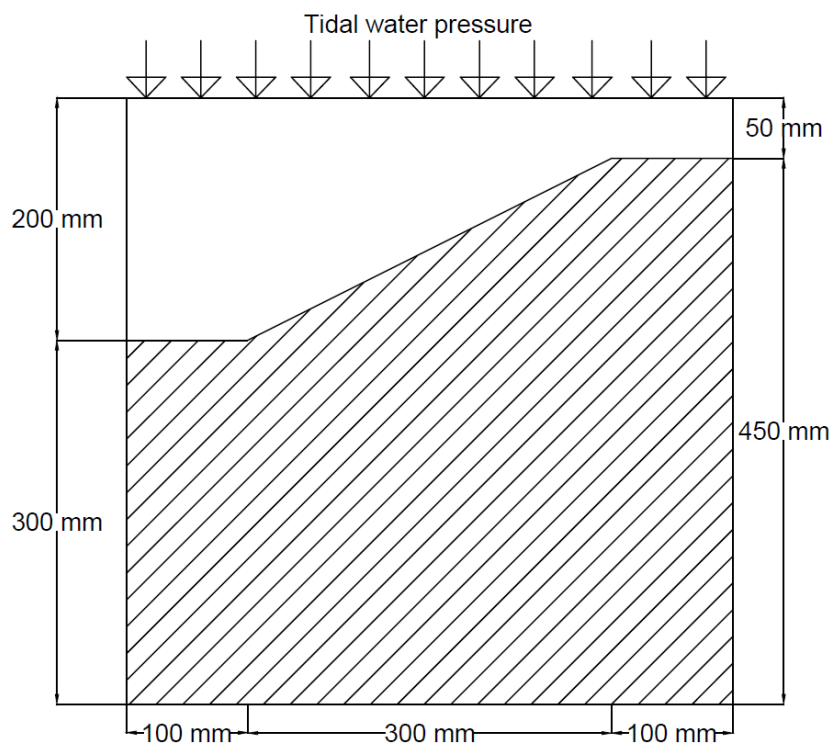

Figure 3.5: Model geometry

\subsection{Model material and relative density}

Byrne (2003), designed the centrifuge model by considering the properties of Fraser River Delta sand. In this study, the slope was constructed from Alwhite \#00 fine silica sand. The sand model was made in the high pressure box by means of air pluviation, similar to the methods by Ueno (1998). Figure 3.6 shows the grain size distribution of Alwhite \#00 fine silica sand. Sand raining method was used to maintain uniformity of the sand model. In the centrifuge proof test model relative density was $60 \%$ and corresponding measured permeability was $3 \times 10^{-5} \mathrm{~m} / \mathrm{sec}$. In second centrifuge test model relative density was $48 \%$ with an estimated permeability of $3.8 \times 10^{-5} \mathrm{~m} / \mathrm{sec}$. This relative density was measured after finishing the sand raining when the model was dry. 


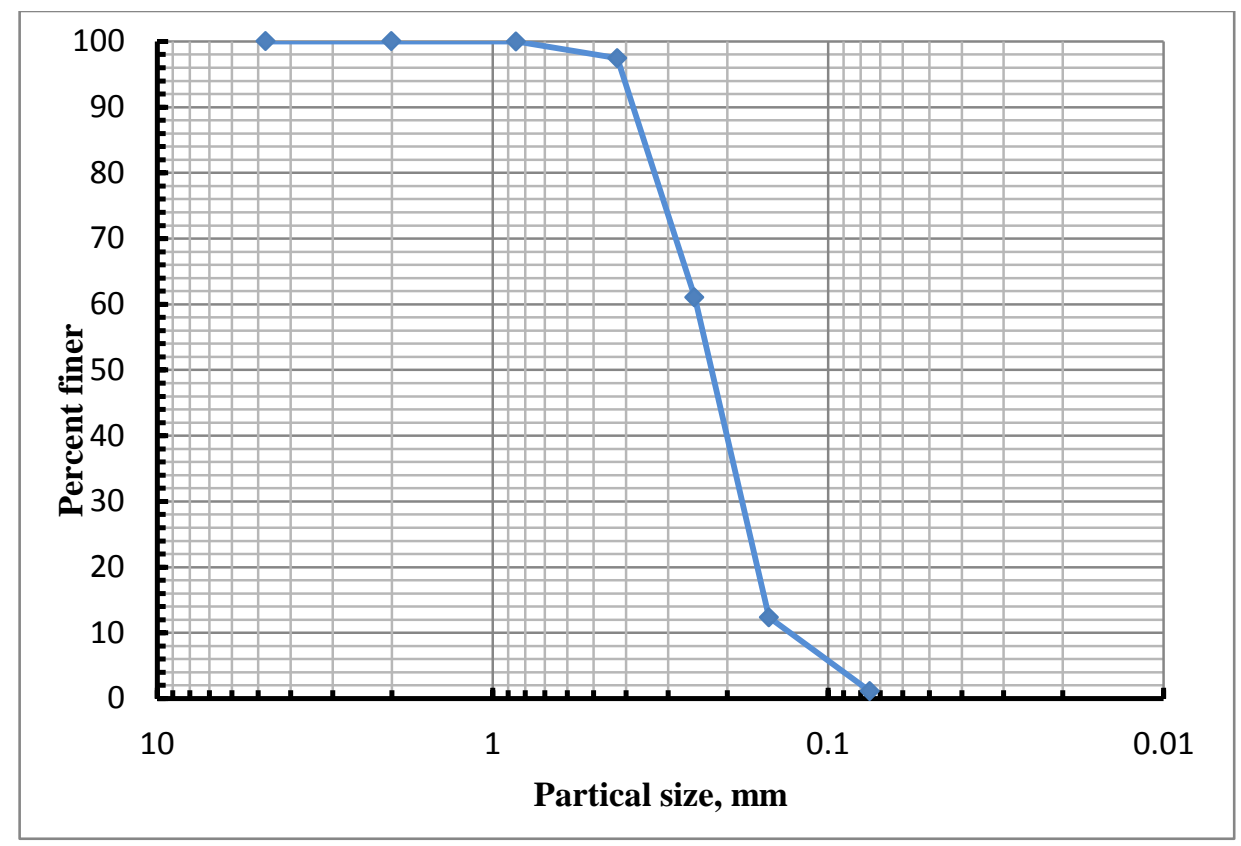

Figure 3.6: Alwhite \#00 silica sand grain size distribution

\subsection{Gas selection and initial pressure}

In order to make an unsaturated gassy soil, the soil was saturated with a gassy liquid under a high pressure of $\mathrm{P}_{1}$ at $1 \mathrm{~g}$. During centrifuge test at $50 \mathrm{~g}$, the pressure drops to a lower value, $\mathrm{P}_{2}$. This causes gas to evolve from solution to form bubbles and result in partial saturation. Moreover, before introducing the gassy liquid to the soil, it was kept under high pressure of $\mathrm{P}_{1}$ at room temperature for 24 hours. The process of saturation was done very slowly not to have a slope failure during the saturation.

The required amount of pressure can be calculated using Henry and Boyle's law which is:

$S_{r}=\frac{P_{2}-P_{1} H}{P_{2}(1-H)}$ 
The Strongbox pressure varies within the soil depth, so the calculation is done for the middle of the slope. The variation in the degree of saturation from top and bottom of the sample is not very significant as shown in Table 3.1.

The main gases found in the marine shallow sediments are carbon dioxide, hydrogen sulfide and ethane, but methane is the most abundant. The solubility coefficient of methane $\left(\mathrm{CH}_{4}\right)$ is $0.034 \mathrm{~L} / \mathrm{L}$ of fresh water at $20^{\circ} \mathrm{C}$ (Yamamoto et.al, 1976). The sealed centrifuge strongbox used in this test program can hold gas saturated water up to $1 \mathrm{MPa}$ pressure. At atmospheric pressure, the lowest degree of sand saturation by using centrifuge strongbox is then $85 \%$ with methane. A gas with higher solubility in water is required to achieve controllable $\mathrm{Sr}$ below 75\%. Carbon dioxide is very soluble, but cannot provide controllable $\mathrm{Sr}$ especially under the pressure gradients across a centrifuge model test. Ethylene $\left(\mathrm{C}_{2} \mathrm{H}_{6}\right)$, krypton and xenon gases are appropriate choices and industrially available. Ethylene was selected as it is most cost effective, as krypton and xenon are very expensive.

For ethylene gas Henry's constant is $\mathrm{H}=0.114982$ (http://www.nanomedicine.com /NMI/Tables/9.2.jpg). Table 3.1 represents the maximum absolute pressure at the bottom of the soil is $980.7 \mathrm{kPa}<1 \mathrm{MPa}$. For argon Henry's constant is $\mathrm{H}=0.03425$ (https://en.wikipedia.org/wiki/Henry\%27s_law\#Henry.27s_law_solubility_constants).

Table 3.2 represents the maximum absolute pressure at the bottom of the soil is 1210.7 $\mathrm{kPa}>1 \mathrm{MPa}$. For lower degree of saturation even higher initial pressures are required, so argon is not a good choice. 
Table 3.1: Strongbox Pressure variation during the test with ethylene as a pore fluid gas [All pressures are absolute]

\begin{tabular}{|c|c|c|c|c|c|c|c|c|c|c|c|c|c|}
\hline \multirow{2}{*}{$\begin{array}{c}\text { Initial } \\
\mathbf{P}_{\mathbf{0 1}} \\
(\mathrm{kPa})\end{array}$} & \multirow{2}{*}{$\begin{array}{c}\text { During } \\
\text { the test }\end{array}$} & \multicolumn{3}{|c|}{ Slope crest } & \multicolumn{3}{|c|}{ Middle of the slope } & \multicolumn{3}{|c|}{ Slope toe } & \multicolumn{3}{|c|}{ Bottom of soil } \\
\hline & & $\begin{array}{c}\mathbf{P}_{\mathbf{s 1}} \\
(\mathrm{kPa})\end{array}$ & $\begin{array}{c}\mathbf{P}_{\mathbf{s 2}} \\
(\mathrm{kPa})\end{array}$ & $\begin{array}{l}S r_{\mathrm{s}} \\
(\%)\end{array}$ & $\begin{array}{c}\mathbf{P}_{\mathbf{m} 1} \\
(\mathrm{kPa})\end{array}$ & $\begin{array}{c}\mathbf{P}_{\mathbf{m} 2} \\
(\mathrm{kPa})\end{array}$ & $\begin{array}{l}S r_{\mathrm{m}} \\
(\%)\end{array}$ & $\begin{array}{c}\mathbf{P}_{\mathbf{t 1}} \\
(\mathrm{kPa})\end{array}$ & $\begin{array}{c}\mathbf{P}_{\mathbf{t} 2} \\
(\mathrm{kPa})\end{array}$ & $\begin{array}{c}S r_{\mathrm{t}} \\
(\%)\end{array}$ & $\begin{array}{c}\mathbf{P}_{\mathbf{b} \mathbf{1}} \\
(\mathrm{kPa})\end{array}$ & $\begin{array}{c}\mathbf{P}_{\mathbf{b} 2} \\
(\mathrm{kPa})\end{array}$ & $\begin{array}{l}S r_{\mathbf{b}} \\
(\%)\end{array}$ \\
\hline 760 & 500 & 833.5 & 573.5 & 95 & 882.6 & 622.6 & 97 & 931.6 & 671.6 & 98 & 980.7 & 720.7 & 99 \\
\hline 760 & 360 & 833.5 & 433.5 & 90 & 882.6 & 482.6 & 92 & 931.6 & 531.6 & 94 & 980.7 & 580.7 & 95 \\
\hline 760 & 280 & 833.5 & 353.5 & 85 & 882.6 & 402.6 & 88 & 931.6 & 451.6 & 91 & 980.7 & 500.7 & 93 \\
\hline
\end{tabular}

Table 3.2: Strongbox Pressure variation during the test with argon as a pore fluid gas [All pressures are absolute]

\begin{tabular}{|c|c|c|c|c|c|c|c|c|c|c|c|c|c|}
\hline Initial & During & \multicolumn{3}{|c|}{ Slope crest } & \multicolumn{3}{|c|}{ Middle of the slope } & \multicolumn{3}{|c|}{ slope toe } & \multicolumn{3}{|c|}{ bottom of soil } \\
\hline $\begin{array}{c}\mathbf{P}_{\mathbf{0 1}} \\
(\mathrm{kPa})\end{array}$ & $\begin{array}{c}\mathbf{P}_{02} \\
(\mathrm{kPa})\end{array}$ & $\begin{array}{c}\mathbf{P}_{\mathbf{s 1}} \\
(\mathrm{kPa})\end{array}$ & $\begin{array}{c}\mathbf{P}_{\mathbf{s 2}} \\
(\mathrm{kPa})\end{array}$ & $\begin{array}{c}S r_{\mathrm{s}} \\
(\%)\end{array}$ & $\begin{array}{c}\mathbf{P}_{\mathbf{m} 1} \\
(\mathrm{kPa})\end{array}$ & $\begin{array}{c}\mathbf{P}_{\mathbf{m} 2} \\
(\mathrm{kPa})\end{array}$ & $\begin{array}{l}S r_{\mathbf{m}} \\
(\%)\end{array}$ & $\begin{array}{c}\mathbf{P}_{\mathbf{t 1}} \\
(\mathrm{kPa})\end{array}$ & $\begin{array}{c}\mathbf{P}_{\mathrm{t} 2} \\
(\mathrm{kPa})\end{array}$ & $\begin{array}{l}S r_{\mathrm{t}} \\
(\%)\end{array}$ & $\begin{array}{c}\mathbf{P}_{\mathbf{b 1}} \\
(\mathrm{kPa})\end{array}$ & $\begin{array}{c}\mathbf{P}_{\mathbf{b 2}} \\
(\mathrm{kPa})\end{array}$ & $\begin{array}{l}S r_{\mathbf{b}} \\
(\%)\end{array}$ \\
\hline 990 & 100 & $1,063.6$ & 173.6 & 81.8 & $1,100.4$ & 210.4 & 85.0 & $1,137.2$ & 247.2 & 87.2 & $1,210.7$ & 320.7 & 90.2 \\
\hline
\end{tabular}

$\mathrm{Ps}_{1}, \mathrm{Pm}_{1}, \mathrm{Pt}_{1}, \mathrm{~Pb}_{1}=$ Initial pressure of slope crest, middle, toe and bottom respectively.

$\mathrm{Ps}_{2}, \mathrm{Pm}_{2}, \mathrm{Pt}_{2}, \mathrm{~Pb}_{2}=$ Pressure during the test of slope crest, middle, toe and bottom respectively.

$S r_{\mathrm{s}}, S r_{\mathrm{m}}, S r_{\mathrm{t}}, S r_{\mathrm{b}}=$ Slope crest, middle, toe and bottom degree of saturation respectively. 
Figure 3.7 shows the pressure definitions used to generate Tables 3.1 and 3.2. Here, $\mathrm{P}_{\mathrm{s}}$, $\mathrm{P}_{\mathrm{m}}, \mathrm{P}_{\mathrm{t}}$ and $\mathrm{P}_{\mathrm{b}}$ represent the pressures at slope crest, middle, toe and bottom respectively. Suffix 1 and 2 represents the initial pressures and reduced pressures during the test.

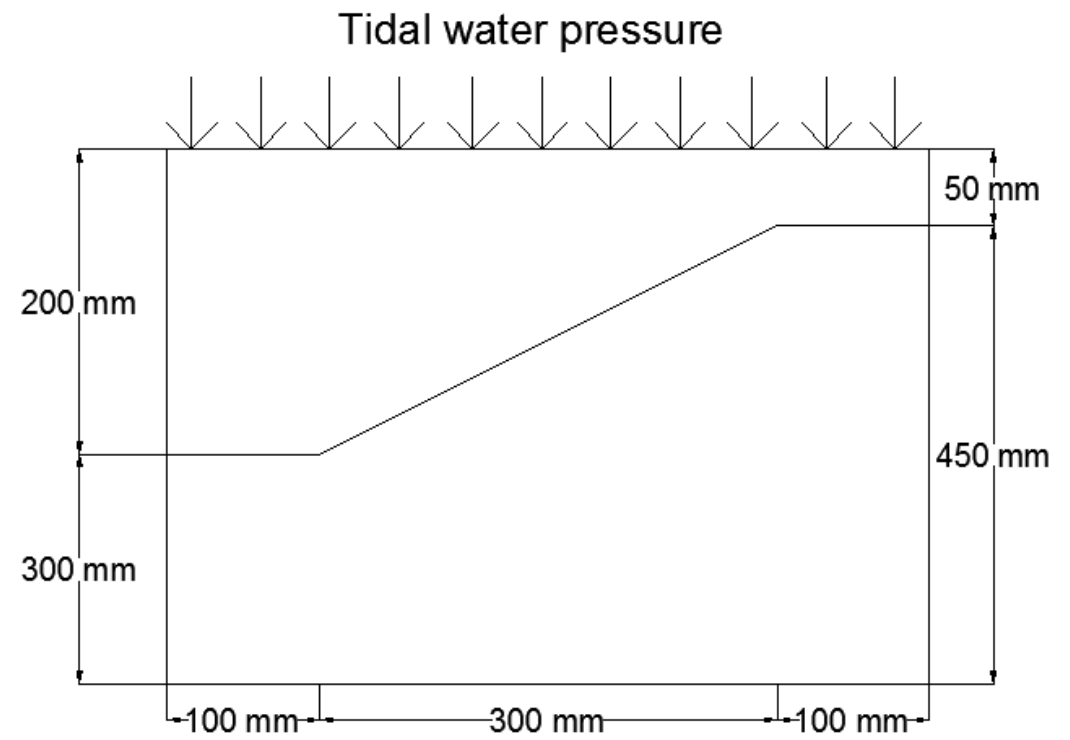

Pressure

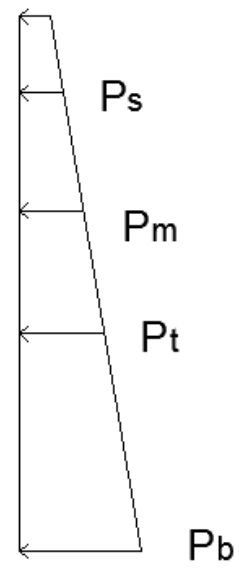

Figure 3.7: Slope geometry with pressure variation

Ethylene, like methane, is flammable and potentially explosive. However, only $100 \mathrm{gm}$ of ethylene is contained within the pressurised strongbox. Ethylene is used commercially to ripen fruit. Special procedures were maintained in the lab to work safely with ethylene especially during model preparation and centrifuge testing. Any ethylene vented was released slowly in well ventilated areas into an air stream away from ignition sources. 


\subsection{Measurement of Degree of saturation}

Under tidal variations on an unsaturated slope, failure is expected to occur for specific combinations of degree of saturation, soil permeability and tidal period, See Figure 3.3. Possibility of failure increases as the degree of saturation and permeability decrease. For a specified degree of saturation and soil permeability, the possibility of failure increases as the tide period decreases. With decreasing the pressure of the strongbox, the gas in the pore fluid expands and reduces the degree of saturation. So during the centrifuge test it is important to know the degree of saturation. In this study, the performance of three different types of sensor was evaluated to find out the one suitable for the centrifuge tests: (i) Water Scout SM 100 Soil Moisture Sensors, (ii) Time Domain Reflectometry (TDR), and (iii) VH400 series soil moisture sensor. The results obtained from the soil moisture sensors and its suitability in centrifuge model testing are explained below.

\subsubsection{Water Scout SM 100 Soil Moisture Sensors}

The Water Scout SM 100 soil moisture sensor is made up of two electrodes that function as a capacitor, with the surrounding soil serving as the dielectric. An $80 \mathrm{MHz}$ oscillator drives the capacitor and a signal proportional to the soil's dielectric permittivity is converted to the output signal. The dielectric permittivity of water is much greater than

air, soil minerals and organic matter. So, changes in water content can be detected and correlated to the soil's moisture content. This sensor measures volumetric water content (VWC) of soil. Figure 3.8 shows the Water Scout SM 100 soil moisture sensor. 


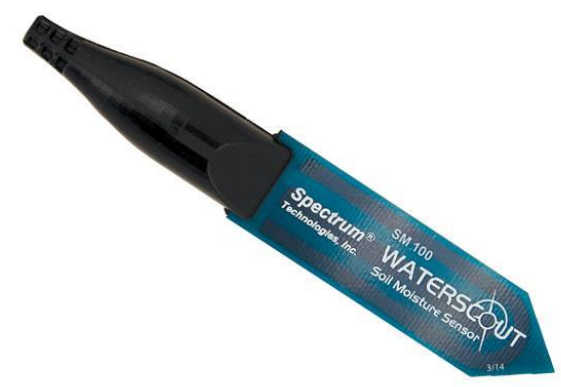

Figure 3.8: Water Scout SM 100 Soil Moisture Sensor. (http://www.specmeters.com/ weather-monitoring/sensors-and-accessories/sensors/soil-moisturesensors/sm 100

To calibrate the SM 100 soil moisture sensor, the sensor was placed in a container filled with Alwhite \#00 fine silica sand and water was used as a pore fluid. Figure 3.9 shows the calibration results where $\mathrm{VWC}, \mathrm{Sr}$ and $\mathrm{v}$ is the volumetric water content, degree of saturation and voltage provided by the sensor respectively.

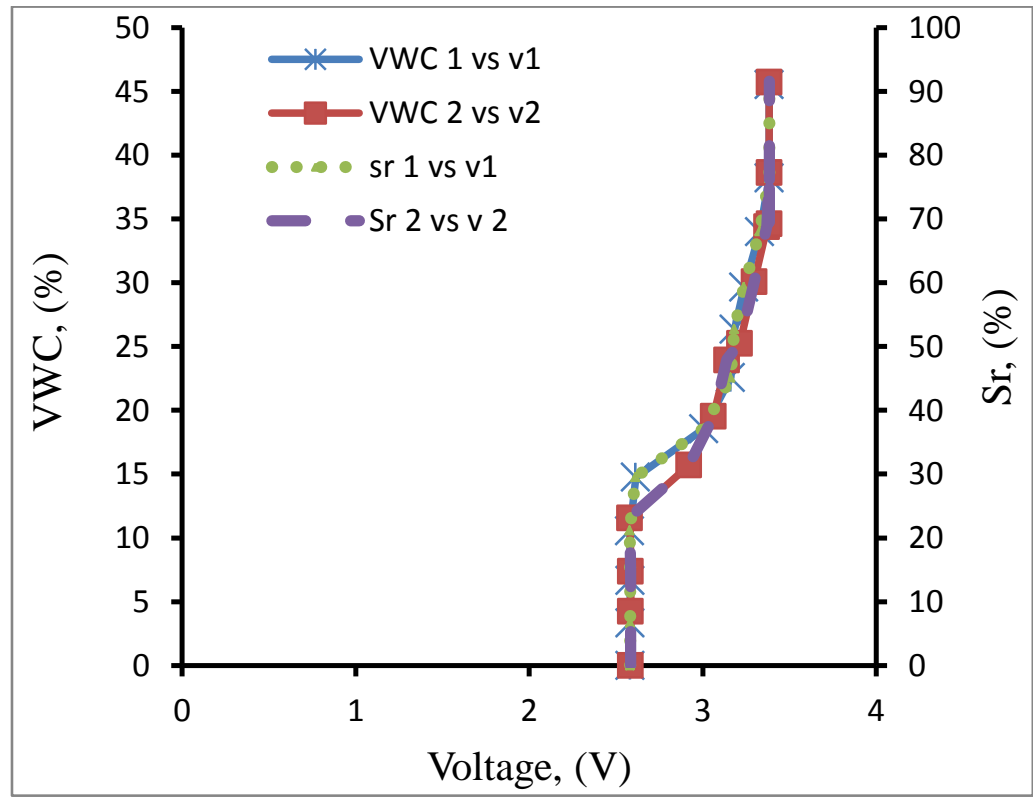

Figure 3.9: Calibration of SM 100 Soil Moisture sensor in Alwhite \#00 fine silica sand 
By using this sensor it is only possible to identify the degree of saturation level between 30 to $70 \%$. At all other degree of saturations levels, it shows a uniform voltage. In this current study, the target degree of saturation level decreases from fully saturated to $70 \%$. So, the SM 100 Soil Moisture sensor is not suitable for this study.

\subsubsection{Time Domain Reflectometry (TDR)}

Time Domain Reflectometry (TDR) is a relatively new method for measurement of soil water content. The main advantages of the TDR method over other methods for repetitive soil water content measurement is better accuracy to within 1 or $2 \%$ of volumetric water content. Figure 3.10 shows the Tektronix 1502 B metallic TDR unit which was used for the calibration test. One TDR cable tester (Tektronix 1502B) was used to get the waveform by using a three prong TDR probe of $15 \mathrm{~cm}$ long.

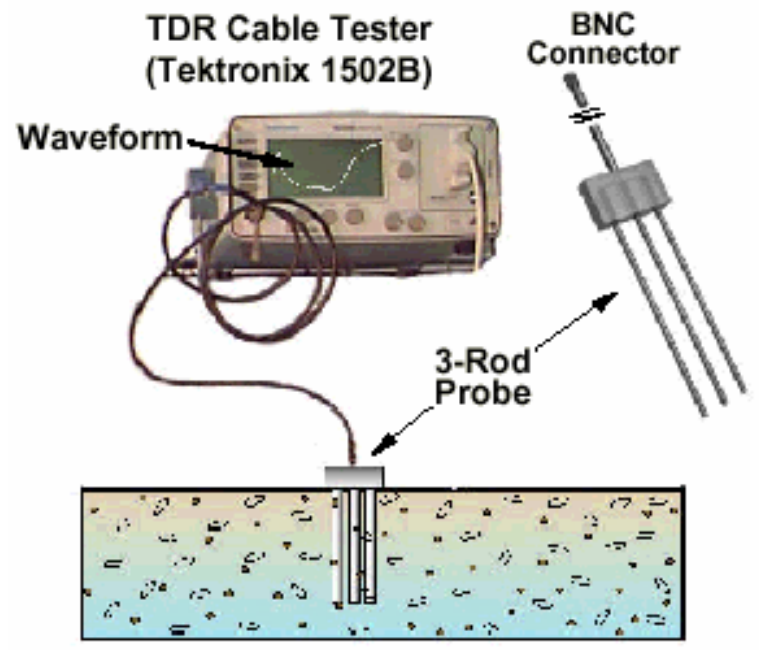

Figure 3.10: Tektronix 1502 B metallic TDR unit. (http://www.testequipmentdepot.com /usedequipment/tektronix/tdrs/1502b1503b.htm?gclid=CN_b4cCZ98gCFc8Y HwmCUBMw) 
This three prong TDR probe was placed in an Alwhite \#00 fine silica sand filled container and water introduced to the container bottom. TDR cable tester provides a waveform for each reading which corresponds to a bulk dielectric constant $\mathrm{K}_{\mathrm{b}}$. Calibration results from Figure 3.11 shows that, the bulk dielectric constant varies with the degree of saturation level between $0-100 \%$. So, Tektronix 1502 B metallic TDR unit is suitable for using in the centrifuge model test. But, the TDR probe was not suitable to submerge into the sand slope because of its probe length and relatively high equipment expense. To get a cheaper soil moisture sensor, VH400 series soil moisture sensor was tested in the lab floor. The results obtained from the test are described below.

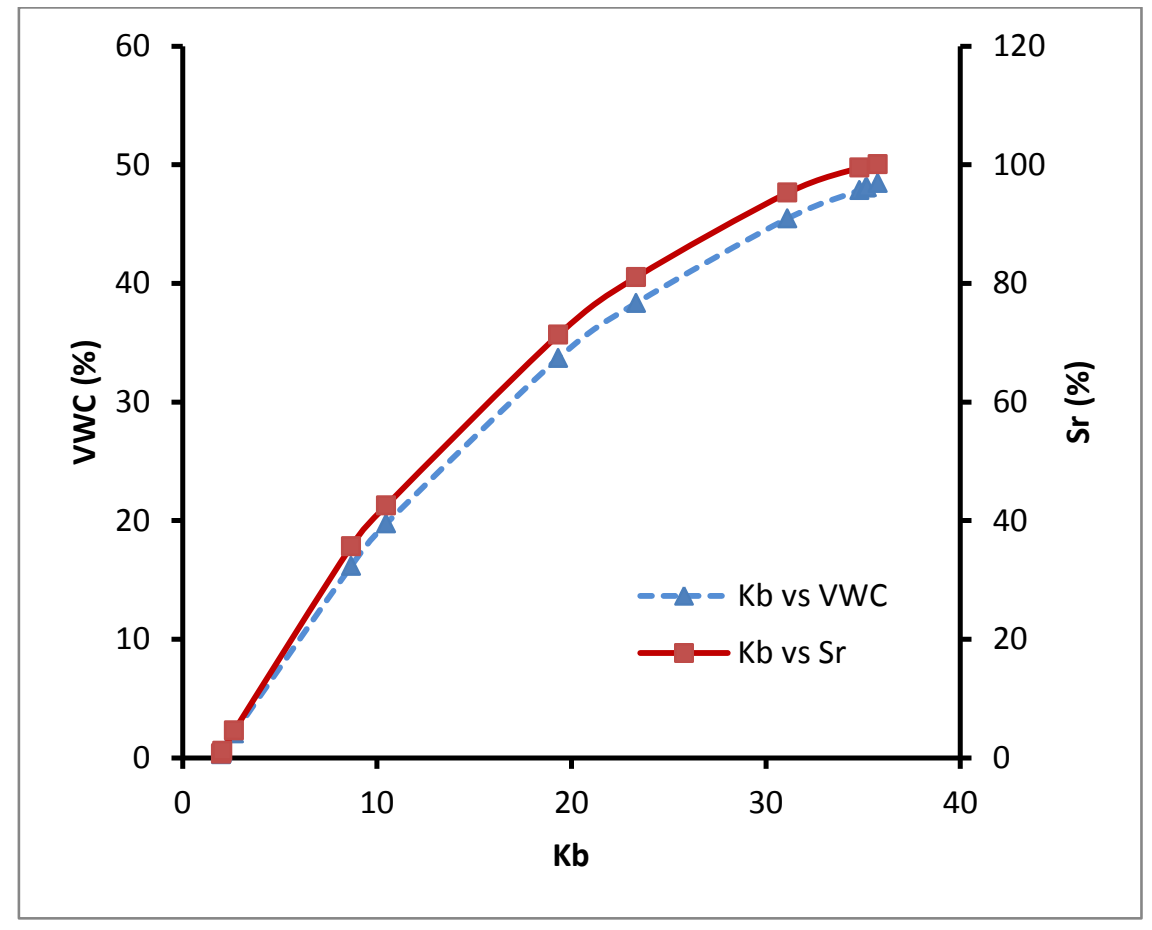

Figure 3.11: Calibration of TDR unit in Alwhite \#00 fine silica sand 


\subsubsection{VH400 Soil moisture sensor}

The low power VH400 series soil moisture sensor has a $94 \mathrm{~mm}$ long probe, Figure 3.12. Output of the sensor is DC voltage which is proportional to water content and provides an accurate reading in less than 1 second. A relation can be made between voltage and volumetric water content, ultimately degree of saturation. VH400 series soil moisture sensor measures the dielectric constant of soil using transmission line techniques. It is insensitive to water salinity, and does not corrode over time.

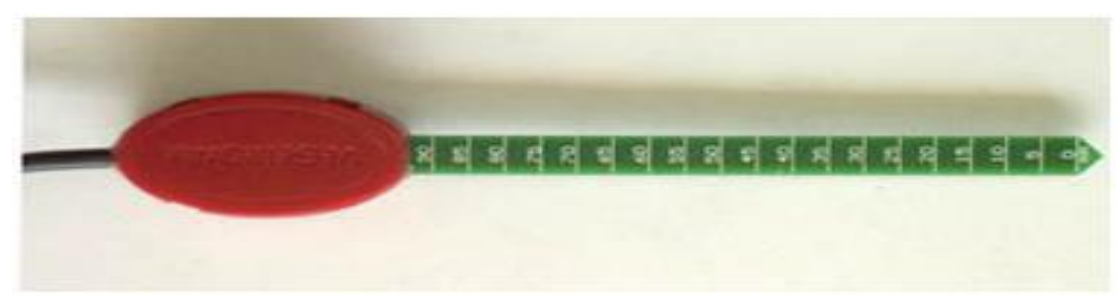

Figure 3.12: VH400 soil moisture sensor

\subsubsection{Simple calibration}

The soil moisture sensor was placed in Alwhite \#00 silica sand container for calibration. Water was added through the bottom and sensor voltage recorded. The amount of water added into the container provided the volumetric water content. Figure 3.13 shows the calibration of VH400 sensor in Alwhite\#00 fine silica sand. It shows a good agreement in degree of saturation while adding water in the soil contrainer. 


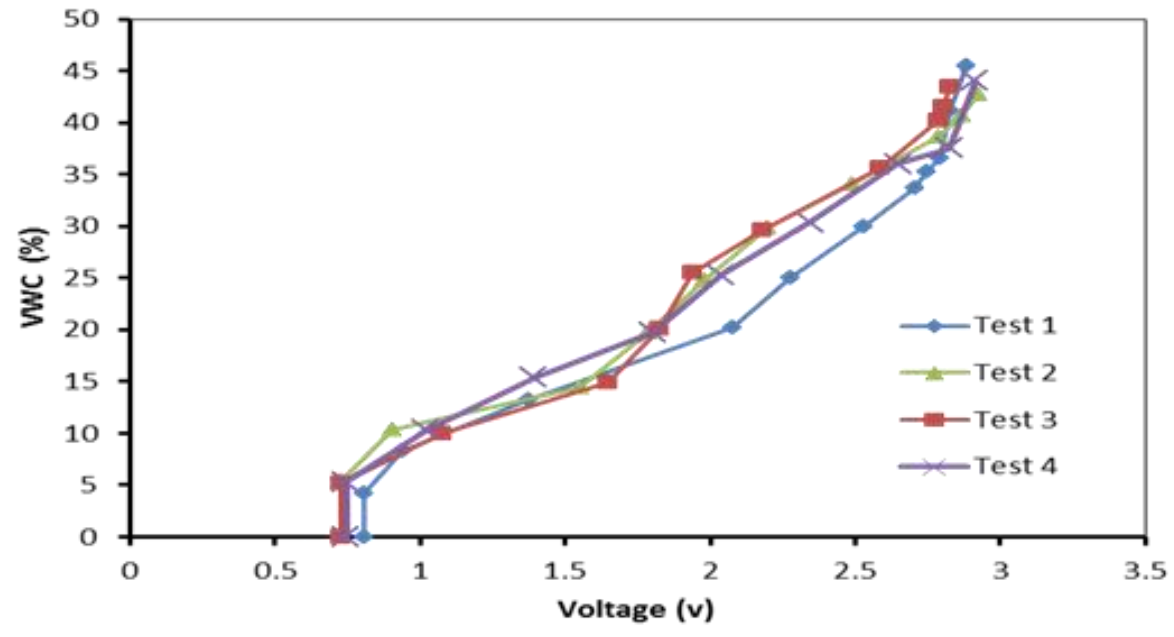

Figure 3.13: Calibration of VH400 sensor in Alwhite \#00 fine silica sand

\subsubsection{Column Calibration}

The sensor was then calibrated in a column to simulate model preparation conditions. Figure 3.14 shows the sand column made of Alwhite \#00 fine silica sand with a coarse sand layer in the bottom. Sample preparation method was the same method as centrifuge model preparation. Figure 3.15 shows the lab setup for sand column test. A data acquisition channel (DAQ channel) was used to read and record data provided by the sensor. 


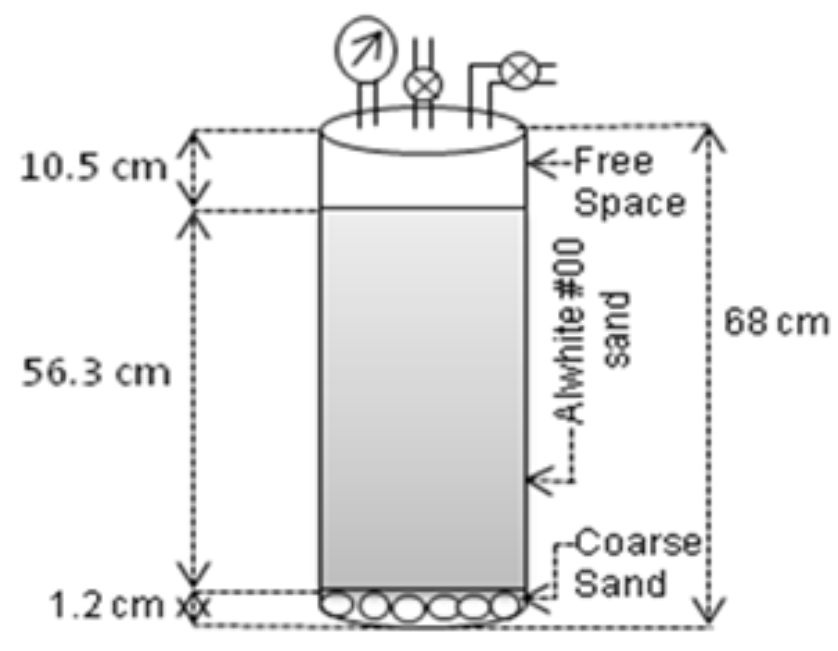

Figure 3.14: Sand column geometry.

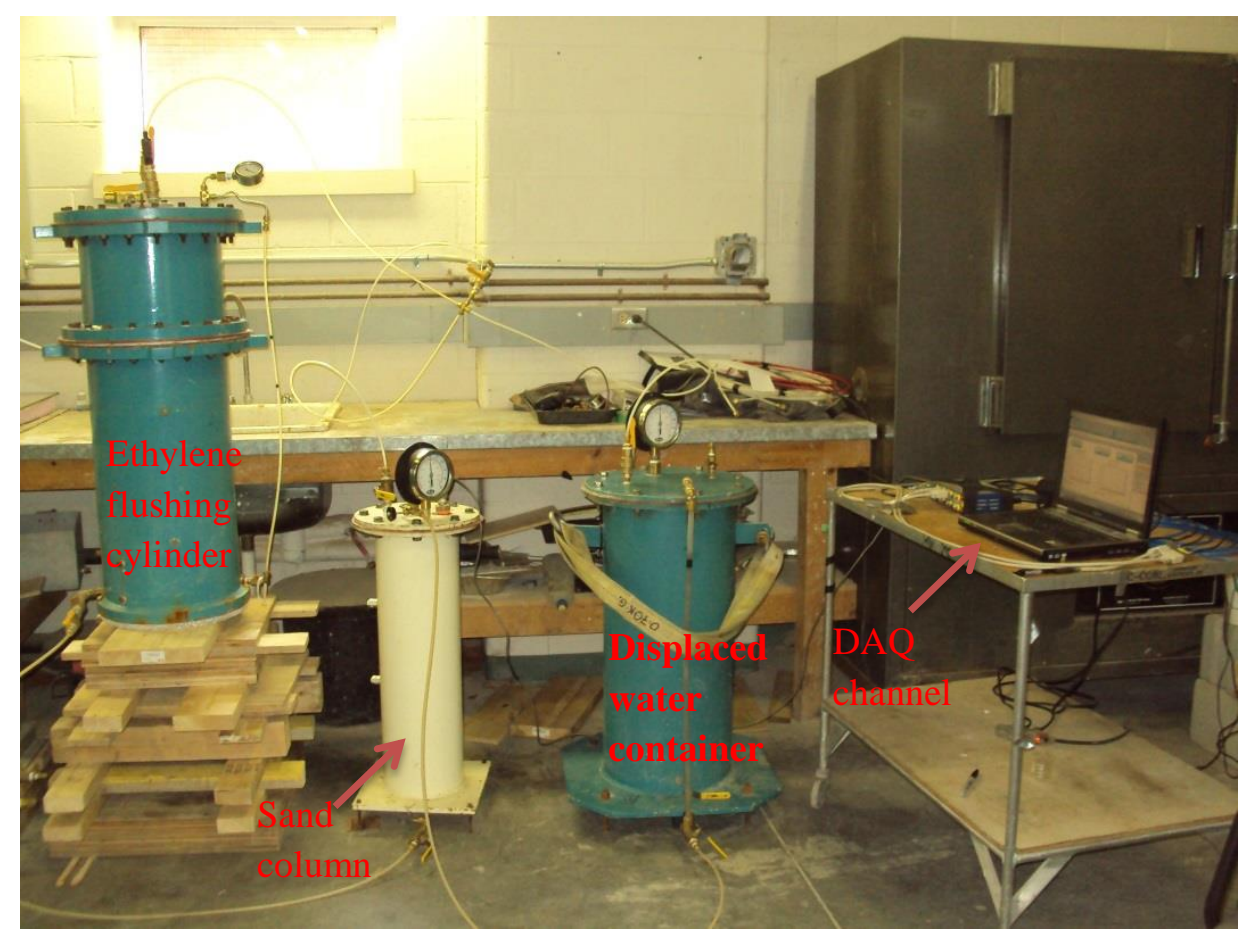

Figure 3.15: Lab setup of sand column test

Figure $3.16 \mathrm{a} \& \mathrm{~b}$ shows the orientation of the sensors in two soil columns in both horizontal and vertical direction. 


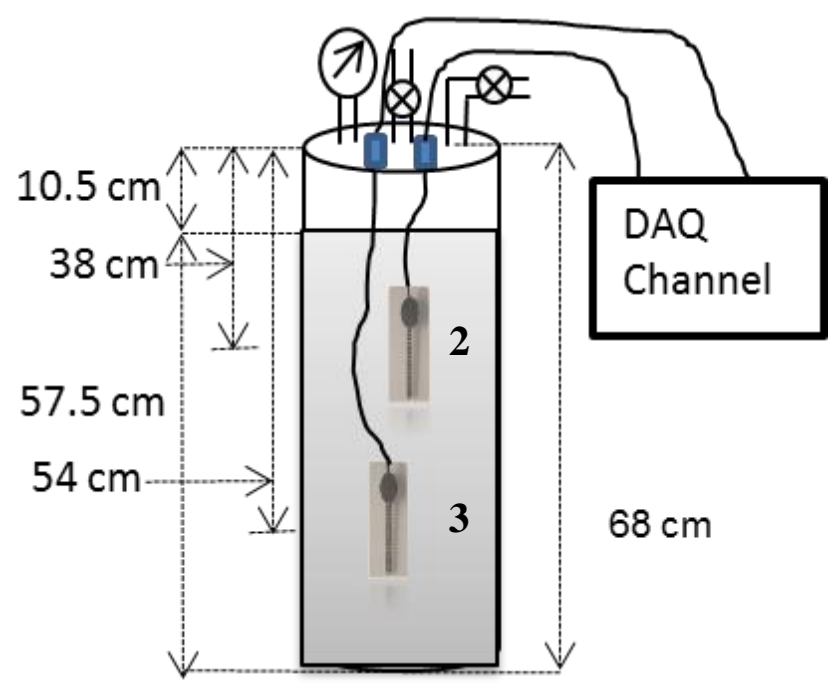

(a)

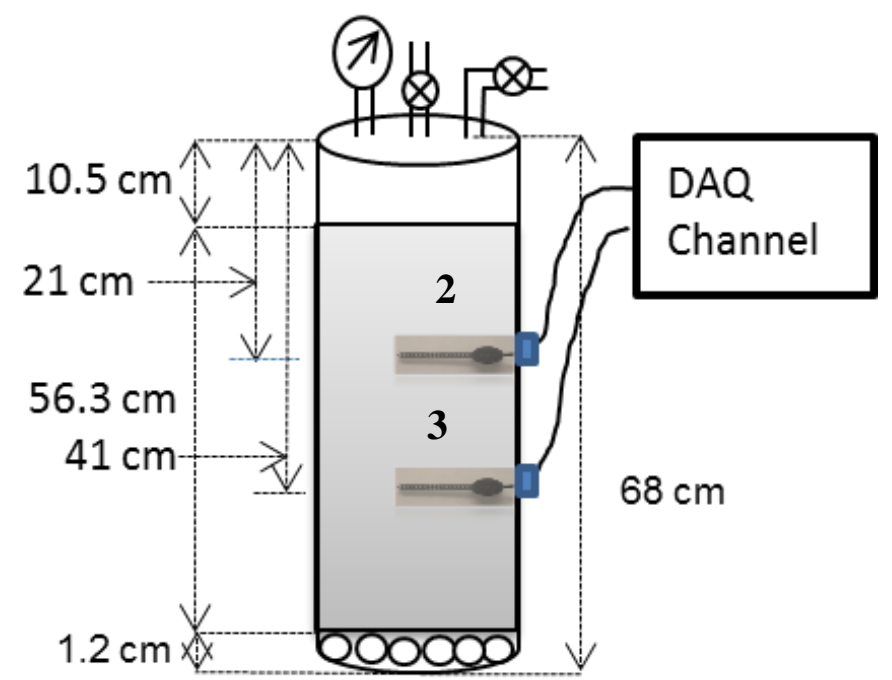

(b)

Figure 3.16 (a) Sensor in vertical direction. (b) Sensor in horizontal direction.

To determine the degree of saturation and ensure the presence of ethylene gas in the submarine gassy slope, sand column tests were done with soil moisture sensors following the process of ethylene saturation to ensure the presence of gas. Soil moisture sensors 
were placed in the sand column in either a horizontal or vertical orientation. The values obtained from soil moisture sensors in the air and water are 0.0851, 2.957 and 0.08564 , 2.971 volts for sensor 3 and sensor 2 respectively.

While flushing with deaired distilled water, the sensor reading changed with the change of the water level (Figure 3.17). Due to capillary rise soil moisture sensors start to respond while the distilled deaired water phreatic surface was below the sensor position. With the rise of distilled water level the degree of saturation increases at the sensor elevation. In all cases soil moisture sensors show $100 \%$ saturation when immersed into water. Another test was done with the change of soil moisture sensor orientation with some coarse material at the soil base. The soil moisture sensors show the same behavior while the sensor was in horizontal direction.

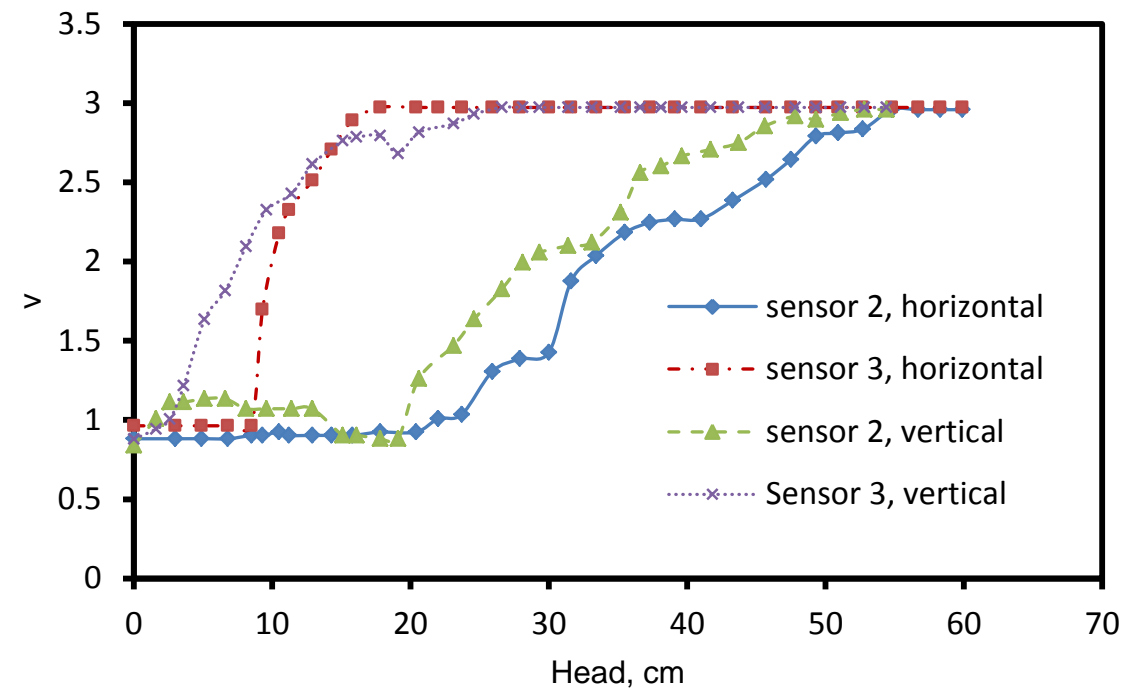

Figure 3.17: Soil moisture reading for both sensor orientations. 
The ethylene saturated water filled sand column was then pressurized to $655 \mathrm{kPa}$, with a degree of saturation of $100 \%$. To reduce the degree of saturation, the fluid pressure in the sand column was gradually reduced. With the reduction of pressure, some gas comes out of solution and existing gas bubbles expand. The response of the soil moisture sensors in both orientations with decreasing pressure is presented in Figure 3.18. The soil moisture sensors did not show any changes in voltage with the sensors in a vertical orientation. The top sensor showed some change with decreasing pressure when the sensor was in the horizontal orientation. However, the bottom sensor has no change in voltage. The top sensor change in voltage may mean with a decrease in pressure gas expansion occurred around the sensor as the degree of saturation decreased. The response from the sensor was not comparable to the expected degree of saturation. These moisture sensors did not provide a voltage corresponding to the degree of saturation with decreasing pressure.

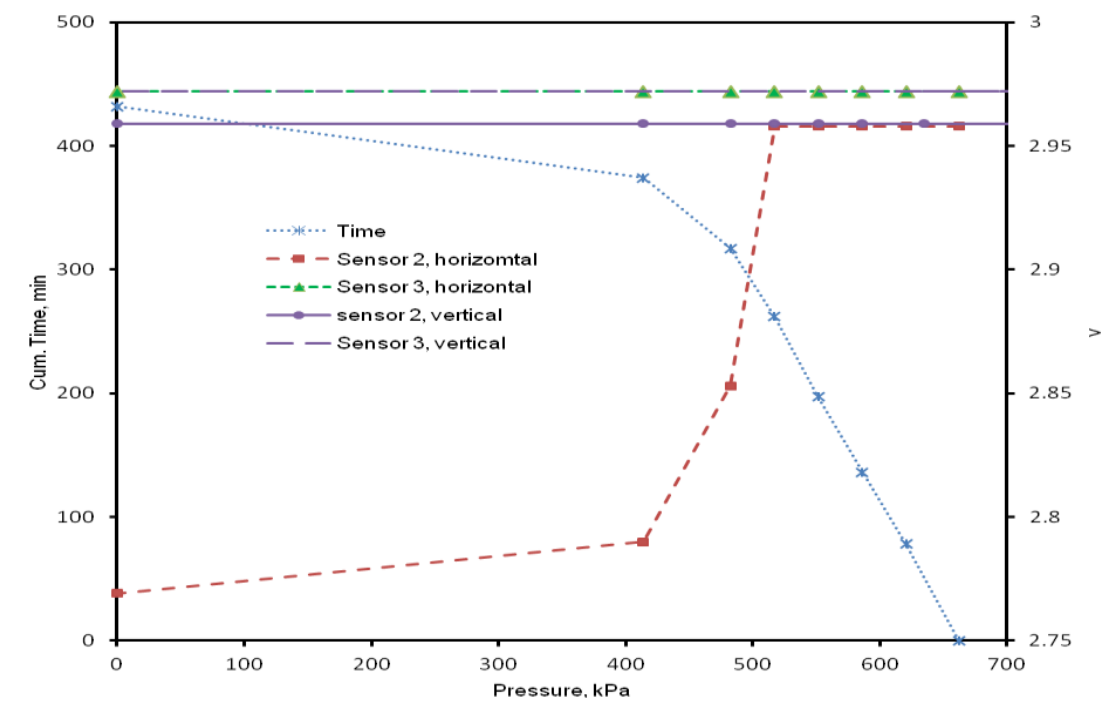

Figure 3.18: Sensor response to decreasing pressure 


\subsection{Measuring of global degree of saturation}

Figure 3.19 shows another method for measuring the global degree of saturation. In this method, the amounts of water and gas released from the sand column while decreasing the pressure were measured. Two more sand columns were made following the same process of making centrifuge model, but without the soil moisture sensors. A gas vessel was used with a very low volume. To reduce the effective volume of the vessel, marbles were used. Two pressure transducers were used to monitor the pressures in the sand column and the gas vessel. The required pressure drop was calculated using equation 1 proposed by Henry and Boyle's discussed in section 3.5.

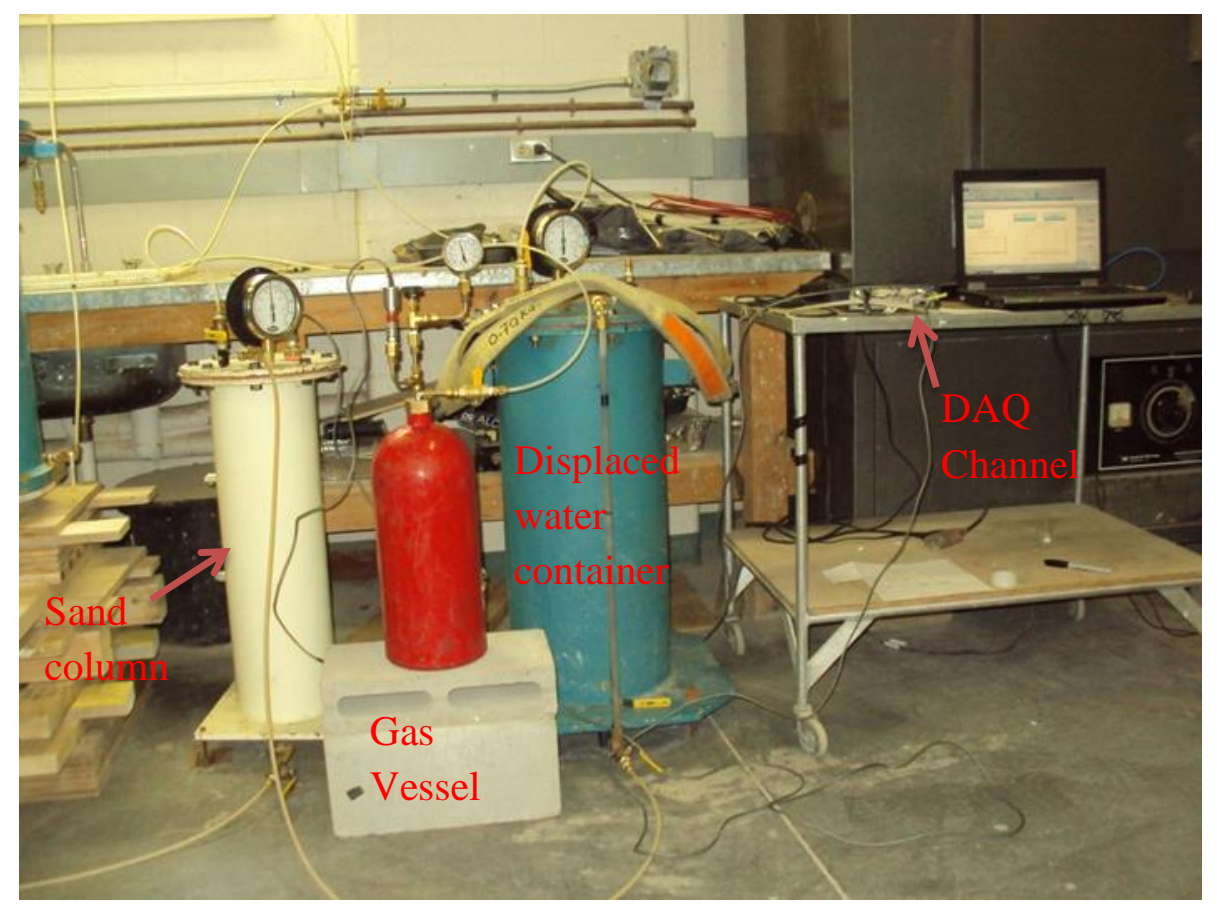

Figure 3.19: Lab setup for measuring global degree of saturation.

At constant temperature,

$\mathrm{P}_{1} V_{1}=\mathrm{P}_{2} \mathrm{~V}_{2}$ 
According to Boyles law (Equation 2), the product of pressure and volume of a gas remains constant at constant temperature. In these tests while reducing the pressure some water and gas will be displaced from the sand column into the gas vessel. The degree of saturation can be assessed from the displaced water volume and the equilibrium gas pressure.

Figure 3.20 shows the data of the global degree of saturation test. The theoretical volume of gas released by decreasing pressure is based on Equations (1) and (2).

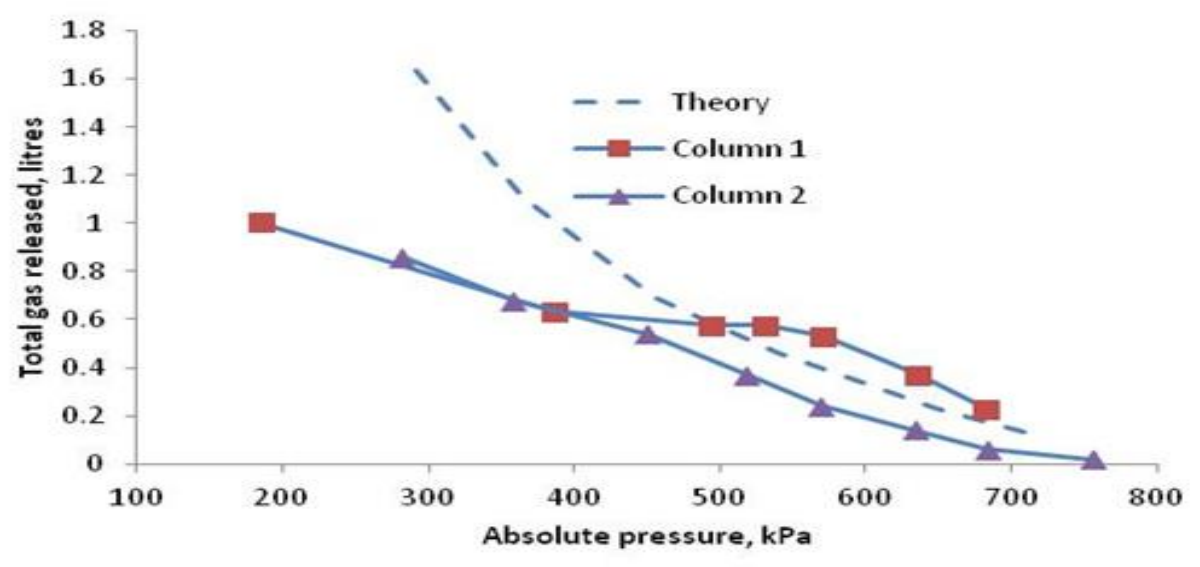

Figure 3.20: Released gas measurements

It was assumed that the gas pressures are the same throughout the system. In fact, pore gas pressures should always be slightly higher than the pore water pressures due to surface tension. The measured gas volumes from the 2 column tests are initially comparable to the expected values down to about $550 \mathrm{kPa}$ absolute pressure in both magnitude and trend, given the accuracy of the volume measurements. This pressure gives a degree of saturation of about $90 \%$ or less. Below this pressure level, the released 
gas volume is only about half the theoretical value of a governing pressure level. The reason for this decrease is unclear. Below 85 to $90 \%$ saturation, gas bubbles in the sand pores merge to form a continuous gas phase and pathways for release pore gas to exit the sand sample. This change in gas transport may be a factor in the observed behavior.

All the sensors tested in the lab floor did not show any reasonable results to use in the centrifuge model. VH 400 soil moisture sensor shows good results with increasing the water content, but could not respond by decreasing the pressure. But, expansion of gas bubbles has been monitored during the pressure release from the sand column. This indicates the decrease of degree of saturation. The experimental process and model preparation techniques are discussed in the next chapter. 


\section{Chapter 4: Centrifuge and Experimental Procedures}

\subsection{Centrifuge modeling}

Centrifuge physical modelling is a well-accepted technique for investigating gravity dependent phenomena, such as soil slope behavior, soil/pipeline interaction, bearing capacity of foundations, earth embankments on soft soils and frost heave using reduced scale physical models. The centrifuge essentially provides a load frame with the centrifuge model placed at the end of centrifuge arm. As the centrifuge rotates, the model experiences a much higher acceleration in the radial direction than that of Earth's gravity. A small scale model in the centrifuge can experience a similar stress profile as a full scale structure as the acceleration field on the model increases. As a full scale soil structure is in equilibrium under earth's gravitational field $\mathrm{g}$, similarly a reduced $1 / 100^{\text {th }}$ scale model on a centrifuge under $100 \mathrm{~g}$ will have stresses due to self-weight similar to the stresses in the full scale soil structure at homologous points. The model can then reproduce the phenomena of cracking, rupture or flow that would be observed in the prototype because the stress dependency of soil behavior has been correctly simulated. This is the main reason for the wide usage of the geotechnical centrifuge.

\subsubsection{Principal of centrifuge modeling}

In most geotechnical centrifuges a horizontal beam is rotated about a vertical axis through the center of the beam, with a bucket containing the centrifuge model on one side and the counter weight on the other shown in the Figure 4.1. The model can experience radial accelerations that simulate gravity during the rotation progress. The increased radial 
acceleration $r \omega^{2}$ is equal to $\mathrm{Ng}$, where $\omega$ is the angular velocity of rotation expressed in radians per second, $\mathrm{r}$ is the distance between the object and its axis of rotation and $\mathrm{g}$ is the gravitational acceleration, Taylor (1995).

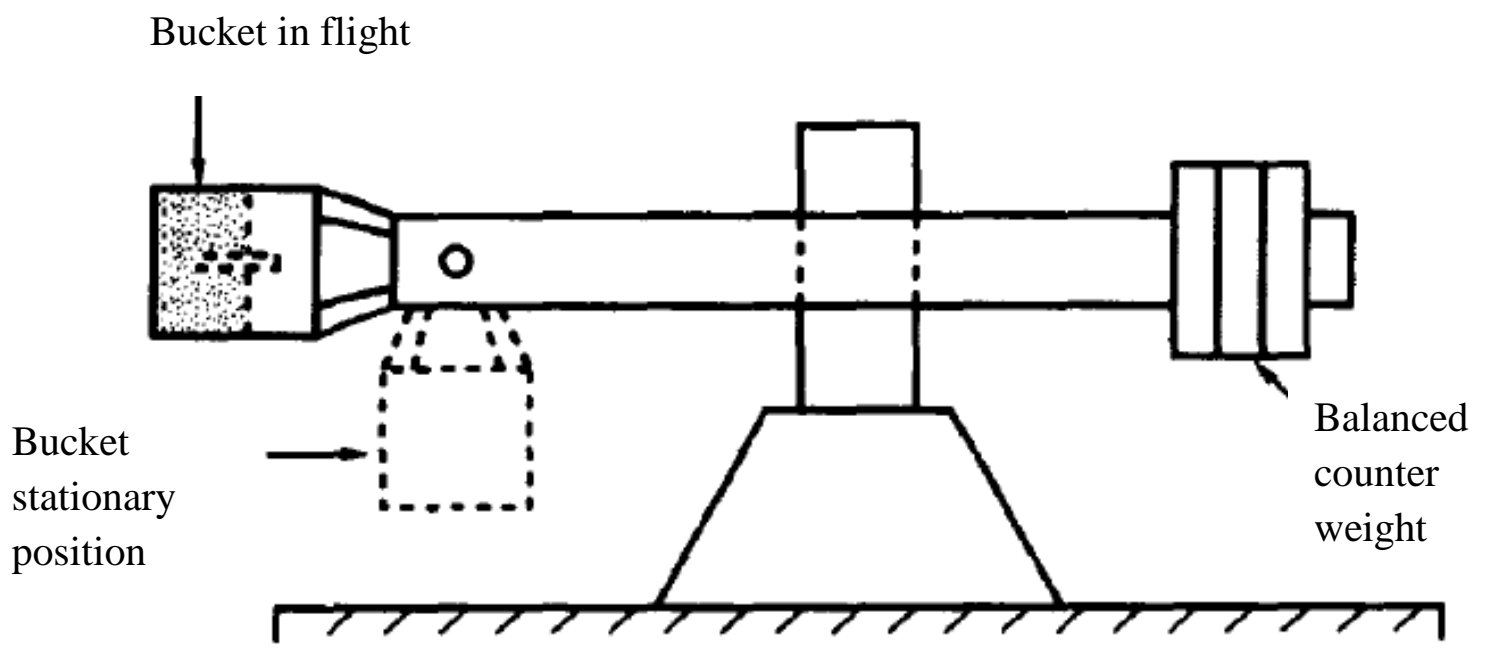

Figure 4.1: Schematic of beam centrifuge (Murff, J.D. 1996)

When the model and the prototype use the same soil and an acceleration of $\mathrm{N}$ times the Earth's gravity, the vertical stress at depth $h_{v}$ will be identical to that in the corresponding prototype at depth $h_{p}$ where $h_{p}=N h_{v}$ (Taylor, 1995, Yang, 2009). This is the basic scaling law of centrifuge modelling.

\subsubsection{Scaling laws}

According to the basic scaling laws, the parameters such as stress and strain between the model and the corresponding prototype are similar if the same soil and same stress history are used. Figure 4.2 represents the vertical stress approximation in model and prototype. 
Prototype

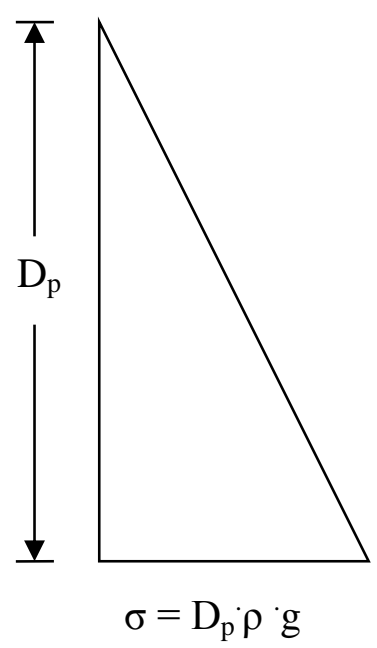

Model

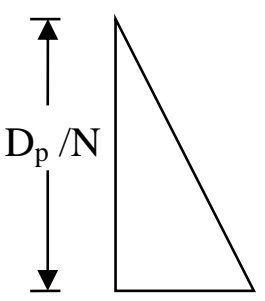

Model with $\mathrm{N}$ times gravity

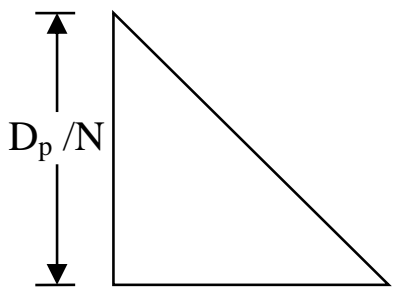

$$
\sigma=1 / \mathrm{N} \cdot \mathrm{D}_{\mathrm{p}} \cdot \rho \cdot \mathrm{g} . \mathrm{N}
$$$$
=D_{\mathrm{p}} \cdot \rho \cdot \mathrm{g}
$$

Figure 4.2: Vertical stress representation in model and prototype.

If the acceleration is $\mathrm{N}$ times Earth's gravity $(\mathrm{g})$ is applied to a material of density $\rho$, then the vertical stress $\sigma_{v}$ at the depth $\mathrm{D}_{\mathrm{m}}$ in the model (subscript m represents model) is given by:

$$
\sigma_{v m}=\rho N g D_{m}
$$

In prototype (subscript $\mathrm{p}$ represents prototype):

$$
\sigma_{v p}=\rho g D_{p}
$$

Thus, for $\sigma_{v m}=\sigma_{v p}$, then $D_{m}=N^{-1} D_{p}$ and the scale factor (model: prototype) for linear dimensions is $1:$ N. Since the model is a linear scale representation of the prototype, then displacements will also have a scale factor of $1: \mathrm{N}$. 


\subsubsection{Scaling errors}

In centrifuge modelling main scaling errors are due to the non-uniform acceleration field and also the difficulty of representing sufficient detail of the prototype in a small scale model, Taylor (1995). Acceleration through the model is not linear in the high acceleration field. The main reason is the radial acceleration $r \omega^{2}$ where $\omega$ is the angular rotational speed of the centrifuge and $r$ is the radius of any element in the soil model. Taylor (1995) noted that this error can be minimized by selecting the radius at which the gravity scale factor $\mathrm{N}$ is determined. There is a location where the stress between model and prototype is the same as shown by Taylor (1995) in Figure 4.3.

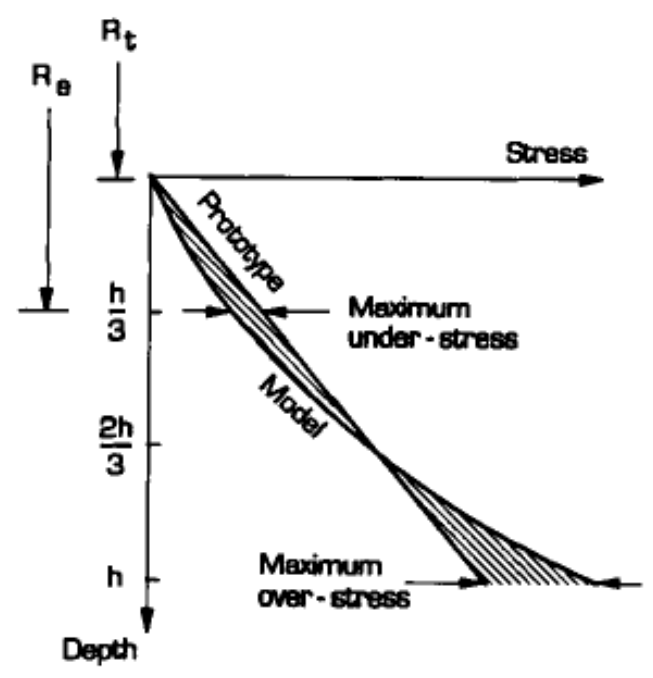

Figure 4.3: Comparison of stress vary with depth in a centrifuge model and its corresponding prototype (Taylor, 1995)

If the vertical stress between model and prototype is same at depth $h_{i}$, the effective centrifuge radius $\left(r_{e}\right)$ for the model can be shown as: 


$$
r_{e}=r_{t}+0.5 * h_{i}
$$

Where, $r_{t}$ is the radius of the top of the model. A convenient rule for minimizing the error in stress distribution is derived by considering the relative magnitudes of under and overstress. The ratio, $\mathrm{r}_{\mathrm{u}}$, of the maximum under-stress, which occurs at model depth $0.5 \mathrm{~h}_{\mathrm{i}}$, to the prototype stress at that depth is:

$$
r_{u}=\frac{h_{i}}{4 * r_{e}}
$$

Similarly, the ratio, $\mathrm{r}_{\mathrm{o}}$, of maximum over-stress, which occurs at the base of the model, $\mathrm{h}_{\mathrm{m}}$, to the prototype stress at that depth is:

$$
r_{0}=\frac{h_{m}-h_{i}}{2 * r_{e}}
$$

Equating the two ratios ru and ro gives:

$$
\begin{gathered}
h_{i}=\frac{2}{3} * h_{m} \\
r_{u}=r_{0}=\frac{h_{m}}{6 * r_{e}}
\end{gathered}
$$

So,

$$
r_{e}=r_{t}+\frac{h_{m}}{3}
$$


Using this rule, there is an exact correspondence in stress between model and prototype at two-thirds model depth and the effective centrifuge radius should be measured from the central axis to one-third the depth of the model. For most geotechnical centrifuges, $\mathrm{h}_{\mathrm{m}} / \mathrm{r}_{\mathrm{e}}$ is less than 0.2 and therefore the maximum error in the stress profile is minor and generally less than $3 \%$ of the prototype vertical stress level.

\subsubsection{Scaling factors}

A properly scaled centrifuge model should be a reasonable representation of a given prototype condition with the acceleration level and geometric scale chosen to correspond to the appropriate prototype conditions (Taylor, 1995). Some basic centrifuge scaling relationships are shown in Table 4.1 after Coulter (2008).

Table 4.1: Scaling factors in centrifuge tests (Coulter, 2008)

\begin{tabular}{|l|c|c|c|c|}
\hline Parameter & Symbol & $\begin{array}{l}\text { Dimensionless } \\
\text { number }\end{array}$ & Similarity requirement & $\begin{array}{l}\text { Scaling } \\
\text { factor }\end{array}$ \\
\hline Acceleration & $\mathrm{a}$ & & $N_{a}=$ & $n$ \\
\hline Model length & 1 & & $N_{l}=$ & $\frac{1}{n}$ \\
\hline Soil density & $\rho$ & & $N_{\rho}=$ & 1 \\
\hline Particle size & $\mathrm{d}$ & $\frac{d}{l}$ & $N_{d}=$ & 1 \\
\hline Void ratio & $\mathrm{e}$ & $e$ & $N_{e}=$ & 1 \\
\hline Saturation & $\mathrm{S}_{\mathrm{r}}$ & $S_{r}$ & $N_{S=}$ & 1 \\
\hline
\end{tabular}




\begin{tabular}{|c|c|c|c|c|}
\hline $\begin{array}{l}\text { Liquid } \\
\text { density }\end{array}$ & $\rho_{1}$ & $\frac{\rho_{l}}{\rho}$ & $N_{\rho l}=N_{\rho}=$ & 1 \\
\hline $\begin{array}{l}\text { Surface } \\
\text { tension }\end{array}$ & $\sigma_{t}$ & $\frac{\sigma_{t}}{\rho_{l} a d l}$ & $N_{\sigma}=N_{a} N_{p} N_{d} N_{l}=$ & 1 \\
\hline Capillary & $\mathrm{h}_{\mathrm{c}}$ & $\frac{h_{c} \rho_{l} a d}{\sigma_{t}}$ & $N_{h}=N_{d} N_{\rho}^{-1} N_{a}^{-1} N_{d}^{-1}=$ & $\frac{1}{n}$ \\
\hline Viscosity & $\eta$ & $\frac{\eta}{\rho_{t} d \sqrt{a l}}$ & $N_{\eta}=N_{d} N_{\rho}^{-1} N_{a}^{-1} N_{d}^{-1}=$ & 1 \\
\hline Permeability & $\mathrm{k}$ & $\frac{k \eta}{\rho_{t} d^{2} a}$ & $N_{k}=N_{d}^{2} N_{p} N_{a} N_{\eta}^{-1}=$ & $n$ \\
\hline $\begin{array}{l}\text { Particle } \\
\text { friction }\end{array}$ & $\varphi$ & $\Phi$ & $N_{\varphi}=$ & 1 \\
\hline $\begin{array}{l}\text { Particle } \\
\text { strength }\end{array}$ & $\sigma_{\mathrm{c}}$ & $\frac{\sigma_{c}}{\rho a l}$ & $N_{\sigma}=N_{a} N_{p} N_{l}=$ & 1 \\
\hline Cohesion & $\mathrm{c}$ & $\frac{c}{\rho a l}$ & $N_{c}=N_{a} N_{p} N_{l}=$ & 1 \\
\hline $\begin{array}{l}\text { Laminar } \\
\text { flow }\end{array}$ & $\mathrm{t}_{2}$ & $\frac{t k}{l}$ & $N_{t}=N_{l} N_{k}^{-1}=$ & $\frac{1}{n^{2}}$ \\
\hline
\end{tabular}

The current study is related to the failure of the submarine gassy slope due to tidal variation. The scaling laws that are considered in this study are model length, soil density, particle size, void ratio, degree of saturation and stress. 


\subsubsection{Applications of centrifuge modeling}

Over the last few decades in the field of geotechnical engineering, small scale modeling using a geotechnical centrifuge has become popular. Centrifuge modeling has been used to examine many problems where gravity loading is important. The applications of centrifuge modeling in the field of geotechnical engineering include retaining wall problems, tunnel collapse, soil liquefaction, slope stability, offshore foundation, and interactions between soil, water and structures. Clark et. al. (1993) listed many areas in which centrifuge modeling has been applied including soil statics such as load bearing capacity of laterally loaded pile, soil dynamics as dynamically loaded gravity based structure, subsea deformation due to ice scour as cold region studies, hazardous waste disposal in seabed as environmental engineering and earth science structure formation and reservoir engineering.

In the past, many researchers did submarine slope stability analysis using centrifuge modeling. The significant benefit of complementary numerical and physical modelling of embankment instability caused by static liquefaction was demonstrated by UBC and CCORE during the CANLEX joint industry project, Puebla et. al. (1997). From this research an elastic - plastic stress-strain model for sand has been presented and used to predict the response of CANLEX field events. Coulter and Phillips (2005) analyzed seismic initiation of submarine slope failures using physical modelling in a geotechnical centrifuge. They investigated the effects of impermeable layer presence in the slope and compared with UBCSAND constitutive effective stress model in FLAC. It is the success of the Puebla and Coulter research that was the basis for analysis of Atigh \& Byrne 
(2004), with the addition of partially saturated behavior into UBCSAND model. This thesis addresses the needs for complementary physical model tests to validate these analyses. Guanghai et. al. (2010) conducted centrifuge model tests on deep water slope stability. Their model test results showed that there is a significant impact on the stability and deformation of a submarine slope with even a percentage of relatively small gas in the soil. Zhang et al. (2015) analyzed centrifuge modeling on submarine landslide triggered by elevated pore pressure. They showed that accumulation of high pore pressure was possible in gentle slopes and thick clay layers and the failed soil mass can be liquefied. In this current study, stability of submarine slopes in gassy sediments will be simulated using centrifuge modeling.

\subsection{Experimental setup}

A new experimental setup was required for this slope stability study. These experiments were conducted using the C-CORE Acutronic 680-2 geotechnical centrifuge. The centrifuge model was made in a high pressure box and transfered to the centrifuge arm. The remainder of the package consisted of a tidal actuator, some PPTs, lights and cameras. The section below describes the setup in more detail.

\subsubsection{C-CORE Geotechnical Centrifuge}

The centrifuge facility located at C-CORE was founded in 1993 on the campus of Memorial University of Newfoundland. C-CORE is a research institute which engages in commercial projects and testing for industry. The C-CORE centrifuge is an Acutronic 680-2 centrifuge shown in Figure 4.4 and is contained in a $13.5 \mathrm{~m}$ diameter chamber and 
$4.5 \mathrm{~m}$ in height with a $0.3 \mathrm{~m}$ thick concrete perimeter wall. The centrifuge includes a swinging platform where models are placed and two parallel steel tubes that are held apart by a central drive box and spacers. A counterweight with a mass of 20.2 tonnes balances both the payload and the platform.

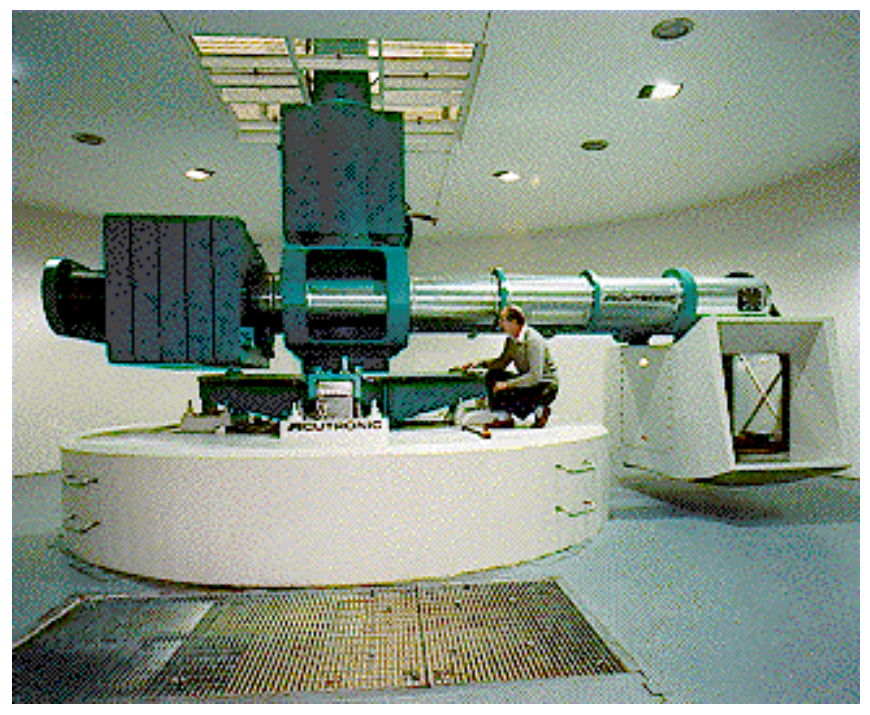

Figure 4.4: C-CORE Acutronic 680-2 Geotechnical Centrifuge (Phillips et al. 1994)

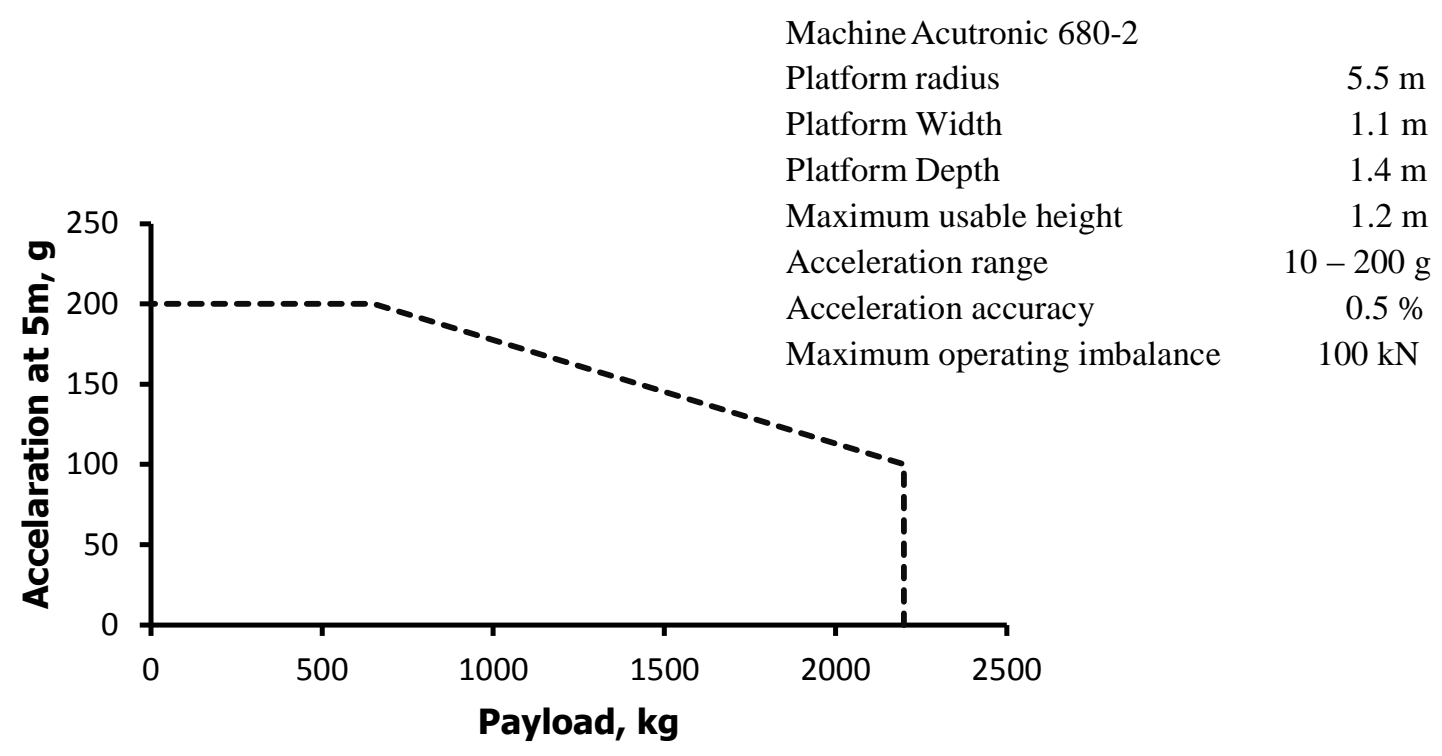

Figure 4.5: C-CORE Centrifuge specification. 
The position of the counterweight can be adjusted by driving a series of gearwheels along screw heads on the outside of the steel arm tubes using an electric motor. The power of the centrifuge is provided by an AC variable speed motor. The centrifuge has a radius of $5.5 \mathrm{~m}$ from the axis of rotation to the floor of the platform. It has the capacity to generate 200 times of earth gravity with a payload of $650 \mathrm{~kg}$, can take a maximum payload of 2200 $\mathrm{kg}$ to a $\mathrm{g}$ level of 100 as shown in Figure 4.5. The maximum size of the payload is about $1.1 \mathrm{~m}$ high x $1.4 \mathrm{~m}$ long x $1.2 \mathrm{~m}$ wide.

\subsubsection{Supporting equipment}

To prepare the centrifuge model supporting equipment was used. These consist of a high pressure box, sand raining equipment, containers for water and ethylene saturation, peristaltic pump, tidal actuator, hydraulic cylinder, lights and camera. Specifications of the supporting equipment are described below.

\subsubsection{High pressure box}

The model submarine slope was built in the high pressure box shown in Figure 4.6. The empty mass of the high pressure box is $536 \mathrm{~kg}$. On one side of the high pressure box there is a viewing window made of $75 \mathrm{~mm}$ thick acrylic. This high pressure box can hold an internal pressure of $1 \mathrm{MPa}$. After preparing the model in the high pressure box it was carried by a forklift and loaded onto the centrifuge platform for the test. 


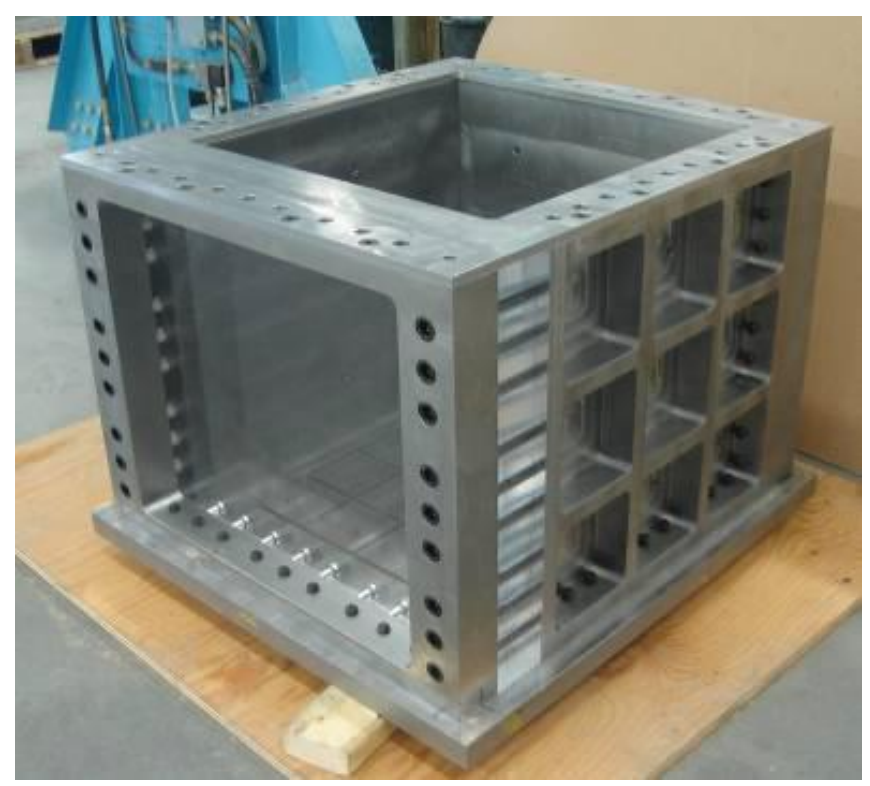

Figure 4.6: High pressure box

\subsubsection{Sand raining equipment}

When preparing the centrifuge sand model it is important to maintain known and uniform densities throughout the model. To maintain uniform density, a sand raining method is widely used. In this method sand is air pluviated into the model through an orifice from a constant height. Typically, the higher the drop height and the lower the flow rate, the denser the model is. Figure 4.7 shows the sand raining equipment. Model container elevation needs to decrease with increase of the sand height in the model to maintain the same drop height. In this case, the target relative density of the first centrifuge test model was $60 \%$ and with a drop height of $104 \mathrm{~cm}$ and relative density of second centrifuge test model was $50 \%$ with a drop height of $85 \mathrm{~cm}$. To prepare a model by using sand raining method, it is very important to follow proper safety rules because of the floating dust in the air. 


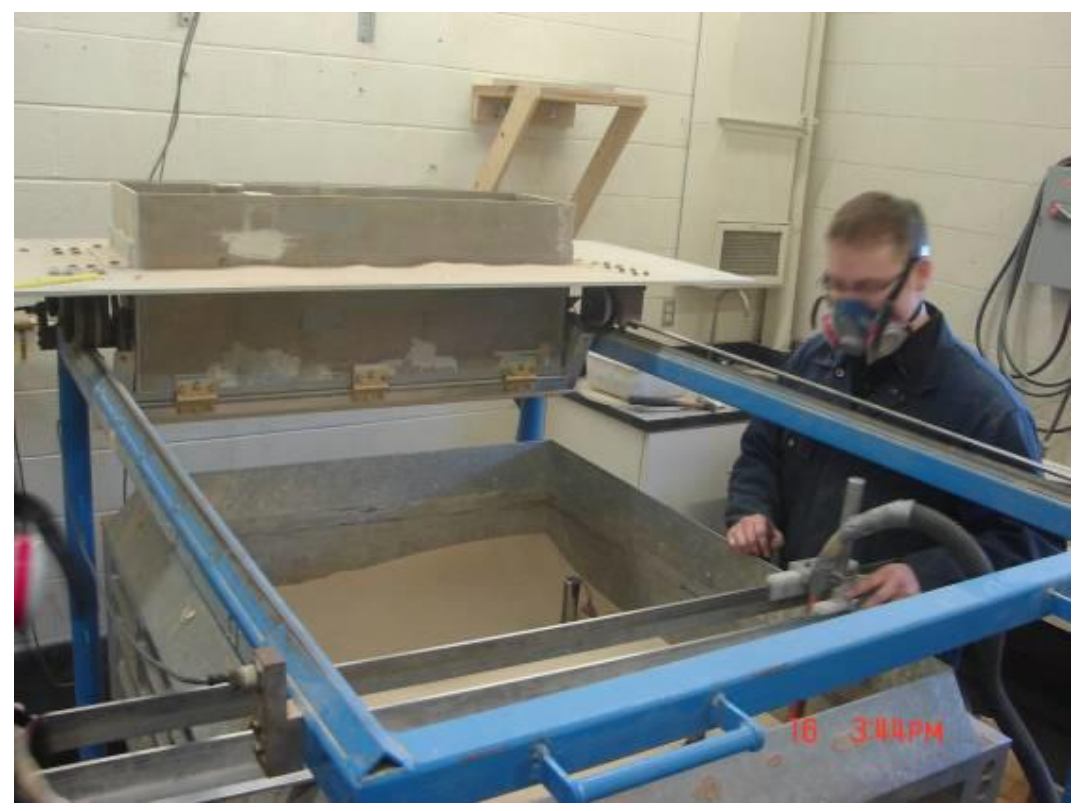

Figure 4.7: Sand raining equipment

\subsubsection{Ethylene mixing container}

To form the centrifuge model as a gassy sediment, it was first saturated with distilled deaired water and then the pore water replaced by pressurized ethylene saturated water following the procedure of Grozic (1999). Ethylene gas was mixed with distilled water in a mixing container shown in Figure 4.8. At the very top of the container is a perforated shelf retained glass marbles. The role of the marbles at the top is to disperse the distilled water when circulated through the top of the mixing container containing an ethylene gas environment, after Waite et al. (2011). 

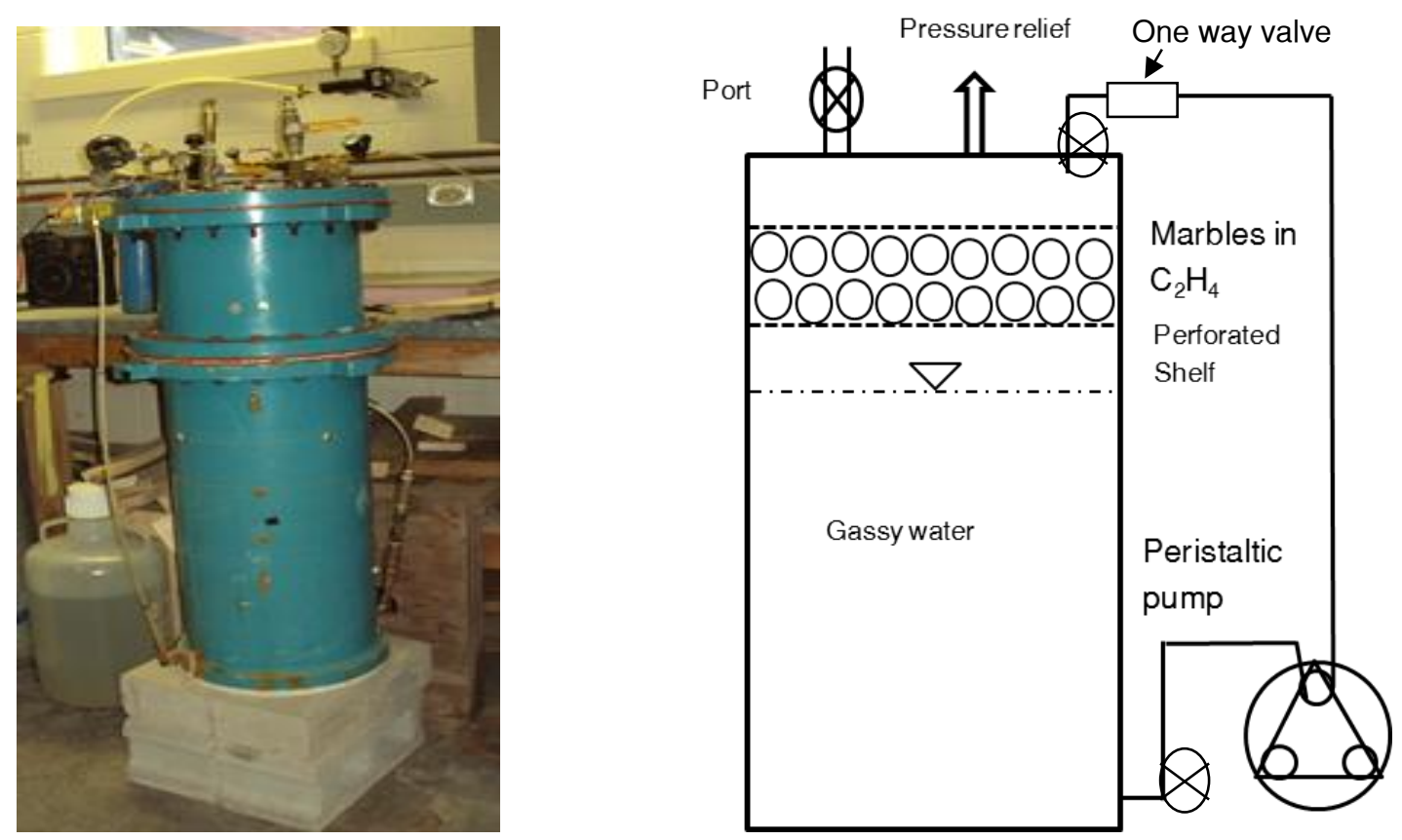

Figure 4.8: water ethylene saturation container

The whole process of mixing ethylene is done under pressure. The container needs to be well sealed to hold the pressure of $689.5 \mathrm{kPa}$ and also needs to hold a vacuum when deairing the distilled water. At the top of the container there is a pressure relief valve set at a pressure of $689.5 \mathrm{kPa}$. In the ethylene mixing container, distilled water was circulated from the bottom to the top of the mixing cylinder by a peristaltic pump rated for 689.5 $\mathrm{kPa}$. A one way valve was placed at the top port to maintain the flow.

\subsubsection{Peristaltic pump}

The peristaltic pump was used to circulate the water in the ethylene mixing container from the bottom to the top. Figure 4.8 shows the placement of the peristaltic pump in the ethylene mixed container setup. Figure 4.9 shows the peristaltic pump from Stenner Pump Company, model number 85MHP40 Classic Series. The maximum capacity of the pump 
is $40 \mathrm{gal} / \mathrm{day}$. One hose is connected through the pump head to the bottom and top of the ethylene mixed cylinder.

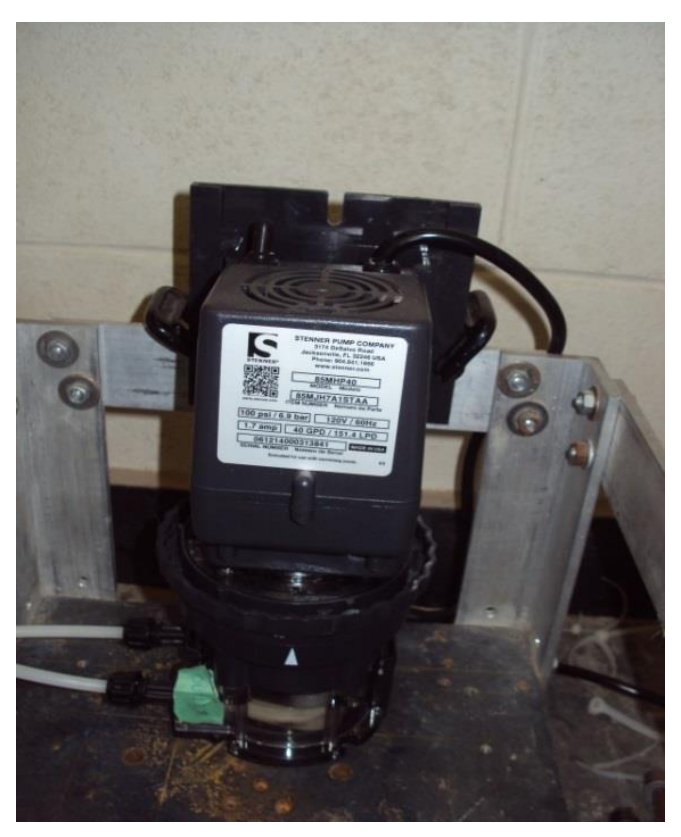

Figure 4.9: Peristaltic pump

\subsubsection{Tidal actuator}

The tidal actuator was required to provide the tidal motions, control the gas pressure and store the fluids released. This actuator basically comprised a hydraulic and a $355 \mathrm{~mm}$ diameter pneumatic cylinder connected to a gas pressure regulator. Figure 4.10 shows the full setup of the tidal actuator. The servo controlled hydraulic cylinder provided the tidal motions. The pneumatic cylinder piston was replaced by a $330 \mathrm{~mm}$ diameter displacement block shown in Figure 4.11 . A $60 \mathrm{~mm}$ thick block was a $25 \mathrm{~mm}$ acrylic disc over $35 \mathrm{~mm}$ strong buoyancy foam used in the first proof test. A $9 \mathrm{~mm}$ immersive movement of the block caused a $25 \mathrm{kPa}$ increase in the water pressure. In the second test the height of the disk was changed to $110 \mathrm{~mm}$ by adding $50 \mathrm{~mm}$ thick buoyancy foam. In that case $15 \mathrm{~mm}$ 
immersive movement of the block caused a $44 \mathrm{kPa}$ increase in water pressure. Figure 4.12a \& $\mathrm{b}$ shows the change in pressure with movement of the piston at a fixed gas pressure levels from atmospheric to $655 \mathrm{kPa}$. The gas regulator allowed the controlled and safe release of excess gas while maintaining the required gas pressure. The large diameter pneumatic cylinder allowed storage of any water displaced by the reduced saturation in the slope as gas bubbles formed, with a small increase in the water elevation head. The tidal actuator elevation was set to the initial water level of the high pressure box. The pneumatic cylinder is a product of Emerson Industrial Automation and dimensions of the cylinder are shown in Figure 4.13 a. Figure $4.13 \mathrm{~b}$ shows the pneumatic cylinder with two pressure transducer one in the top and other at the bottom. The top pressure transducer measures the pressure of the air and the bottom transducer measure the pressure of water.

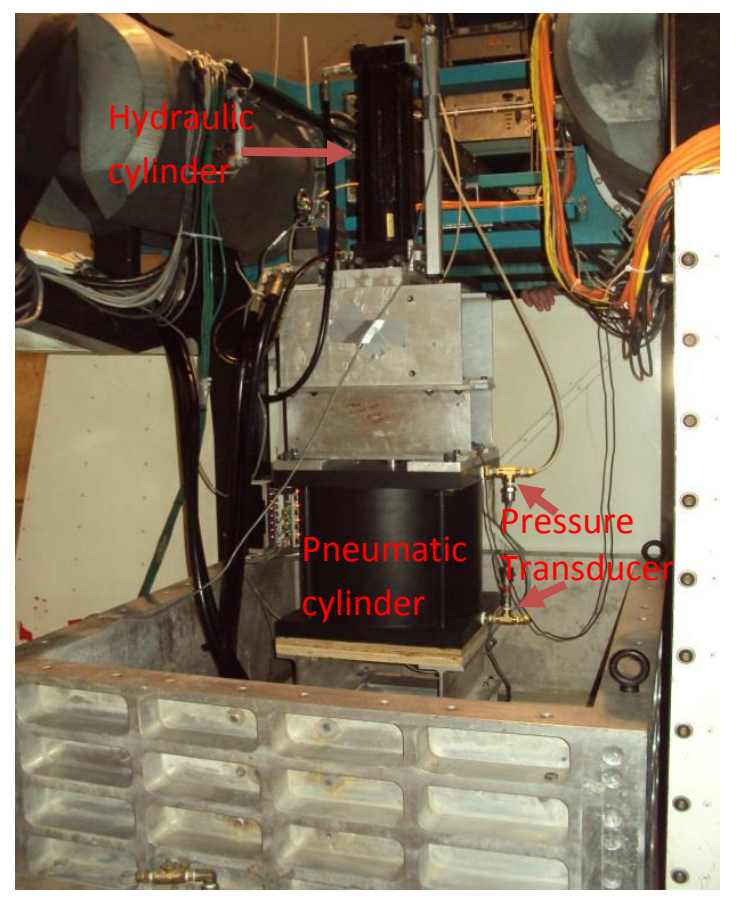

Figure 4.10: Tidal actuator 


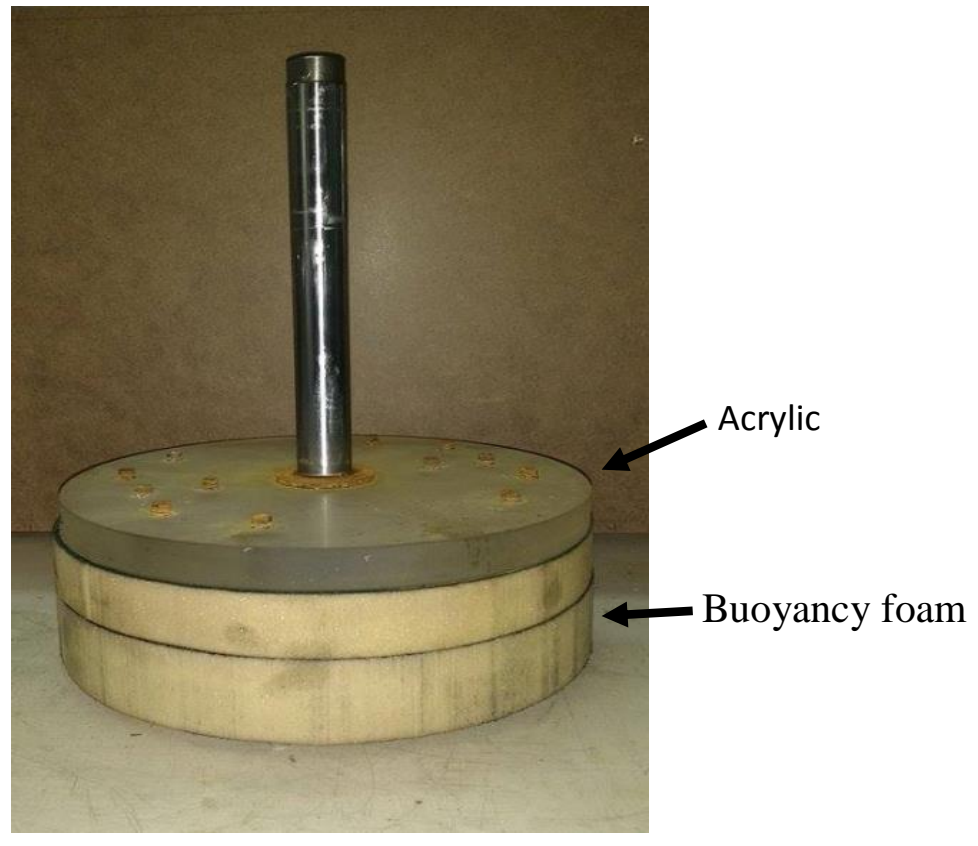

Figure 4.11: Displacement block

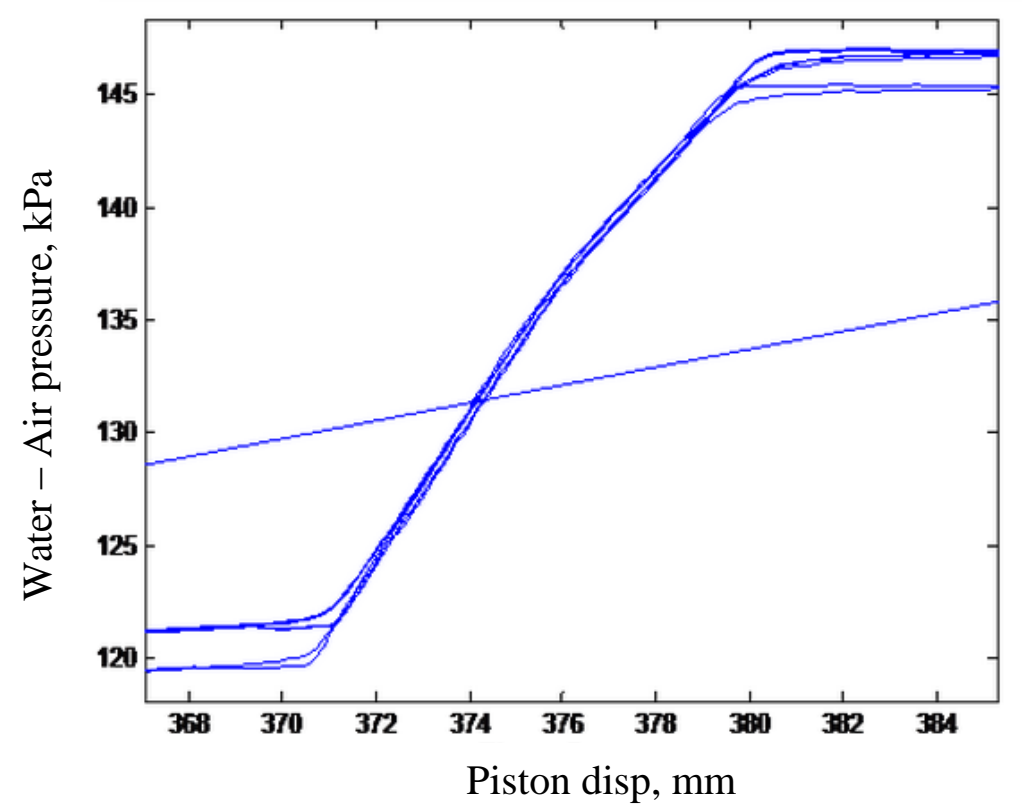

Figure 4.12a: Water pressure vs. piston movement (Centrifuge test 1) 


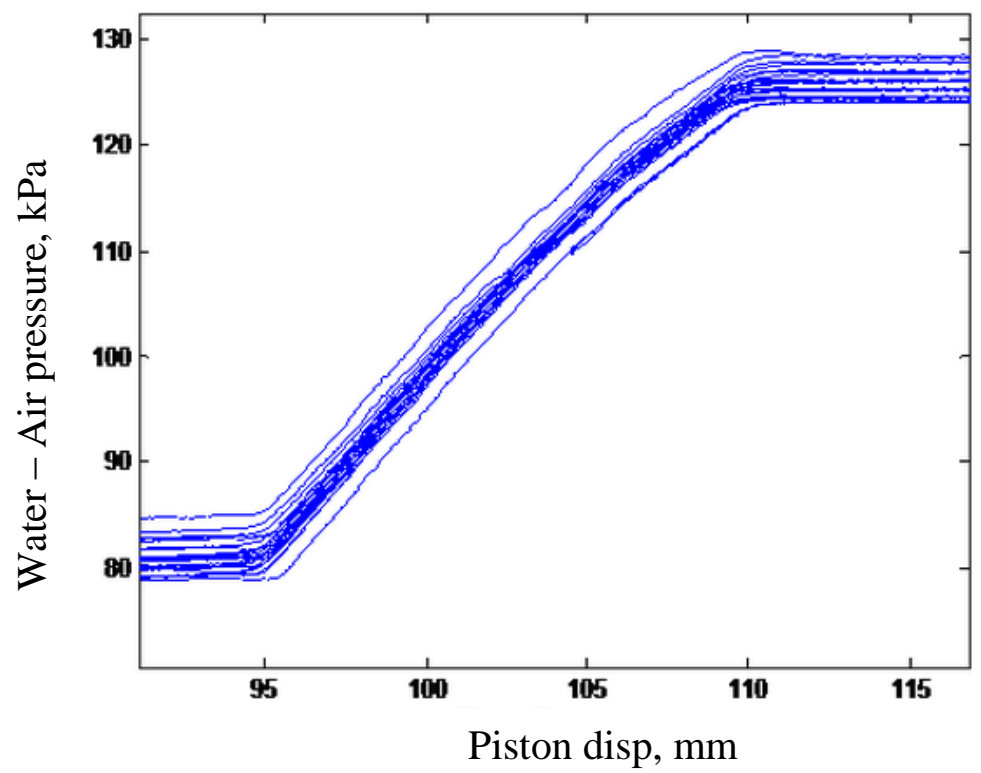

Figure 4.12 b: Water pressure vs. piston movement (Centrifuge test 2)

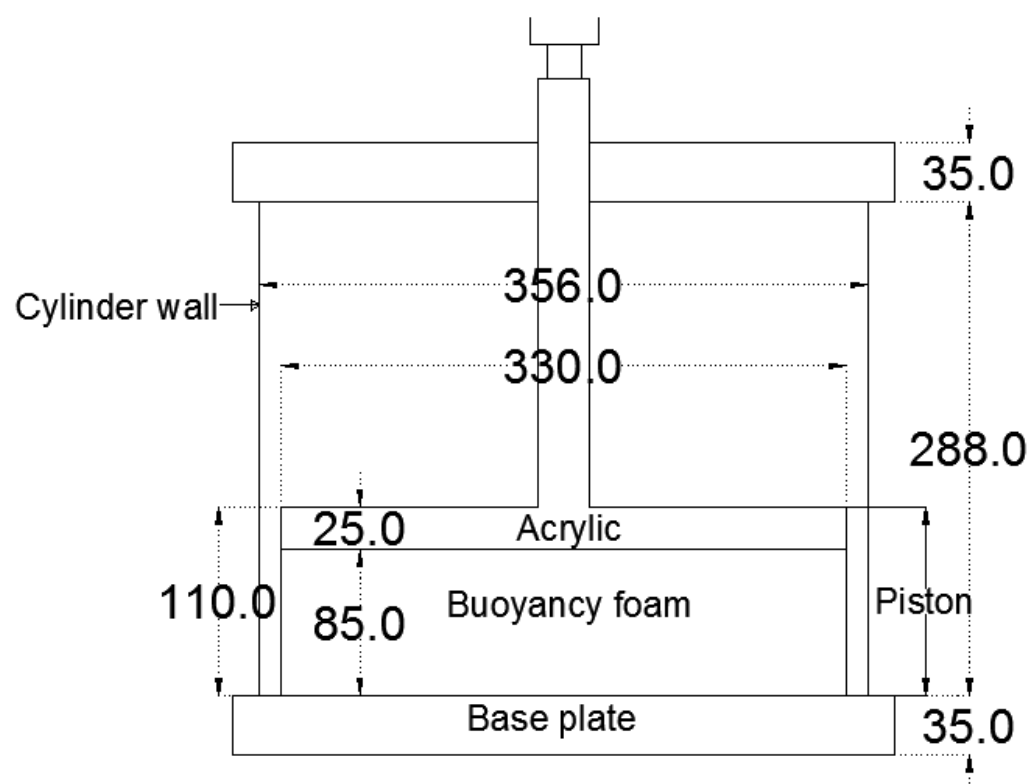

Figure 4.13 a: Dimensions of pneumatic cylinder 


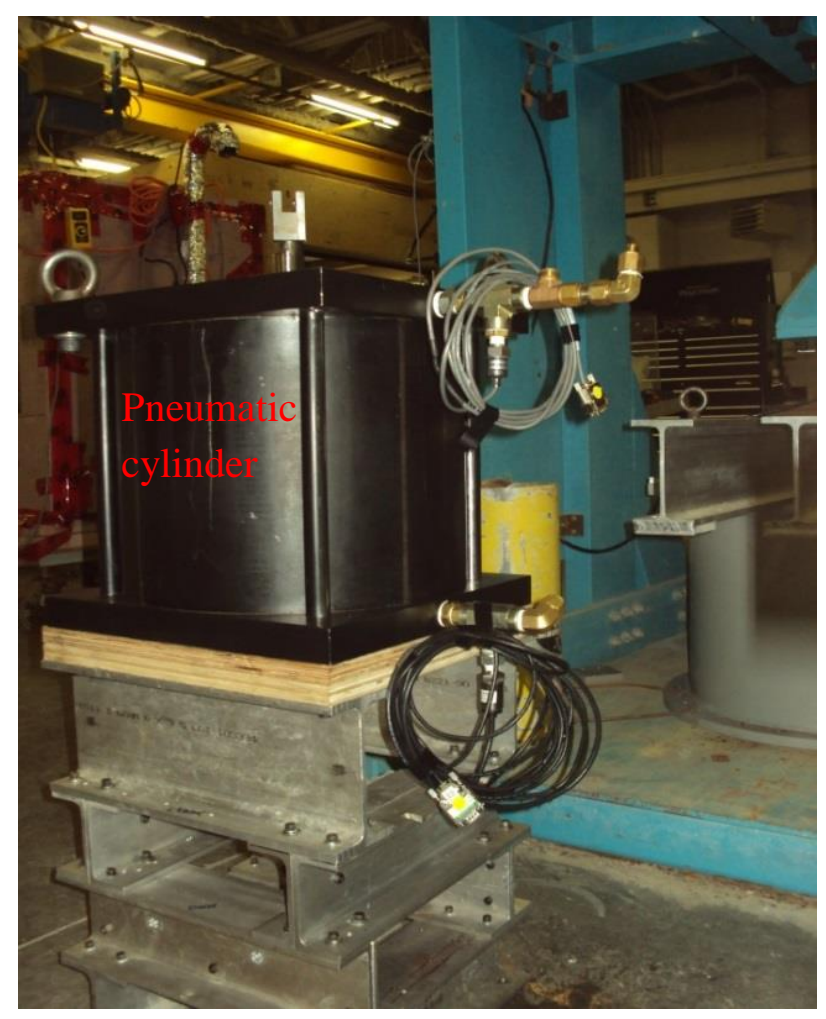

Figure 4.13 b: Pneumatic cylinder

\subsubsection{Hydraulic cylinder}

The main purpose of the servo controlled hydraulic cylinder is to provide tidal motions in the tidal cylinder to increase or decrease the water pressure in the high pressure box. Figure 4.14 shows the hydraulic cylinder with the regulator and LDT. The stroke of this hydraulic cylinder is 14 inches. Movement of the hydraulic cylinder piston is measured by a LDT. The regulator is a servo solenoid valve with electrical position feedback. This regulator is connected to the centrifuge arm hydraulic power supply with a high pressure hose. During the centrifuge flight, the regulator is controlled by providing the value of 
counts in the hydraulics software. The piston rod of the hydraulic cylinder is connected with the tidal cylinder piston rod by a shaft.
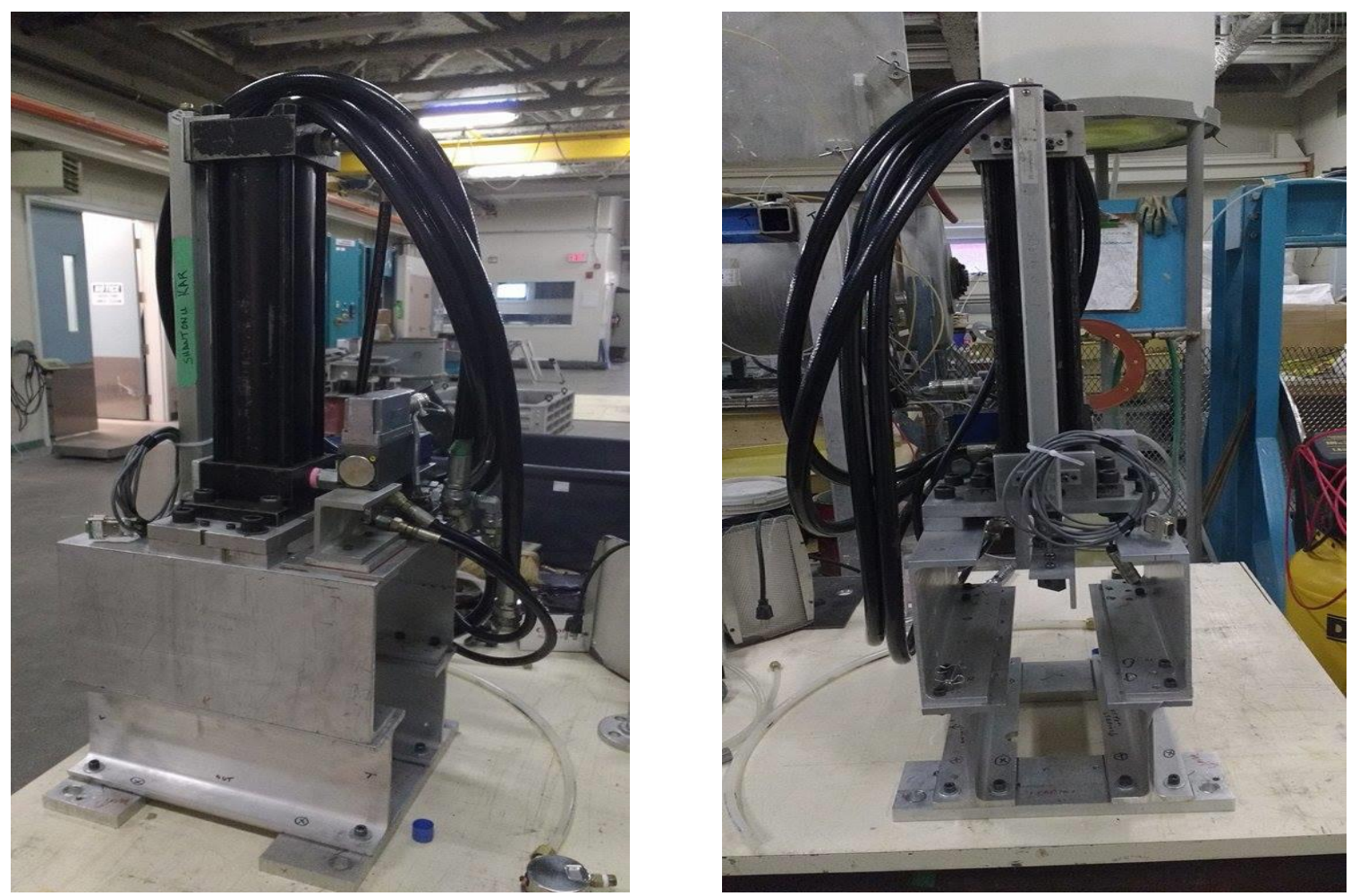

Figure 4.14: Hydraulic cylinder and servo controlled valve

\subsubsection{Lights and camera}

In the test package a Canon Power Shot G7 10MP digital camera was used for capturing still pictures. Two flood lights, one GoPro and a webcam were used for capturing live views of the test. Figure 4.15 and 4.16 shows the picture of mounted flood lights, camera, GoPro and webcam. The camera was connected to the power supply of the centrifuge arm and connected to the video PC by USB cable. 


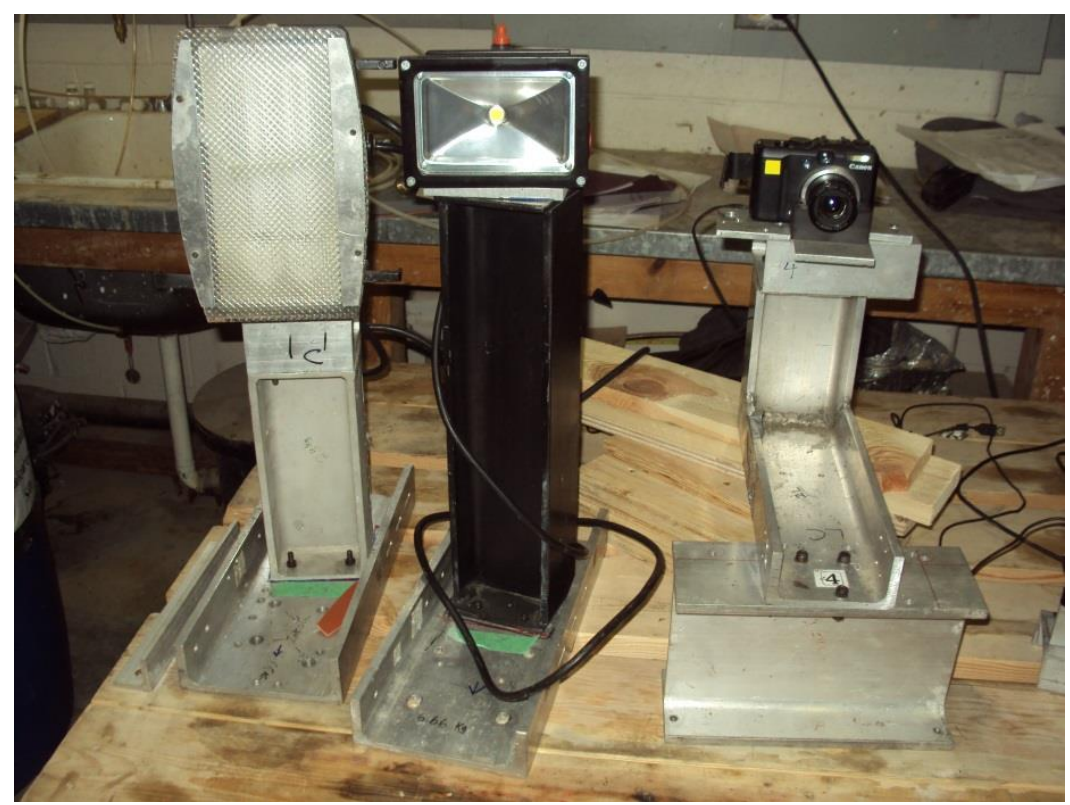

Figure 4.15: Mounted lights and Cannon G7 camera

The camera was monitored from the centrifuge control room computer and pictures captured using PSRemote software. Time lapse of pictures were taken using this software. Canon G7 camera provided images every 7 seconds in the proof test and every 20 seconds in the second test during changes in loading conditions (e.g. swing up, tidal motions and swing down). All these cameras and lights were bolted to an extrusion plate on the centrifuge basket. Some part of the mounting stand was outside the extrusion plate and needed support below the overhanging part of the aluminum plate to resist the downward centrifugal force. Lights and cameras were connected with the extrusion plate after the extrusion plate, high pressure box and tidal cylinder were placed in the centrifuge basket towards the nose part of it. 


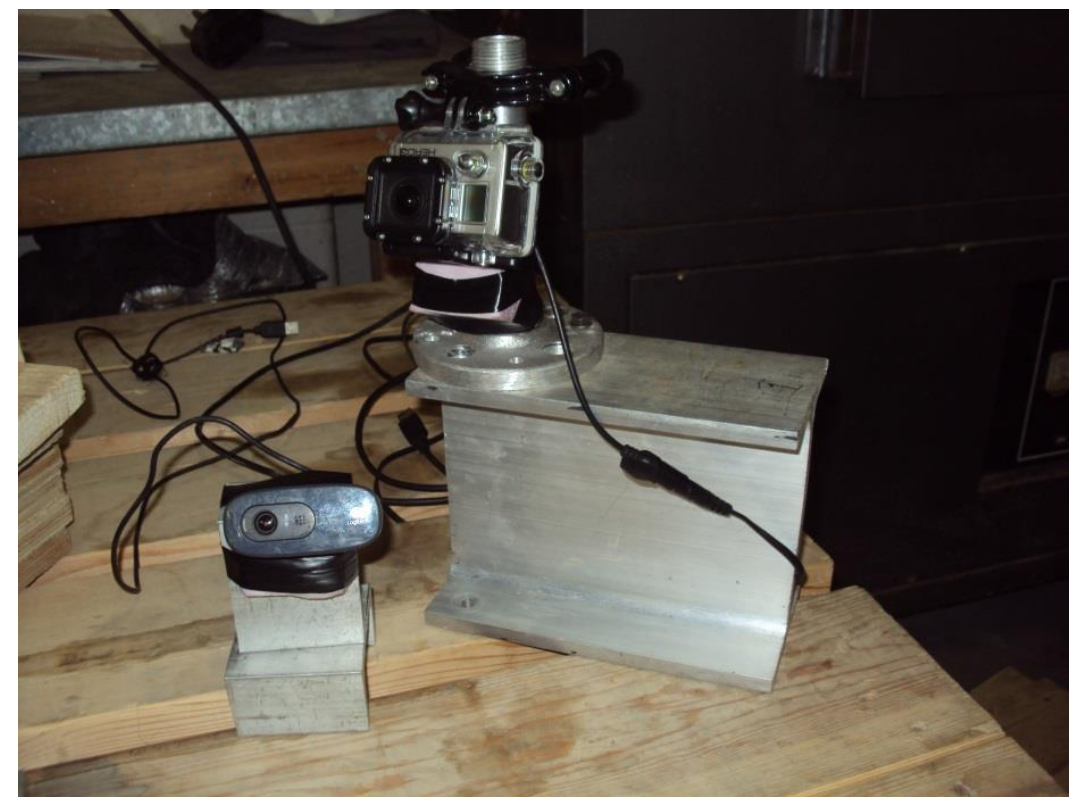

Figure 4.16: Video camera (GoPro and webcam)

\subsection{Centrifuge model preparation}

Two tests were undertaken in the C-CORE geotechnical centrifuge at 50g. Model geometry, material instrumentation and model preparation method are discussed below.

\subsubsection{Instrumentation}

Two centrifuge tests were done in this study. The first one was a centrifuge proof test with minimal instrumentation. Figure 4.17 shows the instrumentation for the second test. Three pressure transducers were used to monitor the pressures at the top and bottom of the the pneumatic cylinder and the top of the high pressure box. For measuring the movement of hydraulic piston, a LDT was used. A temperature sensor was used to monitor the temperature of the package throughout the test. 


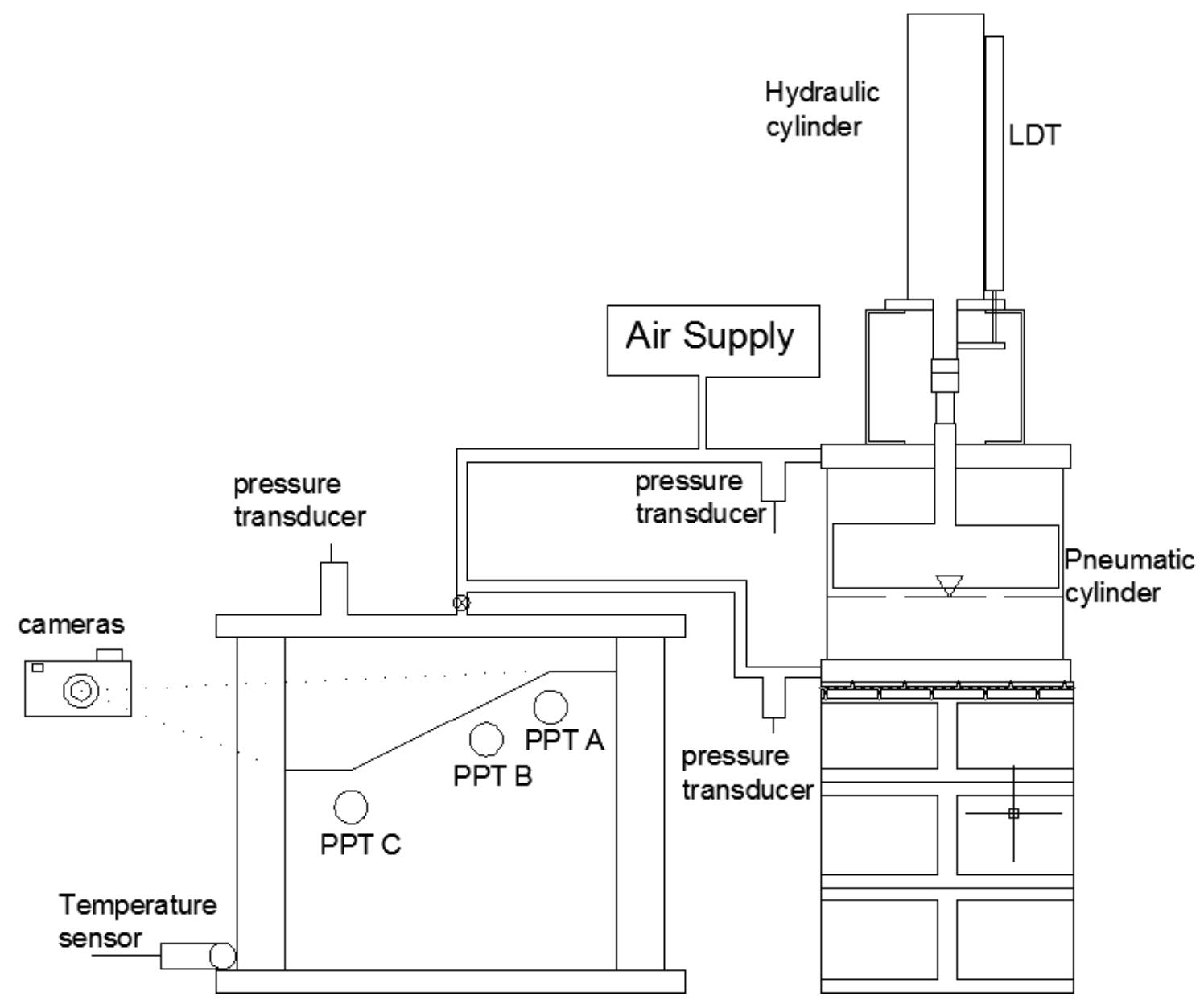

Figure 4.17: Centrifuge test instrumentation

In the second centrifuge test three more pore pressure transducer (PPT) were placed in the sand model. Figure 4.18 shows the positions of these pore pressure transducers in the sand model. 


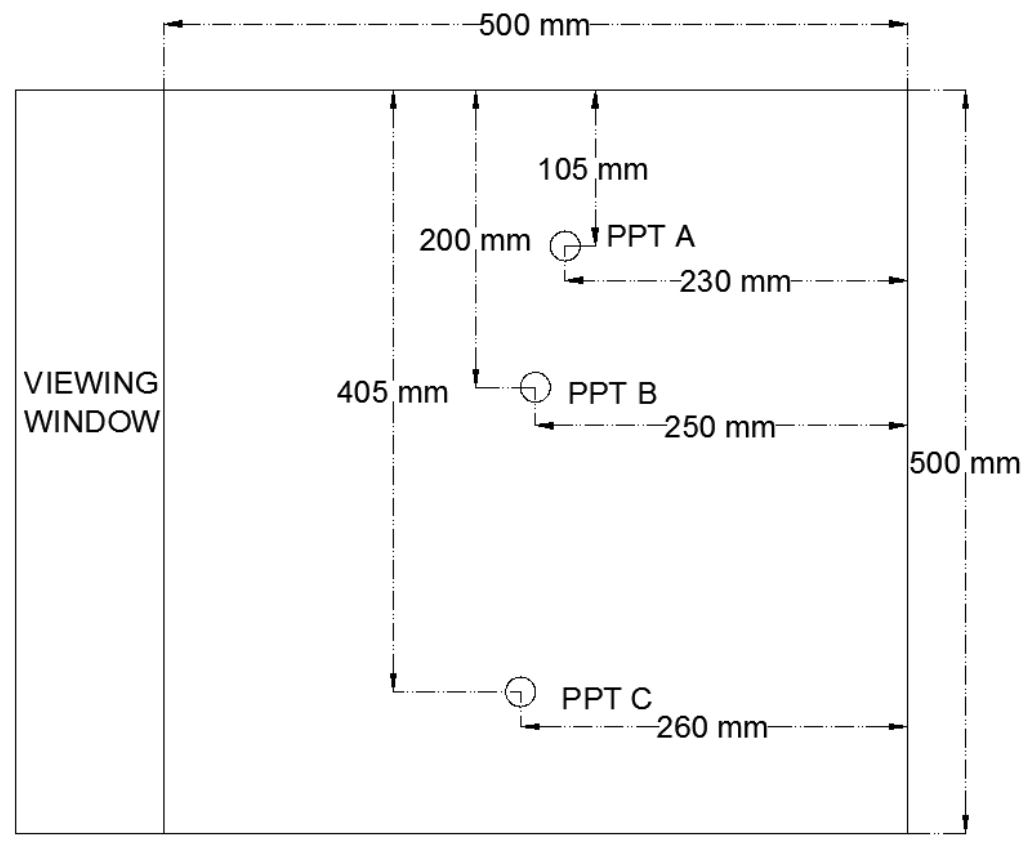

(a)

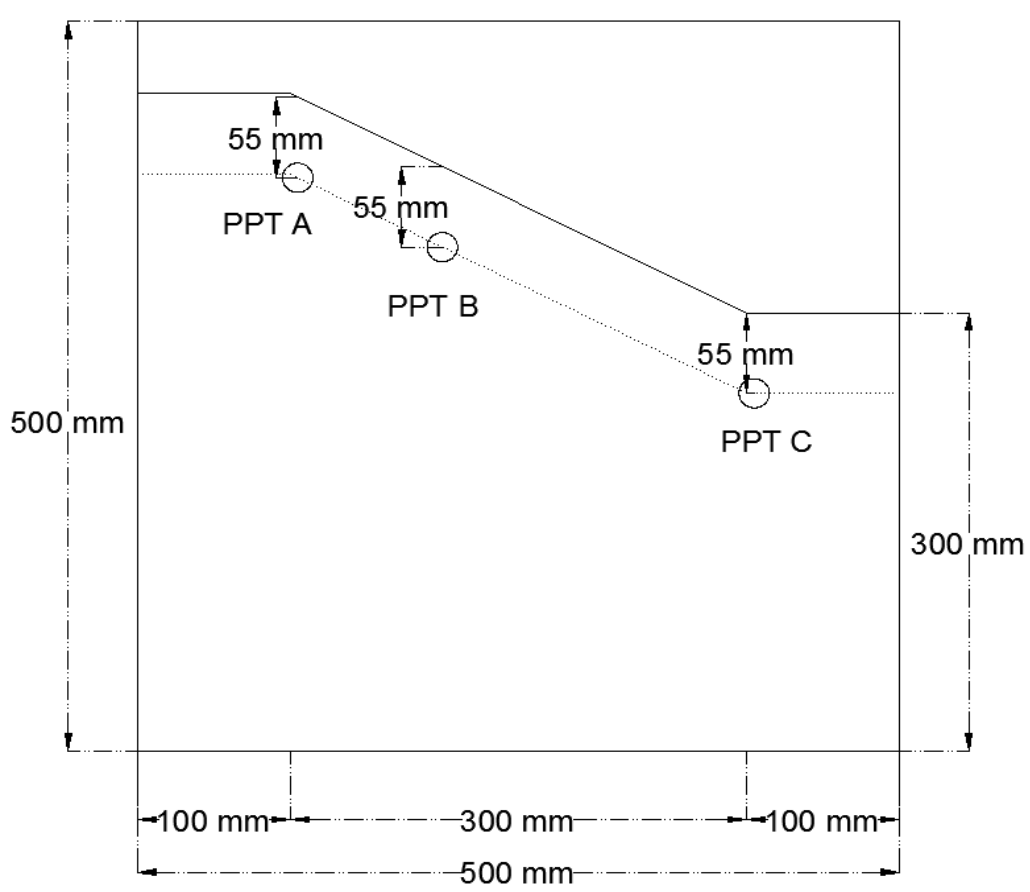

(b)

Figure 4.18: Placement of the pore pressure transducer (PPT) in the sand model 


\subsubsection{Model saturation by vacuum}

For preparing a gassy sand model of known partial saturation it is important to saturate the whole model with water first. A vacuum saturation method was used to ensure the full saturation of the sand model similar to that presented by Ueno (1998) and Coulter (2008). After making the slope profile in the high pressure box, it was sealed with the top lid to hold the vacuum and desired pressure. An O-ring and silicone sealant was used to seal the high pressure box. After using silicone, the high pressure box was left for 48 hours to cure the silicone before applying vacuum. A thin layer of coarse sand was placed at the base of the high pressure box to spread out the carbon dioxide and distilled water uniformly under the sand model. The high pressure box was placed under vacuum of approximately 93 $\mathrm{kPa}$ for 24 hours to remove most of the air from the sand slope. The vacuum pump to the container was shut off after this initial vacuum stage as the high pressure box can hold vacuum. Some air is still in the voids of the sand slope after applying vacuum. Carbon dioxide is then used to displace this air from the sand model. The solubility coefficient of carbon dioxide in water is $0.86 \mathrm{~L} / \mathrm{L}$. So, it can easily dissolve in the water to get a more fully saturated sand model. Carbon dioxide gas is introduced into the bottom of the high pressure box from a depressurization chamber which helps to regulate the high pressure carbon dioxide gas from the compressed gas supply bottle. Figure 4.19 shows carbon dioxide flushing into the high pressure box. After introducing carbon dioxide, the pressure in the sealed high pressure box is brought back to atmospheric from vacuum over the period of an hour. Following this process, the high pressure box was again connected with a vacuum pump for approximately one hour to bring back to $-93 \mathrm{kPa}$. 
After reaching the beginning vacuum level the carbon dioxide flushing process is repeated again for the second and third times to decrease the amount of air inside the model slope. The majority of gas inside the high pressure box should be carbon dioxide which is more soluble than air in water and allows complete saturation of the model slope with water.

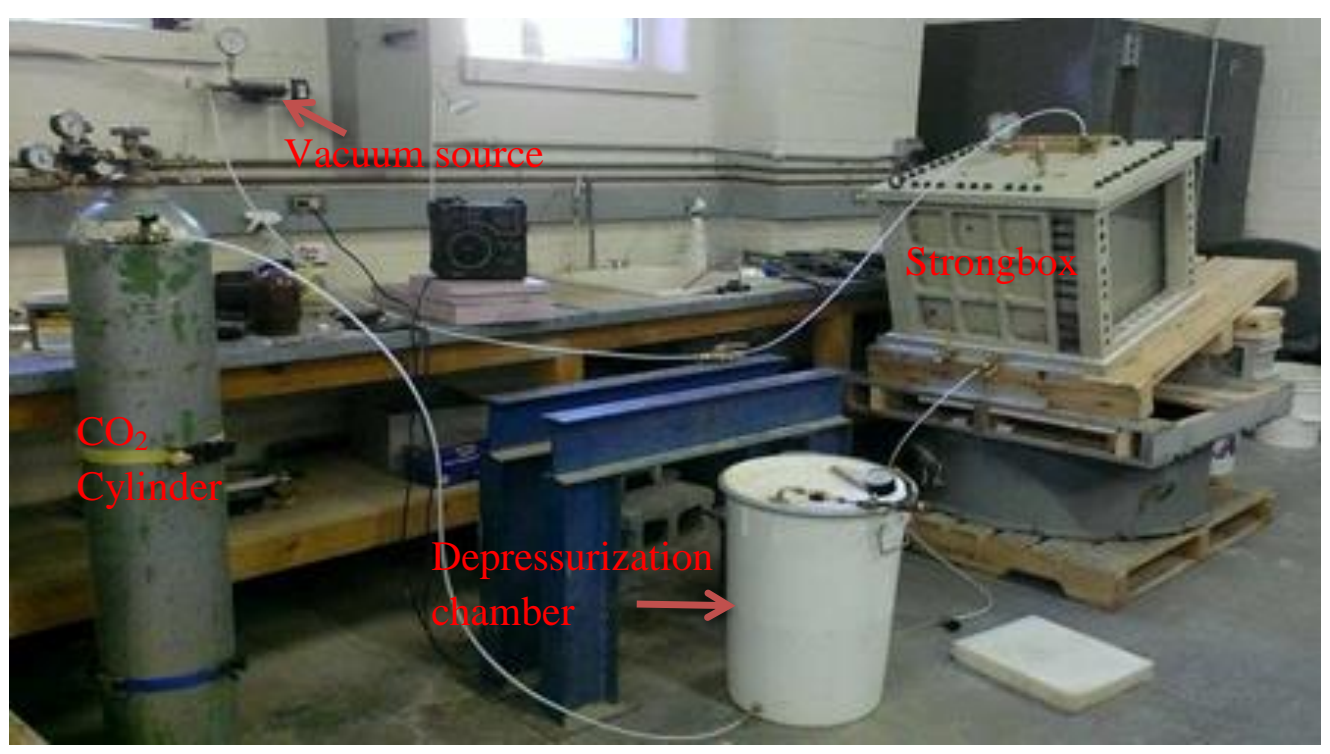

Figure 4.19: Carbon dioxide flushing

After flushing the carbon dioxide, the slope model was saturated by distilled deaired water. Distilled water was poured into the distilled water container and put under vacuum for 24 hours to deaired the water. This was done at the same time as the carbon dioxide flushing. The vacuum was equalized between the distilled deaired water container; the sand model and overflow container. There was no differential pressure when the pore water was introduced into the model slope, to cause disturbance of the model. The model slope container is slightly inclined to prevent seepage induced slope failure and provide more uniform saturation. After equalizing the vacuum in all the containers the base valve 
was opened to allow the distilled deaired water to saturate the model slope from the bottom. Distilled deaired water flows from the model container under the differential head, which is achieved by lifting the container off the laboratory floor. To prevent a quick condition in the model slope a very small head was provided with the distilled deaired water container. Figure 4.20 shows flushing of distilled deaired water into the high pressure box. The total amount of water flushed through the model is 1.4 times the void space of the high pressure box. The excess flushed water is then stored in the overflow container. A period of approximately 25 to 30 days was needed to fully saturate the model slope with this low head. After finishing this process the system vacuum was reduced to atmospheric pressure and the slope model is then ready to flush with ethylene mixed water to make a gassy slope.

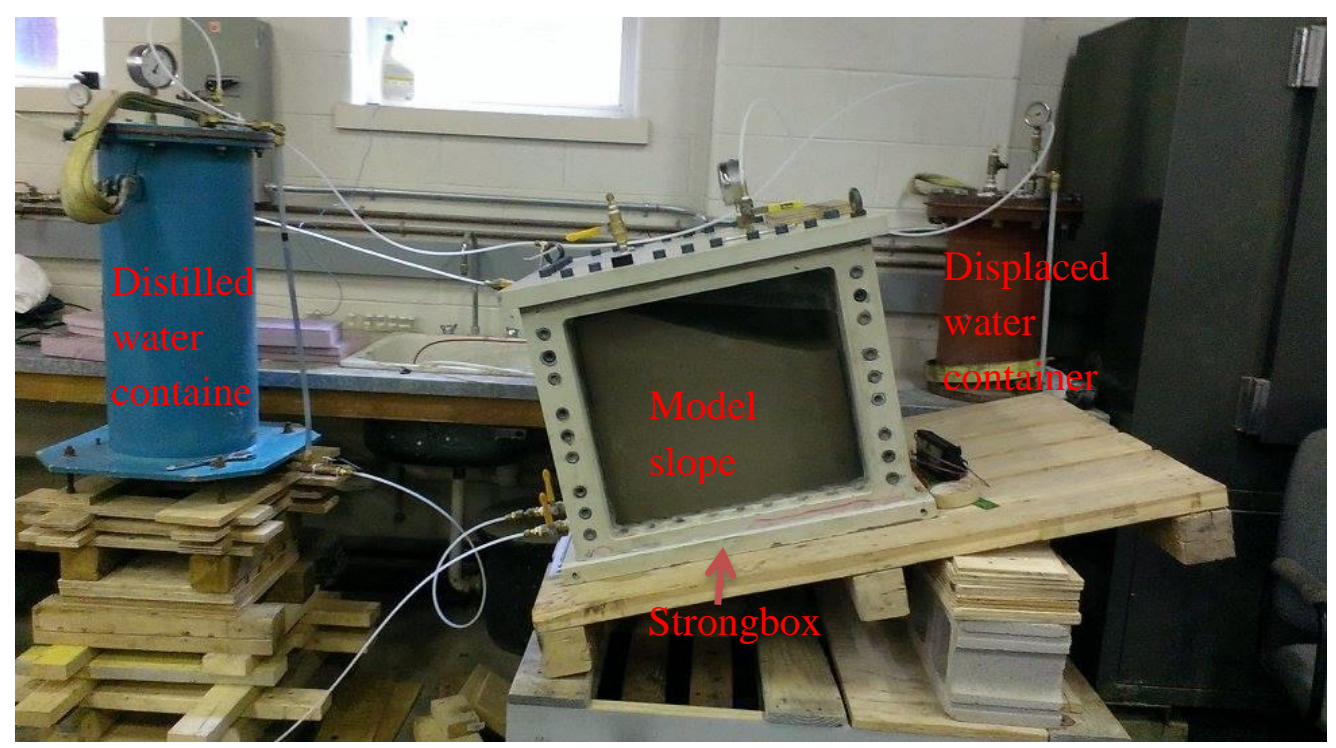

Figure 4.20: Flushing of distilled deaired water into high pressure box 


\subsubsection{Model saturation by ethylene mixed water}

After fully saturating the slope model with water, it is then prepared for flushing with ethylene mixed water. Ethylene gas was mixed with distilled water in a separate room. The process of ethylene mixed with water is described below:

\subsubsection{Preparation of ethylene mixed water}

For preparing the ethylene mixed water the mixing container is first filled with distilled water up to the desired height. The ethylene mixture container is discussed in the experimental setup part 4.2.2.3. Figure 4.21 shows the lab setup for ethylene mixed water. After filling with distilled water, ethylene mixing container was connected to a vacuum source to make the water deaired. After deairation, ethylene was introduced to the mixing container from the pressurized ethylene cylinder at a desired pressure. Initial pressure of the ethylene mixing container was $655 \mathrm{kPa}$.

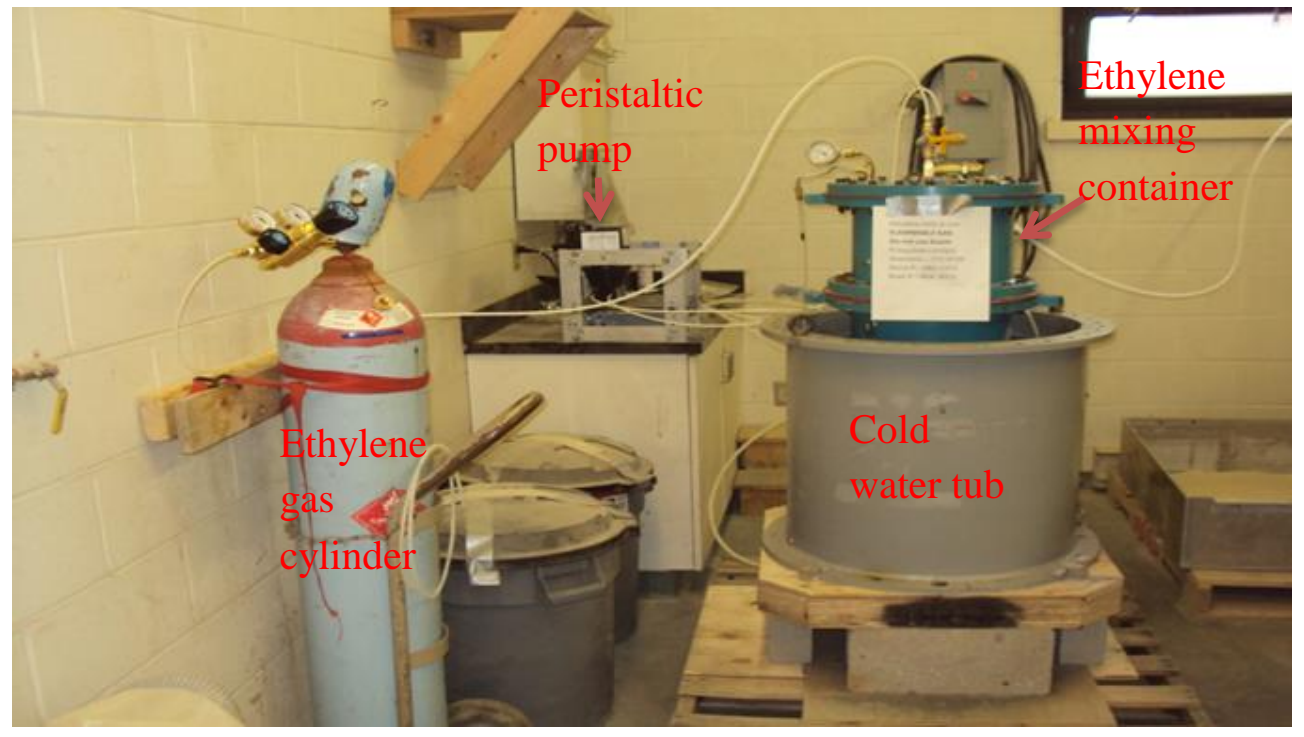


Figure 4.21: Lab setup for ethylene mixed water

Peristaltic pump was connected with the top and bottom port of the mixing container. Before turning on the peristaltic pump the whole setup was monitored to check the pressure drop from the mixing container. A pressure release regulator was used at the top of the mixing container to release the pressure if the mixing container is over pressurized. The pressure of the regulator was set at $690 \mathrm{kPa}$. The main purpose of the peristaltic pump is to transport the water from the bottom of the mixing cylinder to the top. As the mixing cylinder was pressurized, a one way valve at one end of the peristaltic pump was connected with the top of the mixing container. The ethylene mixed water container was placed in a cold water tub to reduce the mixing temperature. Cold water was supplied from the tap and the water from the tub drains back into the sink. More ethylene mixed with water if the temperature of the mixing is low. From Figure 4.22 shows that solubility of ethylene in water is higher when the mixing temperature is low.

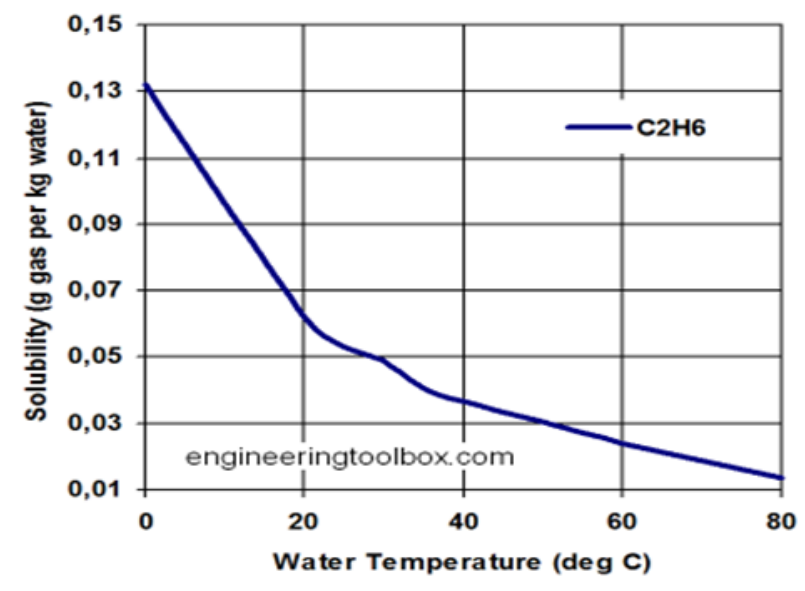

Figure 4.22: Relationship between temperature and solubility of ethylene (http://www.engineeringtoolbox.com/gases-solubility-water-d_1148.html) 
Figure 4.23 shows the pressure of the mixing container and the temperature of cold water tub with time. With running the peristaltic pump, the pressure in the ethylene mixing container decreases with time. Figure 4.23 shows that the pressure of the mixing container dropped from the initial pressure of $655 \mathrm{kPa}$ to $480 \mathrm{kPa}$. The peristaltic pump was turned off at night at $480 \mathrm{kPa}$ as the process was not monitored. Next day, the pressure again reduced to $455 \mathrm{kPa}$ with the running of the pump. The pressure of the mixing container was restored to $655 \mathrm{kPa}$ by adding ethylene. Again with running of the peristaltic pump, the pressure in the mixing container decreased. The rate of decrease was much less compared to the first step. Again the pressure of the mixing container was increased to the initial condition after getting a stable pressure the second time. But after the third time there was no further decrease in pressure of the mixing container. This indicates that ethylene is fully saturated with distilled deaired water and ready for flushing. The average temperature of the tub water was $11.2^{\circ} \mathrm{C}$. The whole process of making ethylene mixed water took around five days.

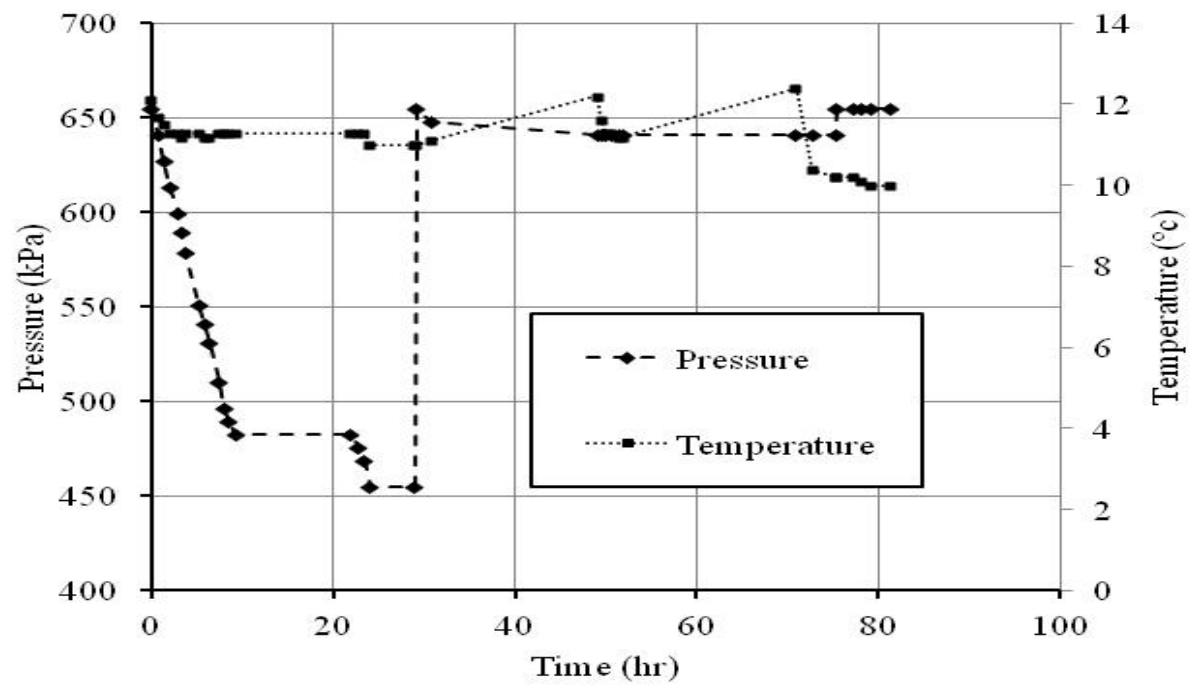

Figure 4.23: Container pressure and tub temperature while ethylene mixed with water 
Two containers of the ethylene mixed water were needed to displace the flushed distilled water from the slope model in the high pressure box.

\subsubsection{Flushing of ethylene mixed water}

After preparing the ethylene mixed water, the ethylene mixing container is taken out of the cold water tub and placed in the lab floor at room temperature for 12 hours. At lab floor temperature, pressure of the ethylene mixed container increased. A hose was connected with the pressure relief valve if the pressure in the container exceeded $689 \mathrm{kPa}$. The ethylene mixing container was again connected to the bottom of the high pressure box. The overflow container is attached to the top lid of the high pressure box to collect the displaced distilled water. Figure 4.24 shows the lab setup for the ethylene mixed water flushing. Ethylene mixing container and the overflow container were connected with each other and to the pressure source.

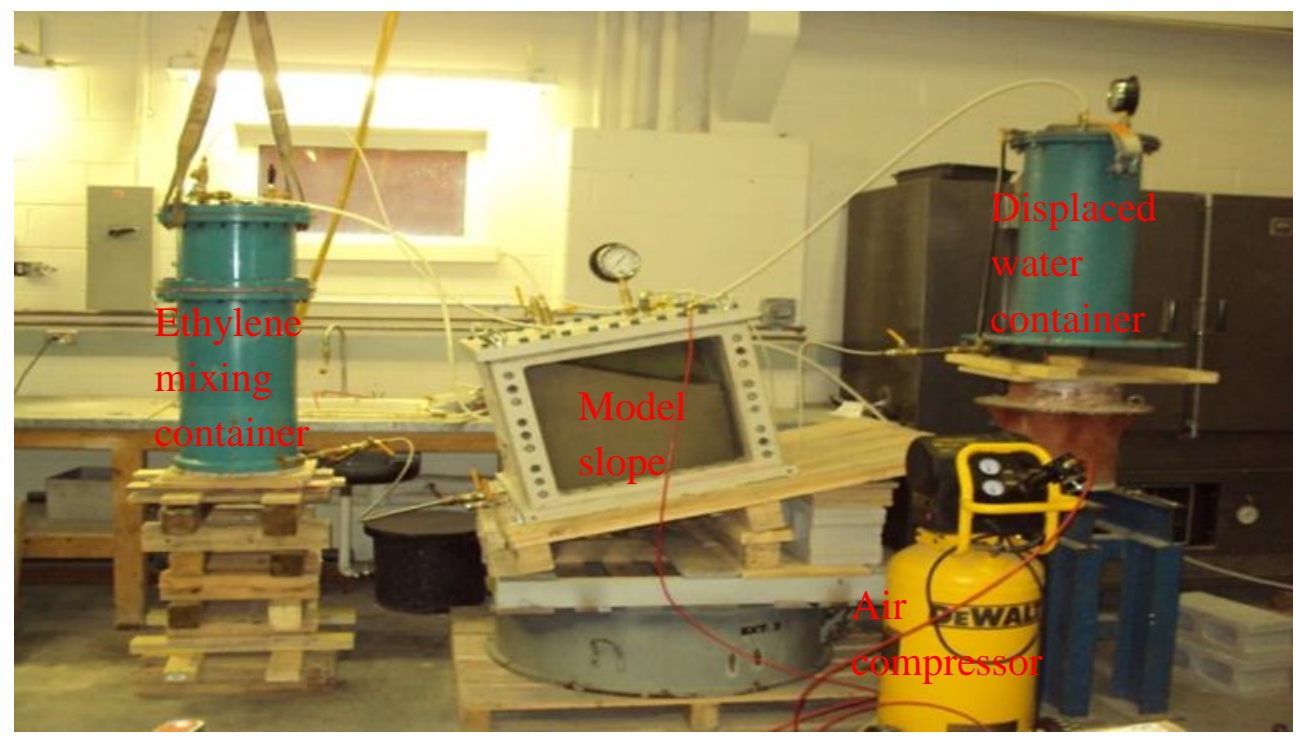

Figure 4.24: Lab setup for ethylene flushing 
At the beginning only the ethylene mixing container is at a pressure of $655 \mathrm{kPa}$ but the high pressure box and displaced water container is at atmospheric pressure. Before flushing the ethylene mixed water high pressure box and the displaced water container they are both pressurized to $655 \mathrm{kPa}$ which is same as the ethylene mixed container. After that closing the pressure source, the top two valves of the containers are opened to equilibrate the pressure. When the pressure became stable, ethylene mixed water is flushed through the bottom of the high pressure box under a very small head difference. This ethylene mixed water displaced the distilled water from the high pressure box into the overflow container. After finishing the $1^{\text {st }}$ batch of ethylene mixed water the mixing and flushing process was repeated. The total amount of water flushed through the sand slope was 1.7 times the void space of the high pressure box. After finishing the ethylene mixed water flushing, the model slope was potentially gassy when depressurized and ready for centrifuge test.

\subsubsection{Data acquisition system}

Data acquisition in the centrifuge was accomplished by using the data acquisition software on the DACPC computer. This computer can be accessed from the computer CENTDAS through fiber optic hubs and rotary joints. DACPC then interfaces to a VXI data acquisition chassis with HBM VT415 and a VT503 data acquisition. These cards receive signals from the $\mathrm{C}$-CORE signal conditioning boxes to which individual transducers/instruments were plugged in. Data processing was done using MATLAB software, which is one of the high performance interactive software programs for scientific and engineering computations. 


\subsubsection{Model placement in centrifuge arm}

Figure 4.25 shows the layout of the centrifuge swinging basket with a high pressure box, tidal actuator, camera and lights mount and DAQ channel.

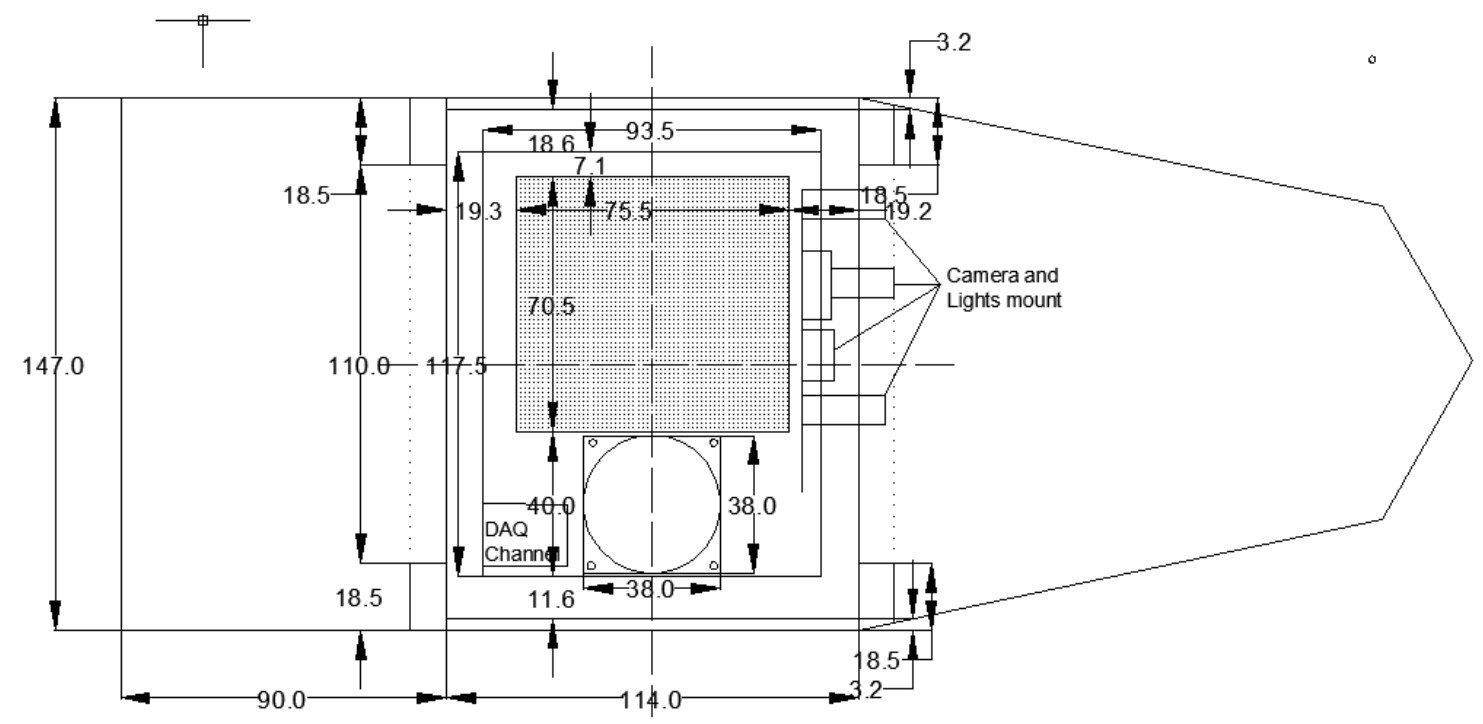

Figure 4.25: Centrifuge platform layout (all units are in $\mathrm{mm}$ ) with whole package

Figure 4.26 a \& b shows the first and second centrifuge models in the centrifuge. The hydraulic cylinder piston is attached to the piston of the pneumatic cylinder and hydraulic hose was connected to the ports on the centrifuge arm. 


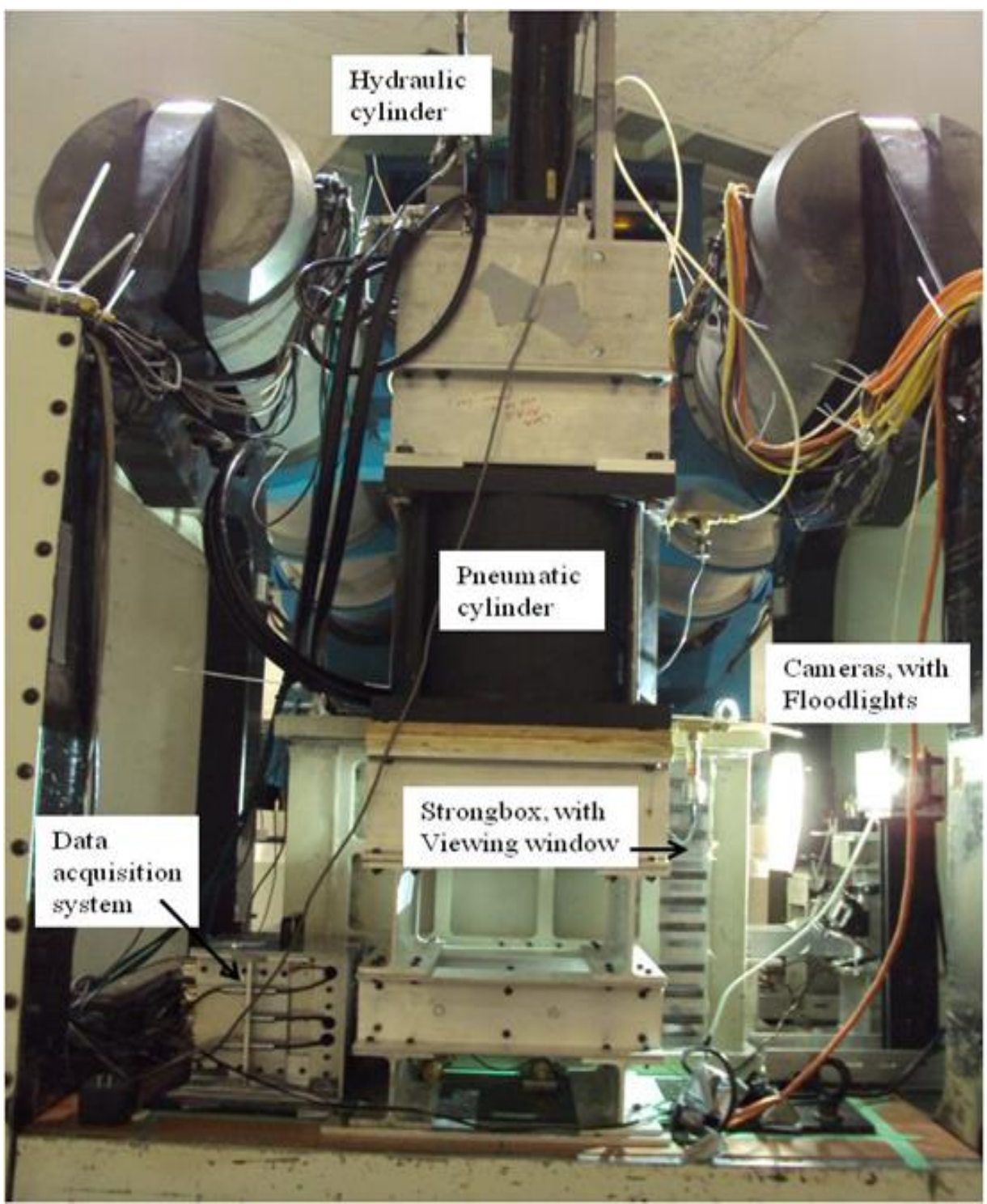

Figure 4.26 (a): After placement of centrifuge model package in first test 


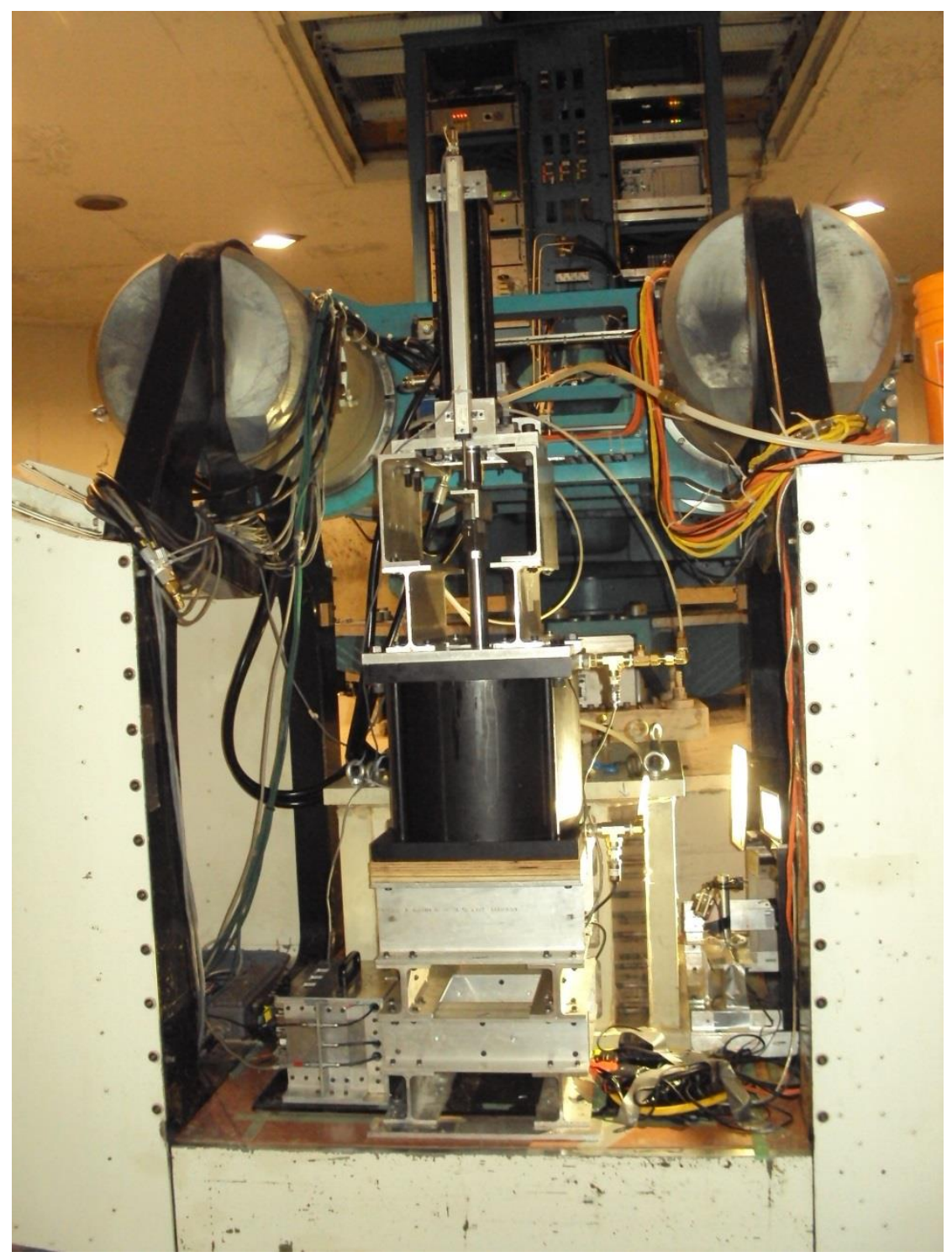

Figure 4.26 (b): After placement of centrifuge model package in second test

Lights and cameras are on the right side of the high pressure box and the lights were turned on throughout the test although the lights produce some heat on the acrylic of the high pressure box. The data acquisition system was placed on the extension plate by the left corner of the tidal actuator. All the cables were tied down during the test. The two side doors of the swinging basket were closed during flight. 


\subsection{Centrifuge test procedures}

Before the centrifuge test, the pneumatic cylinder was filled with water to the desired height. The hydraulics was then turned on and the piston was lifted with the pneumatic cylinder above the water level to identify the upper, lower limits and level of water in the pneumatic cylinder. The pneumatic cylinder was then pressurized at the same pressure as in the high pressure box to check for leakage. After a while, if there was no leak, the valve was opened between the high pressure box and the pneumatic cylinder. The whole system was at the same pressure after opening the valve. During the first centrifuge test, reading was taken of centrifuge rpm, movements of LDT and three pressure transducers. In second centrifuge test, three pore pressure transducers (PPTs) were added in the soil slope. The centrifuge was set to an acceleration of $50 \mathrm{~g}$ by providing an input rpm of 93.06. During the stage of swinging up, the camera was turned on to capture pictures. After reaching the desired acceleration of $50 \mathrm{~g}, 15$ minutes of time was provided for the stability of slope. Analyses by Holocher (2003) show about 15 minutes were required for krypton gas bubbles to dissolve in distilled water, Figure 4.27. Krypton has a similar diffusivity and solubility as ethylene. A period of 15 minutes was therefore allowed after each change in model loading to allow gas to dissolve or come out of solution. The Piston of the pneumatic cylinder was slowly moved to find the water level. By creating cycles with the piston in the pneumatic cylinders tide, was then applied to the soil slope at a degree of saturation level of $100 \%$. Then the pressure of the pneumatic cylinder and strongbox was reduced by using the venting regulator at the top of the pneumatic cylinder. The slope was then brought to a target saturation level of $95 \% .15$ minutes of 
time was provided to allowing gas to come out of solution. Tide was then applied in the soil slope by the same process of moving the piston. Slope was monitored by the video camera and captured pictures by the Canon camera at a fixed interval during the period of tide application. Pressure of the pneumatic cylinder and strongbox was again reduced to target the degree of saturation level in the slope of $90 \%, 80 \%$ and $70 \%$ respectively. Tide was applied by the same process after each pressure reduction step and the movement of the slope was monitored. After finishing all the steps, the centrifuge was stopped. The strongbox was then unloaded from the centrifuge arm and placed in a safe area to vent ethylene slowly and monitor the slope for gas bubble expansion.

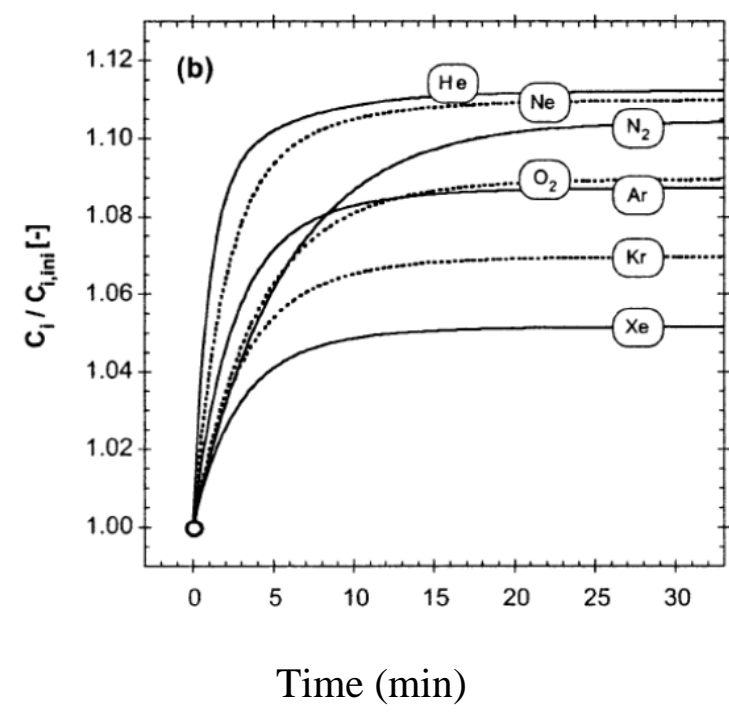

Figure 4.27: Estimated gas solution times, Holocher (2003)

\subsection{Time required for making centrifuge model}

Each centrifuge model test took about 60 to 65 days from the beginning to end of the test. Table 4.2 shows the time required for prepating a centrifuge model. The main portions of time required are to saturate the model with water and ethylene mixed water. 
Table 4.2: Time elapsed for making model slope for centrifuge test

\begin{tabular}{|l|l|}
\hline \multicolumn{1}{|c|}{ Steps } & Time (days) \\
\hline Cleaning and preparing the high pressure box & 2 days \\
\hline Sand raining & 5 days \\
\hline Sealing the high pressure box & 4 days \\
\hline Vacuum saturation & $25-30$ days \\
\hline Making ethylene mixed water $\left(1^{\text {st }} B\right.$ atch $)$ & 5 days \\
\hline Flushing ethylene mixed water $\left(1^{\text {st }} B\right.$ atch $)$ & $6-8$ days \\
\hline Making ethylene mixed water $\left(2^{\text {nd }} B\right.$ atch $)$ & 5 days \\
\hline Flushing ethylene mixed water $\left(2^{\text {nd }}\right.$ Batch $)$ & $6-8$ days \\
\hline Preparing lights, camera and place model in centrifuge arm & 1 day \\
\hline Final test & 1 day \\
\hline
\end{tabular}

The results of the two tests are explained in next chapter. 


\section{Chapter 5: Experimental Testing Results}

\subsection{Overview}

This research investigates the stability of a submarine gassy slope triggered by tidal variations. Under tidal variations on an unsaturated slope, failure may occur under specific combinations of degree of saturation, soil permeability and tidal period. The possibility of failure increases as the degree of saturation and permeability decrease. Also for a specified degree of saturation and permeability, lowering the tidal period increases the failure possibility. Two physical model tests in a geotechnical centrifuge were undertaken of a submarine slope containing gassy sediments. The slope response observed in the tests will be discussed in this chapter. The first test was a proof test of the equipment and procedures described in Chapter four. The second test included refinement of these procedures and more instrumentation.

\subsection{First centrifuge proof test}

In the first centrifuge test, very minimal instrumentation was used in the slope. It was used to check and understand the working process of all parts of the model. Only three pressure transducers were used in the centrifuge model. One transducer in the top of the strongbox, another one at the top of the pneumatic cylinder to measure the air pressure of this cylinder and the last one at the bottom of the pneumatic cylinder to measure the water pressure. Cameras and lights were used to capture pictures. After finishing the test, particle image velocimetry (PIV) analysis was used to check the movements of the slope. 
Figure 5.1 shows the pressure of pneumatic cylinder during calibration and leak testing of the cylinder. It shows linearity with control voltage until $600 \mathrm{kPa}$ and after that a roll off above pressure levels of interest. This change is because of the control limit of the air regulator. After confirming there was no leak in the pneumatic cylinder the test proceeds.

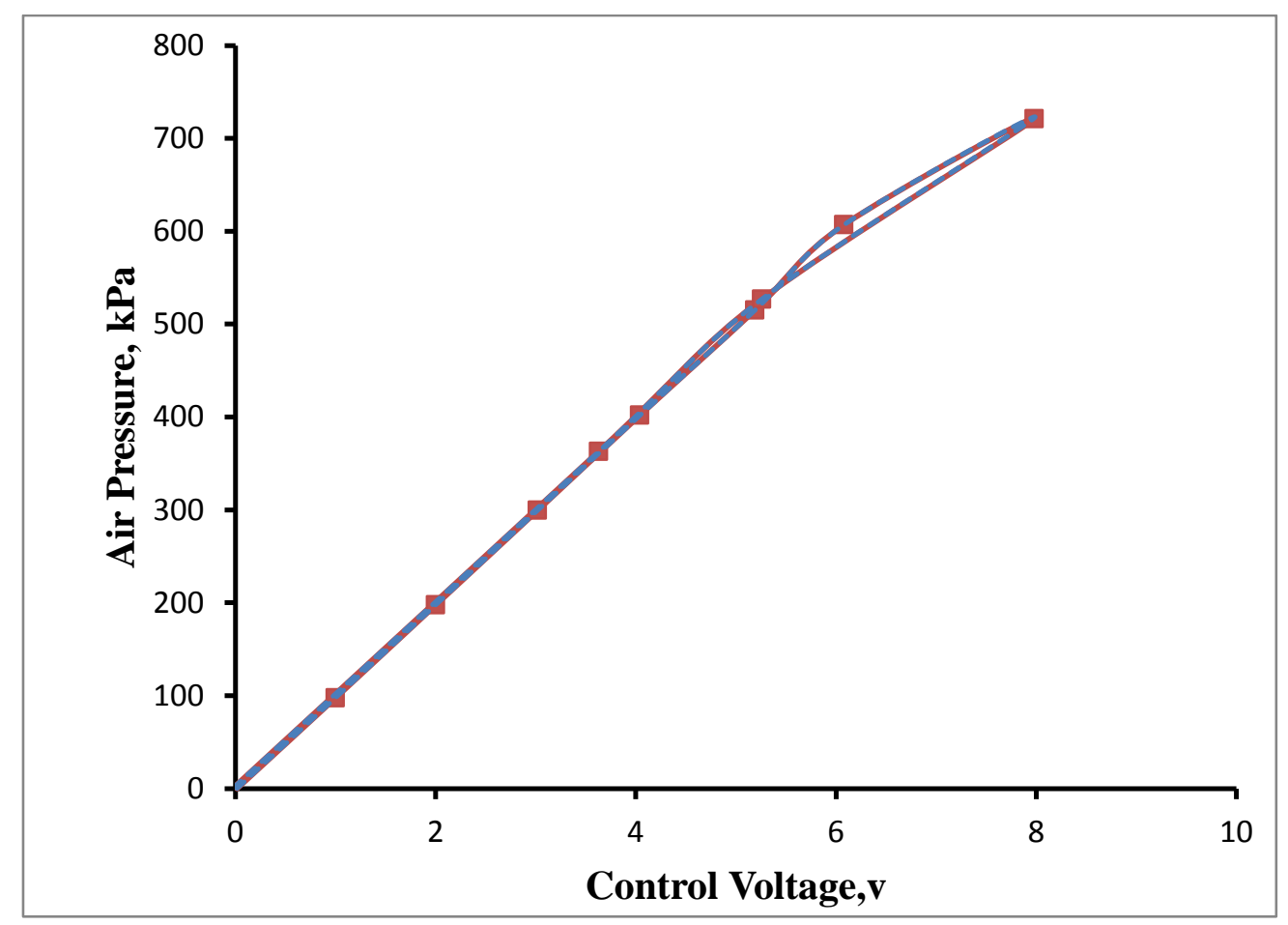

Figure 5.1: Pneumatic cylinder pressure vs. voltage

The centrifuge was accelerated in steps to $10 \mathrm{~g}, 20 \mathrm{~g}, 30 \mathrm{~g}, 40 \mathrm{~g}$ and the desired $50 \mathrm{~g}$ at a calculated rpm of 93.06. Figure 5.2 shows the pressure transducers response during the test. Here, the red, green and blue curves represent the pressures in the strongbox, pneumatic cylinder bottom and pneumatic cylinder top, respectively. Tidal motions were applied at five target degrees of saturation level, $\mathrm{S}_{\mathrm{r}}: 100,95,90,80 \& 70 \%$ with a water pressure variation of $25 \mathrm{kPa}$. The targeted degree of saturation was attempted by reducing the pressure of the strongbox. By decreasing the pressure, gas inside the slope should 
expand and comes out of the solution. This will decrease the degree of saturation within the slope. At each $S_{\mathrm{r}}$ level, there was no measurable change in water level in the pneumatic cylinder bottom, indicating little gas came out of solution. At $\mathrm{S}_{\mathrm{r}}$ levels less than $100 \%$, there were pressure cycles in the strongbox each terminated by reductions in the cylinder air pressure indicating gas venting as seen at 65 minutes.

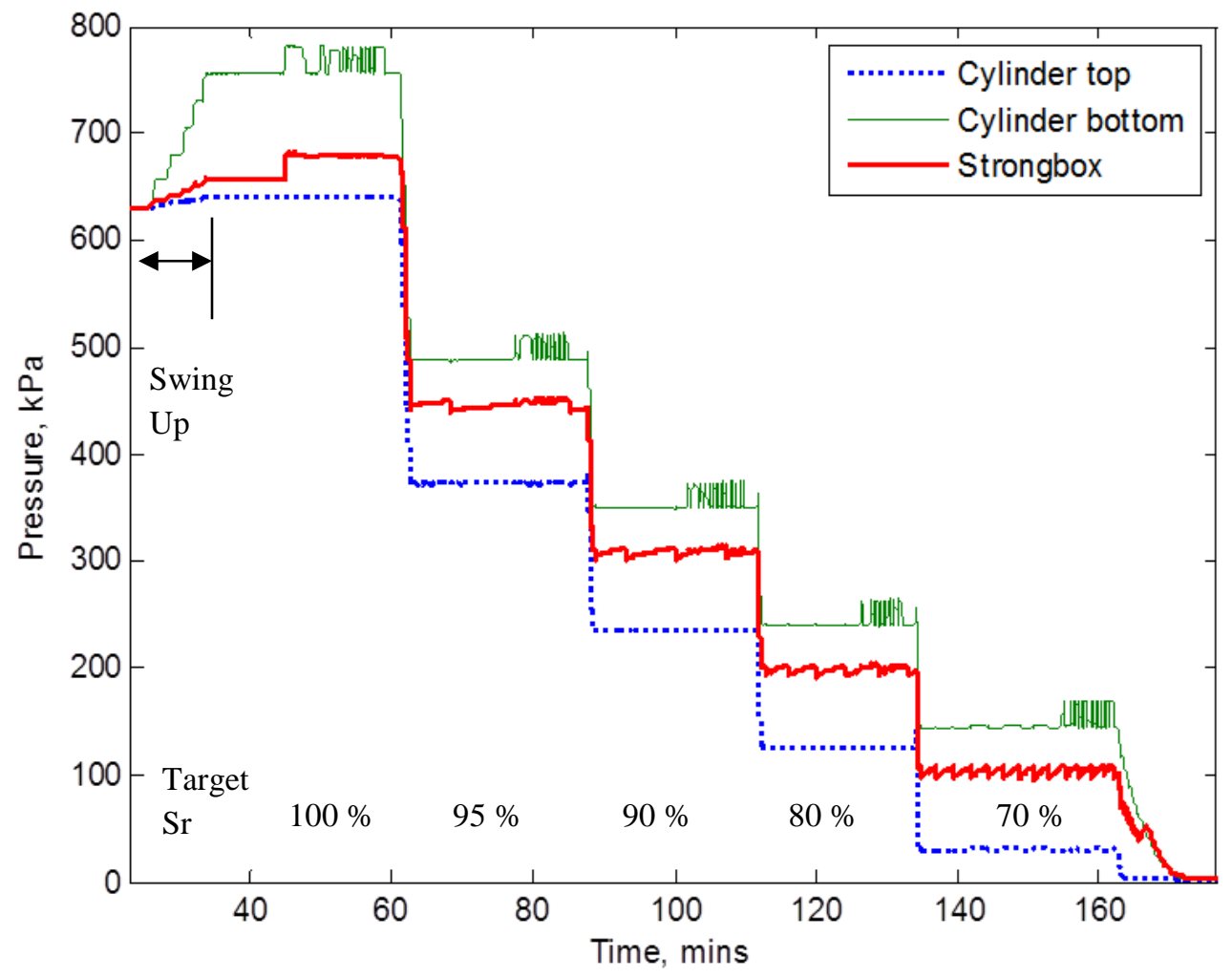

Figure 5.2: Pressure transducer response during the test

The period of these cycles decreased with decreasing $S_{\mathrm{r}}$ indicating more released gas volume, as seen between 110-130 and 130-150 minutes. The strongbox pressure changed in response to the first immersion of the displacement block at 45 minutes, but these 
changes were much less on subsequent block motions, e.g 77 minutes. Gas may have gathered under the transducer in the strongbox and damped its response. Tidal motions of 50 to 5 second periods with up to 5 cycles at each period were applied at the 630 and 360 $\mathrm{kPa}$ air pressure levels. Periods of 20 through 1 second were applied at lower air pressures with up to 50 cycles per tidal period.

\subsubsection{PIV analysis during tidal cycles}

Particle Image Velocimetry (PIV) developed by White et. al. (2003) was used to track slope movements behind the window of the strongbox. This technique tracks the texture (i.e. a map of pixel intensities) of a patch of soil between successive images to provide a displacement vector increment of the patch. Figures 5.3-5.7 shows the PIV analysis of the slope during tidal cycles at target degree of saturation levels of 100, 95, 90, 80 and $70 \%$ respectively. In all the cases a magnification factor of 30 is applied to the vectors. PIV analysis of the first centrifuge test indicates no significant movement of the medium dense slope due to the tidal motions. In all the cases some vector movement was noted at the toe part and the bottom of the heel part of the slope. No significant slope movement was observed by PIV analysis. 


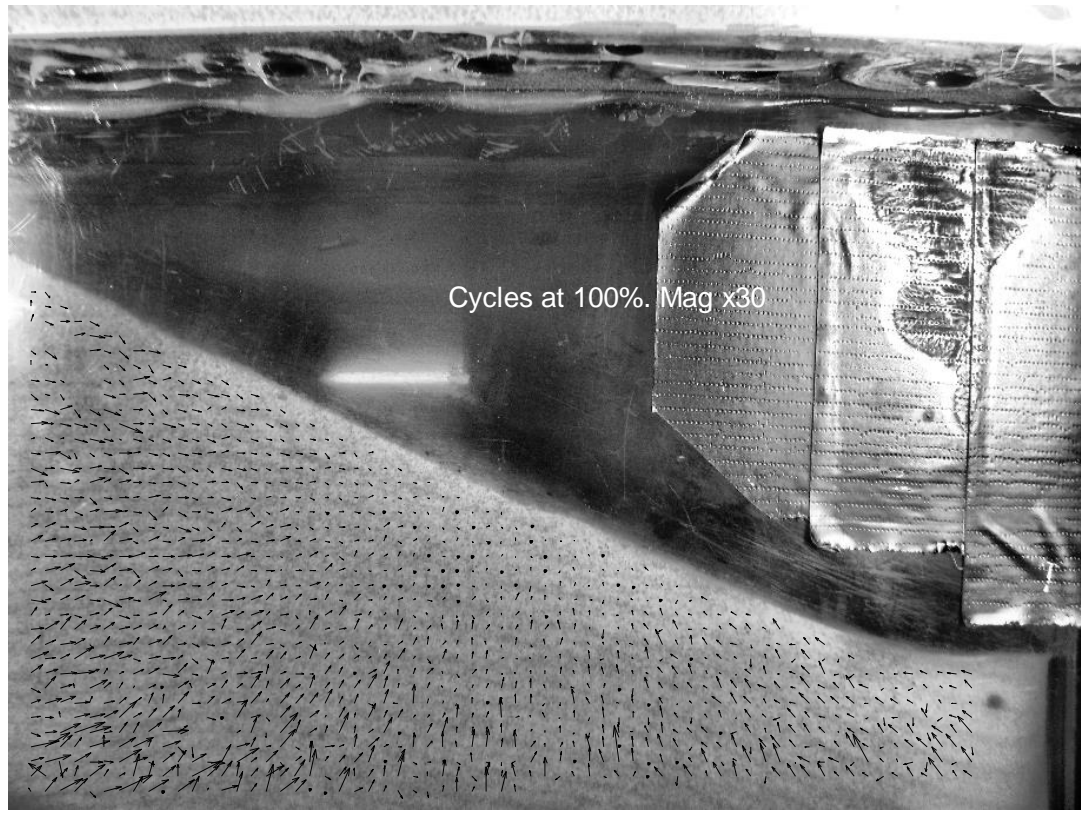

Figure 5.3: PIV analysis during tidal action at $100 \%$ target degree of saturation

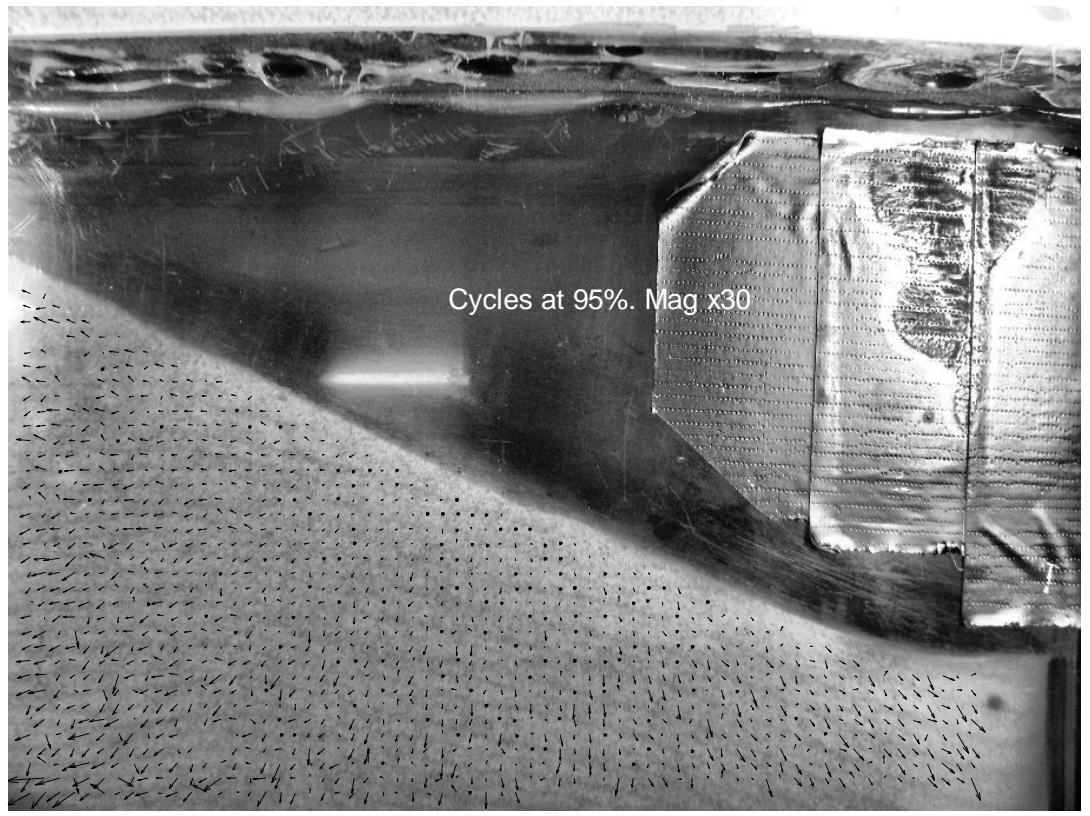

Figure 5.4: PIV analysis during tidal action at 95\% target degree of saturation 


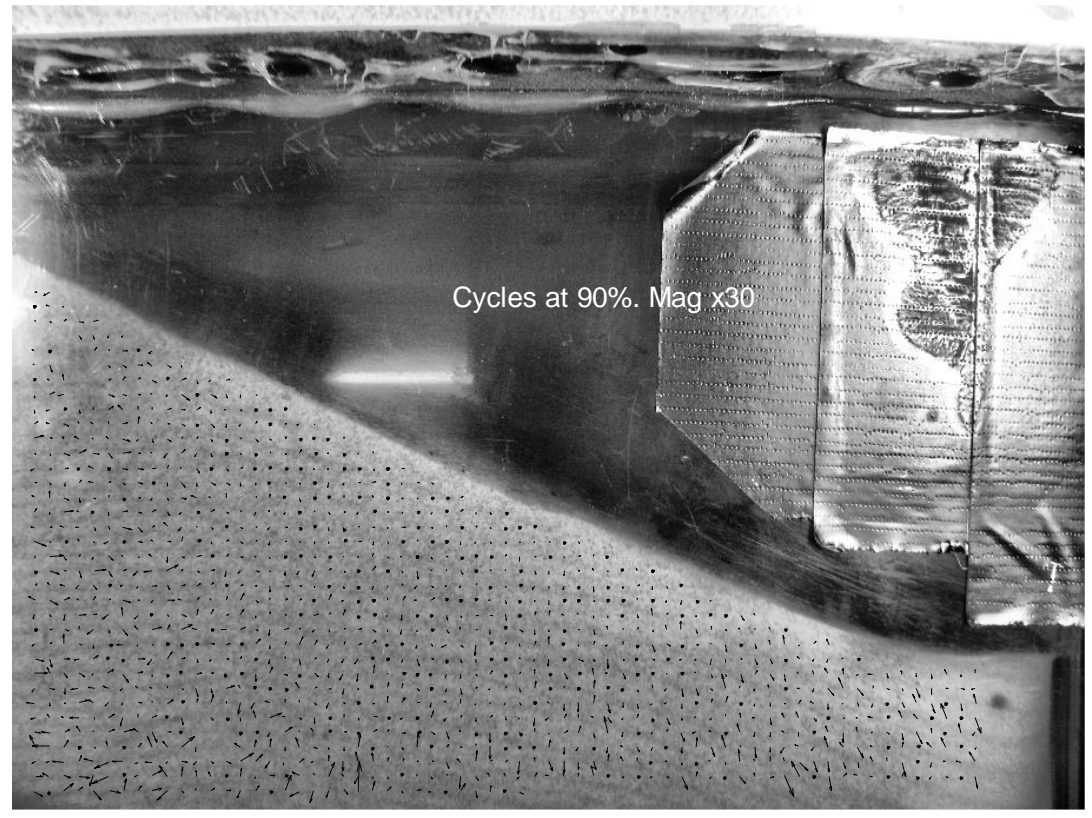

Figure 5.5: PIV analysis during tidal action at $90 \%$ target degree of saturation

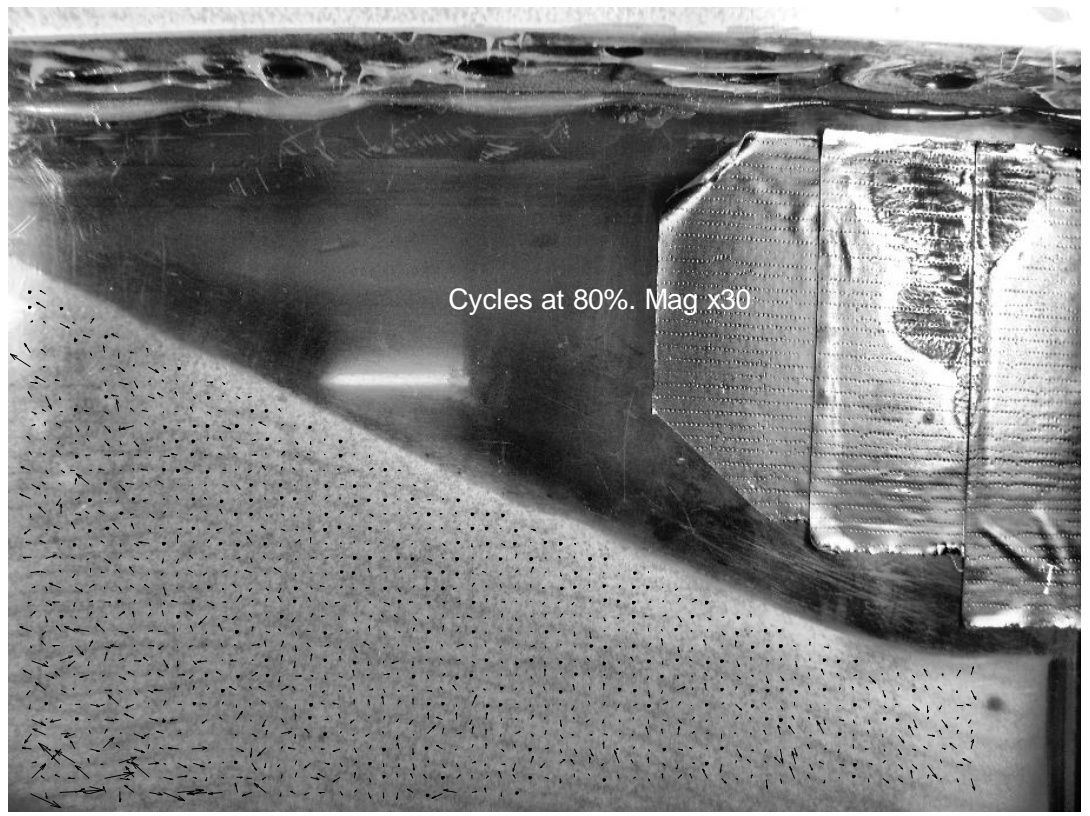

Figure 5.6: PIV analysis during tidal action at $80 \%$ target degree of saturation 


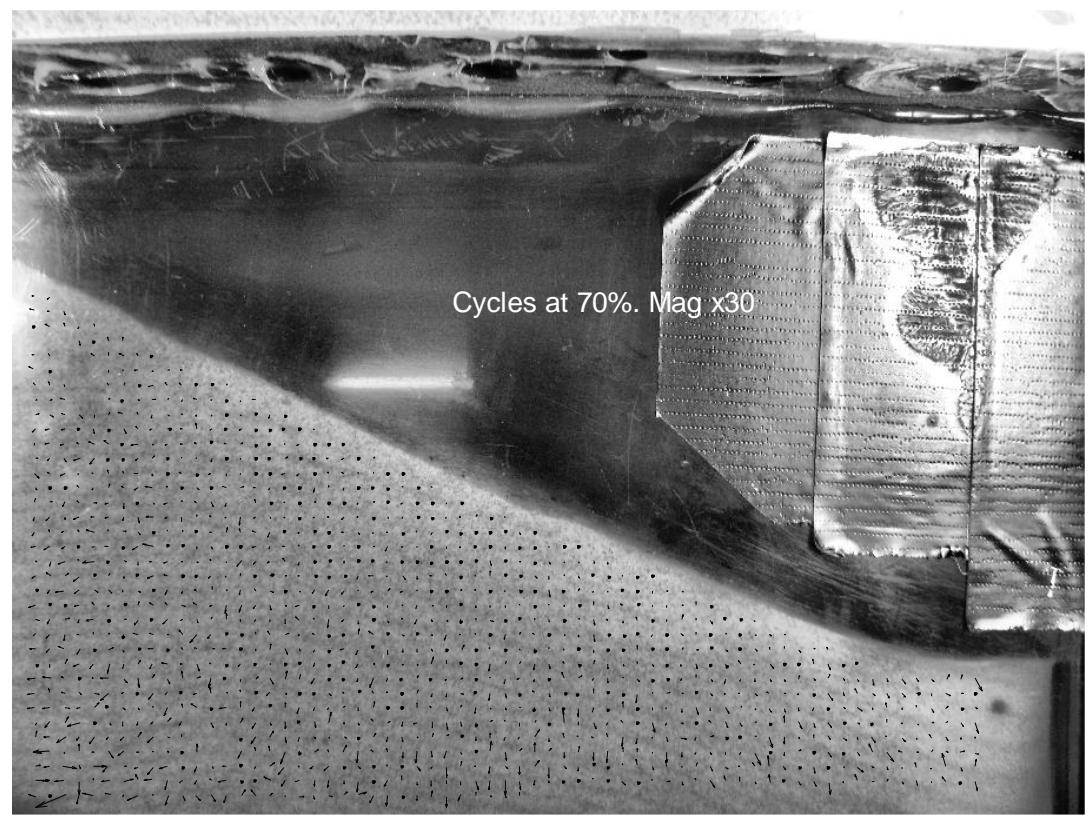

Figure 5.7: PIV analysis during tidal action at $70 \%$ target degree of saturation

Figure 5.8 shows the movement during swing down. This movement occurred due to the decrease in total stress of the slope during swing down. With the decrease of total stress pore gas in the sand slope expands. For the expansion of gas, displacement vectors in PIV analysis suggest volumetric expansion in the slope, with no associated transitional movements. 


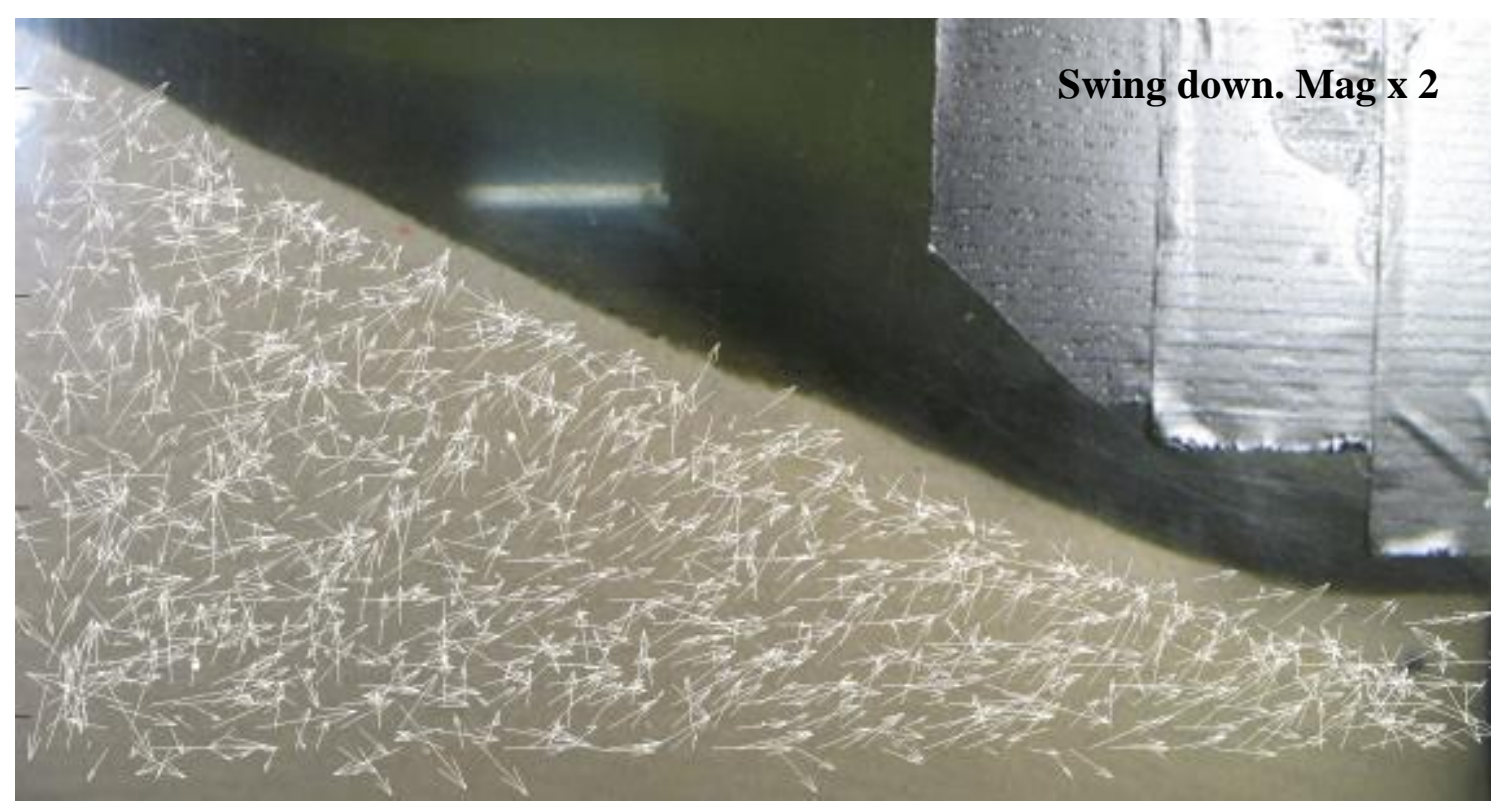

Figure 5.8: PIV analysis during swing down

Figures 5.9-5.12 show the PIV analysis of the slope during pressure reductions. The pressure in the strongbox was decreased after each saturation level and gas allowed to come out of the solution. In each step, 15 minutes of time was provided for gas to come out of solution. With the decrease of degree of saturation, more gas comes out of the solution which can be seen by the increased number of displacement vector movements, similar as described for swing down. During the decrease, the degree of saturation from $80 \%-70 \%$, the maximum amount of gas should come out of solution. PIV analysis with a magnification factor of 30 shows the movement in Figure 5.12. The amount of gas which came out is much less compared to the calculated amount, judging by the absence of a water layer change in the pneumatic cylinder bottom. 


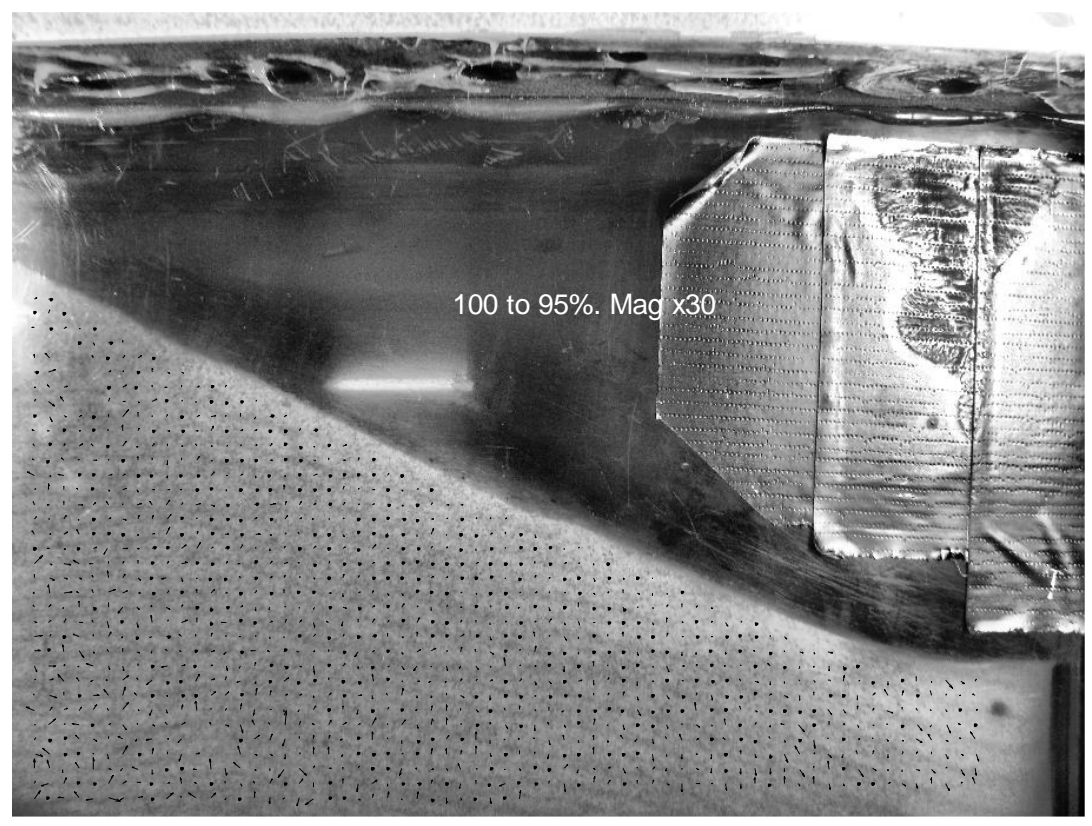

Figure 5.9: PIV analysis during target $\mathrm{Sr},(100-95) \%$,

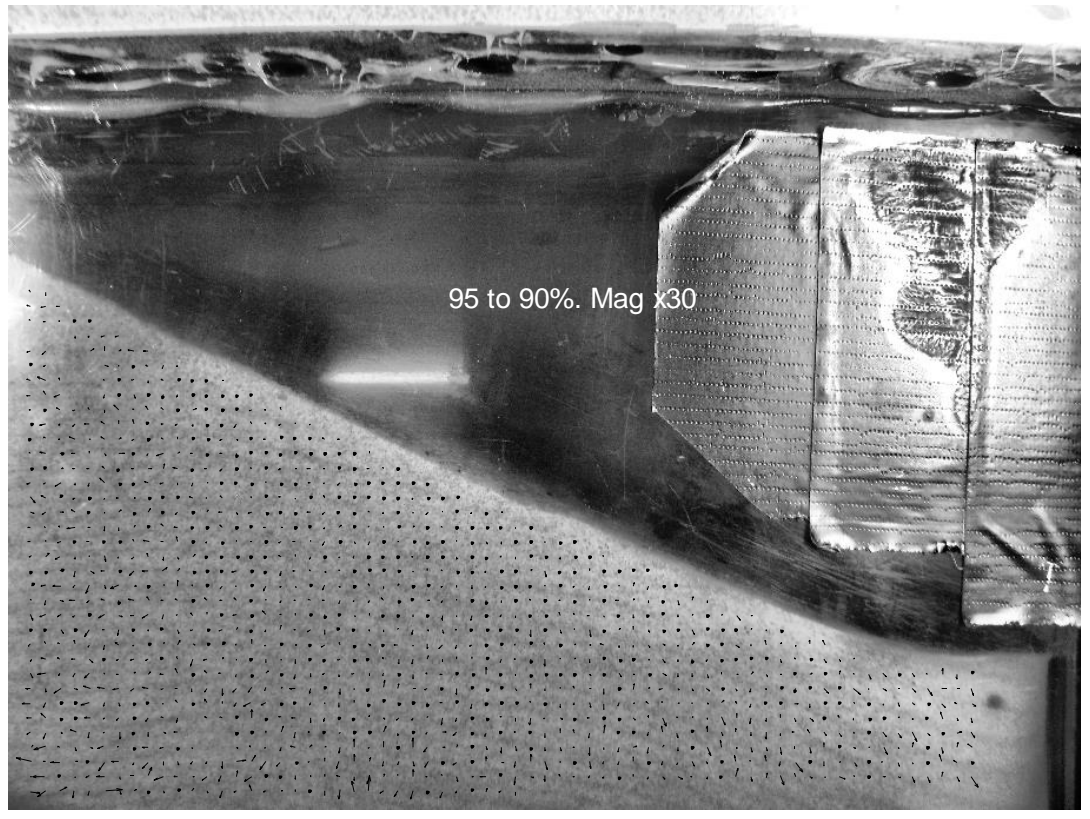

Figure 5.10: PIV analysis during target Sr, (95-90)\% 


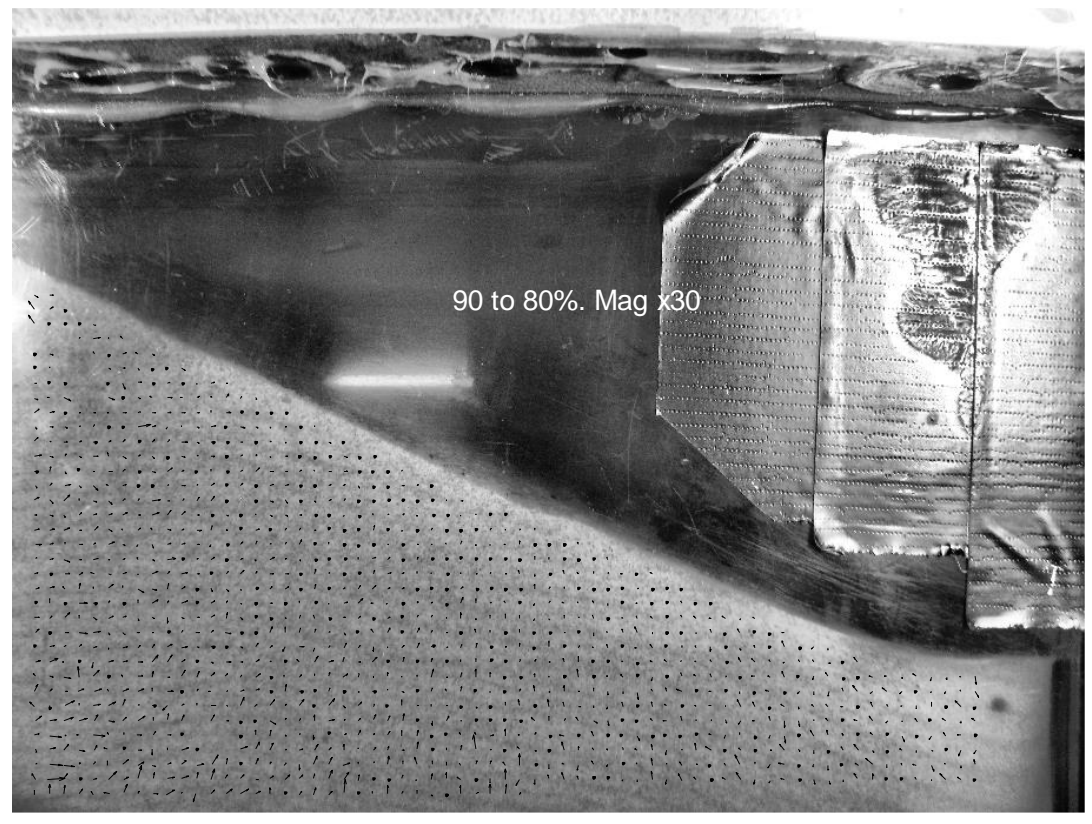

Figure 5.11: PIV analysis during target $\mathrm{Sr},(90-80) \%$

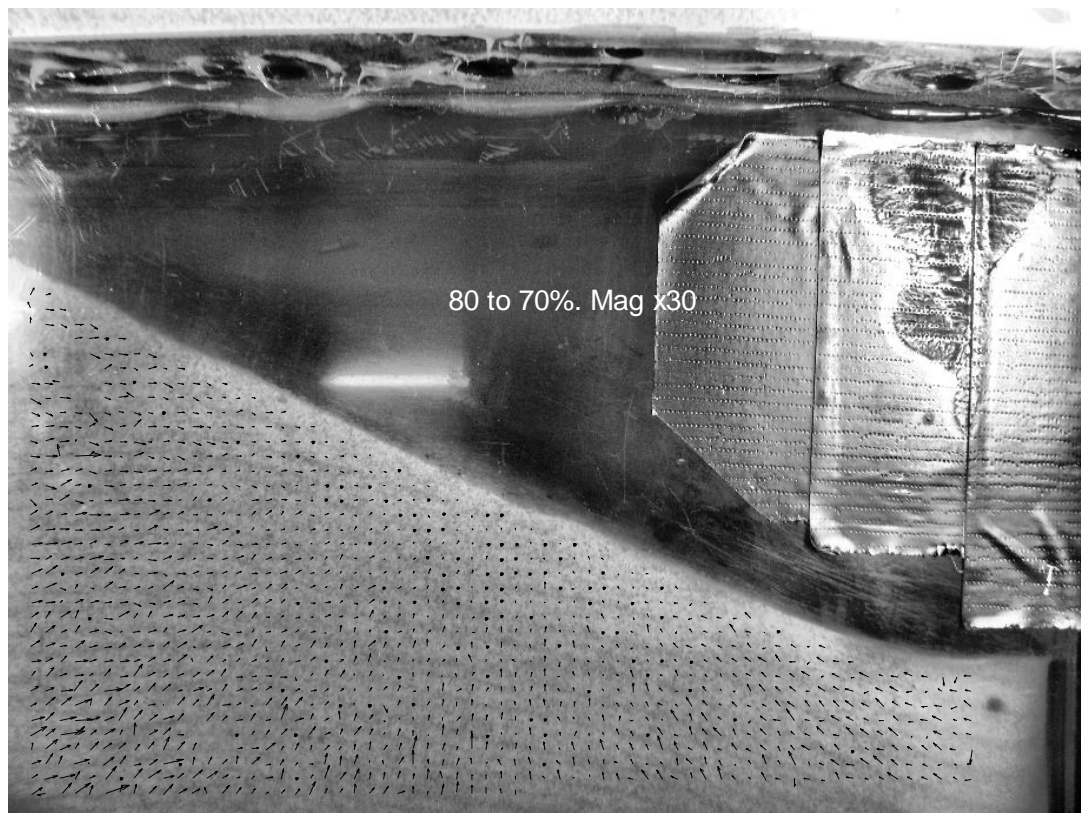

Figure 5.12: PIV analysis during target $\mathrm{Sr},(80-70) \%$ 


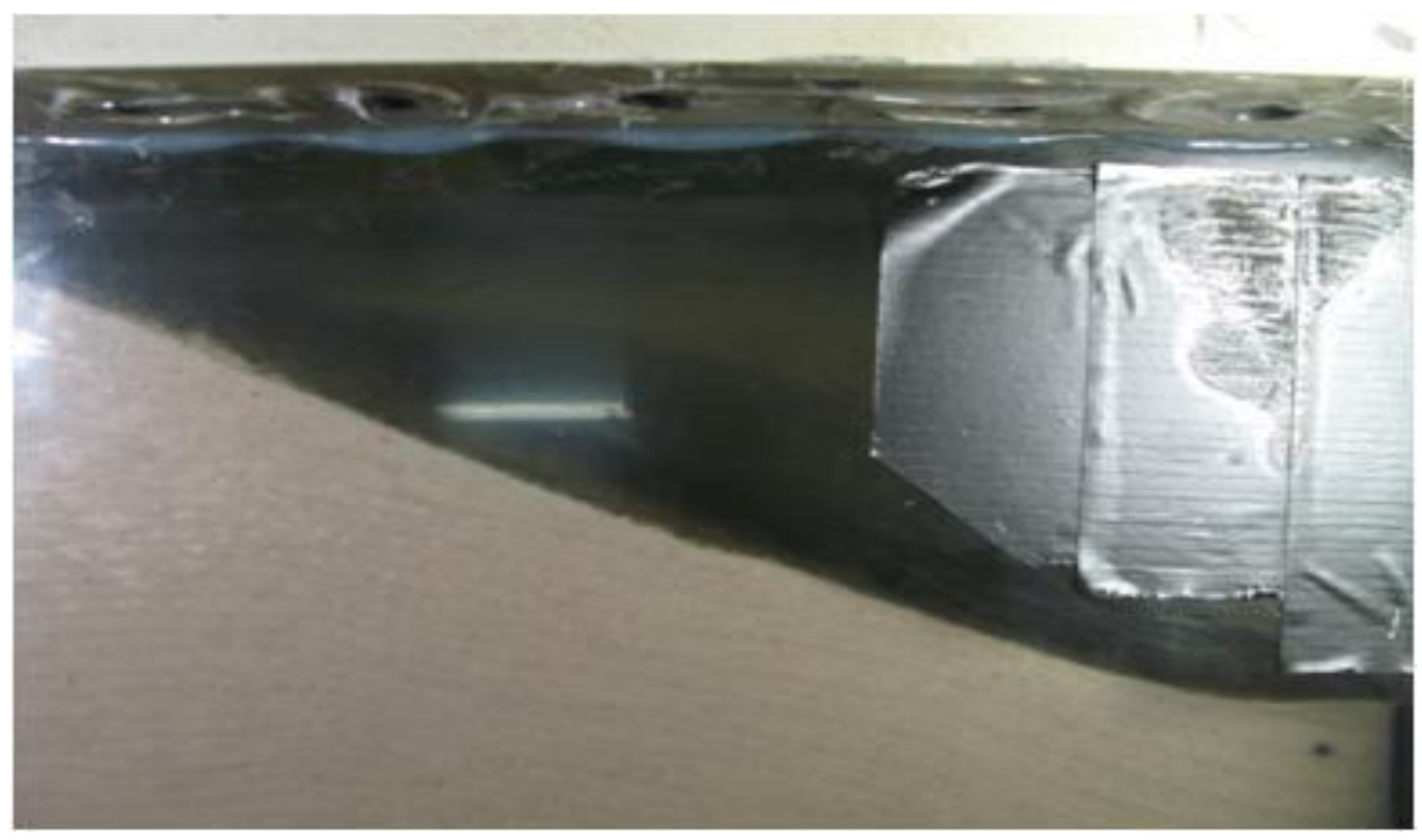

Figure 5.13: Slope immediately after swing down

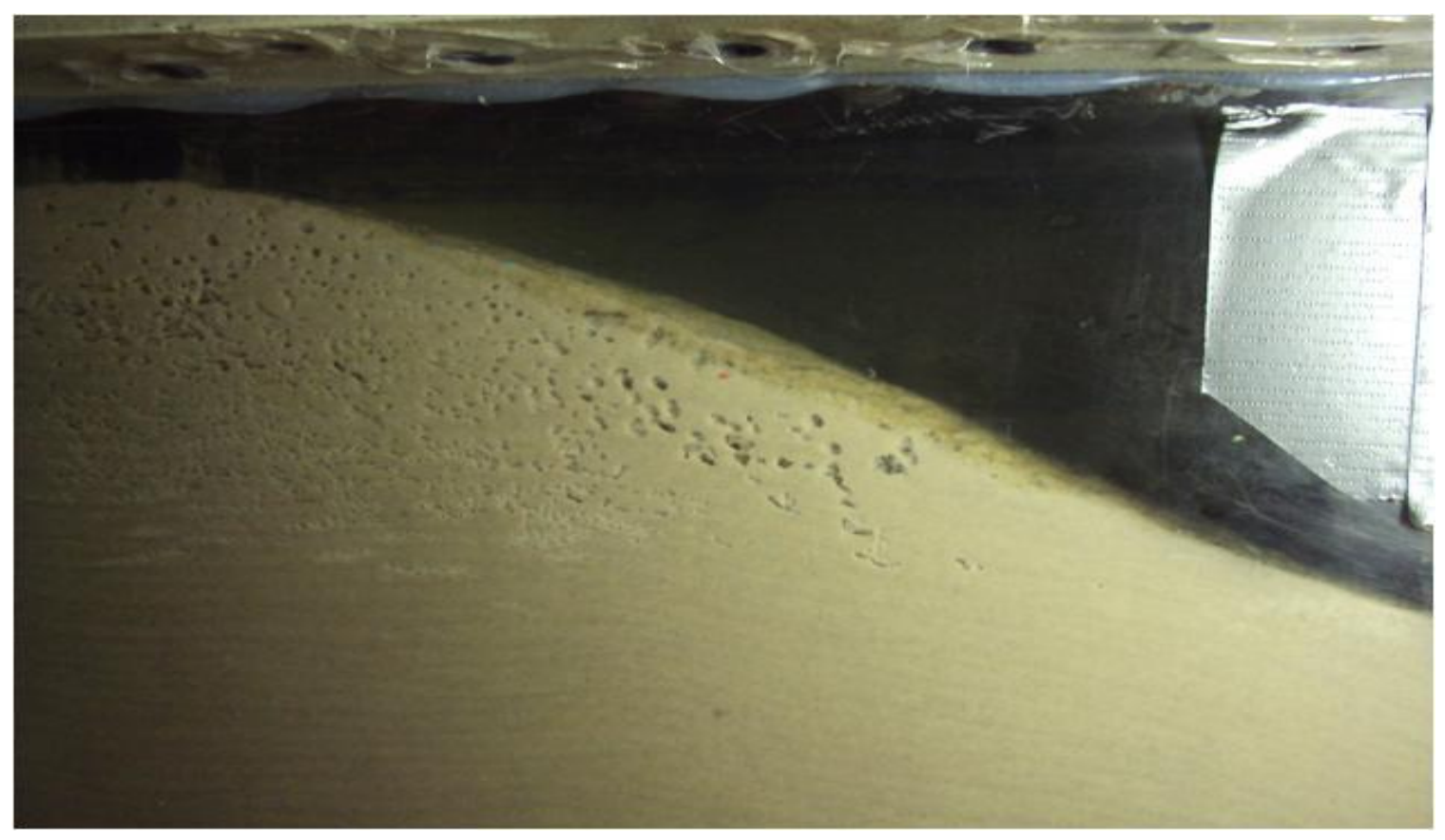

Figure 5.14: Slope after 45 minutes of swing down 
Figure 5.13 shows the slope immediately after swing down. There was evidence of slight volumetric expansion from gas dissolution during swing down. Some white patches of gas were seen through the acrylic of the strongbox which indicates the presence of gas in the sand slope. Figure 5.14 shows much more visible volumetric expansion of the slope and gas bubbles 45 minutes after swing down.

\subsubsection{Test Modifications}

After this test, some changes were made before the second centrifuge test to solve issues like: the constant water level in the pneumatic cylinder even at lower degree of saturation level and no response of the strongbox pressure transducer with the tidal motion. Constant water level in the pneumatic cylinder during a lower degree of saturation implies that the pore fluid in the strongbox was not fully saturated with ethylene gas. There was a glass sheet in the box between the sand model and acrylic. Some pore fluid during saturation may bypass between glass and acrylic rather than through the soil slope. So, this glass sheet was removed for the second test. The strongbox transducer was repositioned to prevent gas accumulation in front of it.

The port in the strongbox lid was increased to a half inch diameter. The tubing from the strongbox to the pneumatic cylinder bottom was also increased to half inch diameter. A "T" connection was used to connect the strong box and the tidal actuator as shown in Figure 5.15. One connection of the $\mathrm{T}$ connects with the pneumatic cylinder bottom to transport the released gas and water from the slope and the other connection of $\mathrm{T}$ connects to the top port of the pneumatic cylinder. This top port is used to provide a free 
path for gas to vent. Other ports were added in the strong box lid to more easily bleed the strongbox. Ports were added in the side to accommodate PPT transducers. The displacement block thickness was also increased, section 4.2.2.5.

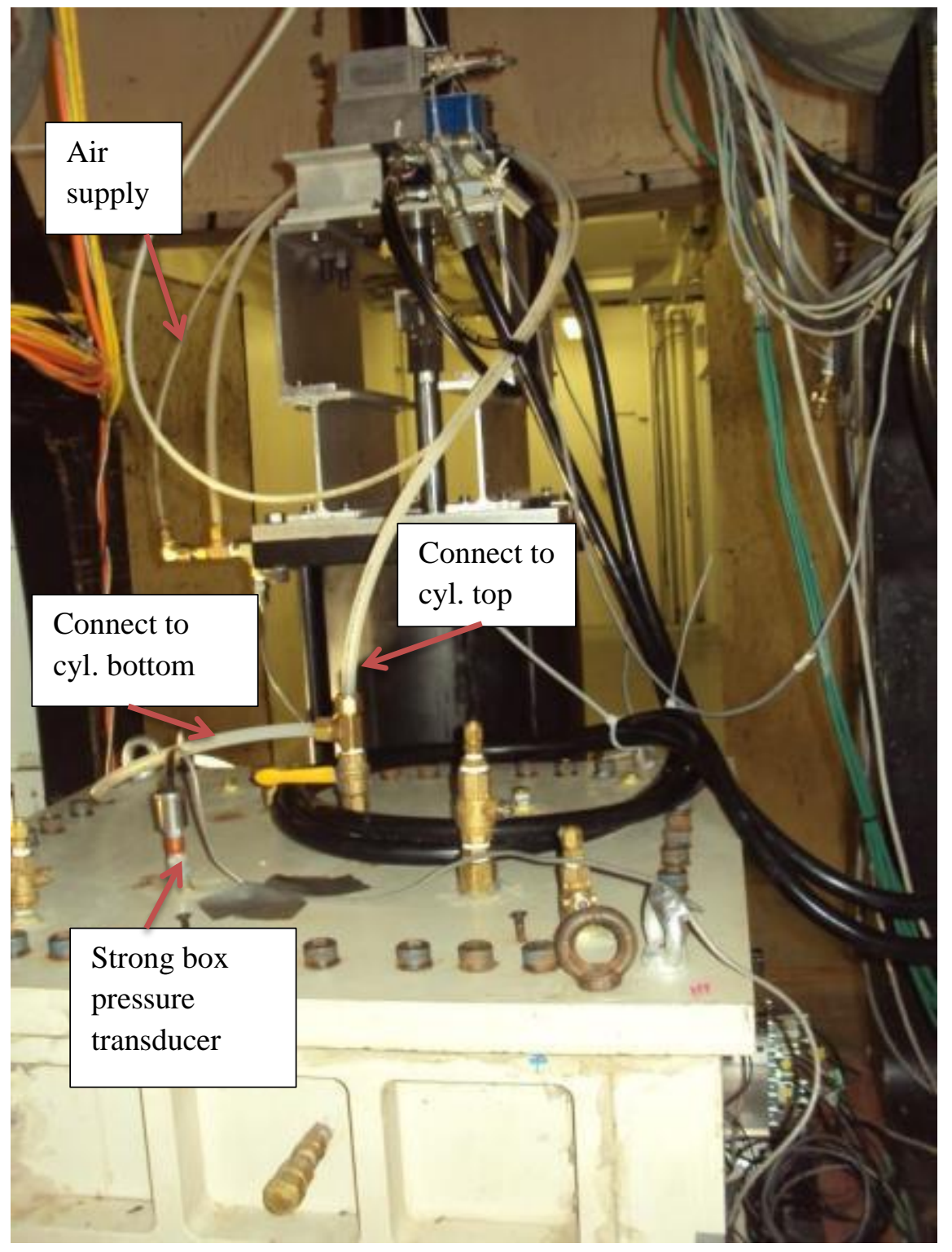

Figure 5.15: Modified strongbox for second test 


\subsection{Second centrifuge test}

In the second centrifuge test three more pressure transducers were used in the soil slope to measure water pressures transferred from the tidal actuator during the test. In this test the centrifuge was also accelerated in steps to $10 \mathrm{~g}, 20 \mathrm{~g}, 30 \mathrm{~g}, 40 \mathrm{~g}$ and $50 \mathrm{~g}$. Figure 5.16 again shows three pressure transducer responses during the test. The test plumbing modifications were successful in transferring the tidal motions into the strongbox. Tidal motions were applied at five target degrees of saturation level: 100, 95, 90, $80 \& 70 \%$ and atmospheric. Water pressure changes of $25 \mathrm{kPa}$ were applied at the target degree of saturation level of 80 and $90 \%$ by the tidal actuator.

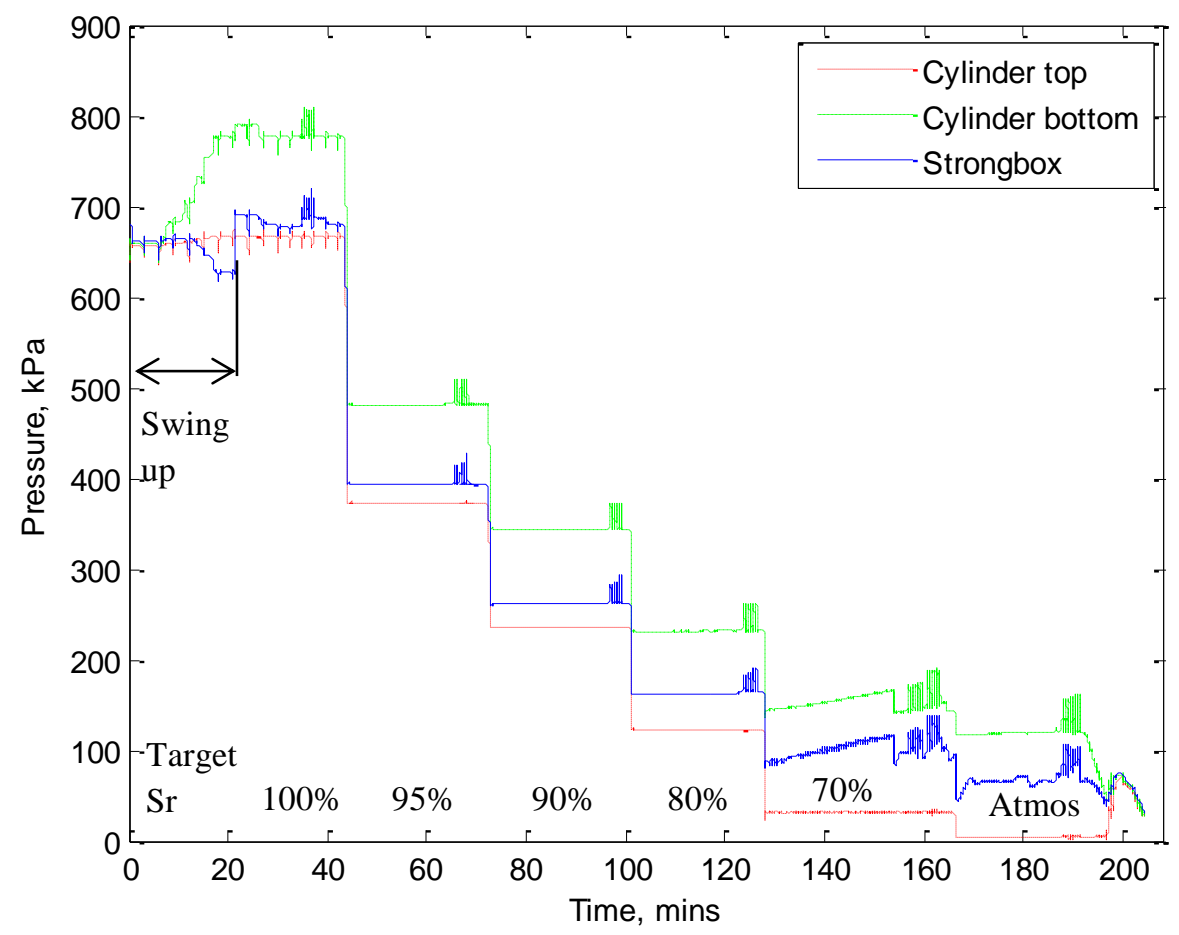

Figure 5.16: Pressure transducer response during the test 
At the target degree of saturation level of $70 \%$ both $25 \mathrm{kPa}$ and $44 \mathrm{kPa}$ of changes water pressures were applied. At atmospheric level, only $44 \mathrm{kPa}$ of water pressure change was applied. In this test, degree of saturation was targeted by the same process as the first centrifuge test. At a target saturation level of $70 \%$, there was a measurable change in water level in the pneumatic cylinder bottom as gas came out of solution. The pressure of the pneumatic cylinder bottom increased as shown in Figure 5.16 by the green line as water came out from the strongbox. This indicates gas in the strongbox expanded due to the reduction of pressure in the box.

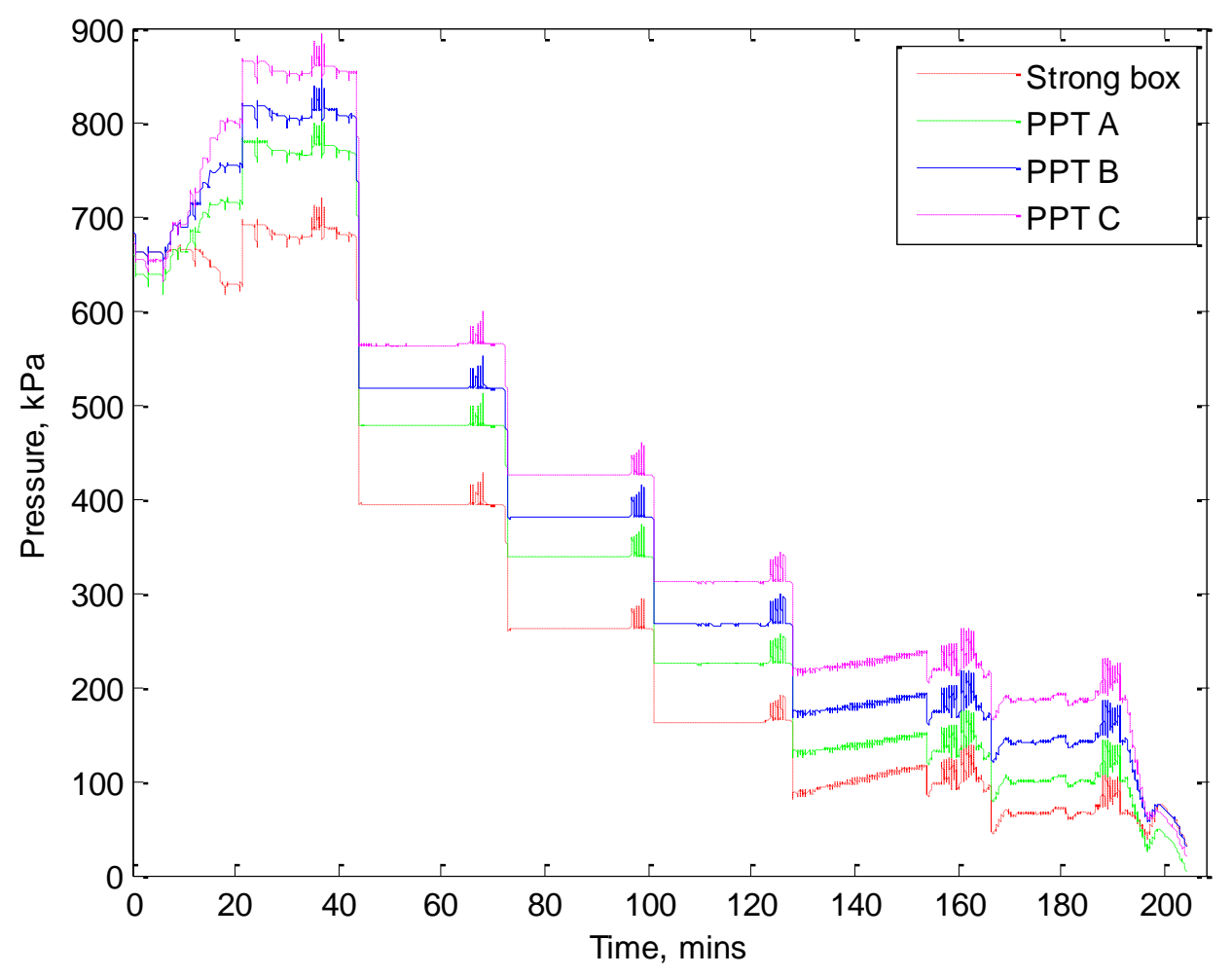

Figure 5.17: PPT and strongbox transducer response during the test 
The strongbox pressure changed in response to the immersion of the displacement block in this test. During tidal cycles, pressure changes were observed by the strongbox and three PPTs shown in Figure 5.17. The applied pressure by tidal cycles was transferred to the sand slope.

Figures $5.18 \mathrm{a} \& \mathrm{~b}$ show the pressure change of the strongbox transducer and three PPTs installed in the sand slope at $90 \%$ degree of saturation. During tidal variation, response of the PPTs in the sand slope changed with the change of strongbox pressure response. There was no phase lag between strong box pressure and PPT response. This indicates that the model slope is still saturated. But, with the decrease of pressure in the strong box gas comes out of solution and decreases the degree of saturation. For all the target degrees of saturation, attenuation between strongbox pressure and PPT response was observed and there was no phase lag. These are shown in Figure 5.18-5.20 for both cases of $15 \mathrm{~s}$ and $2.5 \mathrm{~s}$ tidal periods. 


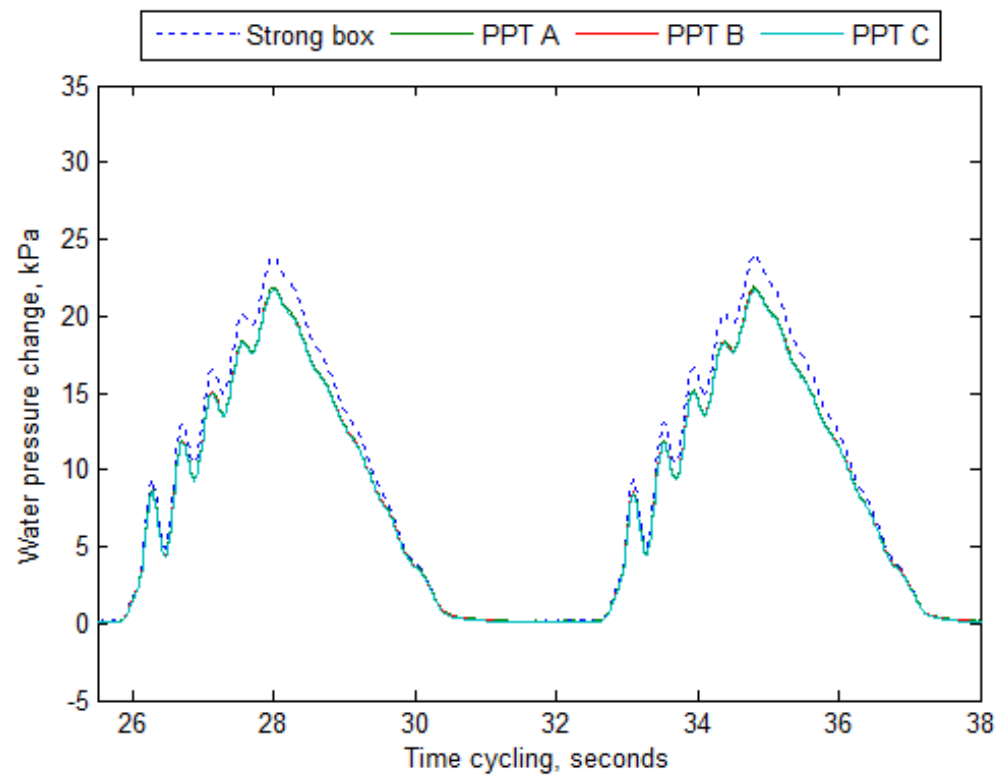

(a)

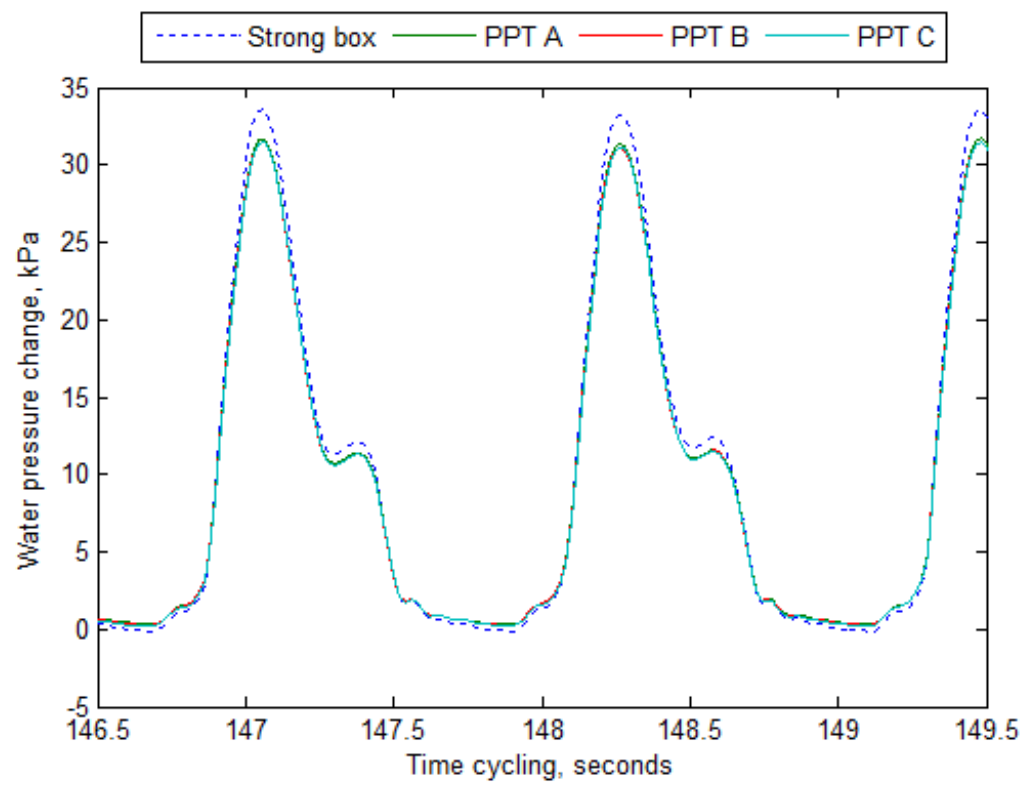

(b)

Figure 5.18: Pressure transducers response with (a) $15 \mathrm{~s}$ (b) $2.5 \mathrm{~s}$ at $90 \%$ target $\mathrm{Sr}$ 


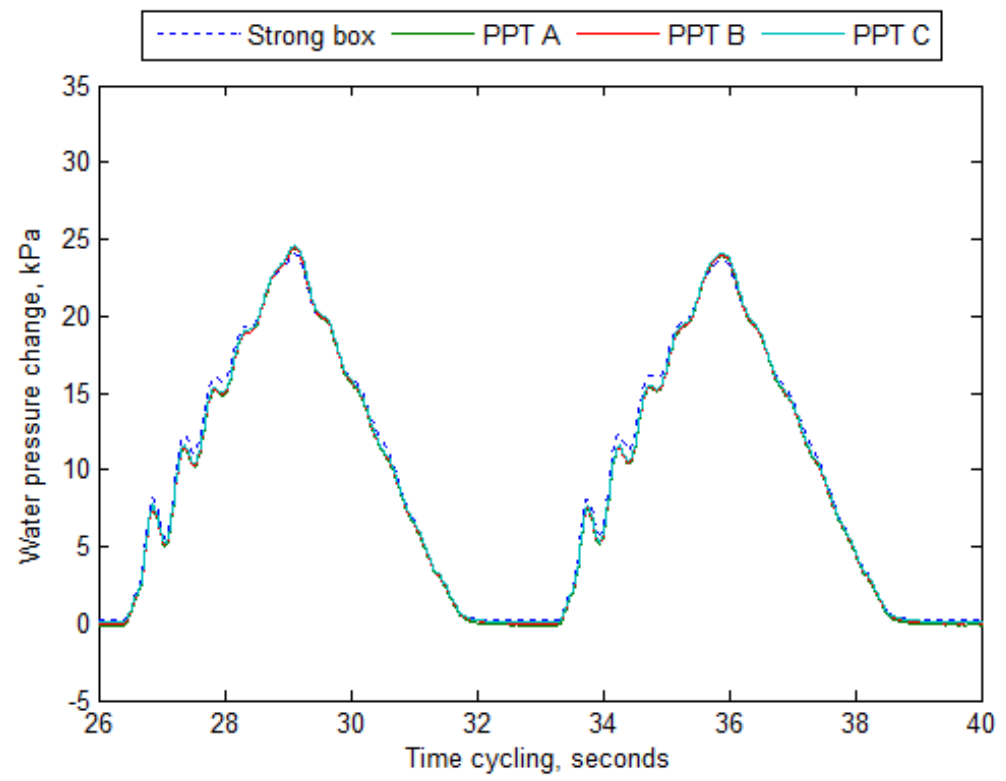

(a)

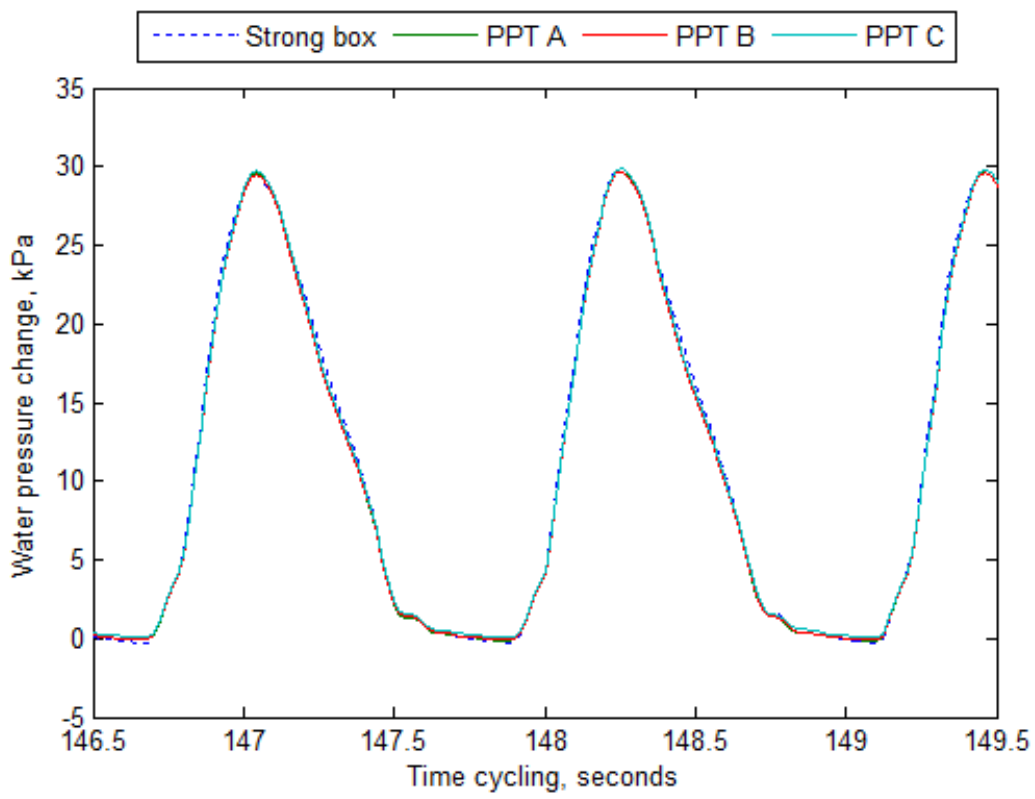

(b)

Figure 5.19: Pressure transducers response with (a) $15 \mathrm{~s}$ and (b) $2.5 \mathrm{~s}$ cycling at $80 \%$ target $\mathrm{Sr}$ 


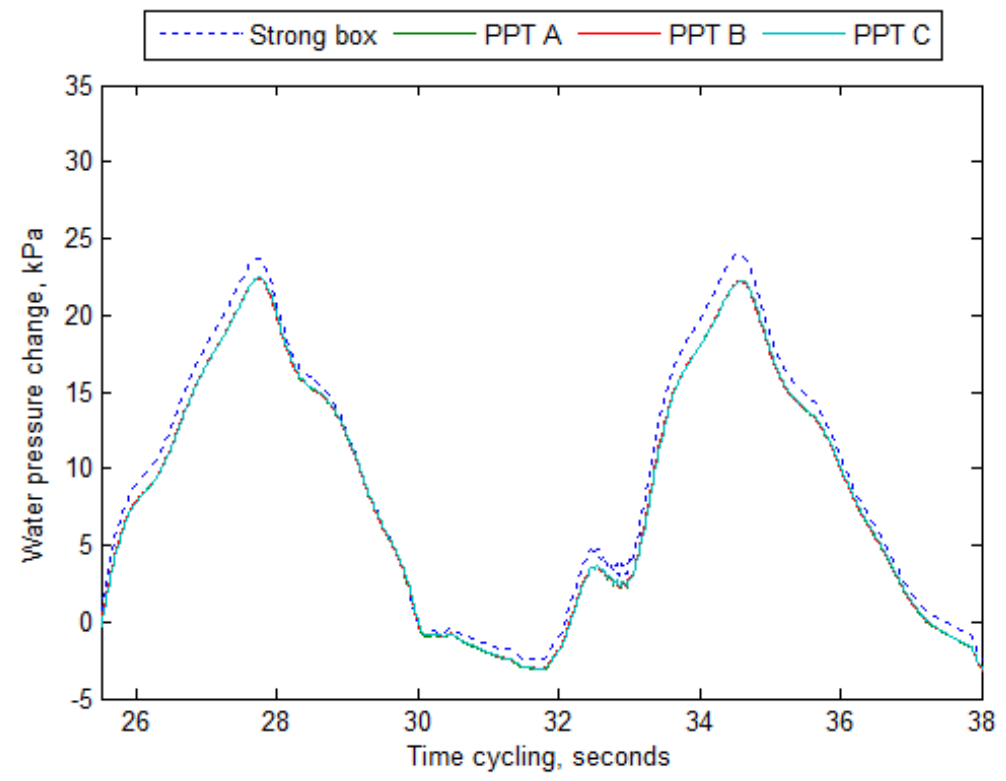

(a)

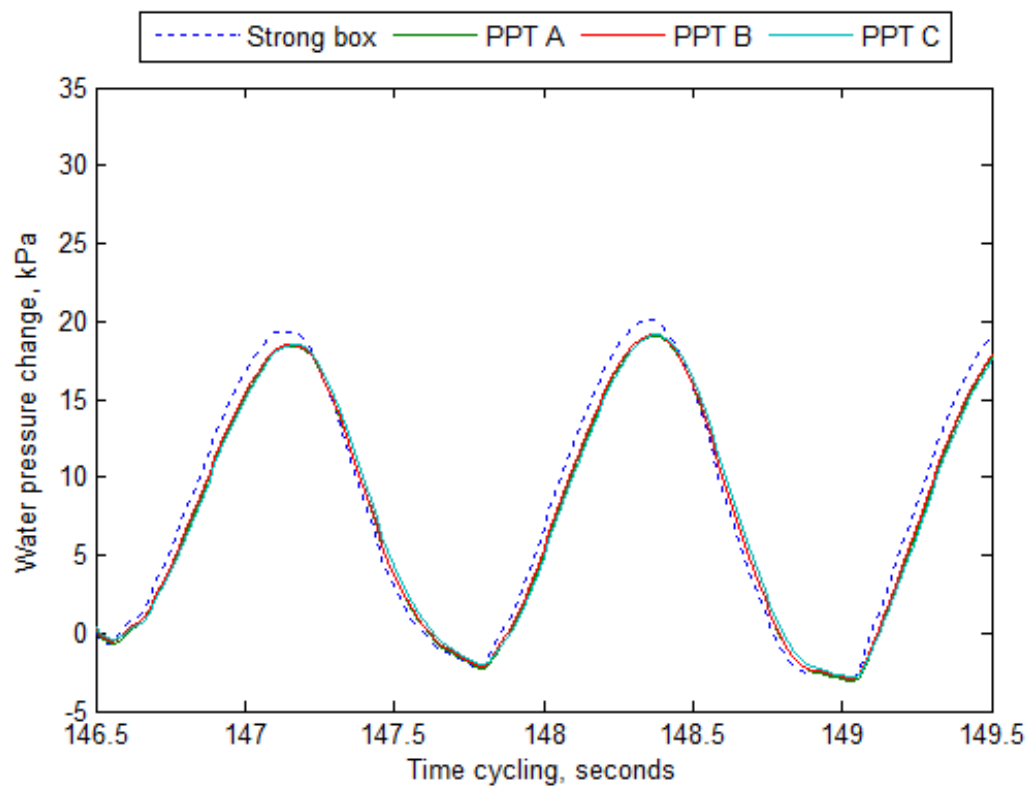

(b)

Figure 5.20: Pressure transducers response with (a) $15 \mathrm{~s}$ and (b) $2.5 \mathrm{~s}$ cycling at $70 \%$ target $\mathrm{Sr}$ 
Table 5.1 shows the pore pressure variations with changes in the strongbox pressure. The tidal period was decreased progressively at each target degree of saturation level. Similar strong box pressure changes were observed for each tidal motion equivalent to a 2-3 m tide. The lower strongbox pressure variations at target saturation $70 \%$ compared to higher target saturation levels may reflect some gas trapped in the line between the strongbox and tidal actuator. The three PPTs were installed at almost the same depth from the slope surface. The same pressure response was observed from these three pressure transducers.

Table 5.1: Pore pressure variation with box pressure change

\begin{tabular}{|c|c|c|c|c|c|c|c|c|c|}
\hline \multirow{2}{*}{$\begin{array}{l}\text { Target } \\
\mathrm{S}_{\mathrm{r}} \\
(\%)\end{array}$} & \multirow{2}{*}{$\begin{array}{l}\text { Tidal } \\
\text { period } \\
\text { (s) }\end{array}$} & \multirow{2}{*}{$\begin{array}{l}\text { Initial } \\
\text { Box } \\
\text { Pressure } \\
(\mathrm{kPa})\end{array}$} & \multirow{2}{*}{$\begin{array}{l}\text { Box } \\
\text { change } \\
(\mathrm{kPa})\end{array}$} & \multicolumn{3}{|c|}{ PPT (kPa) } & \multicolumn{3}{|c|}{ PPT $(\%)$ attenuation } \\
\hline & & & & $\begin{array}{l}\text { PPT } \\
\text { A }\end{array}$ & $\begin{array}{l}\text { PPT } \\
\text { B }\end{array}$ & $\begin{array}{l}\text { PPT } \\
\text { C }\end{array}$ & $\begin{array}{l}\text { PPT } \\
\text { A }\end{array}$ & $\begin{array}{l}\text { PPT } \\
\text { B }\end{array}$ & $\begin{array}{l}\text { PPT } \\
\text { C }\end{array}$ \\
\hline \multirow{4}{*}{90} & 15 & 261.1 & 23.8 & 21.9 & 21.8 & 21.7 & 8.0 & 8.6 & 8.7 \\
\hline & 10 & 261.1 & 26.3 & 23.9 & 23.8 & 23.7 & 9.1 & 9.7 & 9.8 \\
\hline & 5 & 261.1 & 27.8 & 25.2 & 25.1 & 25.0 & 9.4 & 9.9 & 10.3 \\
\hline & 2.5 & 261.1 & 34.4 & 31.5 & 31.3 & 31.3 & 8.6 & 9.0 & 9.1 \\
\hline \multirow{4}{*}{80} & 15 & 163 & 24.8 & 24.1 & 23.9 & 23.8 & 2.9 & 3.8 & 4.0 \\
\hline & 10 & 163 & 26.9 & 26.1 & 26.0 & 26.0 & 2.7 & 3.1 & 3.1 \\
\hline & 5 & 163 & 27.2 & 26.7 & 26.6 & 26.7 & 1.7 & 2.0 & 1.8 \\
\hline & 2.5 & 163 & 30.0 & 29.8 & 29.6 & 29.7 & 0.7 & 1.1 & 0.9 \\
\hline \multirow{4}{*}{70} & 15 & 96.8 & 26.2 & 25.4 & 25.3 & 25.3 & 2.8 & 3.2 & 3.2 \\
\hline & 10 & 96.8 & 22.5 & 21.7 & 21.7 & 21.7 & 3.8 & 3.8 & 3.7 \\
\hline & 5 & 96.8 & 25.4 & 24.2 & 24.2 & 24.1 & 4.7 & 4.9 & 5.0 \\
\hline & 2.5 & 96.8 & 19.7 & 18.5 & 18.5 & 18.2 & 6.2 & 6.1 & 7.9 \\
\hline
\end{tabular}

Figure 5.21 illustrates PPT A response with tidal period at target degree of saturation levels of $90 \%, 80 \%$ and $70 \%$. At target saturation level of $70 \%$ attenuation is between 3 to $7 \%$ with no phase lag. Nagaswaran (1983) found attenuation between $5-10 \%$ and no 
phase lag for similar conditions. Atigh and Byrne (2004) calculated an attenuation of about 30\% with significant phase lag from their FLAC finite difference analysis. Their field measurements showed similar attenuation but no phase lag. The result from the second centrifuge model test is comparable with Nagaswaran (1983) in terms of attenuation and phase lag and also with no phase lag from field measurements from the Fraser River Delta. Nagaswaran (1983), did his study on clayey silt soil from river Parrett and used zeolite to make the sample gassy. $5 \mathrm{~m}$ of tide was used to observed the behaviour of seabed. The results are not comparable with Atigh and Byrne (2004) FEA attenuation and phase lag.

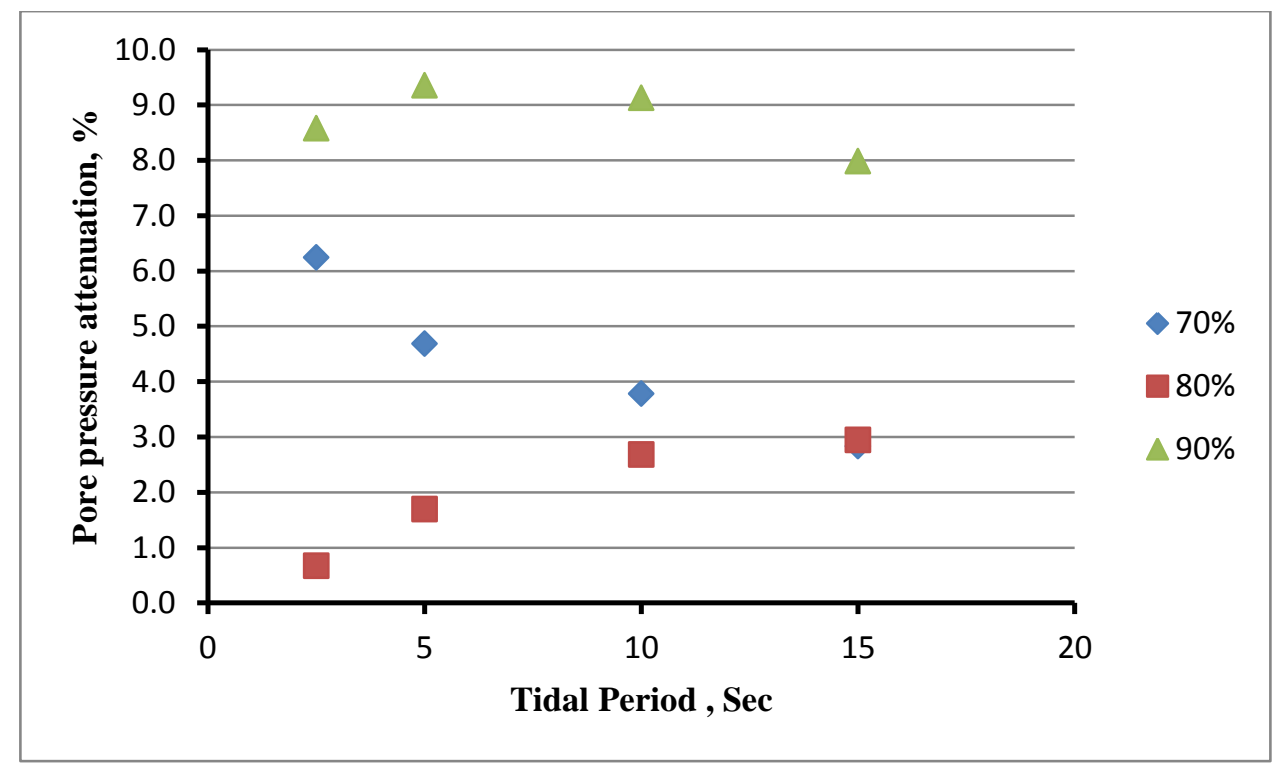

Figure 5.21: PPT A attenuation with tidal period at different target $\mathrm{Sr}$

\subsubsection{PIV Analysis during tidal Cycles}

Figure 5.22-5.24 shows the movements of the displacement vectors during gas coming out solution. In this test, 20 minutes of time was provided for gas coming out solution. To 
analyze the movements with PIV a magnification factor of 30 was used in all the cases. Radial movement of the displacement vector with the decrease of pressure indicates changing curvature of the viewing window, Figure 5.24. This shows that PIV vectors are reliable to 30 times magnification, and are not random noise at these displacement levels. The maximum amount of gas comes out while the target degree of saturation changes from $70 \%$ to atmospheric. In all the cases the amount of gas which came out is much higher than the first centrifuge test.

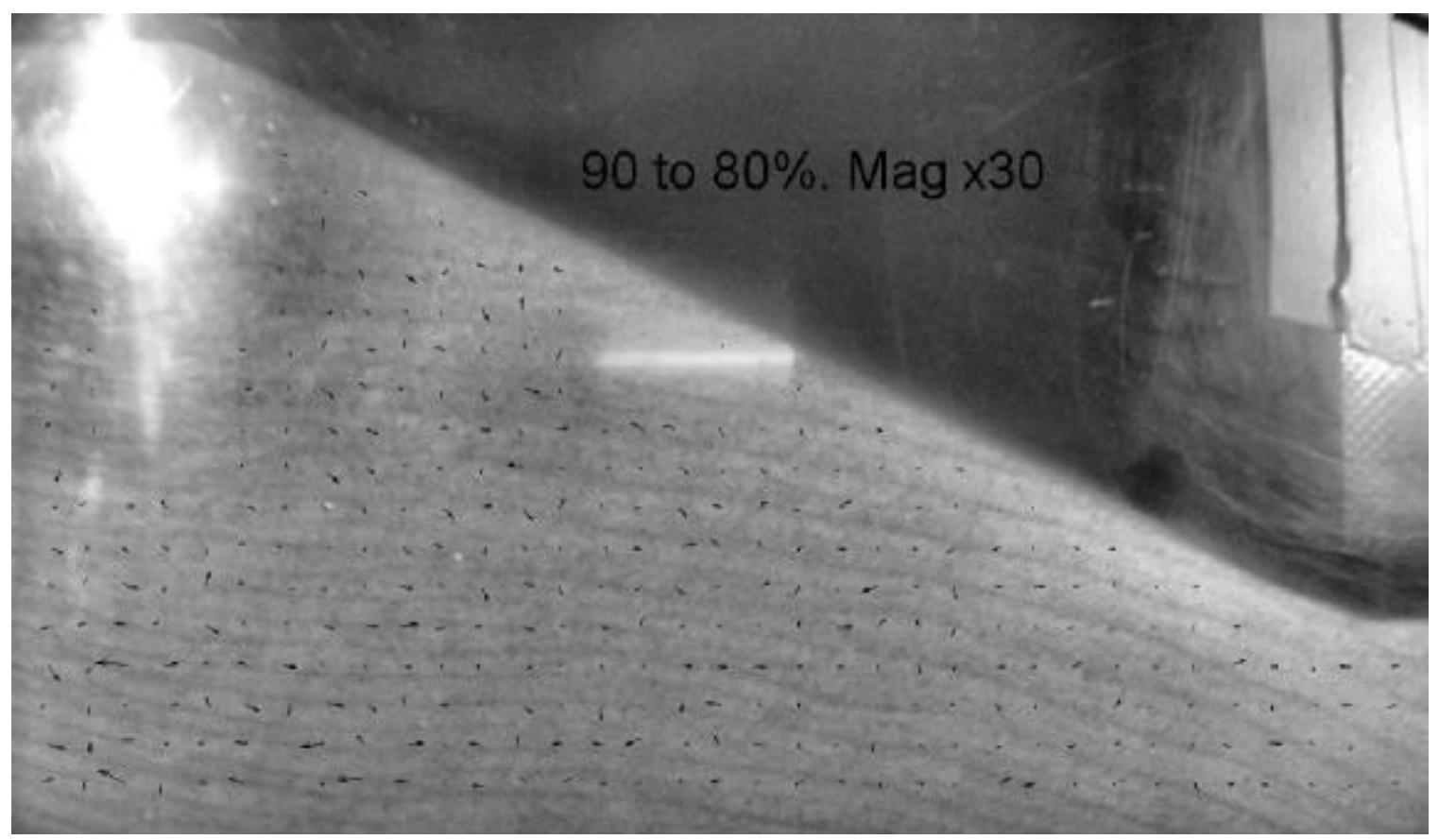

Figure 5.22: PIV analysis during target $\mathrm{Sr},(90-80) \%$ 


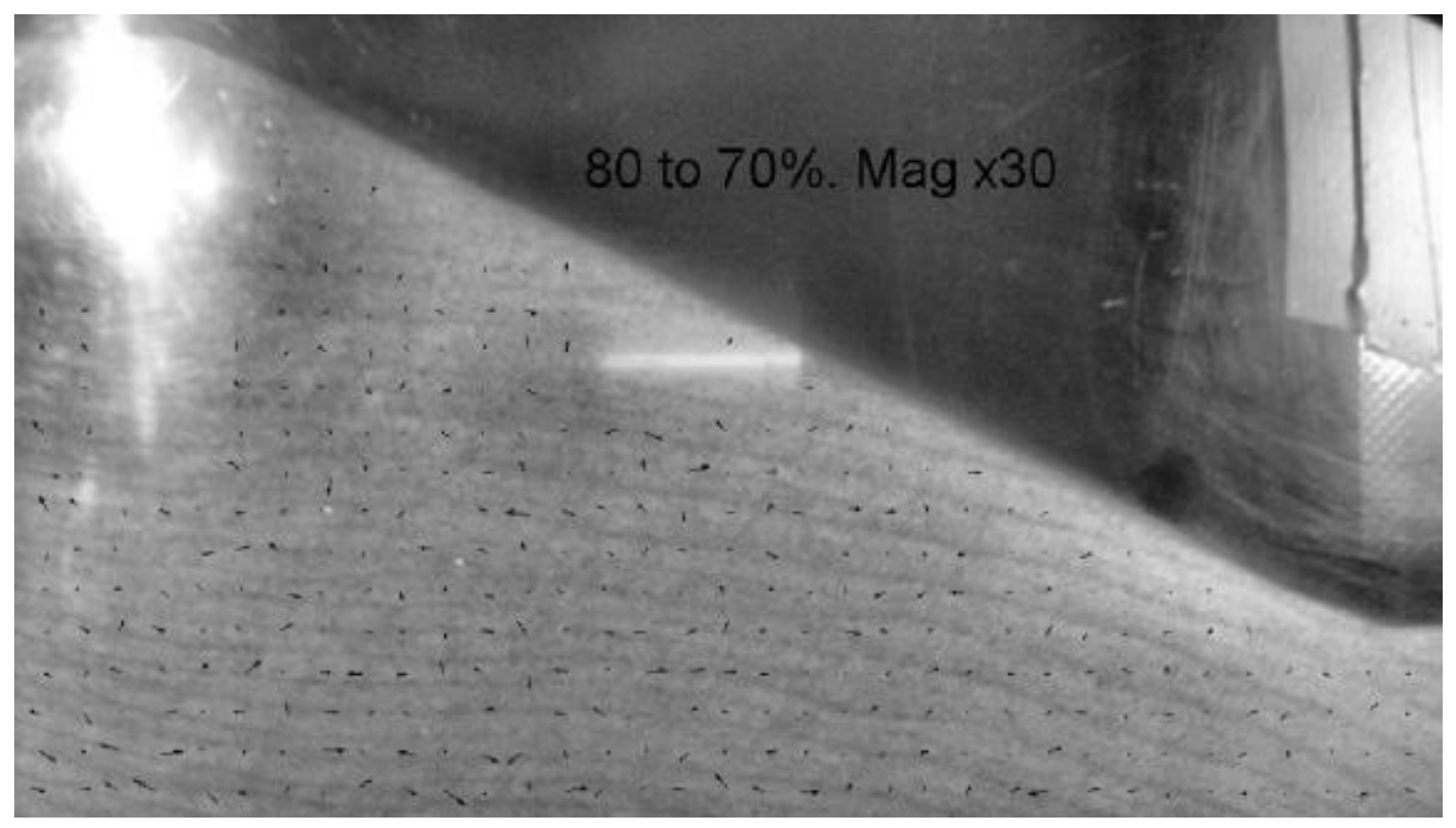

Figure 5.23: PIV analysis during target $\mathrm{Sr},(80-70) \%$

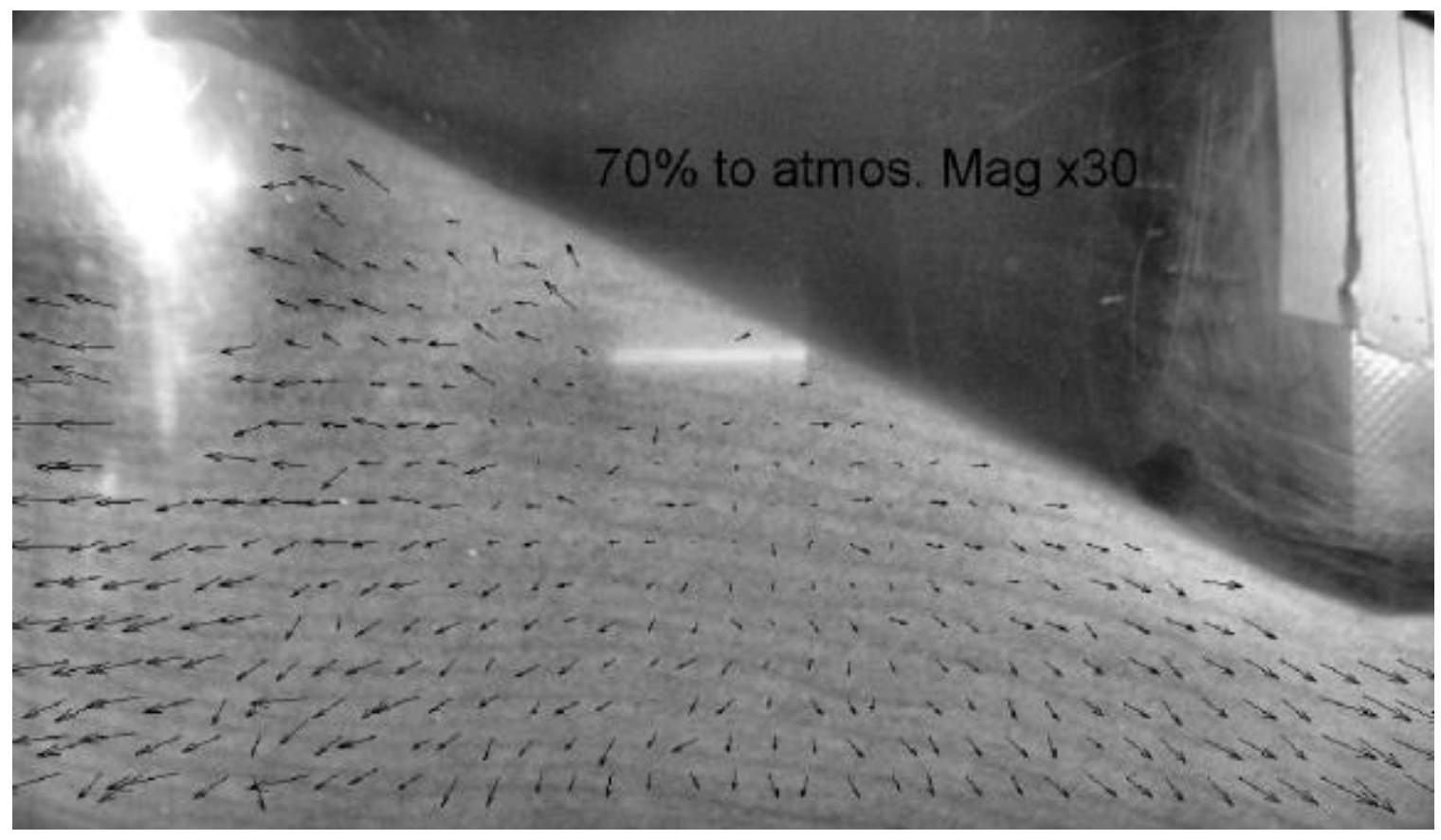

Figure 5.24: PIV analysis during target $\mathrm{Sr}, 70 \%$ to atmospheric 
Figure 5.25-5.28 show the PIV analysis of the slope during tidal cycles at the degree of saturation levels 90, 80, 70\% and atmospheric condition. In all cases magnification factor of displacement vector is 30 . In this test, PIV analysis does not indicate a significant systematic pattern of soil movement during cyclic motions. But, vector magnitudes are much higher compared to the first centrifuge test. This indicates the presence of gas in the slope and that the gas was well distributed throughout the slope.

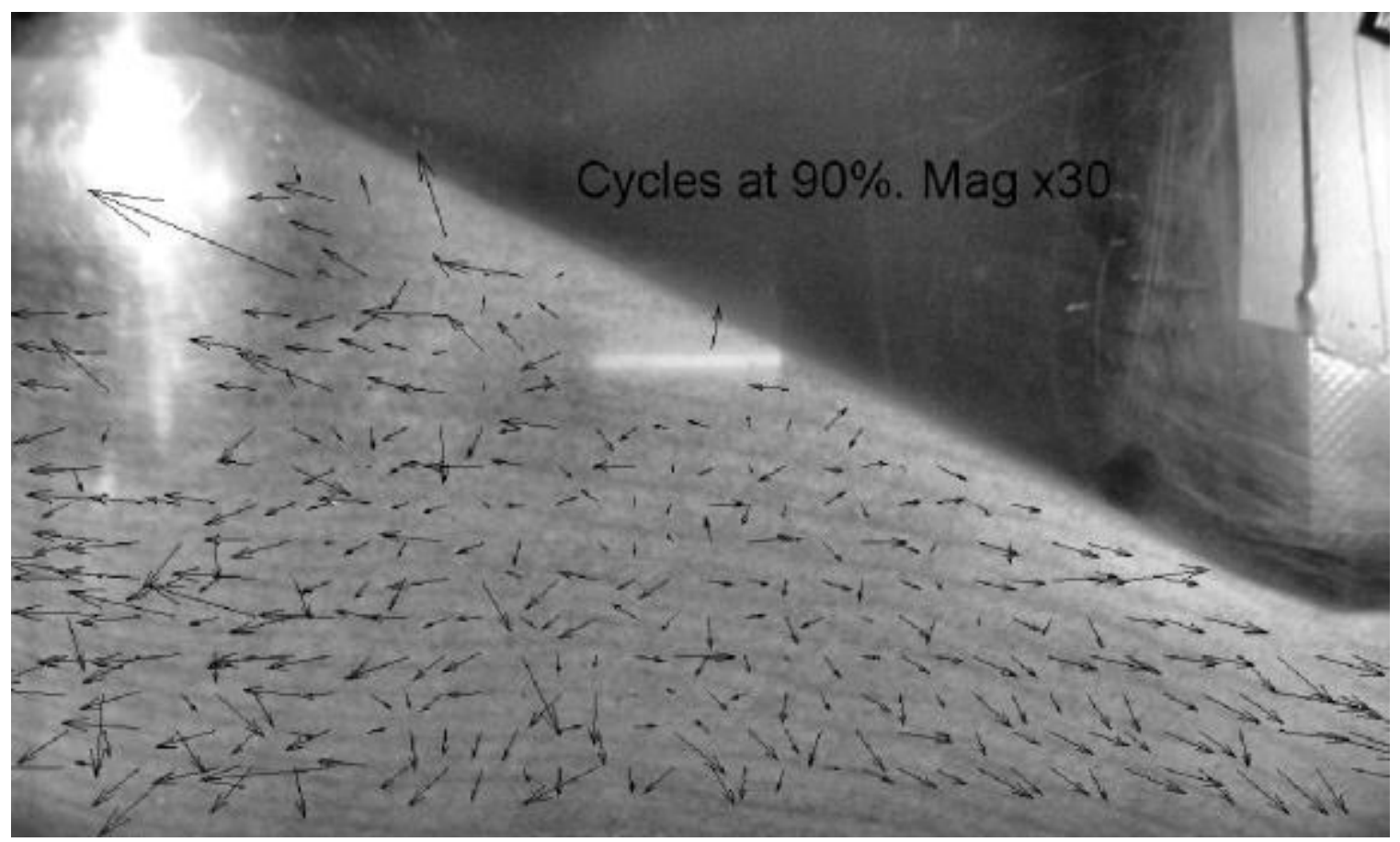

Figure 5.25: PIV analysis during tidal action at 90\% target degree of saturation 


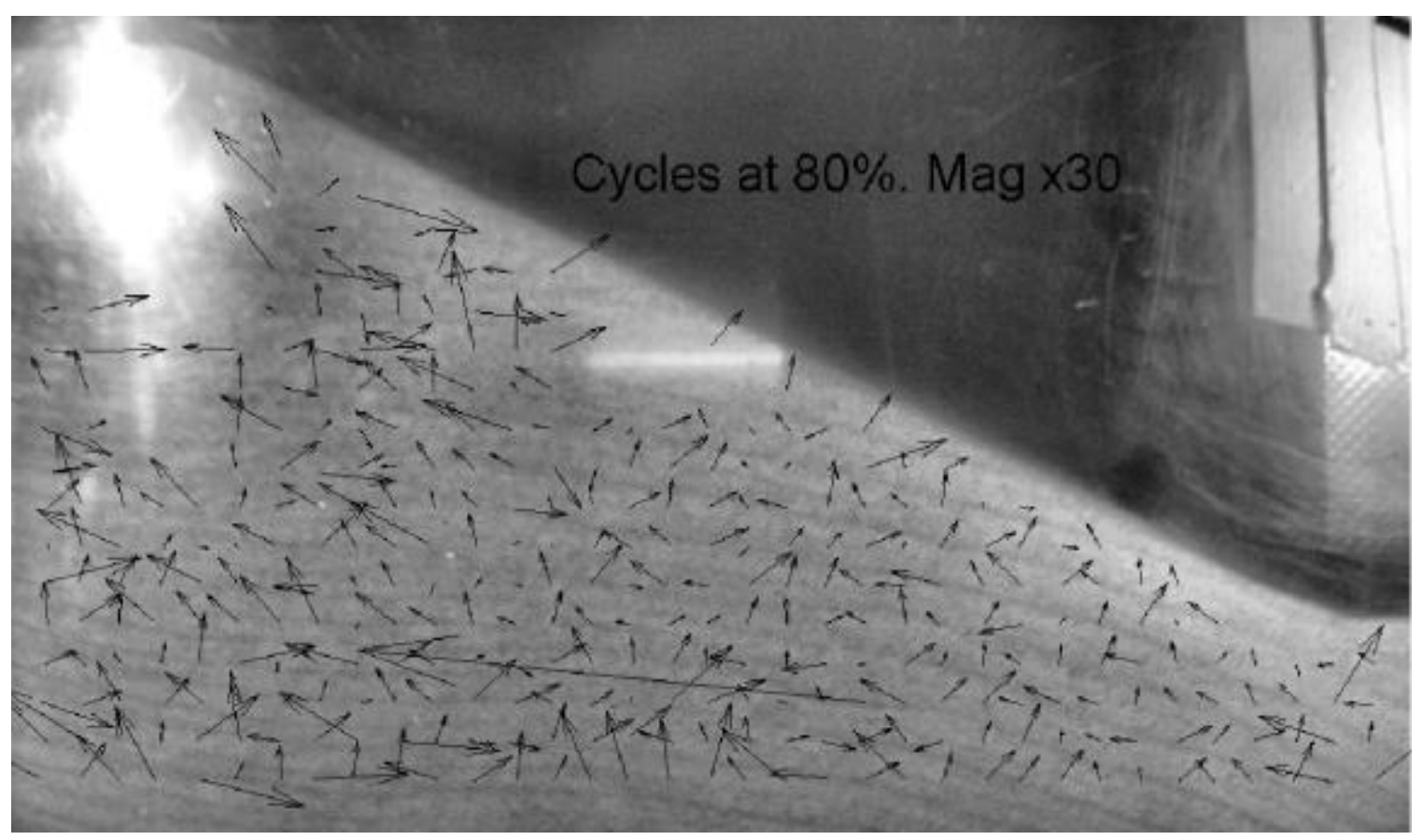

Figure 5.26: PIV analysis during tidal action at $80 \%$ target degree of saturation

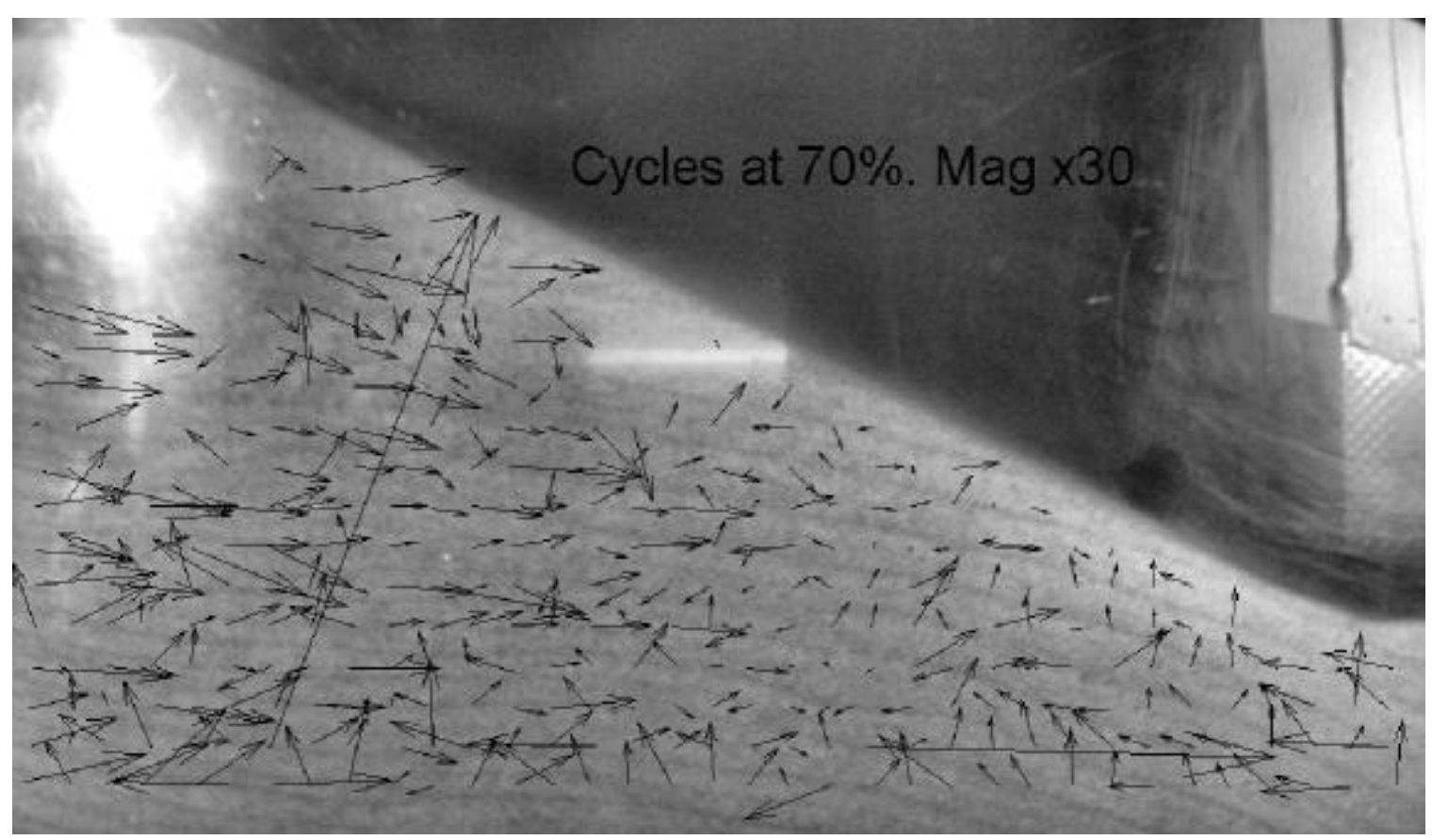

Figure 5.27: PIV analysis during tidal action at 70\% target degree of saturation 


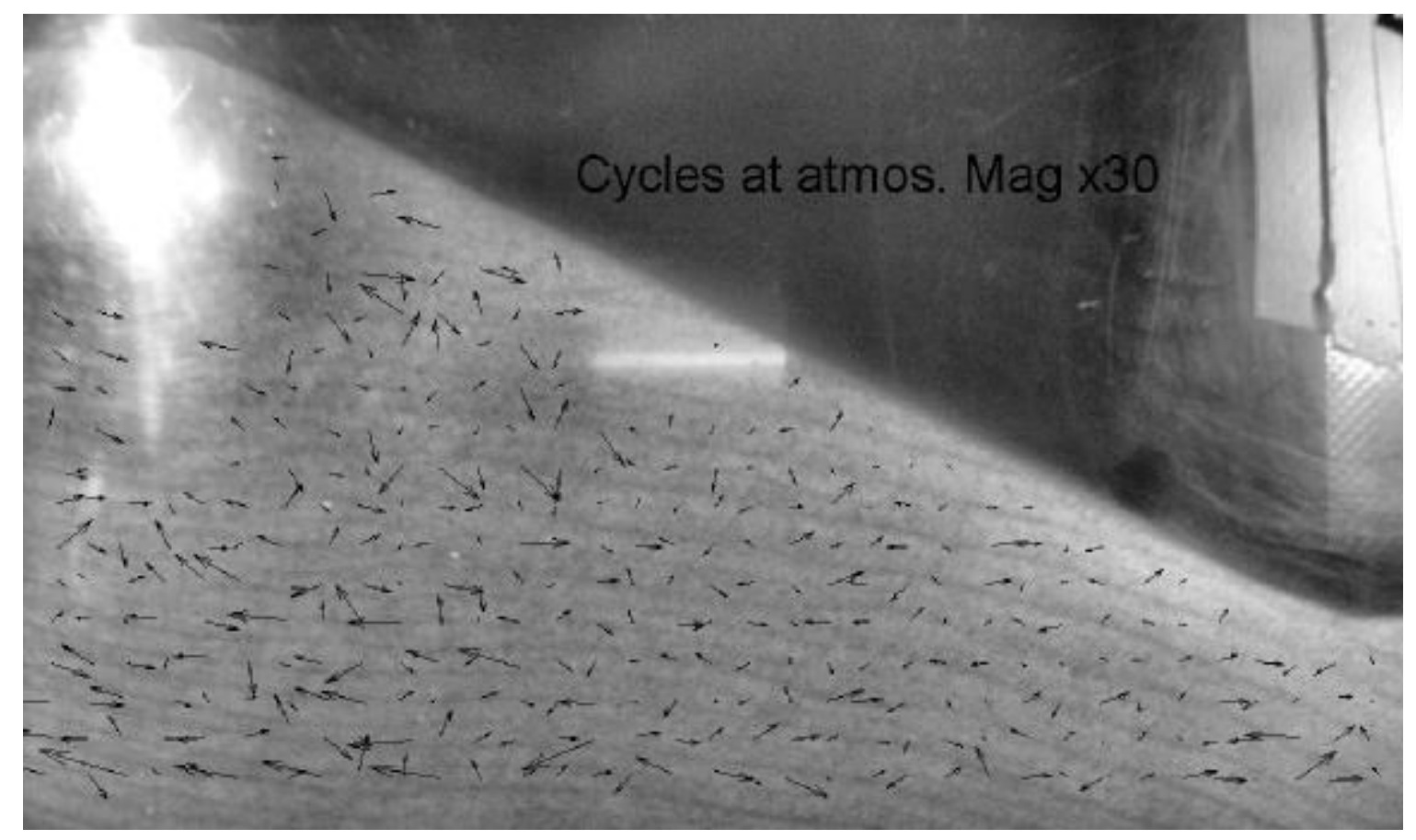

Figure 5.28: PIV analysis during tidal action at atmospheric condition

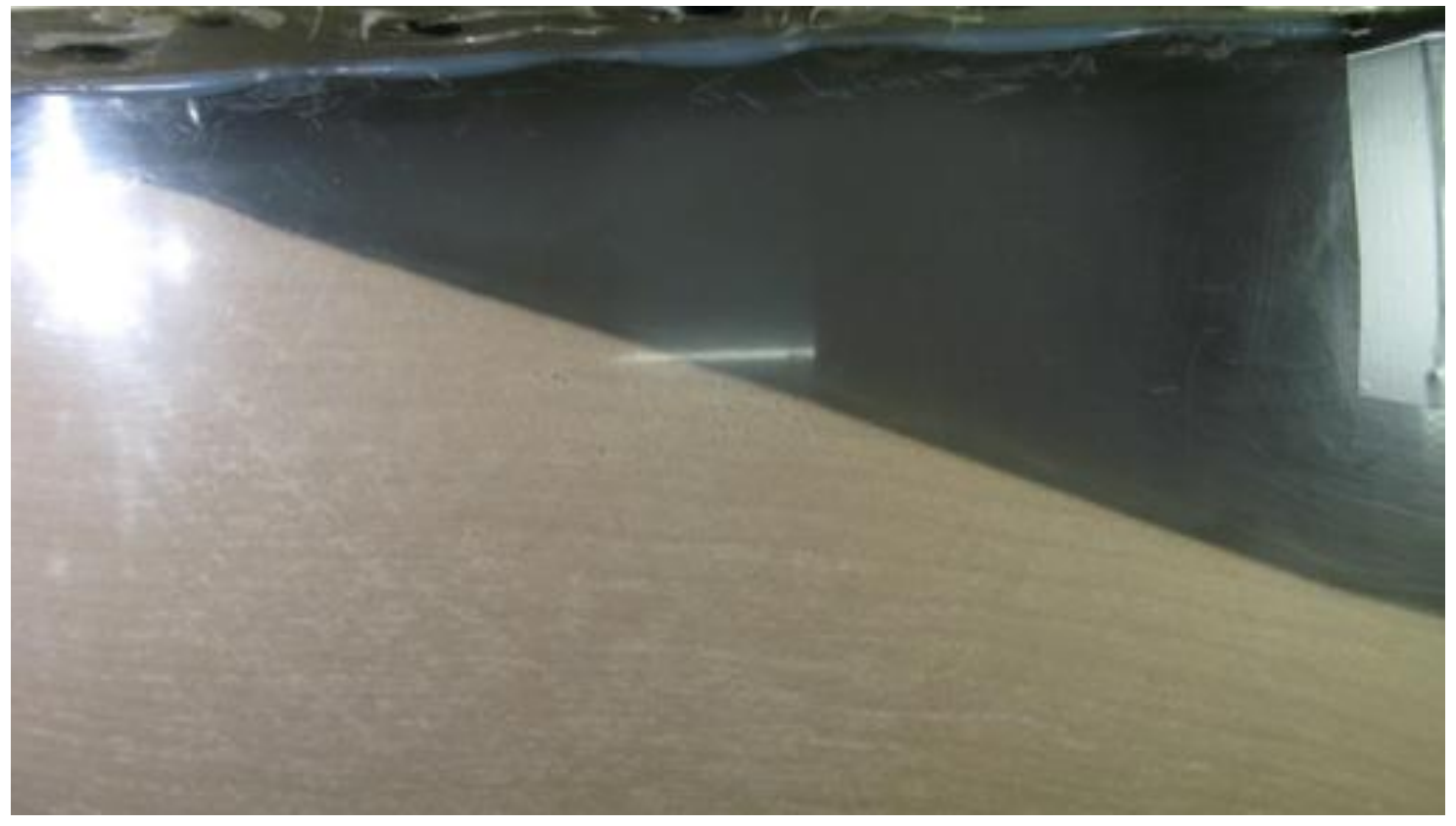

Figure 5.29: Slope immediately after swing down in second test 


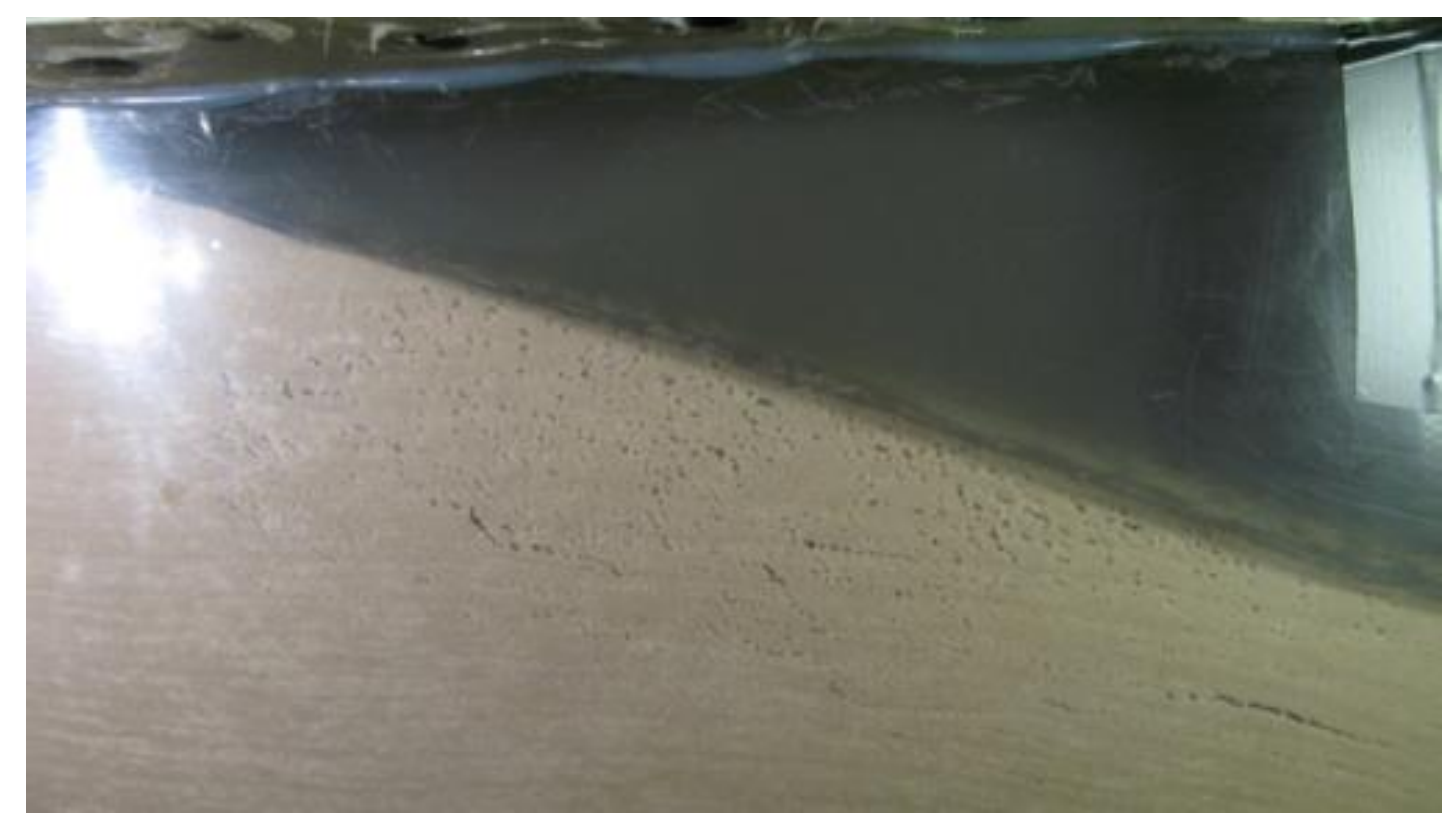

Figure 5.30: Slope after 45 minutes of swing down in second test

Figure 5.29 shows the slope immediately after swing down. There was evidence of volumetric expansion from gas dissolution during swing down. The white patches indicate the presence of gas in the sand slope. This gas follows the texture of the sand slope which was created by the sand raining. Figure 5.30 shows much more volumetric expansion of the slope after 45 minutes of the swing down.

Figure 5.31 to 5.35 shows the presence and development of gas bubbles at different target degrees of saturation level. With a decrease of pressure, the gas bubbles expand which indicates the degree of saturation decreases. Figure 5.34 and 5.35 shows the bubble expansion at target degree of saturation $70 \%$ and atmospheric. The expanded bubbles are much larger than the normal particle size as explained by Wheeler (1988), Figure 2-4b. The gas pushes back the soil skeleton in the region of each bubble leaving a large gas 
filled void. This soil with large gas bubbles may not follow the same effective stress law as saturated soil. This may partly explain the inconsistency between Atigh \& Bryne predictions and the observed slope behaviour.

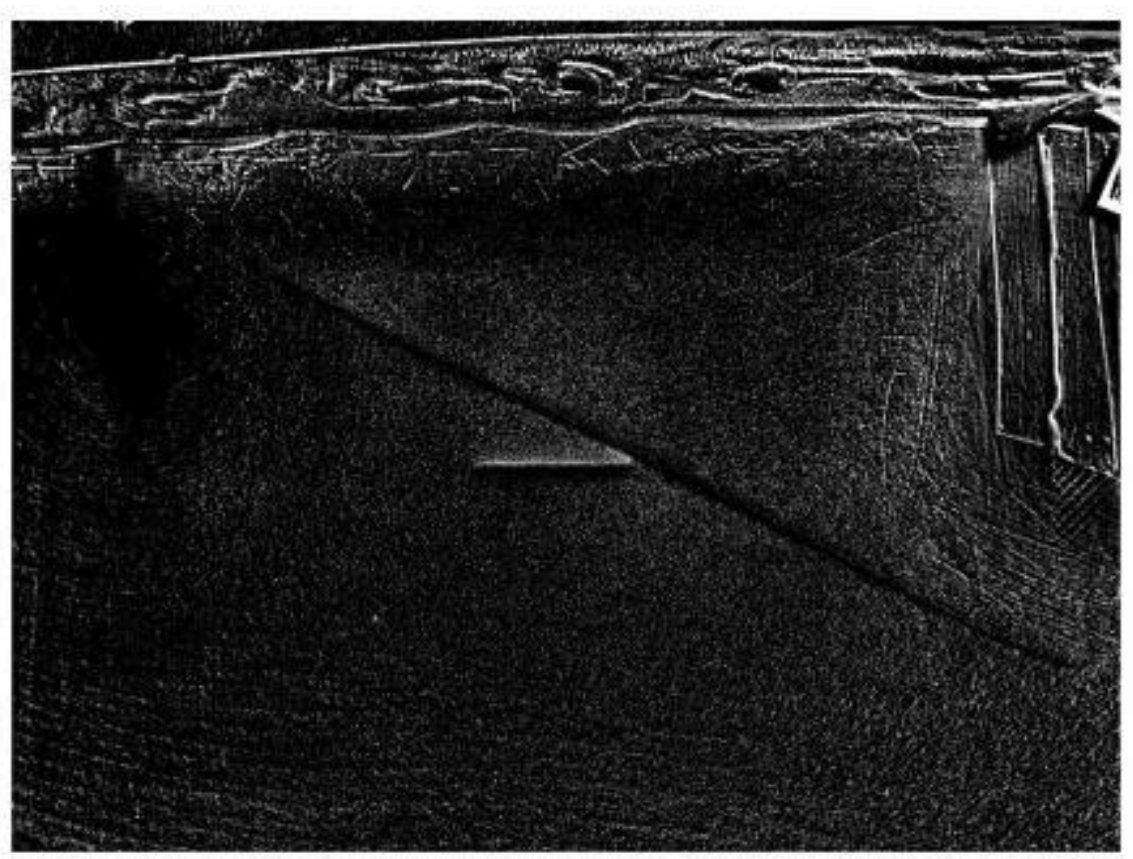

Figure 5.31: Presence of gas bubbles at 95\% target $\mathrm{Sr}$ 


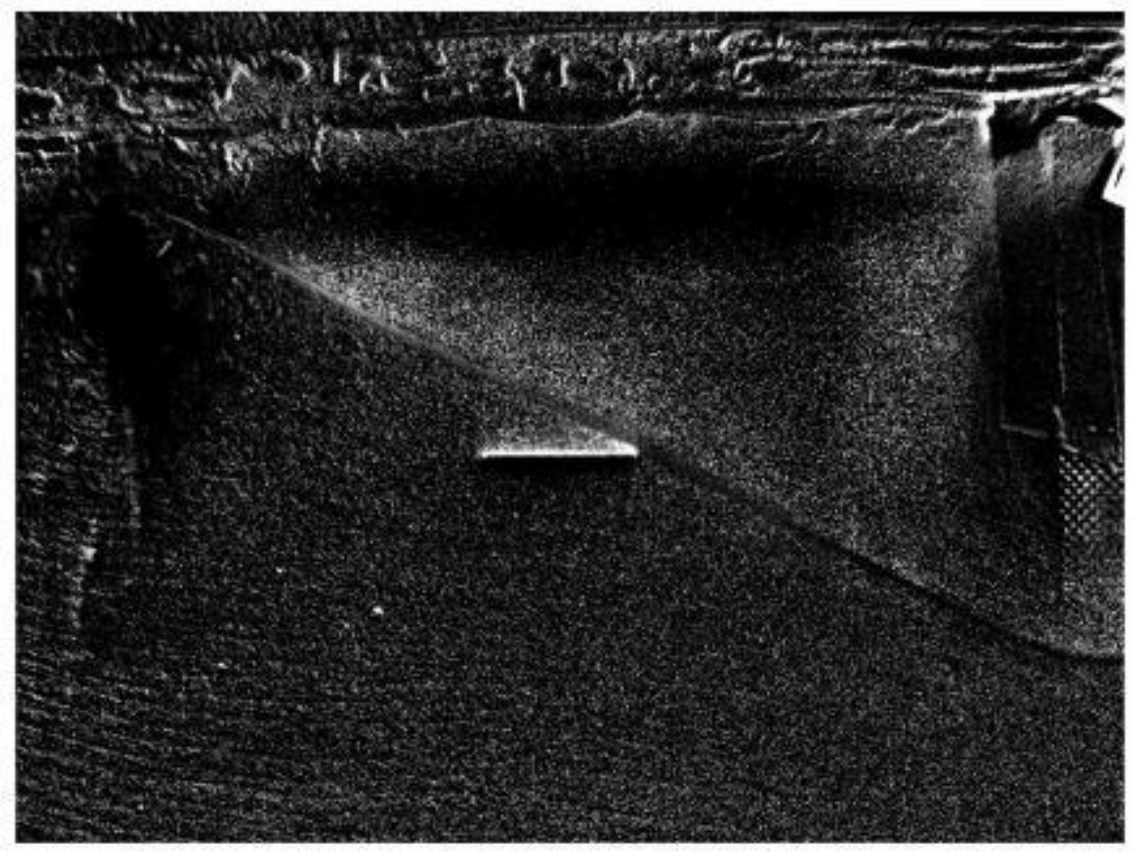

Figure 5.32: Presence of gas bubbles at $90 \%$ target $\mathrm{Sr}$

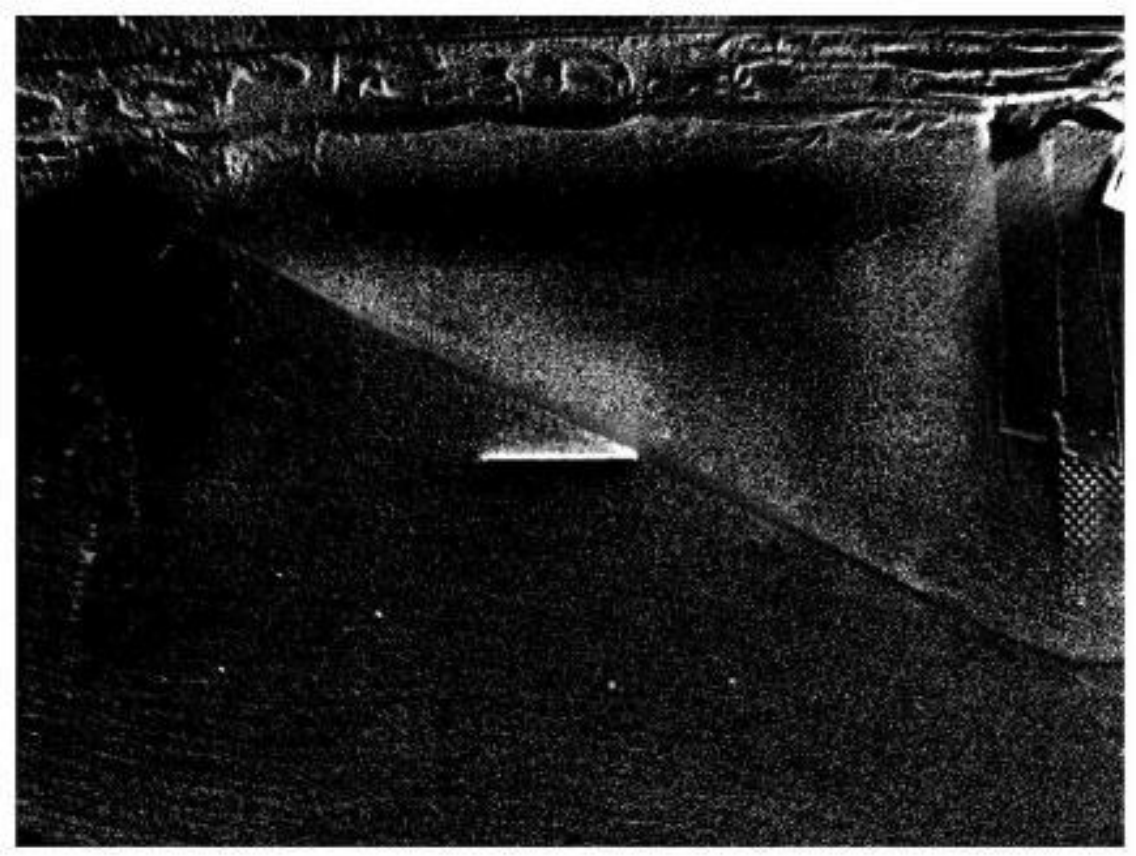

Figure 5.33: Presence of gas bubbles at $80 \%$ target $\mathrm{Sr}$ 


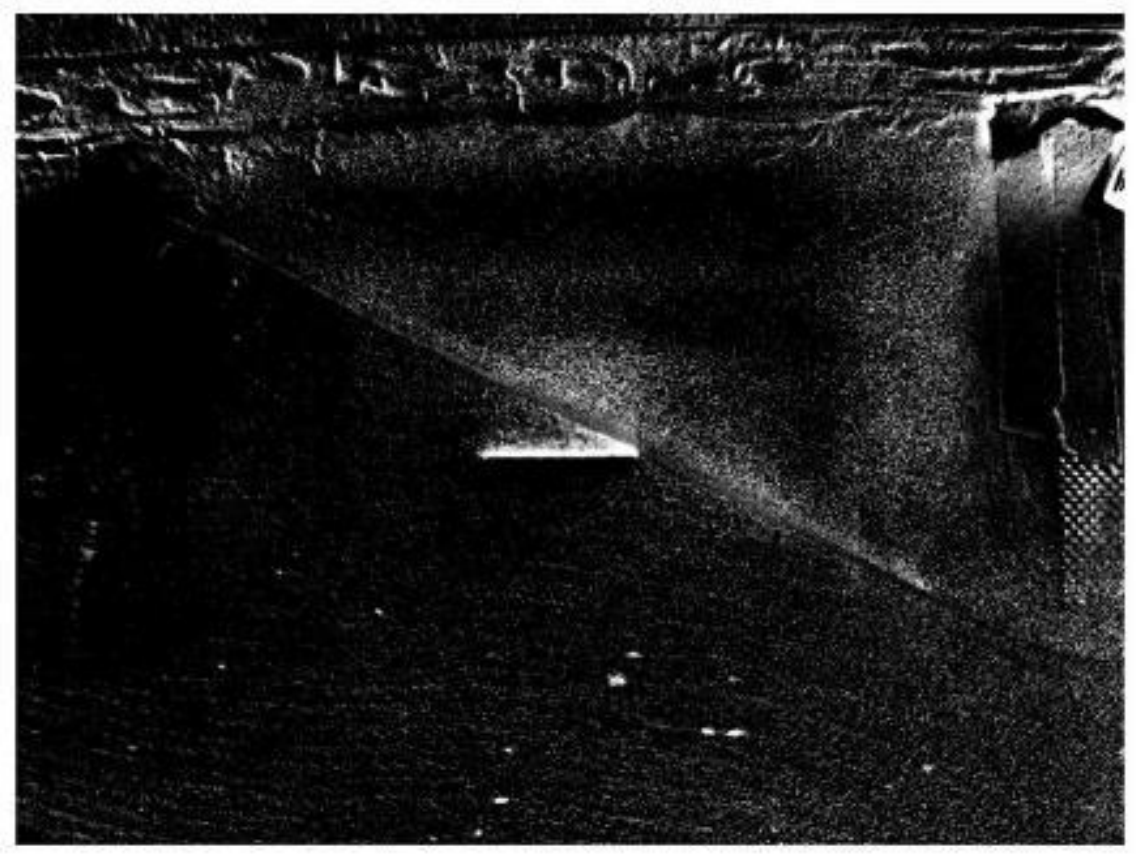

Figure 5.34: Presence of gas bubbles at 70\% target $\mathrm{Sr}$

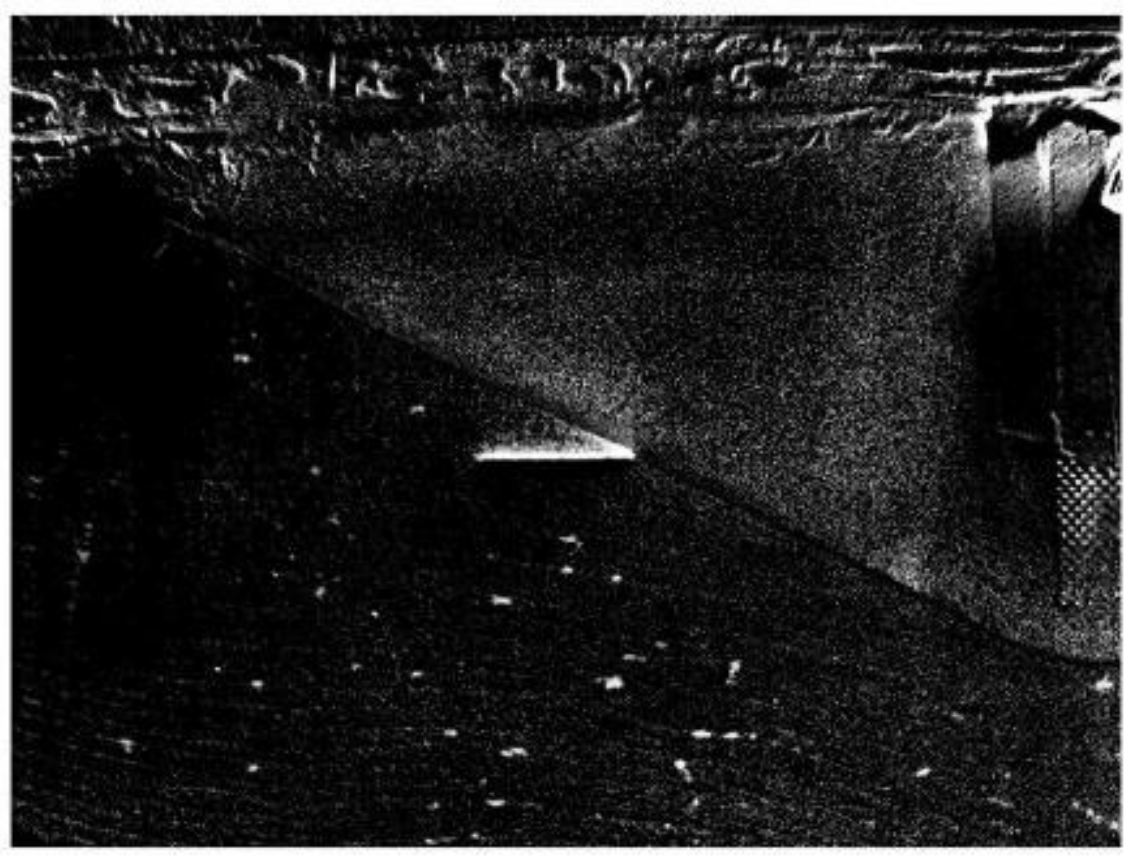

Figure 5.35: Presence of gas bubbles at atmospheric 


\subsection{Discussions}

A novel physical model test in a geotechnical centrifuge was undertaken of a submarine slope containing gassy sediments. In the first centrifuge test there were some issues with the instrumentation and the model did not work properly. There was also suspicion about the presence of pore gas in the centrifuge model. Some modifications were done before the second centrifuge test. These modifications helped to mitigate the issues of the first test. Gas expansion was observed coming out of pore fluid in a lower degree of saturation level. All the PPTs in the sand model also respond with tidal cycles. The results obtained from the PPTs are comparable in terms of phase lag and attenuation with Nagaswaran, (1983) and with field measurements of Atigh and Byrne (2004) in terms of phase lag. No significant flow liquefaction failure was observed by PIV analysis except some volumetric expansion. The accumulation of large gas bubbles at a lower degree of saturation indicates the presence of gas in the submarine slope. Model preparation techniques and measurement systems were developed by this research to check the stability of submarine gassy slope triggered by tidal variation. 


\section{Chapter 6: Conclusions and Recommendations}

\subsection{Conclusions}

Failure of submarine slopes is an important issue for offshore structures that must be considered in offshore structure design. In this current study, two centrifuge model tests were conducted to investigate the stability of submarine gassy slopes triggered by tidal variations in the $\mathrm{C}-\mathrm{CORE}$ Geotechnical Centrifuge. The appropriate novel model preparation techniques and control and measurement systems were successfully developed. Ethylene was selected as the dissolved gas with water as the pore fluid, to provide the necessary control of the degree of sand saturation. Model construction and saturation processes with ethylene saturated water were improved to ensure minimal disturbance and to obtain the desired relative density of the model sand during model preparation. The first centrifuge test was with very minimal instrumentation to develop and understand the testing procedure. The main issue of this test was no measurable gas came out of solution with a reduction of pressure. A second issue was restricted communication between the tidal actuator and strongbox, which attenuated the tidal motions. In the second test, some modification in instrumentation and plumbing of the strongbox was done. The water level in the pneumatic cylinder increased when the pressure of the strongbox was sufficiently decreased. This indicates that at low pressure,

gas bubbles expanded and came out of solution. Failure was expected to occur for specific combinations of degree of saturation, soil permeability and tidal period. However, slope failure was not triggered in both centrifuge tests of this setup under a 
wide range of tidal motions and gas pressures. But, the response obtained from the buried PPT's are comparable in terms of attenuation and phase lag with Nagaswaran (1983) and with field measurements of Atigh and Byrne (2004) in terms of phase lag.

A liquefaction flow slide of submarine gassy slope triggered by tidal variation at Fraser River Delta was numerically analyzed by Atigh and Byrne (2004) assuming a uniform degree of saturation throughout the slope. Their fully coupled FLAC finite-difference analysis showed triggering of liquefaction resulting in retrogressive flow slides in an unsaturated underwater Fraser River Delta slope. The aim of this current study was to validate this numerical work in a geotechnical centrifuge. The material used in this test to make the centrifuge model was Alwhite \#00 fine silica sand. The permeability of this sand is approximately $3 \times 10^{-5} \mathrm{~m} / \mathrm{s}$ which is low compared to the Fraser River Delta sand.

For identifying the degree of saturation, several instruments including Water Scout SM 100 Soil Moisture Sensors, Time Domain Reflectometry (TDR), and VH400 series soil moisture sensor were tested at $1 \mathrm{~g}$ condition at lab floor. The VH400 series soil moisture sensor showed good results when the degree of saturation increased, but did not respond under depressurization.

\subsection{Recommendations}

This present study was the first attempt in using a geotechnical centrifuge for analysing the stability of submarine gassy slopes triggered by tidal variation. There is a sufficient advancement in the model preparation technique and test procedures. According to the experience obtained in this research, it is recommended that further research on stability 
of submarine gassy slope triggered by tidal variation should be concentrated on the following aspects:

$>$ In this current study, model saturation by ethylene mixed water has been done after applying vacuum, flushing $\mathrm{CO}_{2}$ and flushed with distilled deaired water. In any future studies it is recommended to apply another method of saturation, for example: after vacuum and $\mathrm{CO}_{2}$ flushing, instead of flushing distilled deaired water flushed with ethylene mixed water to make the slope gassy. By this process the presence of ethylene in the model slope will be potentially higher.

To monitor the displacement of the submarine slope by PIV analysis it is needed to add control markers on the strongbox window to calibrate for the lens effect.

$>$ Further work should be performed to develop a system to determine the degree of saturation during the centrifuge model test. 


\section{References}

Anthony, E.J., and Julian, M. (1997). The 1997 Var Delta Landslide on the Franch Riviera: A Retrospective Analysis. Journal of Coastal Research, Vol. 13, No. 1

Atigh, E., and Byrne, P.M. (2004). Liquefaction flow of submarine slopes under partially undrained conditions: an effective stress approach. Can. Geotech. J. 41: 154-165.

Baraza, J., and Ercilla, G. (1996). Gas-charged sediments and large pockmark - like features on the Gulf of Cadiz (SW Spain). Marine and petroleum geology, 13(2): 253-261

Baraza, J., Ercilla, G., and Nelson, C.H. (1999). Potential geologic hazards on the eastern Gulf of Cadiz slope (SW Spain). Marine Geology 155: 191-215

Batterson, M., Liverman, D.D.E., Ryan, J., and Taylor, D. (1999). The assessment of geological hazards and disasters in Newfoundland: An update. Geological survey report 99-1. Newfoundland department of mines and energy.

Bea, R.G., Wright, S.G., Sircar, P., and Niedoroda, A.W. (1983). Wave induced slides in South pass block 70, Mississippi Delta Journal of Geotechnical Engineering, ASCE, 109(4), 619-644

Bouma, A., Sangrey, D., Coleman, J., Prior, D., Trippet, A., Dunlap, W., and Hopper, J. (1981). offshore geologic hazards. Education Course Note, Series Electronic Index of AAPG Special Publications. Vol 18.

Bryant, W. R. and Roemer, L. B. (1983). Structure of the continental slope of the northern Gulf of Mexico and its geohazards and engineering constraints. In: CRC Handbook of Geophysical Exploration at Sea (Eds R. A. Geyer and J. R. More), CRC Press, Boca Raton, Florida, 123-184 
Byrne, P.M. (2003). Personal communication, Centrifuge modelling of submarine slopes under tidal variations - Test procedures.

Chiocci, F.L. and Cattaneo, A. (2011). Seafloor mapping for geohazard assessment: state of the art. Mar Geophys Res, 32:1-11

Christian, H.A., Woeller, D.J., Robertson, P.K., and Courtney, R.C. (1997 a). Site investigations to evaluate flow liquefaction slides at Sand Heads, Fraser River Delta. Canadian Geotechnical Journal, 34(3): 384-397

Christian, H.A., and Cranston, R.E. (1997 b). A methodology for detecting free gas in marine sediments. Canadian Geotechnical Journal, 34(2): 293-304.

Chillarige, A.V., Robertson, P.K., Morgenstern, N.R., and Christian, H.A. (1997 a). Evaluation of the in situ state of Fraser River sand. Canadian Geotechnical Journal, 34(4): 510-519.

Chillarige, A.V., Robertson, P.K., Morgenstern, N.R., and Christian, H.A. (1997 b). Seabed instability due to flow liquefaction in the Fraser River Delta. Canadian Geotechnical Journal, 34(4): 520-533.

Clark, J.I., Paulin, M.J., Lach, P., Phillips, R. (1993). Centrifuge modeling for offshore development. NOIA conference 93 proceedings, St. John's, Canada. 136-149.

Coleman, J. M., Suhayda, J. N., Whelan, T., and Wright. L. D. (1974). Mass Movement of Mississippi River Delta Sediments. Gulf Coast Association of Geological Societies Transactions Vol. 24 , 49-68

Coleman, J.M., Prior, D.B., Garrison, L.E., and Lee, H.J. (1991). Slope failures in area of high sedimentation rate: Offshore Mississippi River Delta. In Submarine landslides: Selected studies in the U.S Exclusive Economic Zone, Edited by Schwab, W.C., Lee, H.J. and Twichell, D.C. 
Coulter. S.E., \& Phillips. R. (2005). Seismic initiation of submarine slope failures using physical modelling in a geotechnical centrifuge, 58th Canadian Geotechnical Conference, Saskatoon

Coulter, S.E. (2008).Seismic initiation of submarine slope failures using physical modeling in a geotechnical centrifuge. Memorial University of Newfoundland, St. John`s, NL, Canada.

Dillon, W.P., and Max, M.D. (2000). Oceanic gas hydrates. In Natural gas hydrates in oceanic and permafrost environments. Edited by M.D. Max, Kluwer academic publishers, Dordecht, the Netherlands. 61-76.

Esring, M.I., and Kirby, R.C. (1977). Implication of gas content for predicting the stability of submarine slopes. Marine Geotechnology 2, 81-100.

Floodgate, G.D., and Judd, A.G. (1992). The origins of shallow gas. Continental Shelf Research. Vol 12. No 10, 1145-1156.

Gu,W.H., Morgenstern, N.R., and Robertson, R.K. 1993. Progressive failure of the lower San Fernando dam. Journal of Geotechnical Engineering, ASCE, 119: 333-348

Grozic, J.L.H. (1999). The Behavior of Loose Gassy Sand and its Susceptibility to Liquefaction. PhD thesis. University of Alberta, Edmonton, Alberta.

Grozic. J.L., Robertson. P.K., Morgenstern. N.R. (1999). The behavior of loose gassy sand. Canadian Geotechnical Journal. 36: 482-492

Guanghai. Hu.,Chenglin. CAO.,Yujing. HOU. (2010). Simulation of gas effect on submarine slope stability. ISOPE 2010. Beijing, China.

Hampton, M.A., Lee, H.J., and Locat, J. (1996). Submarine landslides. Reviews of Geophysics, vol 34, no 1, 33-59. 
Haththotuwa, C.K., and Grozic, J.L.H. (2011). Effect of fines content on instability behavior of loose silt - sands containing gas bubbles. Pan-Am CGS Geotechnical Conference, Toronto, Ontario, Canada.

Holocher, J., Peeters, F., Aeschbach-Hertig, W., Kinzelbach, W. and Kipfer, R. (2003). Kinetic model of gas bubble dissolution in groundwater and its implications for the dissolved gas composition. Environ. Sci. Technol., 37, 1337- 1343.

Hovland, M. (1993). Submarine gas seepage in the North Sea and adjacent areas. Petroleum Geology of Northwest Europe: Proceedings of the 4th Conference. . Published by The Geological Society, London, 1333-1338.

http://www.engineeringtoolbox.com/gases-solubility-water-d_1148.html

https://en.wikipedia.org/wiki/Gulf_of_C\%C3\%A1diz\#/media/File:Alboran_Sea_map.png https://en.wikipedia.org/wiki/Henry\%27s_law\#Henry.27s_law_solubility_constants http://www.nanomedicine.com/NMI/Tables/9.2.jpg

http://www.specmeters.com/weather-monitoring/sensors-and-accessories/sensors/soil$\underline{\text { moisture-sensors/sm100/ }}$

http://www.testequipmentdepot.com/usedequipment/tektronix/tdrs/1502b1503b.htm?gclidC Nb4cCZ98gCFc8YHwodmCUBMw

Jung, W.Y., and Vogt, P.R. (2004). Effect of bottom water warming and sea level rise on Holocane hydrate dissociation and mass wasting along the Norwegian-Barents Continental Margin. Journal of Geophysical Research.

Kenyon, P.M., and Turcotte, D.L. (1985). Morphology of a delta Implications prograding by bulk sediment transport. Geological Society of America Bulletin, 96: 14571465. 
Kostaschuk, R.A., and McCann, S.B. (1989). Submarine slope stability of a Fjord Delta: Bella Coola, British Columbia, Geographie physique et quaternaire, vol. 43. No 1, 87-95.

Kostaschuk, R.A., and Luternauer, J.L. (1989). The Role of the Salt-Wedge in Sediment Resuspension and Deposition: Fraser River Estuary, Canada. Journal of coastal research. Vol. 5 no. 1: 93-101

Kostaschuk, R.A., Luternauer, J.L., Mckenna, G.T., and Moslow, T.F. (1992). Sediment transport in a submarine channel system: Fraser River Delta, Canada. Journal of Sedimentary Petrology. Vol 62, No 2, 273-282.

Kramer, S.L. (1988). Triggering of liquefaction flow slides in coastal soil deposits. Engineering Geology (Amsterdam) 26: 17-31.

Locat, J., and Lee, H.J. (2000). Submarine Landslides: Advances and Challenges, Proceedings of the 8th International Symposium on Landslides, Cardiff, U.K.

MacDonald, I. R., Reilly, J. F. II, Guinasso, N. L. Jr, Brooks, J. M., Carney, R. S., Bryant, W. A., and Bright, T. J. (1990). Chemosynthetic mussels at brine-filled pockmark in the Northern Gulf of Mexico, Science. 248, 1096-1099

Masson, D., Harbitz, C., Wynn, R., Padersen, G., and Lovholt, F. (2006). Submarine Landslides: Processes, Triggers and Hazerds Prediction. Philosophical Transection of Royal Society, 364: 2009-2039

McKenna, G.T., Luternauer, J.L., and Kostachuk, R.A. (1992). Large scale mass wasting events on the Fraser River Delta front near sand heads, British Columbia, Canadian Geotechnical Journal, 29: 151 - 156. 
Mienert, J., Vanneste, M., Bunz, S., Andreassen, K., Haflidason, H., and Sejrup, H.P. (2005). Ocean warming and gas hydrate stability on the mid-Norwegian margin at the strogga slide. Marine and petroleum geology , 22: 233-244.

Milliman, J.D. (1980). Sedimentation in the Fraser River and its estuary, southwestern British Columbia, Canada. Estuarine and Coastal Marine Science, 10: 609-633

Mitchell, R. J., Tsui, K. K., and Sangrey, D. A. (1972). Failure of submarine slope under wave action. Coastal Engineering Proceedings.

Mosher, D.C., Moscardelli, L., Shipp, R.C. , Chaytor, J.D., Baxter, C.D.P., Lee, H.J., and Urgeles, R. (2010). Submarine Mass Movements and Their Consequences, Advances in Natural and Technological Hazards Research, Vol 28.

Murff, J.D. (1996). The geotechnical centrifuge in offshore engineering. OTC Honors Lecture, Offshore Technology Conference, Houston, USA.

Nageswaran, S. (1983). Effect of gas bubbles on the seabed behaviour. University of Oxford.

Nixon, M.F., and Grozic, J.L.H. (2006). A simple model for submarine slope stability analysis with gas hydrates. Norwegian Journal of Geology, Vol. 86, 309-316.

Parkes, R.J., Cragg, B.A., Fry, J.C., Herbert, R.A., Wimpenny, J.A., Allen, J.A., and Whitfield, M. (1990). Bacterial biomass and activity in deep sediment layers from the Peru Margin. Philosophical Transaction of Royal society, London. 331, 139153.

Phillips, R., Clark, J.I., Paulin, M.J., Meaney, M., Millan, D.E.L., Tuff, K. (1994). Canadian national centrifuge centre with cold region capabilities.Centrifuge 1994, Balkema, Rotterdam. 57-62 
Piper, D.J.W., Cochonat, P., and Morrison, M.L. (1999). The sequence of events around the epicenter of the 1929 Grand Bank Earthquake: Initiation of debries flows and turbidity current inferred from sidescan sonar. Sedimentology, 46, 79-97

Poulos, H.G. (1988). Marine geotechnics. Unwin Hyman, London, UK.

Premchitt. J., Rad. N.S., To, P., Shaw. R., and James. W.C. (1992). A study of gas in marine sediments in Hong Kong. Continental Shelf Research, Vol 12, No 10, 1251-1264.

Puebla, H., Byrne, P.M., and Phillips, R. (1997). Analysis of CANLEX liquefaction embankments: prototype and centrifuge models. Canadian Geotechnical Journal. 34: 641-657.

Robertson, P.K., and Fear, C.E. (1995). Liquefaction of sands and its evaluation. 1st international conference on Earthquake Geotechnical Engineering, Tokyo, Keynote lecture.

Schwab, W.C., Danforth, W.W., Scanlon, K.M., and Masson, D.G. (1991). A giant submarine slope failure on the northern insular slope of Puerto Rico. Marine Geology, Vol. 96. 237-246

Seed, H.B., Seed, R.B., Schlosser, F., Blondeau, F., and Juran, I. (1988). The landslide at the port of Nice on October 16, 1979. University of California, College of Engineering, Report no. UCB/EERC-88/10

Sills, G.C., and Wheeler, S.J. (1992). The significance of gas for offshore operations. Continental Shelf Research, 12(10): 1239-1250.

Silvis. F., and de Groot, M.B. (1995). Flow slides in the Netherlands: experience and engineering practice. Canadian Geotechnical Journal, 32: 1086-1092. 
Sobkowicz, J.C. (1982). The mechanics of gassy sediments. Ph.D. thesis, Civil Engineering Department, University of Alberta, Edmonton

Sobkowicz, J.C. and Morgenstern, N.R. (1984). The undrained equilibrium behavior of gassy sediments. Canadian Geotechnical Journal, 21, 439-448.

Soderberg, P., and Floden, P. (1992). Gas seepages, gas eruptions and degassing structures in the seafloor along the Stromma tectonic lineament in the crystalline Stockholm Archipelago, east Sweden Cont. Shelf. Res, 112 (10), 1157-1171.

Sultan, N., Cochonat, P., Foucher, J.P., and Mienert, J. (2004). Effects of gas hydrates melting on seafloor slope stability. Marine Geology, 231: 379-401

Sultan. N., Savoya. B., Jouet. G., Leynaud. D., Cochonat. P., Henry. P., Stegmann. S., and Kopf. A. (2010). Investigation of a possible submarine landslide at the Var Delta front (Nice slope-SE France). Canadian Geotechnical Journal. Vol. 47, No 4. 486-496.

Taylor, D. I. (1992). Nearshore shallow gas around the UK coast. Cont. Shelf. Res. 12 (10), 1135-1144

Taylor, R.N. (1995). Geotechnical Centrifuge Technology, Blackie Academic Press.

Ueno, K. (1998). Methods for preparation of sand samples. Centrifuge 98. Balkema. Rotterdam, Netherlands.

Vanneste, M. (2010). Offshore Geohazard. International research for geohazard.

Waite. W., Bratton. P. M., and Mason. D. H. (2011). Laboratory formation of noncementing, methane hydrate-bearing sands.Proceedings of the 7th International Conference on Gas Hydrates (ICGH 2011), Edinburgh, Scotland, United Kingdom, 17-21. 
Watts, B.D., Seyers, W.C., and Stewart, R.A. (1992), Liquefaction susceptibility of Greater Vancouver area soils. In Geotechnique and natural Hazards, symposium sponsored by Vancouver Geotechnical Society and the Canadian Geotechnical society, 6-9 May, 145-157

Wheeler, S.J. (1988). A conceptual model for soils containing large gas bubbles. Géotechnique, 38, 389-397

Whelan, T. III., Coleman, J.M., and Suhayda, J.N. (1975). The geochemistry of recent Mississippi River Delta sediments: Gas concentration and sediment stability. Proceedings of the Offshore Technology Conference; OTC 2342, Houston, Texas, 71-77.

Whelan, T. III., Ishmael, J.T., and Rainet, G.B. (1978). Gas-sediment interactions in Mississippi Delta sediments. In proceedings of the Offshore Technology Conference: OTC 3166, Houston, Texas, 1029-1032.

White, D.J., Take, W.A and Bolton, M.D. (2003). Soil deformation measurement using particle image velocimetry (PIV) and photogrammetry. Géotechnique Vol.53, No.7, 619-631.

Wiegel, R.L. (1964). Oceanographical Engineering. Prentice Hall, Inc. Englewood Cliffs, New Jersey.

Wroth, C.P., and Houlsby, G.T. (1985). Soil mechanics: Property characterization and analysis procedures. Proceedings of the eleventh international conference on soil mechanics and foundation engineering, San Francisco.

Yamamoto, S., Alcauskas, J.B., and Crozier, T.E. (1976). Solubility of methane in distilled water and sea water. Journal of Chemical and Engineering Data, Vol. 21, No. 1, 78- 80 . 
Yang, W. (2009). Physical modeling of subgouge deformations in sand.Memorial University of Newfoundland, St. John`s, NL, Canada.

Zhang. J.H., Lin. H.L., Wang. K.Z. (2015). Centrifuge modeling and analysis of submarine landslide triggered by elevated pore pressure. Ocean Engineering. 109 $419-429$ 
Appendix A 


\section{OMAE2015-41829}

\section{SUBMARINE SLOPE FAILURES IN GASSY SOILS}

\author{
Shantanu Kar \\ Faculty of Engineering and Applied Science \\ Memorial University of Newfoundland \\ St. John's, NL, Canada
}

\author{
Ryan Phillips \\ C-CORE \\ St. John's, NL, Canada
}

\begin{abstract}
This paper investigates the stability of a submarine gassy slope triggered by tidal variations. Under tidal variations on an unsaturated slope, failure may occur under specific combinations of increasing degree of saturation and soil permeability, and decreasing tidal period. A novel physical model test in a geotechnical centrifuge was undertaken of a submarine slope containing gassy sediments. The model preparation techniques, measurement systems and preliminary results are presented. The response observed in the model test is discussed and further developments proposed. Existing numerical simulations may provide a basis for verification and validation of future physical model test results.
\end{abstract}

\section{INTRODUCTION}

Submarine slope instability may generate tsunamis which impact the safety of people and coastal structures such as jetties, breakwaters, lighthouses, pipelines, and offshore platforms. Submarine slope failure can be initiated by a variety of potential triggering factors such as earthquakes and static effects such as tidal variation and other changes in water level. A flow liquefaction observed in the Fraser River delta was largely caused by the presence of gas especially methane dissolved in pore water, [1]. A major source of instability in sediments containing gas bubbles may occur due to a drop of pore water pressure. In the Fraser River delta residual pore pressure in sediments during low tide conditions leads to the instability of soil slopes and triggering of flow liquefaction failures, [2]. Methane gas was found in the soil column up to $30 \mathrm{~m}$ below the seabed, with the degree of saturation ranging from $100 \%$ to $85 \%$. Tidal drawdown in the presence of gassy sediments was the triggering factor for the 1985 slope failure in the Fraser River delta, [3]. Haththotuwa et al. presented several case studies of flow slides in coastal marine deposits, [4]. Most of the failures mentioned in their work are liquefaction flow slides in sand and initiated by tidal variation.
Tidal variations cause unequal pore-pressure generation with depth and time in such soils. Such changes reduce the effective stresses during low tides and may induce liquefaction flow of slopes due to partial drainage conditions. An effective stress approach based on an elastic-plastic stress-strain relationship was developed at the University of British Columbia (UBC) to model liquefaction flow of sand, [5]. Their fully coupled FLAC finite-difference analysis evaluated the behavior of both saturated and gassy deposits of loose Fraser River sand and Ottawa sand. Triggering of liquefaction resulting in retrogressive flow slides was predicted for an unsaturated underwater $3 \mathrm{H}$ : $1 \mathrm{~V}$ slope similar to those observed near Sand Heads at the front of the Fraser delta, Figure 1.

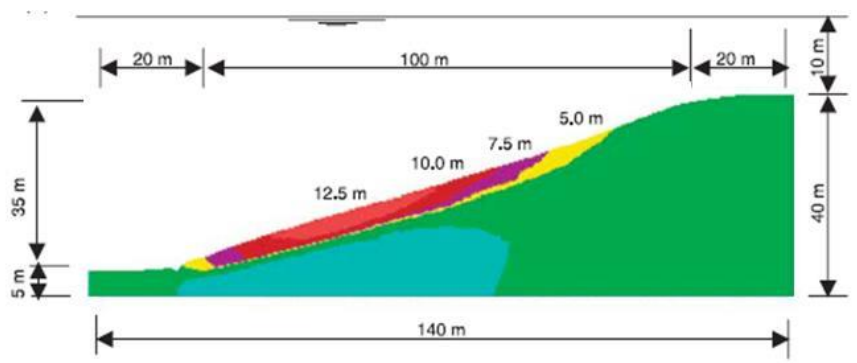

Figure 1 Horizontal movements caused by $2.5 \mathrm{~m}$ tide [5]

The significant benefit of complementary numerical and physical modelling of slope instability (caused by static liquefaction) was demonstrated by UBC and C-CORE during the CANLEX joint industry project, [6].

Centrifuge physical modelling is a technique for investigating gravity dependent phenomena, such as soil slope behaviour, using reduced scale physical models. As a full scale soil structure is in equilibrium under earth's gravitational field $\mathrm{g}$, similarly a reduced $1 / 100^{\text {th }}$ scale model on a centrifuge under $100 \mathrm{~g}$ will have stresses due to self-weight similar to the stresses in the full scale soil structure at homologous points. The model can then reproduce the phenomena of cracking, rupture or, flow 
that would be observed in the prototype because the stress dependency of soil behaviour has been correctly simulated. The principles, scaling laws and some applications of centrifuge modelling are more fully described by [7] and [8].

The authors of [5] designed a $1 / 50^{\text {th }}$ scale physical model test for $50 \mathrm{~g}$, [9] of a $2.5 \mathrm{~m}$ tidal range failure of a gassy loose sand $2 \mathrm{H}$ : $1 \mathrm{~V}$ slope within some constraints of the C-CORE centrifuge, Figure 2. A uniform degree of saturation was assumed throughout the slope.

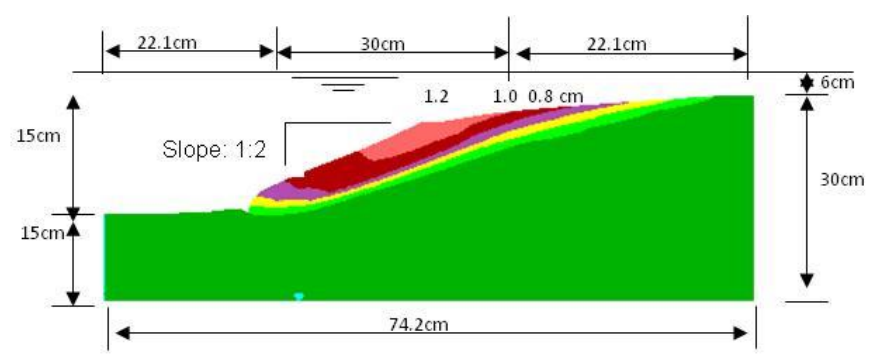

Figure 2 Predicted horizontal model movements [7]

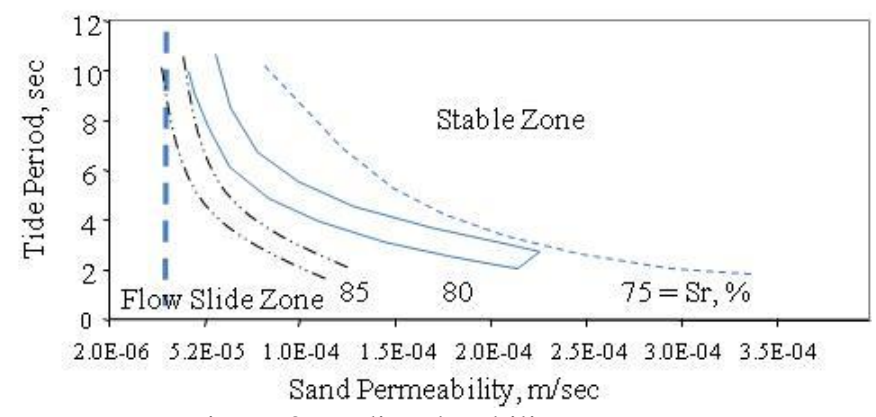

Figure 3 Predicted stability zones [9]

The tidal periods expected to cause model slope instability under $50 \mathrm{~g}$ were assessed using their FLAC analysis for loose gassy sand of varying degrees of saturation, $S_{\mathrm{r}}$ and saturated sand permeability, [9]. The expected delineations between a stable slope and a flow slide are shown in Figure 3.

This paper presents the first physical model test based on the above design of submarine slopes containing gas and triggered by tidal variation. Tidal variations can cause unequal pore-pressure generation with depth and time in submarine gassy slopes. The effective stresses will be reduced during low tides and may induce liquefaction flow of slopes due to partial drainage conditions. The first ever centrifuge test has been done to investigate the stability of the submarine gassy slopes under tidal variation.

To make an unsaturated gassy soil, the sand model was first saturated under a high pressure at $1 \mathrm{~g}$ with water containing dissolved gas. During the test at $50 \mathrm{~g}$, this pressure was reduced which caused gas to evolve from solution to form bubbles resulting in partial saturation. The tidal effect was simulated by changing the water head at the top of the model. The tidal variation was applied with different model time periods ranging from 50 seconds to 1 seconds. Failure of the unsaturated submarine slope was expected to occur under the correct combination of degree of saturation, tide period and soil permeability as shown in Figure 3.

\section{SEABED \& SELECTED GASES}

Gassy soils are defined as those which contain a relatively large amount of gas dissolved in the pore fluid, [10]. Gas can occur in seabed soils basically in three ways: in solution in the pore water, undissolved gas-filled voids, or as clathrates (gas hydrates). In the first case, the gas will have little effect on the physical properties of the seabed unless the ambient pressures are reduced. In the second case, the gas will affect the engineering properties of the seabed due to the high compressibility of the gas. In the third case, the gas only becomes hazardous if the clathrate melts, [11]. In the marine shallow sediments carbon dioxide, hydrogen sulfide, ethane gases are found, but methane is the most abundant.

The solubility coefficient of methane $\left(\mathrm{CH}_{4}\right)$ is $0.034 \mathrm{~L} / \mathrm{L}$ of fresh water at $20^{\circ} \mathrm{C},[12]$. The sealed centrifuge strongbox can hold gas saturated water up to $1 \mathrm{MPa}$ pressure. At atmospheric pressure, the lowest degree of sand saturation is then $85 \%$ with methane. A gas with higher solubility in water is required to achieve controllable $S_{\mathrm{r}}$ below $75 \%$, Figure 3 . Carbon dioxide is very soluble, but cannot provide controllable $S_{r}$ especially under the pressure gradients across a centrifuge model test. Ethylene $\left(\mathrm{C}_{2} \mathrm{H}_{6}\right)$, krypton and xenon gases are appropriate choices and industrially available. Ethylene was selected as it is most cost effective, as krypton and xenon are very expensive. The solubility coefficient of ethylene is $0.15 \mathrm{~L} / \mathrm{L}$ of fresh water at $20^{\circ} \mathrm{C}$, [13]. Ethylene, like methane, is flammable and potentially explosive. However, only $100 \mathrm{gm}$ of ethylene is contained within the pressurised strongbox. Ethylene is used commercially to ripen fruit. Special procedures were maintained in the lab to work safely with ethylene especially during model preparation and centrifuge testing. Any ethylene vented was released slowly in well ventilated unmanned areas into an air stream away from ignition sources.

\section{MODEL PREPARATION}

\section{SLOPE MATERIAL AND GEOMETRY}

The internal dimensions of the sealed strongbox are 500 $\mathrm{mm}$ long, $500 \mathrm{~mm}$ wide and $500 \mathrm{~mm}$ deep with an internal pressure rating of $1 \mathrm{MPa}$. The design slope geometry, Figure 2 was curtailed in the toe and crest to $100 \mathrm{~mm}$ to fit the strongbox, Figure 4. The model height was increased to 450 $\mathrm{mm}$ to minimise the pore fluid volume within the strongbox. The slope angle of $26.5^{\circ}(2 \mathrm{H}: 1 \mathrm{~V})$ is steeper than the $18.4^{\circ}$ submarine slopes identified to be susceptible to flow liquefaction by [14]. 


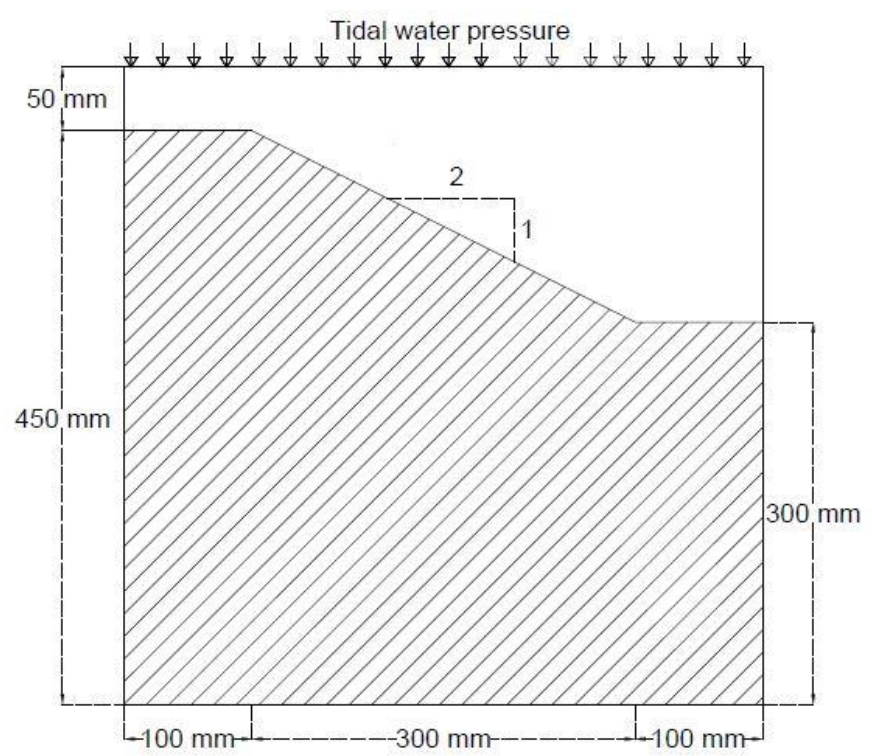

Figure 4 Submarine slope model geometry

The slope was constructed from Alwhite \#00 fine silica sand with a permeability of $3 \mathrm{e}-05 \mathrm{~m} / \mathrm{sec}$. The sand model was made in the strongbox by means of air pluviation, similar to methods by [15]. A hopper containing the test sand was moved over the model container at a specified drop height to provide a relative sand density of approximately $60 \%$. A vacuum was used to shape the slope after finishing sand raining.

The initial saturation of the model ground was done under vacuum in a method similar to [15]. Vacuum was applied to the model container to remove the air and then carbon dioxide was introduced to displace less soluble air particles that may be present in the voids. Following this step, the model slope was tilted to optimise the wetting front progress through the sand model. De-aired water was slowly introduced under vacuum conditions by means of a small differential driving head so as not to cause any disturbance in the sample.

\section{WATER - ETHYLENE SATURATION}

Ethylene saturated water was used as the pore fluid to make the slope model from a gassy sediment. Figure 5 shows the setup for saturation of the water pore fluid with ethylene gas, after [16]. The cylindrical pressure vessel contained marbles on a suspended perforated shelf. Water is placed in the bottom of the cylinder and deaired for a few days under vacuum. Ethylene was fed at $655 \mathrm{kPa}$ from a compressed gas bottle through the port into the cylinder. The pressure relief valve was vented to a safe area. The port was closed and the cylinder placed in a re-circulating water bath at $11^{\circ} \mathrm{C}$. This decrease of temperature increases the solubility of ethylene to ensure better saturation of the water. A pressure rated flexible tubing and a peristaltic pump system set to 182 litres/day was used to circulate the water from the bottom of the cylinder into the top through a distributor. The increased surface flow area over the marbles allowed rapid saturation the water.

The gas pressure dropped to $455 \mathrm{kPa}$ after 25 hours, (the flow was stopped overnight), Figure 6 . This pressure change is consistent with $100 \%$ gas saturation of the water at $455 \mathrm{kPa}$, based on the initial gas and water volumes. The gas pressure was increased twice back to $655 \mathrm{kPa}$ to achieve target saturation level.

The cylinder was removed from the water bath and allowed to warm slowly to room temperature under $655 \mathrm{kPa}$. Any free gas released exsolution was vented safely through the relief valve.

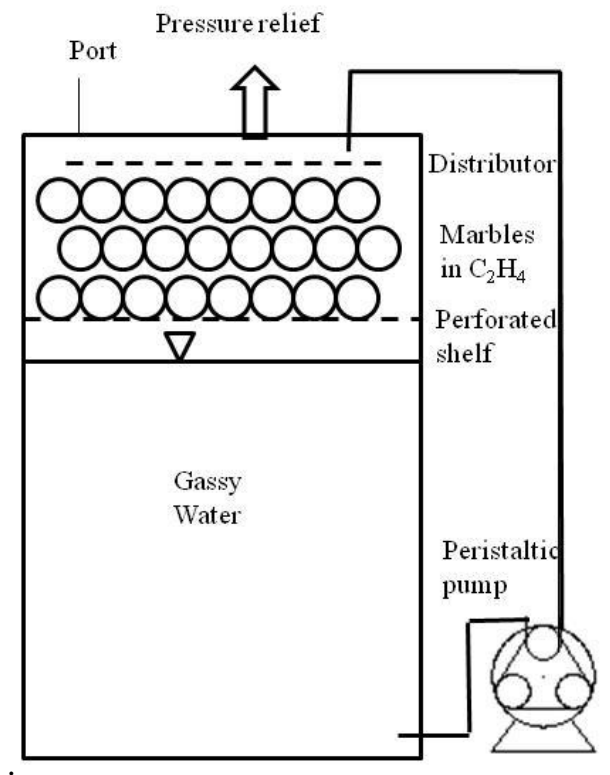

Figure 5 Water saturation with ethylene

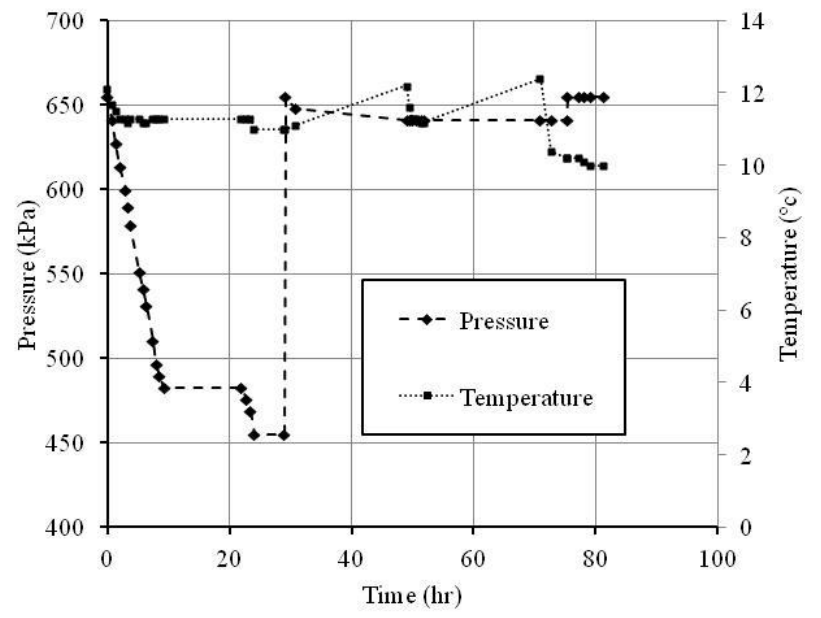

Figure 6 Gas pressure and bath temperature 


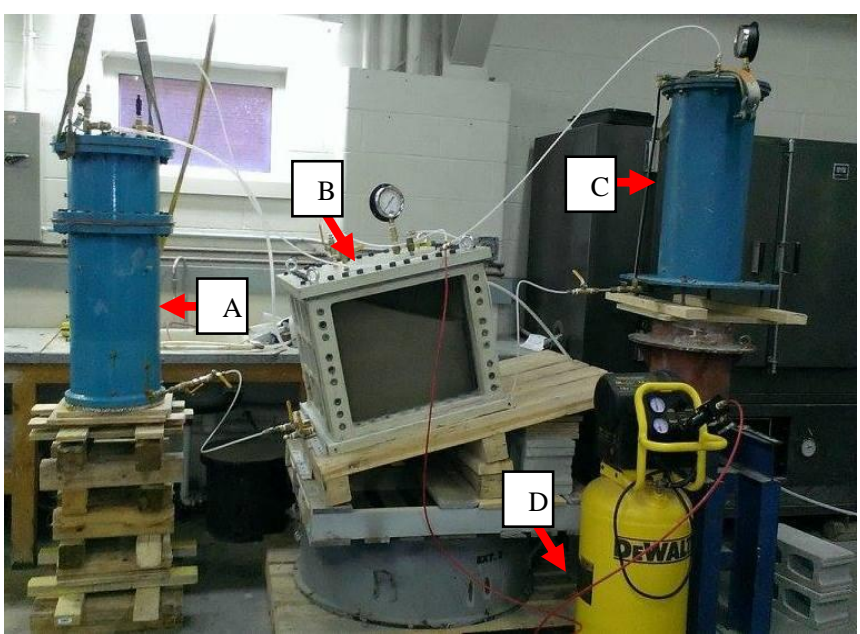

Figure 7 Setup for ethylene water saturation

The cylinder A was connected to the bottom port of the strongbox B though closed valves, Figure 7. The top of the strongbox was connected to the bottom of the empty overflow cylinder, C. The tops of A \& C were connected together, and through a valve to an air compressor D. Cylinders A \& $\mathrm{C}$ were set to $655 \mathrm{kPa}$ air pressure, the compressor valve was then closed and left to equilibrate. The ethylene mixed pore fluid was introduced slowly into the inclined slope model under a small differential fluid head maintained between cylinders A \& C. The gaseous water was intended to displace the deaired water into the overflow cylinder, C. More than one pore volume of gaseous water was passed through the strongbox. The model slope, now under $655 \mathrm{kPa}$ pressure, was ready for centrifuge testing.

\section{TIDAL ACTUATOR}

The model design of [9] proposed successively decreasing the tidal period from say 20 to $2.5 \mathrm{sec}$ with a fixed tidal range of $25 \mathrm{kPa}$, on a slope model with a uniform degree of saturation, $\mathrm{S}_{\mathrm{r}}$. The slope model $\mathrm{S}_{\mathrm{r}}$ could be decreased between tidal motions, releasing gas from the sand slope and the overlying free fluid. Up to 32 and 7 litres of gas and water were expected to be released from decreasing the $655 \mathrm{kPa}$ air pressure to atmospheric.

The tidal actuator was then required to provide the tidal motions, control of the gas pressure and storage of the fluids released. The actuator basically comprised a hydraulic and a $355 \mathrm{~mm}$ diameter pneumatic cylinder connected to a gas pressure regulator, Figure 8 . The servo controlled hydraulic cylinder provided the tidal motions. The pneumatic cylinder piston was replaced by a $330 \mathrm{~mm}$ diameter displacement block. The $60 \mathrm{~mm}$ thick block was a $25 \mathrm{~mm}$ acrylic disc over $35 \mathrm{~mm}$ strong buoyancy foam. A $9 \mathrm{~mm}$ immersive movement of the block caused a $25 \mathrm{kPa}$ increase in the water level. The gas regulator allowed the controlled safe release of excess gas while maintaining the required gas pressure. The large diameter pneumatic cylinder allowed storage of any water displaced by the reduced saturation in the slope as gas bubbles formed, with a small increase in the water elevation head. The tidal actuator elevation was set so the initial water level was slightly above the top of the strongbox.

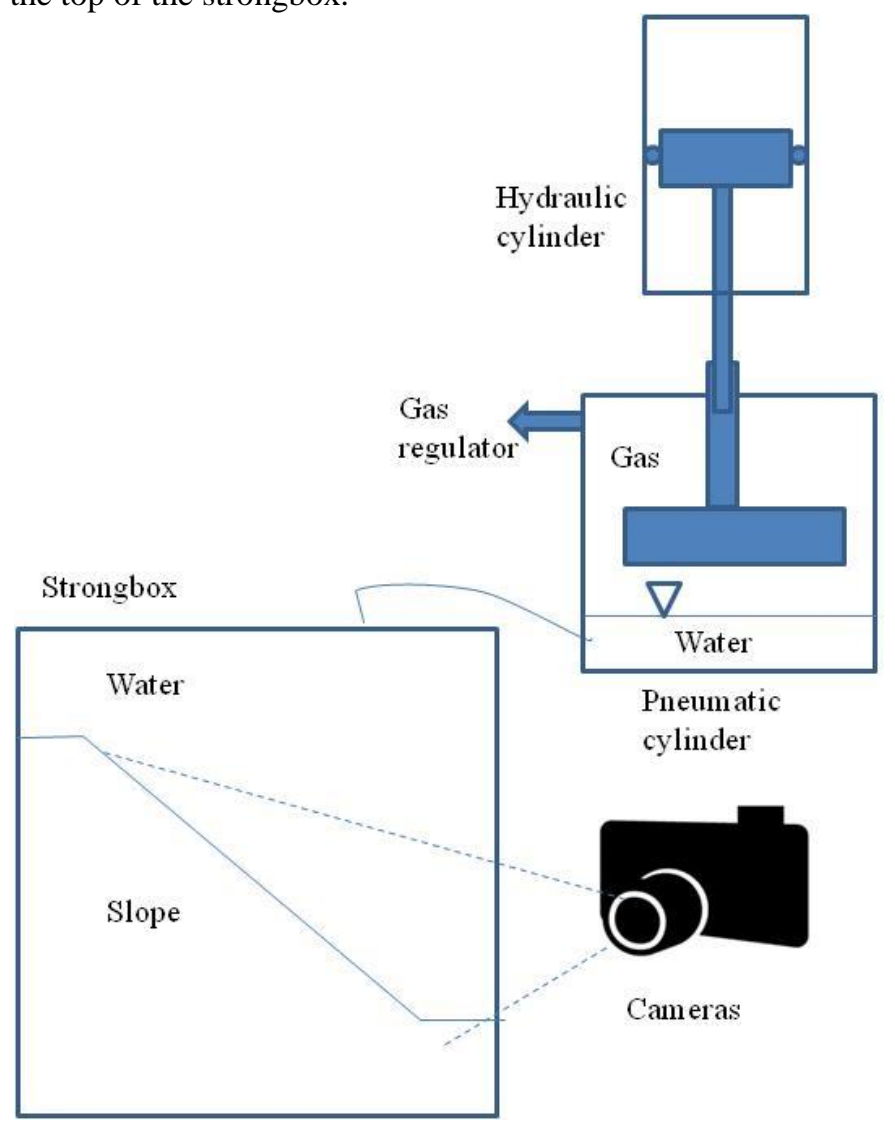

Figure 8 Centrifuge model setup

\section{INSTRUMENTATION}

In this first systems proof test, the instrumentation was minimal. Three transducers were used to monitor the pressures in the top and bottom of the pneumatic cylinder and the top of the strongbox. A fourth transducer monitored and used to control the hydraulic piston movement. Three cameras were used to view the slope. A GoPro video camera and a webcam were used to provide real time monitoring of the test.

A Canon G7 camera with 2 flood lights provided images every 7 seconds during changes in loading conditions (e.g. swing up, tidal motions and swing down). Particle Image Velocimetry (PIV) developed by [17] was used to track slope movements behind the window. This technique tracks the texture (i.e. a map of pixel intensities) of a patch of soil between successive images to provide a displacement vector increment of the patch.

In future tests, additional transducers will be added including pore water pressures and volumetric water content. An inexpensive TDR sensor is being evaluated for water content measurement, [18]. The low power VH400 series soil 
moisture sensor has a $94 \mathrm{~mm}$ long probe, Figure 9. Its output DC voltage is proportional to water content and provides an accurate reading in less than 1 second. Calibration tests have shown its sensitivity at high water contents, i.e. degree of saturation, $S_{\mathrm{r}}$ and repeatability, Figure 10, after initial sensor wetting in Test 1. Further tests show it's insensitive to vacuum and up to $655 \mathrm{kPa}$ water pressure over extended periods. Tests on a buried sensor are next.

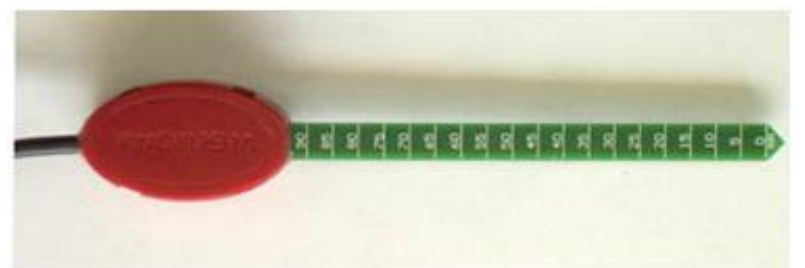

Figure 9 VH400 series soil moisture sensor, [18]

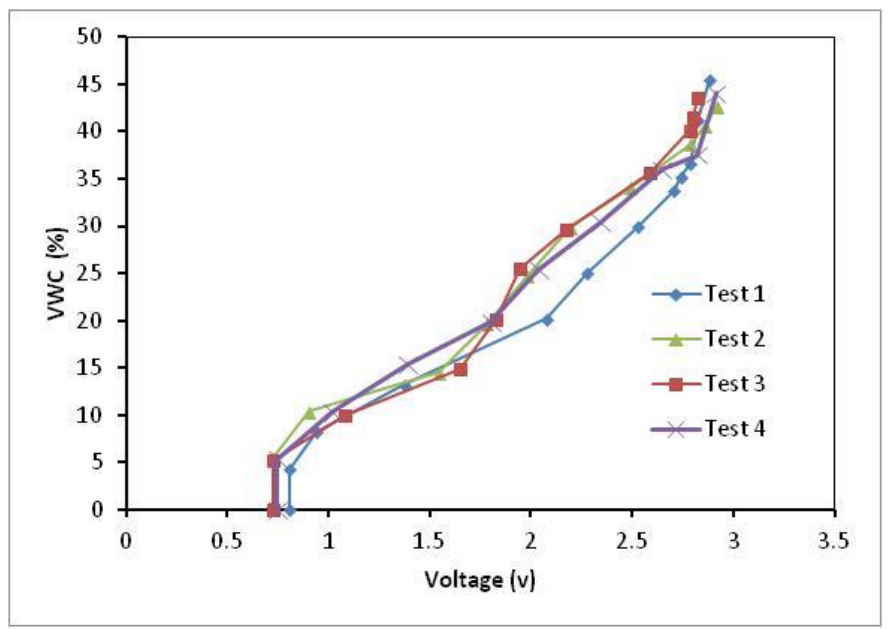

Figure 10 VH400 sensor calibration in Alwhite 00 sand

\section{CENTRIFUGE PROOF TEST}

The model test was assembled on the centrifuge swing, Figure 11. The displacement block was set above the water level, and the pneumatic cylinder was pressurized to $655 \mathrm{kPa}$ air pressure. The port to the strongbox was opened. The centrifuge was started after 30 minutes of data acquisition, Figure 12 and accelerated in $10 \mathrm{~g}$ increments to the $50 \mathrm{~g}$ test level. The strongbox pressure transducer was at a higher elevation than that in the cylinder base.

Analyses by [19] show about 15 minutes are required for krypton gas bubbles to dissolve in still water, Figure 13. Krypton has a similar diffusivity and solubility as ethylene. A period of 15 minutes was therefore allowed after each change in model loading to allow gas to dissolve or come out of solution.

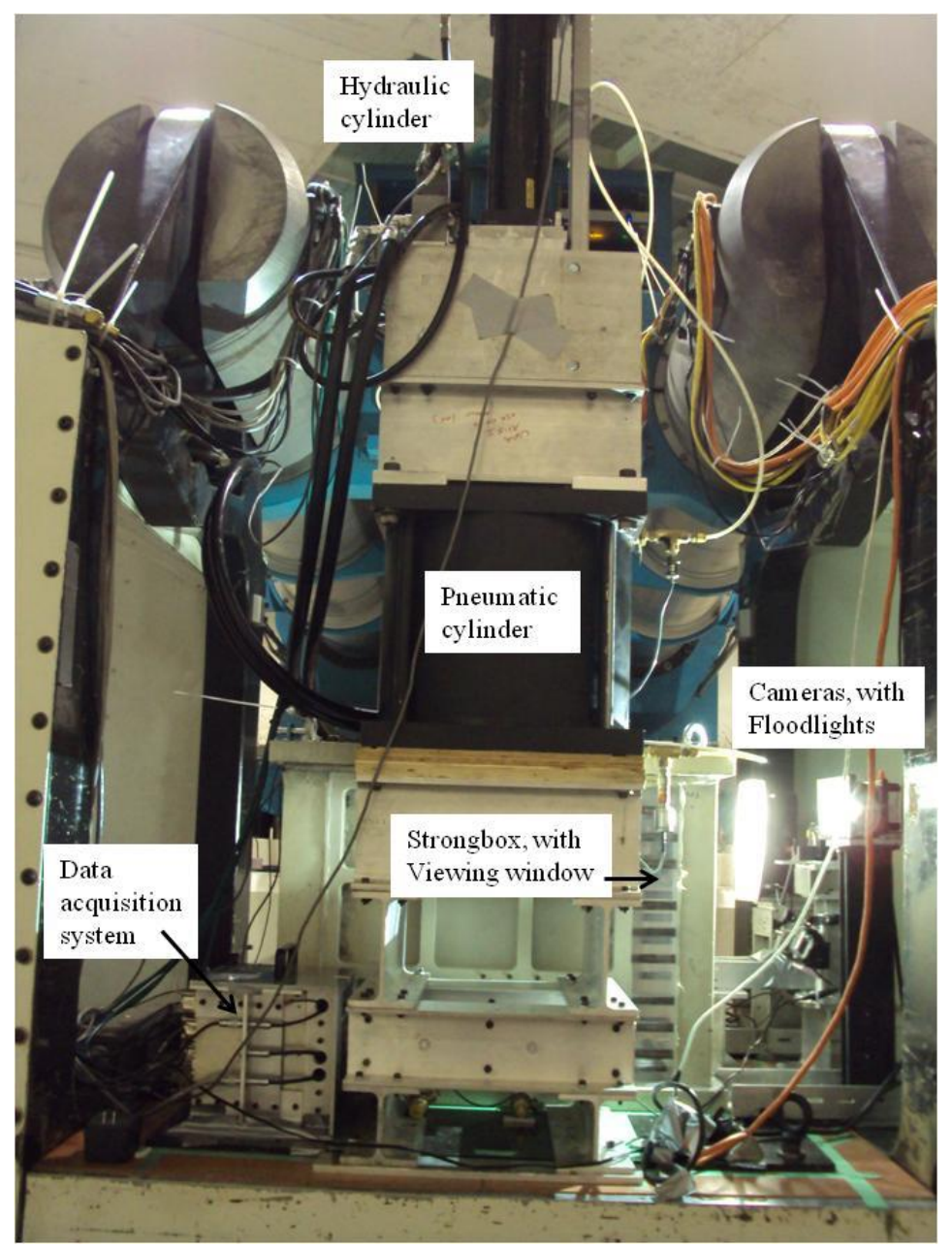

Figure 11 Centrifuge model package on swing

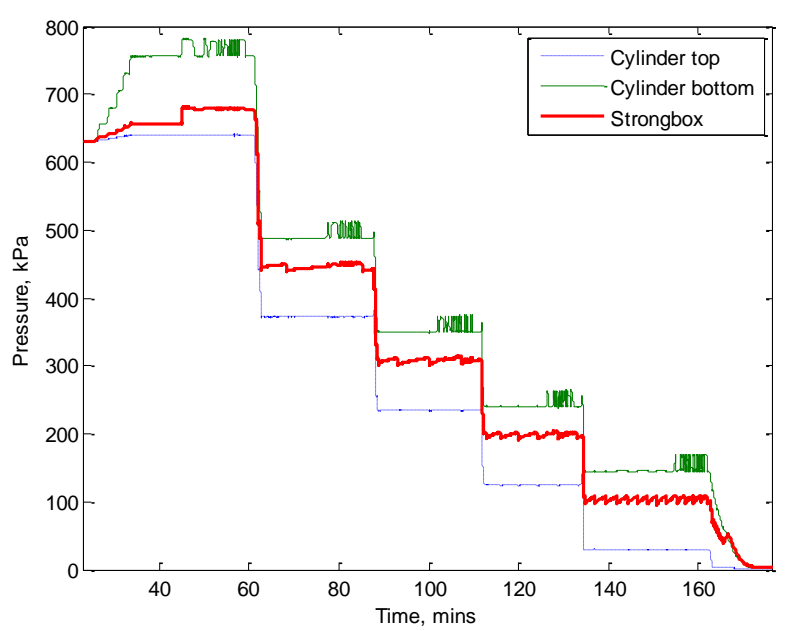

Figure 12 Centrifuge proof test transducer readings 


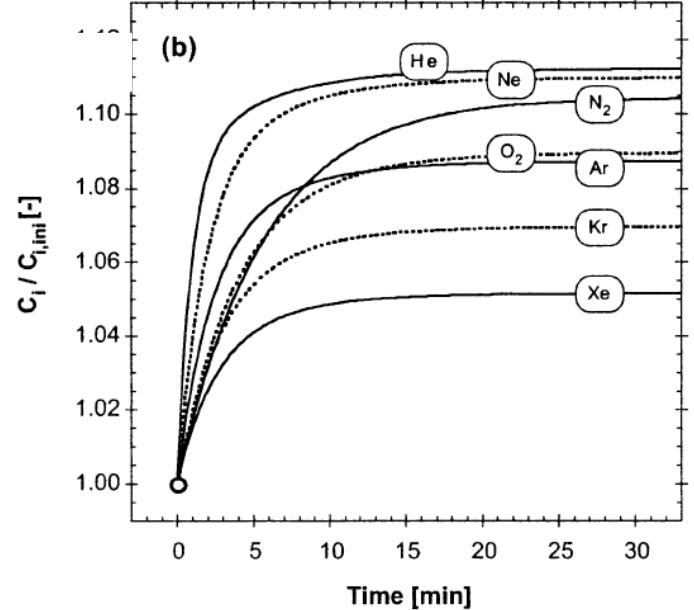

Figure 13 Estimated gas solution times, [19]

Tidal motions were applied at five target degrees of saturation, $S_{\mathrm{r}}: 100,95,90,80 \& 70 \%$, Figure 12. At each $\mathrm{S}_{\mathrm{r}}$ level, there was no measurable change in water level in the pneumatic cylinder bottom as gas came out of solution. At $\mathrm{S}_{\mathrm{r}}$ less than $100 \%$, there were pressure cycles in the strongbox each terminated by fluctuations in the cylinder air pressure indicating gas venting. The period of these cycles decreased with decreasing $S_{r}$ indicating more released gas volume.

The constant water level implies that the pore fluid in the strongbox was not initially fully saturated with gas. Improvements and measurements will be needed to improve this in future tests.

After allowing for gas equilibration, the displacement block was slowly immersed into the water to find the initial water level, e.g. at 45 seconds in Figure 12. The strongbox pressure changed in response to this on first immersion, but these changes were much less on subsequent block motions. Gas may have gathered under this transducer damping its response. The transducer will be repositioned in future tests, and the pipe size increased from the actuator to the strongbox lid. Lid ports will also be repositioned to maximize gas venting from the strongbox.

Tidal motions of 50 to 5 second periods with up to 5 cycles at each period were applied at the 630 and $360 \mathrm{kPa}$ air pressure levels. Periods of 20 to 1 second were used at lower air pressures with up to 50 cycles.

The PIV analysis indicated no significant movement of the medium dense slope throughout the tidal motions. (A lower density slope will be made for the next test). There was evidence of slight volumetric expansion from gas dissolution under 50g. Much more volumetric expansion was seen while stopping the centrifuge from $50 \mathrm{~g}$, Figure 14 , due to the associated decrease in total stresses in the sand. The noise in the displacement vectors indicates the effects of expanding gas bubbles, as seen near the slope crest at 1g, Figure 15. These gas bubbles expanded during the 45 minute period after swing down, Figure 16 but did not change much more over the next 60 hours.

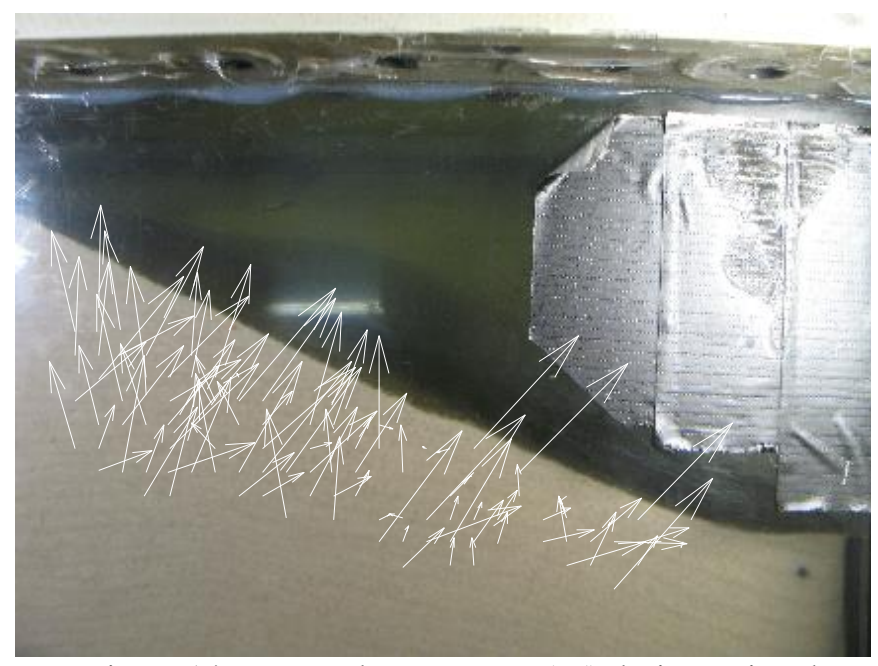

Figure 14 PIV sand movements (x5) during swing down

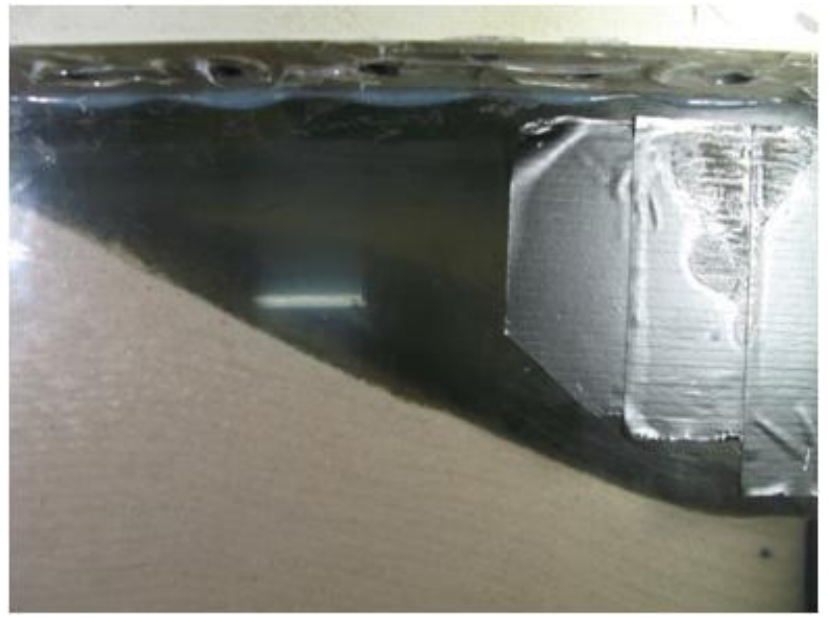

Figure 15 Slope immediately after swing down

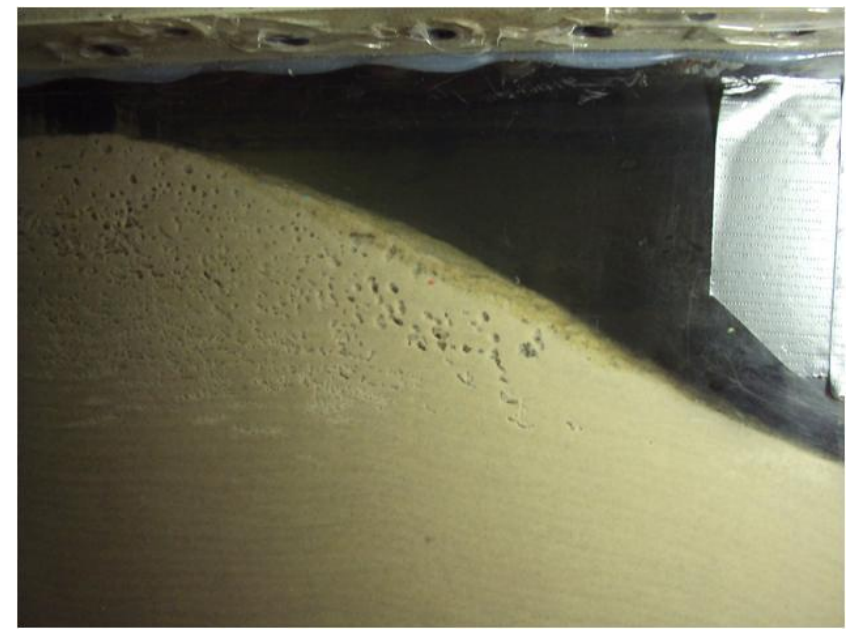

Figure 16 Slope 45 minutes after swing down

During stopping, the cameras also showed movement of pore fluid and free gas between the protective glass sheet and 
the acrylic strongbox window. This gap may provide a bypass during pore fluid saturation, so the glass may be removed for the next test.

\section{CONCLUSIONS}

A novel physical model test was designed to investigate the stability of submarine gassy slopes triggered by tidal variations in a geotechnical centrifuge. The appropriate model preparation techniques and control and measurement systems were successfully developed. Ethylene was selected as the dissolved gas with water as the pore fluid, to provide the necessary control of the degree of sand saturation. A slope failure was not triggered in the first proof test of this setup under a wide range of tidal motions and gas pressures. The medium dense fine sand may not have been fully saturated with the gaseous pore fluid. A series of improvements and additional measurements will be implemented in future tests to provide better control of the model tests.

\section{ACKNOWLEDGEMENTS}

The authors are very thankful to Dr Peter Byrne of University British Columbia and Dr Jocelyn Grozic of University of Calgary for their interest and guidance in the physical model design and preparation techniques. The assistance of the geotechnical engineering team at C-CORE is much appreciated. The financial support of Chevron Canada Limited for the research, and Hibernia Management \& Development Corporation for C-CORE centrifuge access for graduate students, is gratefully acknowledged.

\section{REFERENCES}

[1] Christian, H.A., and Cranston, R.E. 1997. A methodology for detecting free gas in marine sediments. Canadian Geotechnical Journal, 34(2): 293-304.

[2] Christian, H.A., Woeller, D.J., Robertson, P.K., and Courtney, R.C. 1997. Site investigations to evaluate flow liquefaction slides at Sand Heads, Fraser River delta. Canadian Geotechnical Journal, 34(3): 384-397.

[3] Chillarige, A.V., Robertson, P.K., Morgenstern, N.R., and Christian, H.A. 1997. Seabed instability due to flow liquefaction in the Fraser River delta. Canadian Geotechnical Journal, 34(4): 520-533.

[4] Haththotuwa, C.K., and Grozic, J.L.H. 2011. Effect of fines content on instability behaviour of loose silt - sands containing gas bubbles. Pan-Am CGS Geotechnical Conference, Toronto, Ontario, Canada.

[5] Atigh, E., and Byrne, P.M. 2004. Liquefaction flow of submarine slopes under partially undrained conditions: an effective stress approach. Can. Geotech. J. 41: 154-165.
[6] Puebla, H., Byrne, P.M., and Phillips, R., 1997. Analysis of CANLEX liquefaction embankments: prototype and centrifuge models. Can. Geotech. J. 34: 641-657.

[7] Murff, J.D., 1996. The geotechnical centrifuge in offshore engineering. OTRC Honors Lecture, Offshore Technology Conference, Houston, USA.

[8] Taylor, R.N., 1995. Geotechnical Centrifuge Technology, Blackie Academic \& Professional. London, UK.

[9] Personal communication from Byrne, P.M., 2003. Centrifuge modelling of submarine slopes under tidal variations - Test procedures. April, 2003.

[10] Sobkowicz, J.C. and Morgenstern, N.R. 1984. The undrained equilibrium behavior of gassy sediments. Canadian Geotechnical Journal, 21, 439-448.

[11] Sills, G.C., and Wheeler, S.J. 1992. The significance of gas for offshore operation. Continental Shelf Research, 12(10): 1239-1250.

[12] Yamamoto, S., Alcauskas, J.B., and Crozier, T.E. 1976. Solubility of methane in distilled water and sea water. Journal of Chemical and Engineering Data, Vol. 21, No. 1, 7880 .

[13] http://www.engineeringtoolbox.com/gases-solubilitywater-d_1148.html

[14] Silvis. F., and de Groot, M.B., 1995. Flow slides in the Netherlands: experience and engineering practice. Canadian Geotechnical Journal, 32: 1086-1092.

[15] Ueno, K., 1998. Methods for preparation of sand samples. Centrifuge 98. Balkema. Rotterdam, Netherlands.

[16] Waite, W., Bratton, P.M., and Mason, D.H., 2011. Laboratory formation of non-cementing, methane hydratebearing sands. 7th Int. Conf. on Gas Hydrates.

[17] White, D.J., Take, W.A and Bolton, M.D. 2003. Soil deformation measurement using particle image velocimetry (PIV) and photogrammetry. Géotechnique Vol.53, No.7, 619631 .

\section{[18] http://vegetronix.com/Products/VH400/}

[19] Holocher, J., Peeters, F., Aeschbach-Hertig, W., Kinzelbach, W. and Kipfer, R. 2003. Kinetic model of gas bubble dissolution in groundwater and its implications for the dissolved gas composition. Environ. Sci. Technol., 37, 13371343. 
Appendix B 


\title{
Physical modelling of submarine gassy slope failures
}

\author{
Shantanu Kar, Ryan Phillips, \& Bipul Hawlader \\ Faculty of Engineering and Applied Science, Memorial University of \\ Newfoundland, St. John's, NL, Canada. \\ C-CORE St. John's, NL, Canada
}

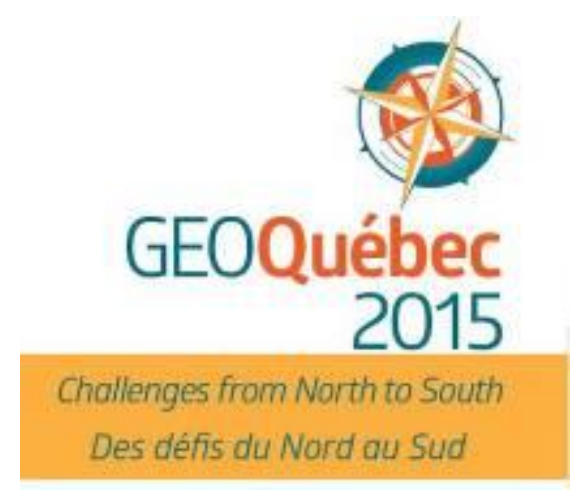

\begin{abstract}
This paper investigates the stability of a submarine gassy slope triggered by tidal variations. Under tidal variations on an unsaturated slope, failure may occur under specific combinations of degree of saturation and soil permeability, and decreasing tidal period. A novel physical model test in a geotechnical centrifuge was undertaken of a submarine slope containing gassy sediments. The model preparation techniques, measurement systems and preliminary results are presented. The response observed in the model test is discussed and further developments proposed. Existing numerical simulations may provide a basis for verification and validation of future physical model test results.
\end{abstract}

\section{RÉSUMÉ}

Cet article étudie la stabilité d'une pente gazeuse sous-marin déclenchée par les variations des marées. Sous variations de marée sur une pente insaturés, une rupturepeut se produire dans des combinaisons spécifiques de l'augmentation du degré de saturation et de la perméabilité du sol, et la diminution de la période de marée . Un nouveau modèle physique d'une pente sous-marine contenant des sédiments gazeux a été réalisé dans une centrifugeuse géotechnique. Les techniques de préparation de modèle, les systèmes de mesure et les résultats préliminaires sont présentés .La réponse observée sur le modèle pendant l'essai est discuté et des développements futures sont proposés. Les simulations numériques existantes peuvent fournir une base.

\section{INTRODUCTION}

Submarine slope stability is an important concern and matter of research as offshore exploration becomes more prevalent and technologically advanced over the next few decades. Geohazards and associated ground movements in an offshore environment are a great threat to offshore infrastructure. Therefore the stability of a submarine slope is an important issue that must be taken into consideration during the design and operation of offshore facilities. The consequences of slope failure to oil and gas facilities would have a large financial, safety and regulatory impact. Moreover, submarine slope failures and tsunamis generated due to associated landslides near shore areas may cause considerable loss of life. The failure of a submarine slope might be initiated by a variety of potential triggering factors such as earthquakes, wave action, gas hydrate dissociation, tidal variation, sea level change, over steepening by erosion and minor slides, glaciations and volcanic activities (Locat and Lee 2002, Masson et al. 2006). Flow liquefaction in cohesionless sediments is a key source of submarine slope instability. Chillarige et al. (1997 a) mentioned that off the west coast of Canada submarine liquefaction flow slides occurred in deltaic sand and silts which contain gas and were mainly triggered by tidal drawdown. Wheeler (1990) noted a large number of seabeds around the world which contained gas bubbles at very shallow depth. Several case studies were presented by Chillarige et al. (1997 b) and Haththotuwa et al. (2011) on flow liquefaction of submarine gassy slopes triggered by tidal variation especially at low tides. Partially saturated seabeds of newly deposited Fraser River sands contain methane gas and possess susceptibility to flow liquefaction due to a time lag between tidal drawdown and pore pressure response as noted by Christian et al. (1997). Atigh et al. (2003) mentioned that reduction in pore pressure response with depth and time occurs from tidal variation on gassy seabed soil due to compressibility of pore fluid. Reduction of effective stress may lead to flow liquefaction of submarine slope because changes in pore pressure lag the reduction of seabed pressure changes during low tide. To model liquefaction flow of sand Atigh et al. (2004) developed an effective stress approach based on an elastic-plastic stress-strain relationship. To understand the behavior of both saturated and gassy deposits of loose Fraser River sand and Ottawa sand they used a fully coupled FLAC finitedifference analysis. Retrogressive flow slides were predicted from triggering of liquefaction for an unsaturated underwater slope similar to those observed near Sand Heads at the front of the Fraser River delta.

Geotechnical centrifuge testing is a well accepted physical modeling technique that has been used successfully to study various geotechnical engineering problems such as soil pipeline interaction and soil slope behavior using reduced scale physical models. A full scale soil structure is in equilibrium under earth's gravitational field $\mathrm{g}$, similarly a reduced $1 / 100^{\text {th }}$ scale model on a centrifuge under $100 \mathrm{~g}$ will have stresses due to self-weight similar to the stresses in the full scale soil structure at homologous points. The model can then reproduce the phenomena of cracking, rupture or, flow that would be observed in the prototype because the stress dependency of soil behavior has been correctly simulated. The principles, scaling laws and some 
applications of centrifuge modelling are more fully described by Taylor et al. (1995) and Murff (1996).

Byrne (2003) designed a $1 / 50^{\text {th }}$ scale physical model test of a gassy submarine slope failure for $50 \mathrm{~g}$. The slope material was gassy loose sand with a dimension of $2 \mathrm{H}$ : $1 \mathrm{~V}$. For failure of this gassy slope a tidal range of $2.5 \mathrm{~m}$ was selected. Under tidal variations on an unsaturated slope, failure is expected to occur at a specific combination of degree of saturation, soil permeability and tidal period. For a specified degree of saturation and soil permeability, the possibility of failure increases with decreasing tidal period.

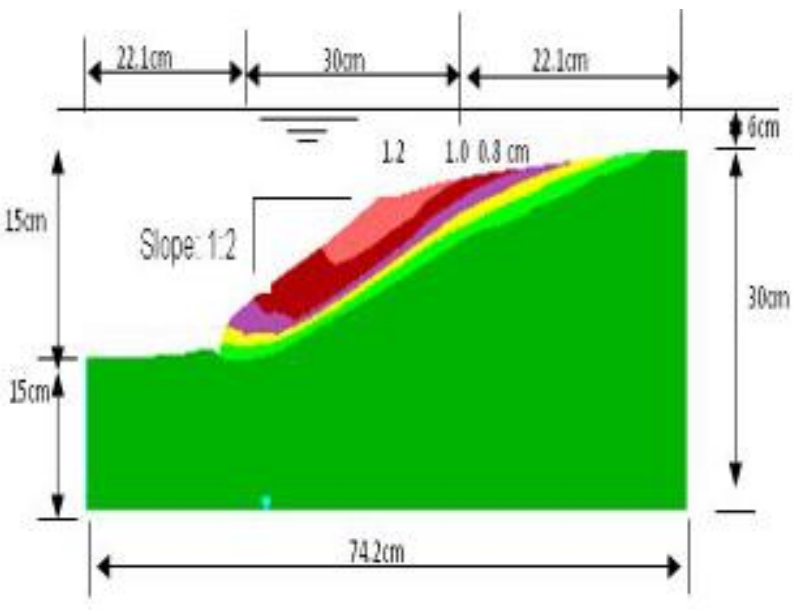

Figure 1 Predicted horizontal model movements

According to this design shown in Figure 1, a physical model test has been conducted in C-CORE centrifuge to investigate the stability of the submarine gassy slope under tidal variation by Kar and Phillips (2015). Appropriate model preparation techniques and control and measurements systems were developed for that test. Offshore soft sediments contain undissolved gas bubbles of carbon dioxide, hydrogen sulfide, ethane but mostly methane as noted by Esrig et al. (1977) \& Jones et al. (1986). Ethylene was selected as the dissolved gas with water as the pore fluid to provide the necessary control of degree of sand saturation. Slope failure was not triggered in the first proof test of this setup under a wide range of tidal motions and gas pressures. The medium dense fine sand may not have been fully saturated with the gaseous pore fluid which may be the reason for no significant failure in that submarine gassy slope.

In this paper, authors mainly investigate the presence of gas in the pores of the soil slope and a suitable technique to measure the degree of saturation. Kar and Phillips (2015) introduced a soil moisture sensor VH400 to determine the degree of saturation of the soil sample. Some proof test results on sand columns will be presented in this paper.

\section{SATURATION TECHNIQUE INSTRUMENTATION}

AND

\subsection{Sand Column Material and Geometry}

The sand column was made in a sealed steel cylinder of $19.8 \mathrm{~cm}$ diameter and $68 \mathrm{~cm}$ height. The sand used in the test was Alwhite \#00, the same sand was used in centrifuge proof test. The cylinder is capable of holding a gauge pressure of $760 \mathrm{kPa}$ and a vacuum of $30 \mathrm{in}$ of $\mathrm{Hg}$. A small layer of coarse sand was placed at the bottom of the column to distribute the fluid uniformly. A free space of $10.5 \mathrm{~cm}$ was at the top of the sand column. Figure 2 shows the geometry of the sand column.

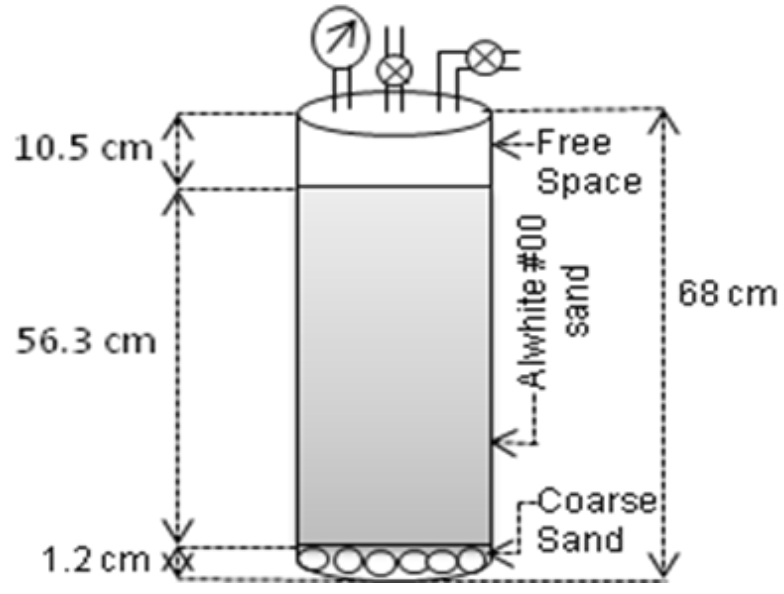

Figure 2 Sand column geometry.

\subsection{Pore Fluid and Gas Selection and Saturation Process}

To make the sand sample gassy, a large amount of gas was entrained in the pore fluid. In fresh water methane $\left(\mathrm{CH}_{4}\right)$ has a solubility coefficient of $0.034 \mathrm{LIL}$ at $20^{\circ} \mathrm{C}$, Yamamoto et al. (1976). To achieve the desired degree of saturation in the model, very high pressure would have to be used because of the solubility coefficient of methane. The solubility coefficient of carbon dioxide $\left(\mathrm{CO}_{2}\right)$ is 0.86 $\mathrm{LIL}$ in fresh water and stronger gas exsolution and expansion occurs as the gas is more soluble as explained by Red et al. (1994). Amaratunga et al. (2009) show that under a pressure gradient carbon dioxide $\left(\mathrm{CO}_{2}\right)$ cannot provide a controllable degree of saturation because of its high solubility. For a controllable degree of saturation ethylene, krypton and xenon are suitable choices and industrially available. Krypton and xenon are very expensive as compared to ethylene.

In this research, ethylene was used as the pore fluid gas with a solubility coefficient of $0.15 \mathrm{LIL}$ at $20^{\circ} \mathrm{C}$ (www.engineering toolbox.com). Figure 3 shows the saturation setup of ethylene gas with water pore fluid, after Waite et al. (2011). Distilled water was used as the pore fluid and deaired for a few days under a vacuum of 30 in of $\mathrm{Hg}$. Ethylene gas was then mixed with water under a gauge pressure of $655 \mathrm{kPa}$. The container of ethylene and water was placed in a cold water tub to reduce the mixing temperature. This decrease of ethylene water mixture temperature increases the solubility of gas in the water to ensure better saturation. A peristaltic pump was used to circulate the water for better mixing in a closed system. The gas pressure decreased with the circulation of ethylene mixed water. When the pressure was stable the cylinder pressure was again increased 
back to $655 \mathrm{kPa}$. The pressure of ethylene water mixture decreased through several cycles following the same process until the gas pressure stayed at the starting pressure. The data from the ethylene water saturation operation is shown in Figure 4.

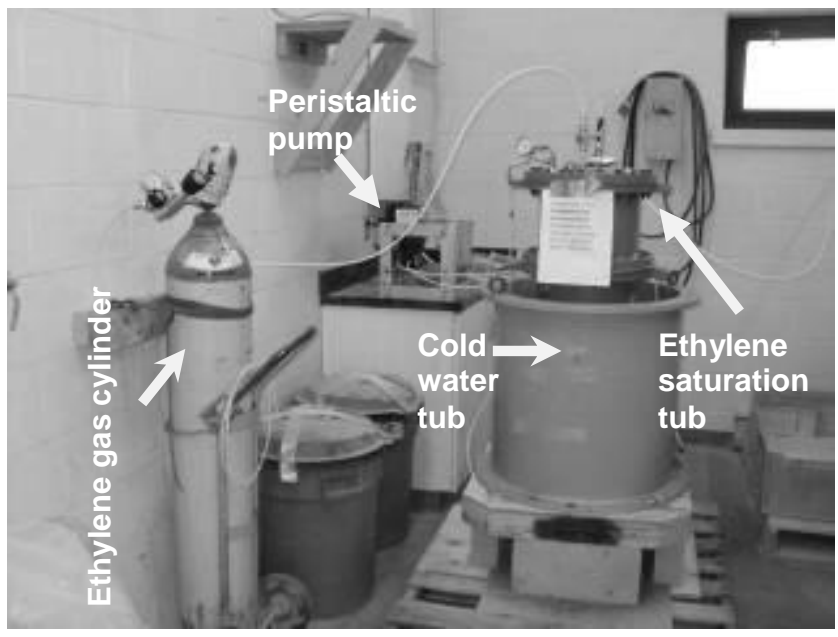

Figure 3 Lab setup of water saturation with ethylene.

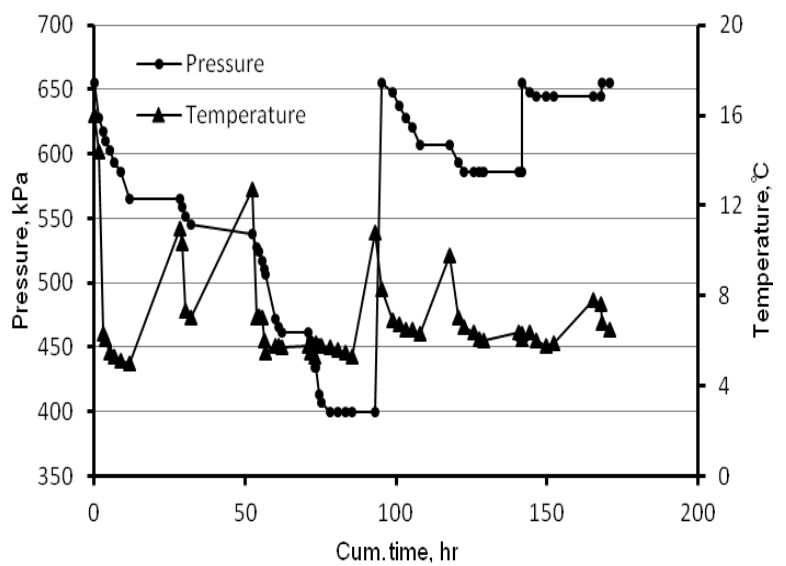

Figure 4 Gas pressure and temperature change with time.

\subsection{Instrumentation}

For measuring the degree of saturation of the sand column a soil moisture sensor was evaluated which determines moisture content. VH400 series soil moisture sensor is a very low power operational sensor with a probe length of $94 \mathrm{~mm}$. This probe measures dielectric constant of soil using transmission line techniques. It is insensitive to water salinity, and does not corrode over time. A data acquisition channel (DAQ channel) was used to read and record data provided by the sensor. The output of this sensor is DC voltage proportional to the water content and it provides reading within a second. Figure 5 shows the orientation of the sensors in two soil columns in both horizontal and vertical direction

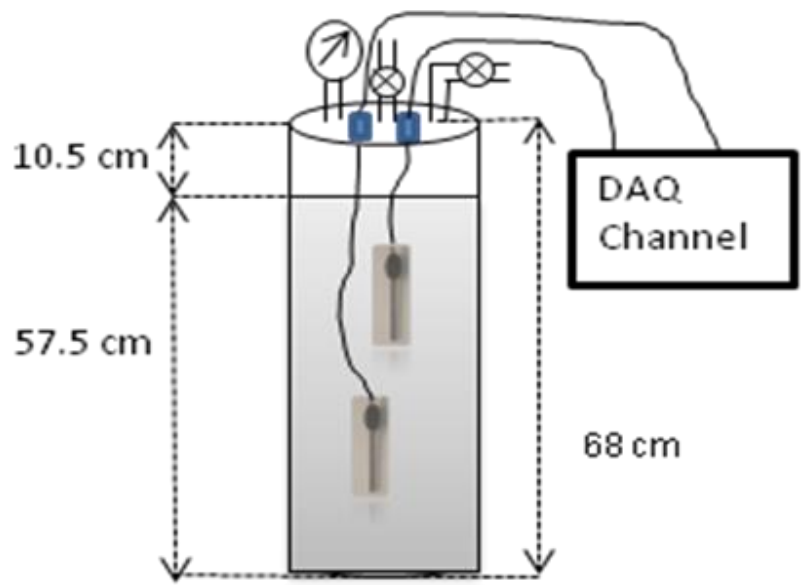

(a)

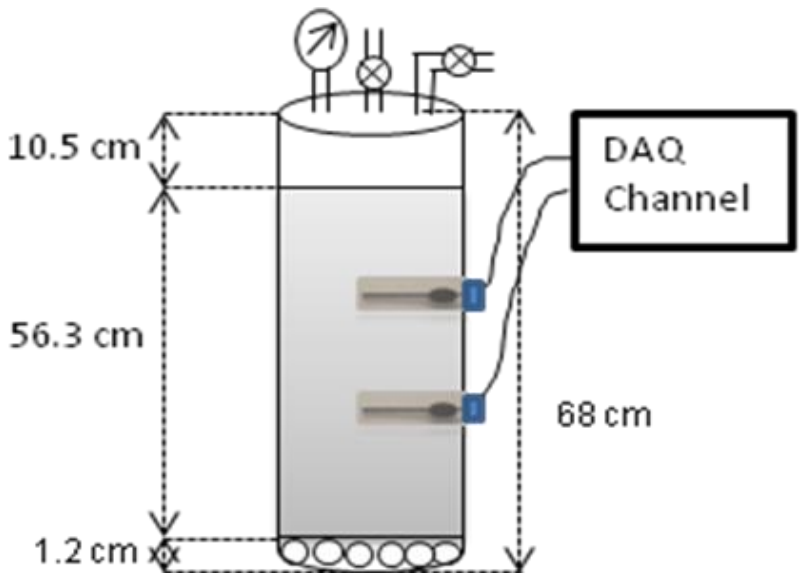

(b)

Figure 5 (a) Sensor in vertical direction. (b) Sensor in horizontal direction.

\section{TEST PROCEDURE}

In the centrifuge model test, the slope was first saturated using distilled deaired water with a very low head to prevent piping after vacuum and carbon dioxide displacement of air. Carbon dioxide was used to replace the remaining air as the solubility coefficient of carbon dioxide in water is much higher than air. Then the whole system including strong box and water container was brought to the same pressure as ethylene mixed water. Ethylene mixed water was then passed through the slope in the strong box displacing the distilled deaired water into the water container. Figure 6 shows the lab setup for centrifuge model test preparation.

This same process of sample preparation was followed to make the sand column samples. Centrifuge strongbox was replaced by a sand column for simplicity. Dry sand was poured into the sand column and deaired under vacuum. The same flushing process was applied a couple of times. 


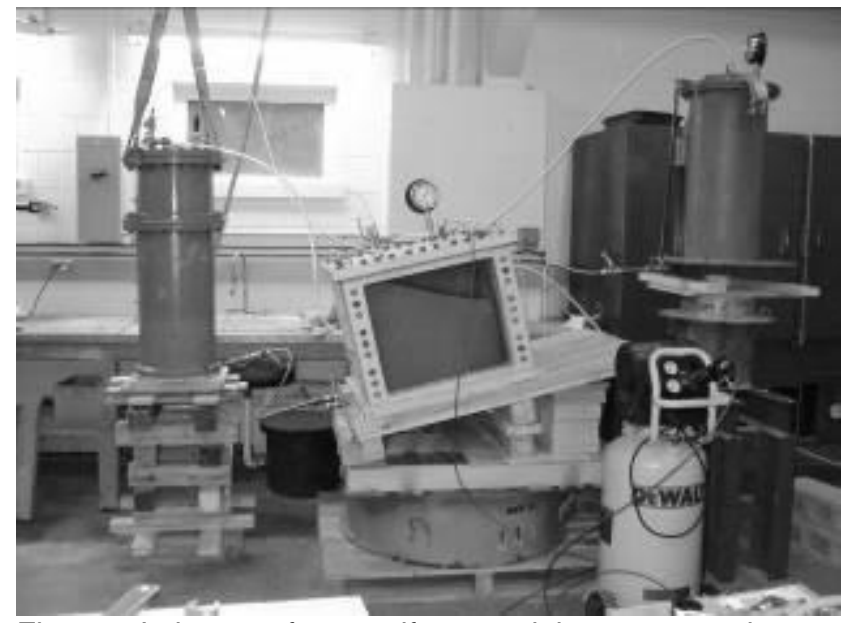

Figure 6 Lab setup for centrifuge model test preparation

Distilled deaired water then flushed through the sand column with a very low head. Biggar et al. (1960) noted that the water flow velocity can vary between $0.30 \mathrm{~cm} / \mathrm{hr}$ and $2.49 \mathrm{~cm} / \mathrm{hr}$ for a sand grading like Alwhite \#00 during inundation. In these tests, the initial flow velocity was 1.77 $\mathrm{cm} / \mathrm{hr}$ and decreased to $0.49 \mathrm{~cm} / \mathrm{hr}$ to $0.84 \mathrm{~cm} / \mathrm{hr}$ during inundation. The initial flow velocity was higher because of the coarse grain layer. Figure 7 shows the whole setup for the sand column test.

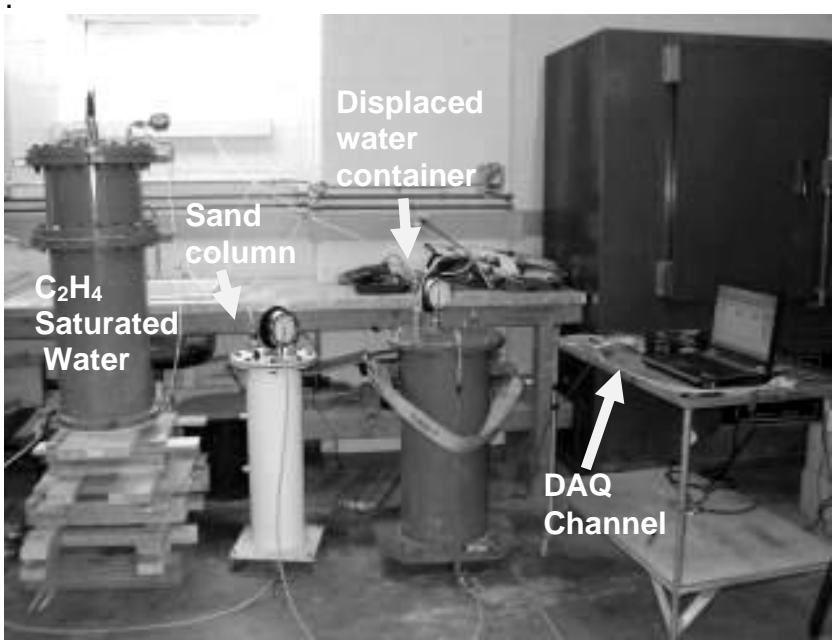

Figure 7 Lab setup of sand column test

After saturating with deaired water under vacuum, the pressure in the cylinder was brought to $655 \mathrm{kPa}$ which is the same pressure as the ethylene saturated water container. Ethylene saturated water was passed through the sand column under a very low driving head. This ethylene saturated water displaced the water in the sand column. Ethylene saturated water was flushed up to 1.7 times of sand column pore volume to ensure the presence of gas in the sand column sample. When the model was ready, the pressure was reduced in steps and the moisture sensors monitored. The required pressure drop was calculated using Equation 1 proposed by Henry and Boyle's, where $\mathrm{H}$ is the Henry's constant and for ethylene
Henry's constant of $0.114982 . S_{r}$ is the degree of saturation.

$S_{Y}=\frac{P_{2}-P_{1} \cdot H}{P_{2}(1-H)}$

The sensor reading should change with pressure reduction because with decreasing pressure gas bubbles expand reducing the degree of saturation. Figure 8 shows another method for measuring the global degree of saturation. In this method, the amounts of water and gas released from the sand column while decreasing the pressure were measured. Two more sand columns were made following the same process as above, but without the soil moisture sensors. A gas vessel was used with a very low volume. Two pressure transducers were used to monitor the pressures in the sand column and the gas vessel. At constant temperature,

$$
\mathrm{P}_{1} V_{1}=\mathrm{P}_{2} \mathrm{~V}_{2}
$$

According to Boyles law Equation 2, the product of pressure and volume of a gas remains constant at constant temperature. In these tests while reducing the pressure some water and gas will be displaced from the sand column into the gas vessel. The degree of saturation can be assessed form the displaced water volume and the equilibrium gas pressure.

$\mathrm{Sr}=\frac{\mathrm{P}_{2}-\mathrm{P}_{1} \cdot \mathrm{H}}{\mathrm{P}_{2}(1-\mathrm{H})}$

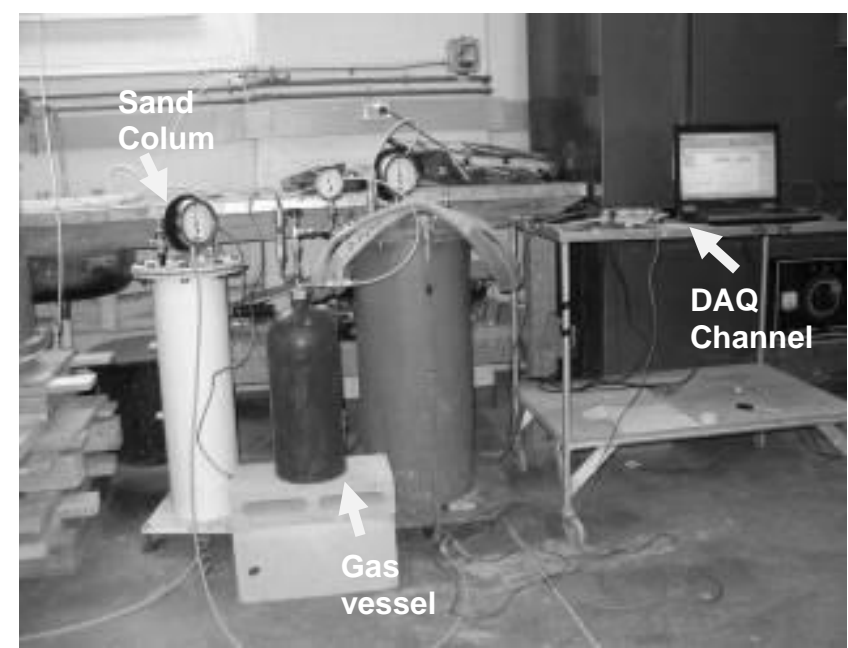

Figure 8 Lab setup for measuring global degree of saturation.

\section{$4 \quad$ RESULTS}

To determine the degree of saturation and ensure the presence of ethylene gas in the submarine gassy slope, sand column tests were done with soil moisture sensors following the process of ethylene saturation to ensure the presence of gas. Soil moisture sensors were placed in the sand column in either a horizontal or vertical orientation. The values obtained from soil moisture sensor in air and water are 0.0851, 2.957 and 0.08564, 2.971 
volts for sensor 3 and sensor 2 respectively. While flushing with deaired distilled water, from Figure 9, the sensor reading changed with the change of the water level. Due to capillary rise soil moisture sensors start to respond while the distilled deaired water phreatic surface was below the sensor position. With the rise of distilled water level the degree of saturation increases at the sensor elevation. In all case soil moisture sensors show $100 \%$ saturation after they are immersed. Another test was done with the change of soil moisture sensor orientation with some coarse material at the soil base. The soil moisture sensors show the same behavior while the sensor was in horizontal direction.

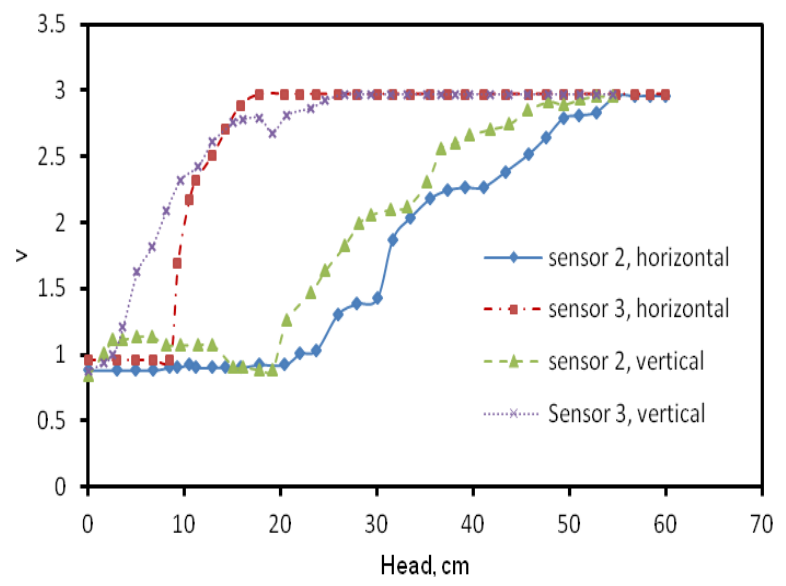

Figure 9 Soil moisture reading for both sensor orientations.

The ethylene saturated water filled sand column was pressurized to $655 \mathrm{kPa}$, with a degree of saturation of 1 . To reduce the degree of saturation,the pressure of the sand column was gradually reduced. With the reduction of pressure, some gas comes out of solution and existing gas bubbles expand.

Holocher et al. (2003) shows time required for different gas diffusion in water, Figure 10. The time required for krypton and xenon gas bubbles diffusion in water is about 15 minutes. Diffusivity and solubility coefficient of Ethylene is same as Krypton. So, the time required for ethylene gas diffusion is assumed to be similar to krypton. Same diffusion time as Krypton was therefore allowed as a minium for dissolved gas to come out of solution.

The response of the soil moisture sensors in both orientations with decreasing pressure is presented in Figure 11. Soil moisture sensors do not show any changes in voltage with the sensors in a vertical orientation. Top sensor shows some change with decreasing pressure when sensor was in horizontal orientation. The bottom sensor however has no change in voltage.

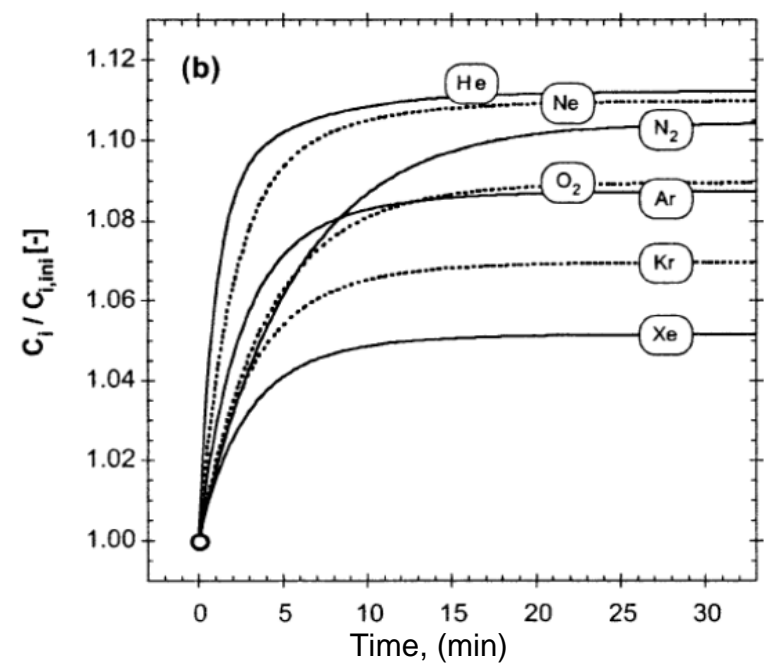

Figure 10 Estimated gas solution time, Holocher et al. (2003)

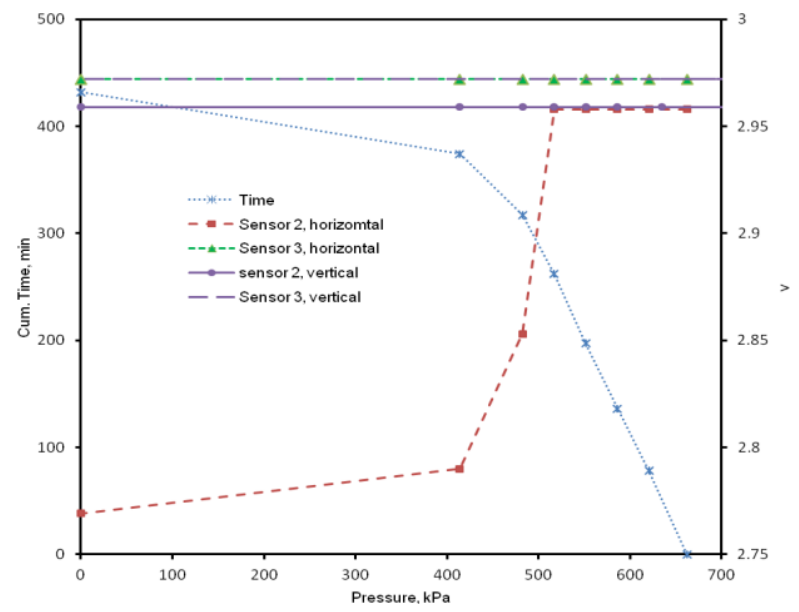

Figure 11 Sensor response to decreasing pressure

The top sensor change in voltage may mean with a decrease in pressure gas expansion occured around the sensor as the degree of saturarion decreased. A calibration of soil moisture sensor $\mathrm{VH} 400$ was presented by Kar and Phillips (2015). Figure 12 shows this soil moisture sensor VH400 calibration in Alwhite 00 sand. The response from the sensor was not comparable with the expected degree of saturation. These moisture sensors did not provide a voltage correspondent to degree of saturation with decreasing pressure.

The data of the global degree of saturation tests are presented in Figure 13. The theoretical volume of gas released with decreasing pressure is based on equations 1 and 2. It is assumed that the gas pressures are the same throughout the system. In fact, gas pore pressures should always be slightly higher than the pore water pressures due to surface tension. The measured gas volumes from the 2 column tests are initially comparable to the expected values down to about $550 \mathrm{kPa}$ absolute pressure in both magnitude and trend, given the accurate 
of the volume measurements. This pressure gives a degree of saturation of about $90 \%$ or less. Below this pressure level, the released gas volume is only about half the theoretical value at a goven pressure level. The reason for this decrease is unclear. Below 85 to $90 \%$ saturation, gas bubbles in the sand pores merge to form a continuous gas phase and pathways for released pore gas to exit the sand sample. This change in gas transport may be factor in the observed behaviour.

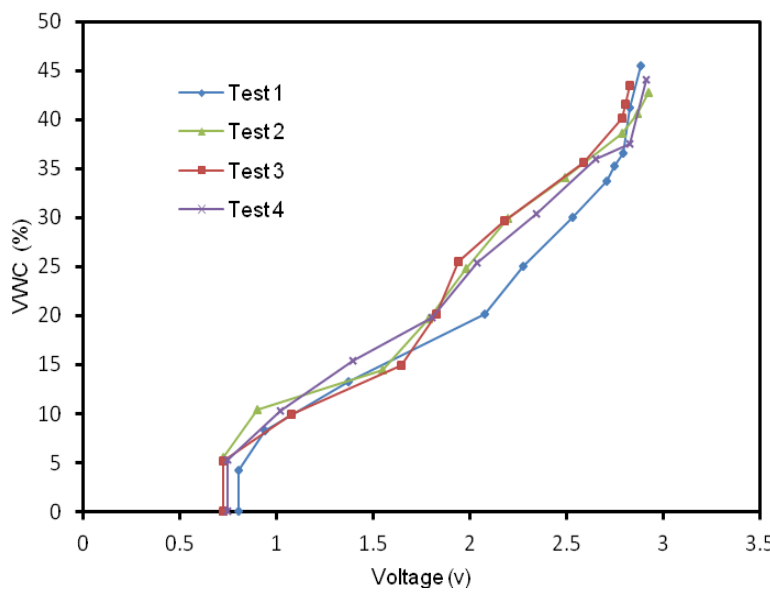

Figure $12 \mathrm{VH} 400$ sensor calibration in Alwhite 00 sand Kar et al. (2015).

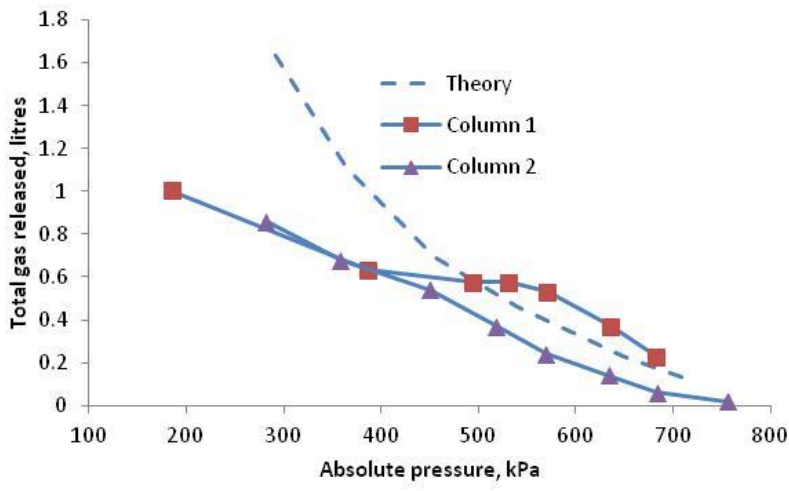

Figure 13 Released gas measurements

In the centrifuge model test, failure of submarine slope was expected to occur for specific combinations of degree of saturation, soil permeability and tide period. For a specified degree of saturation and soil permeability, possibility of failure increases as the tide period decrease. A slope failure was not triggered in the first proof test of this setup under a wide range of tidal motions and gas pressures. There was evidence of slight volumetric expansion from gas dissolution under $50 \mathrm{~g}$. Much more volumetric expansion was seen while stopping the centrifuge from $50 \mathrm{~g}$. Figure 14 a shows PIV analysis, which indicates the evidence of volumetric expansion due to the associated decrease in total stresses in the sand. The noise in the displacement vectors indicates the effects of expanding gas bubbles, as seen near the slope crest at 1g, Figure 14b, These gas bubbles expanded during the 45 minute period after swingdown. This volumetric expansion confirms the presence of some gas in the slope model.

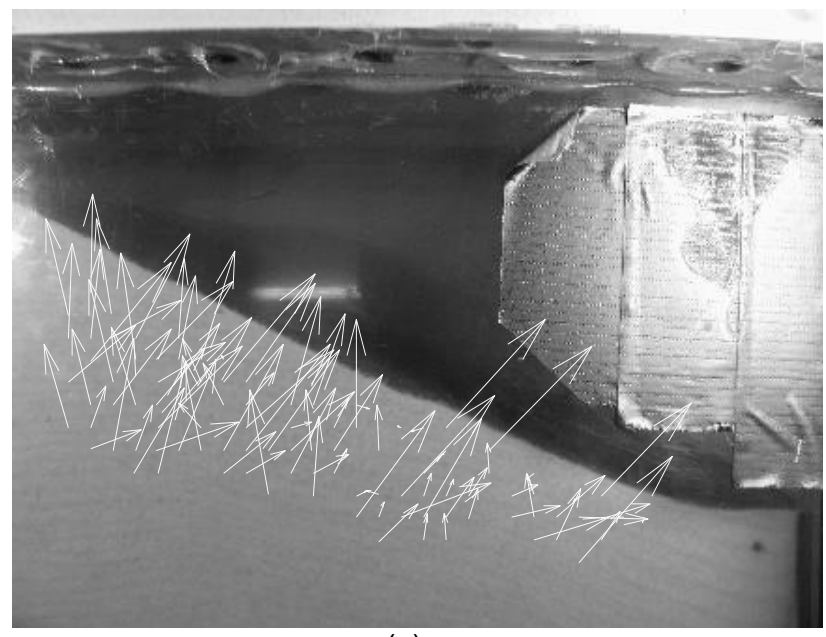

(a)

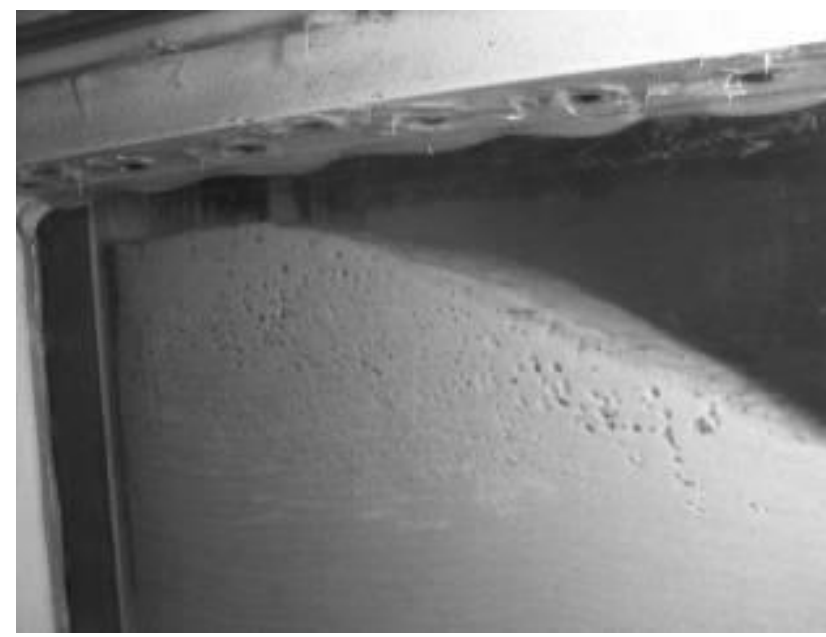

(b)

Figure 14 (a \& b) Volumetric expansion of slope after swing down.

To better understand the presence of gas in the centrifuge slope mode, some experimental tests were conducted to measure the degree of saturation of sand column. Figure 15a-c shows the presence of ethylene mixed water in the sand column. While decreasing the pressure, gas comes out of solution and the bubbles expand. A transparent standpipe was attached to the water column. Gas bubbles were also seen in that pipe during depressurization of the sand column. Excavation of the sand column after removing the cylinder lid also showed evidence of gas bubbles. There were also some bubbles around the top soil moisture sensor. Gas was therefore present throughout the column. 
For investigating failure of a submarine gassy slope under tidal variation in the geotechnical centrifuge, some supporting lab tests have been done. Proposed ethylene saturation process has been applied on a sand column. Some evidence of gas exsolution and bubble expansion with depressurizationis are presented in this paper. This means ethylene gas was dissolved in the water and present in the soil pores. Soil moisture sensor VH400 shows good response while soil column was saturated with water. These soil moisture sensors do not work properly with decreasing pressure. A better method for determining degree of saturation will be developed for future submarine gassy slope tests.

\section{ACKNOWLEDGEMENTS}

The assistance of the geotechnical engineering team at $\mathrm{C}$-CORE is much appreciated. The financial support of Chevron Canada Limited for the research, and Hibernia Management \& Development Corporation for C-CORE centrifuge access for graduate students, is gratefully acknowledged.

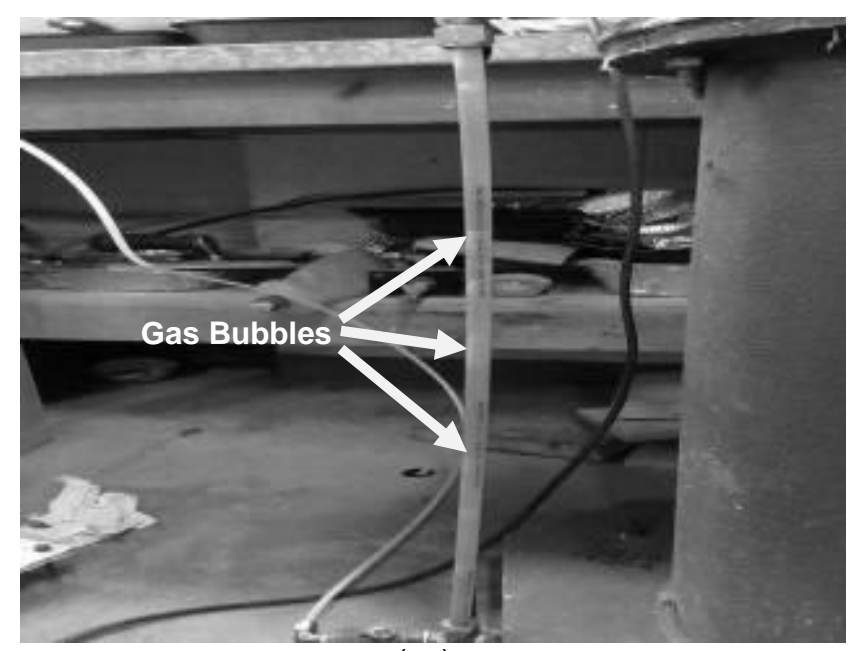

( a )

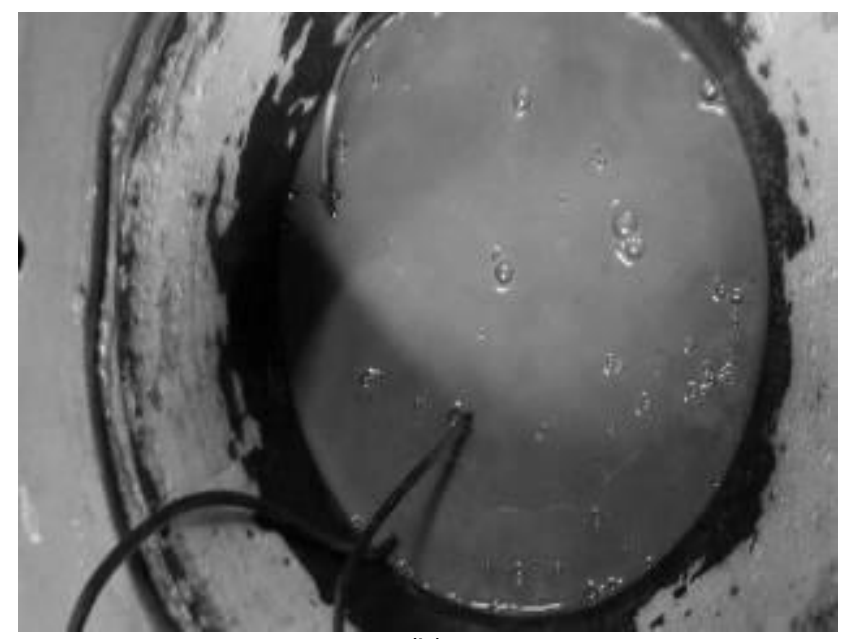

(b)

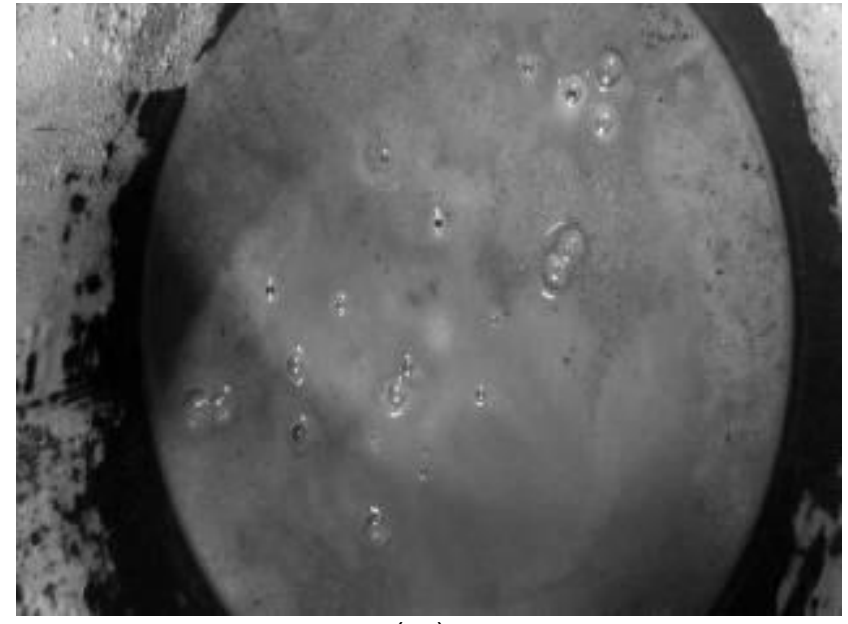

( c )

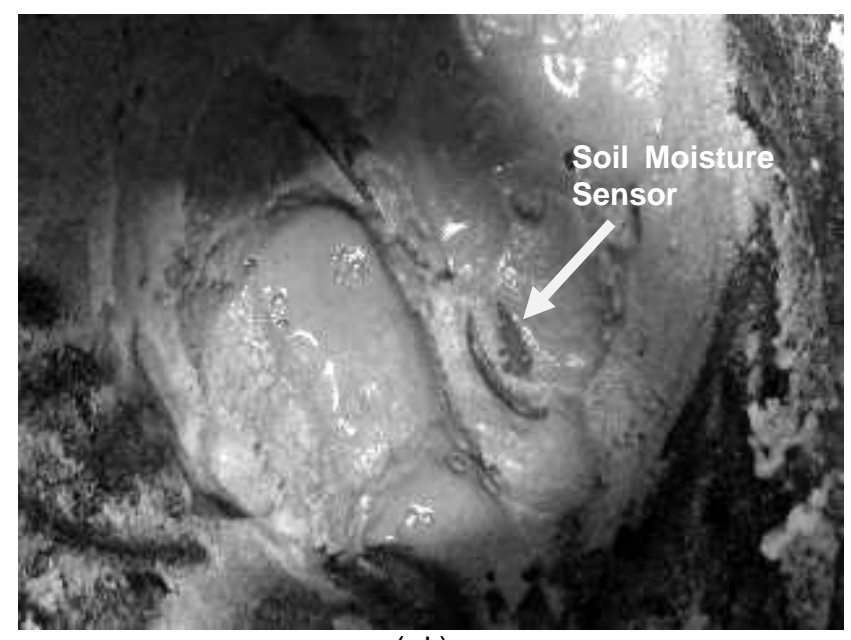

(d)

Figure 15 (a) Standpipe gas bubbles. (b \& c) gas bubbles at vertical and horizontal position of sensors. (d) bubbles beside soil moisture sensor.

\section{REFERENCES}

Amaratunga, A., Grozic, J.L.H., 2009, On the undrained unloading behaviour of gassy sands. Canadian Geotechnical Journal, 46: 1267-1276.

Atigh, E., and Byrne, P.M. 2003. Flow liquefaction failure of submarine slopes due to monotonic loading-an effective stress approach. Submarine Mass Movements and Their Consequences, Advances in Natural and Technological Hazards Research, 19: 310.

Atigh, E., and Byrne, P.M. 2004. Liquefaction flow of submarine slopes under partially undrained conditions: an effective stress approach. Can. Geotech. J. 41: 154-165.

Biggar, J.W., Nielsen, D.R., 1960, Duffusion effects in miscible displacement occurring in saturated and unsaturated porous materials. Journal of Geophysical Research, 65(9): 2887-2895. 
Byrne, P.M., 2003. Personal communication. Centrifuge modelling of submarine slopes under tidal variations Test procedures. April, 2003.

Chillarige, A.V., Robertson, P.K., Morgenstern, N.R., and Christian, H.A. (1997 a). Seabed instability due to flow liquefaction in the Fraser River delta. Canadian Geotechnical Journal, 34(4): 520-533.

Chillarige, A.V., Robertson, P.K., Morgenstern, N.R., and Christian, H.A. (1997 b). Evaluation of the in situ state of Fraser River sand. Canadian Geotechnical Journal, 34: 510-519.

Christian, H.A., Woeller, D.J., Robertson, P.K., and Courtney, R.C. 1997. Site investigations to evaluate flow liquefaction slides at Sand Heads, Fraser River delta. Canadian Geotechnical Journal, 34(3): 384-397.

Esrig, M.I. \& Kirby, R.C (1977) Implication of gas content for predicting the stability of submarine slope. Marine Geotechnology, 2: 81-100.

Haththotuwa, C.K., and Grozic, J.L.H. 2011. Effect of fines content on instability behavior of loose silt - sands containing gas bubbles. Pan-Am CGS Geotechnical Conference, Toronto, Ontario, Canada.

http://www.engineeringtoolbox.com/gases-solubility-waterd_1148.html

Holocher, J., Peeters, F., Aeschbach-Hertig, W., Kinzelbach, W. and Kipfer, R. 2003. Kinetic model of gas bubble dissolution in groundwater and its implications for the dissolved gas composition. Environ. Sci. Technol., 37, 1337-1343.

Jones, G.B., Floodgate, G.D. \& Bennell, J.D. (1986). Chemical and microbiological aspects of acoustically turbid sediments: Preliminary investigations. Marine Geotechnology, 3: 315-332.

Kar, S. and Phillips, R. 2015. Submarine slopes failure in gassy soils. International Conference on Ocean, Offshore and Arctic Engineering (OMAE 2015). St. John's, Newfoundland, Canada.

Locat, J. and Lee, H.J. 2002. Submarine landslides: advances and challenges. Canadian Geotechnical Journal, 39: 193-212.

Masson, D.G., Harbitz, C.B., Wynn, R.B., Pedersen, G. and Løvholt, F. 2006. Submarine landslides: processes, triggers and hazard prediction. Phil. Trans. R. Soc. A, 364: 2009-2039.

Murff, J.D., 1996. The geotechnical centrifuge in offshore engineering. OTRC Honors Lecture, Offshore Technology Conference, Houston, USA.

Red, N.S., Vianna, A.J.D., and Berre, T. 1994. Gas in soils. II: Effect of gas on undrained static and cyclic strength of sand. Journal of Geotechnical Engineering, 120(4): 716-737.

Taylor, R.N., 1995. Geotechnical Centrifuge Technology, Blackie Academic \& Professional. London, UK.

Waite, W., Bratton, P.M., and Mason, D.H., 2011. Laboratory formation of non-cementing, methane hydrate bearing sands. $7^{\text {th }}$ Int. Conf. on Gas Hydrates.

Wheeler, S.J. 1990. Movement of large gas bubbles in unsaturated fine-grained sediments. Marine Geotechnology, 9: 113-129.
Yamamoto, S., Alcauskas, J.B., and Crozier, T.E. 1976. Solubility of Methane in distilled water and sea water. Journal of Chemical and Engineering data. Vol. 21, No. $1,78-80$. 